\title{
RESHAPING AN ENDURING SENSE OF SELF: THE PROCESS OF RECOVERY FROM A FIRST EPISODE OF SCHIZOPHRENIA
}

by

Donna M. Romano

\begin{abstract}
A thesis submitted in conformity with the requirements for the degree of Doctor of Philosophy

Graduate Department of the Institute of Medical Science University of Toronto
\end{abstract}

Copyright $(C)$ Donna Romano, 2009 


\begin{abstract}
Reshaping an Enduring Sense of Self: The Process of Recovery From a First Episode of Schizophrenia, Donna M. Romano, Doctor of Philosophy. Graduate Department of the Institute of Medical Science, University of Toronto, 2009
\end{abstract}

Although many advances in the treatment of schizophrenia have been made over the past decade, little is known about the process of recovery from a first episode of schizophrenia (FES). To date, the study of recovery in the field of mental health has focused on long-term mental illness. This in depth qualitative study drew upon Charmaz's (1990) constructivist grounded theory methodology to address the following questions: How do individuals who have experienced a FES describe their process of recovery? How does an identified individual (e.g. friend, family member, teacher, or clinician) describe their role during the participant's process of recovery, and their perception of the recovery process? Ten primary participants (who self-identified as recovering from a FES) had two interviews; in addition, there was a one-time interview with a secondary participant, for a total of 30 interviews. Data collection sources included participant semi-structured interviews, participant selected personal objects that symbolized their recovery, and clinical records. The results provide a substantive theory of the process of recovery from a FES. The emergent process of recovery model for these participants is comprised of the following phases: 'Lives prior to the illness', 'Lives interrupted: Encountering the illness', 'Engaging in services and supports', 'Reengaging in life', 'Envisioning the future'; and the core category, 'Re-shaping an enduring sense of self,' that occurred through all phases. A prominent distinctive feature of this model is that participants' enduring sense of self were reshaped versus reconstructed throughout their recovery. The emergent model of recovery from a FES is unique, and as such, provides implications for clinical care, future research, and policy development specifically for these young people and their families. 


\section{Dedication}

I dedicate my thesis to my parents Anne and the late John Czuchta, and to my husband Anthony, for their tremendous support, patience, encouragement, and love. 


\section{Acknowledgements}

My sincere appreciation and respect is extended to all the participants who took part in this study. It was truly a privilege to have met them and an honour to have listened to their experiences. Many blessings to them for a lifetime full of health and happiness. My deep appreciation is also extended to my thesis co-supervisors Dr. Elizabeth McCay and Dr. Paula Goering. Beth, thank you for your words of wisdom and valuable contributions, and Paula, for your continued support and insights. I would also like to thank my thesis committee members, Dr. Katherine Boydell and Dr. Robert Zipursky for their valuable feedback and expertise during this research process. It was a privilege to have worked with all of you. Thank you as well to Noreen, Marianne, and Linda for their administrative assistance. I would like to thank Mount Sinai Hospital, Nursing Administration, Jocelyn, Nathalie, and my colleagues of 9 South for their encouragement and support of my time to complete this research. As well, I also valued the insightful feedback I received from Andria and Dr. Flak. To my loving parents, Anne and John Czuchta. My heart felt appreciation for your constant encouragement throughout my school years. Daddy, though you passed away before the completion of this study, I will forever admire and respect your wisdom, inspiration, and love of learning which will always remain with me. To my friends, and members of my family: Deanne, Deborah, John, Colin, Steve, Jonathan, Adam, Lauren, Ryan, Brandon, Joshua, Victoria, Uncle John, “Mom Candy”, Mary, John, Marc, Danielle, and Carm, thank you for your continued support, laughter and belief in the completion of this research. Thank you to Jesus' Divine Mercy, St. Anthony, and my intercessors in heaven for your guidance. Finally, a very special and loving thank you to my dear husband and "Editor in Chief," Anthony, I could have not reached this point without your unwavering patience, unconditional love, and constant support even in the early hours of the morning. I am truly grateful. 


\section{Table of Contents}

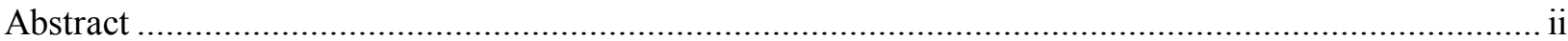

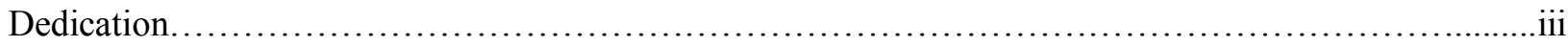

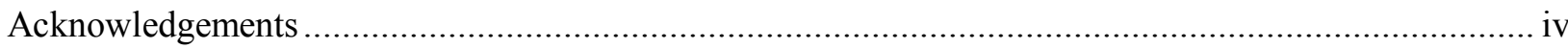

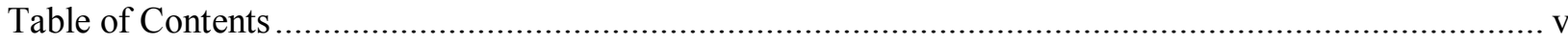

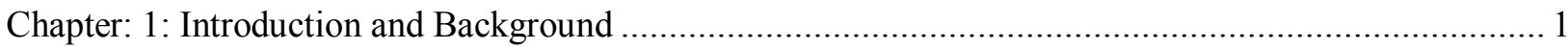

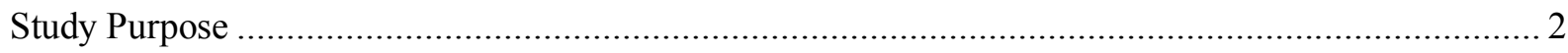

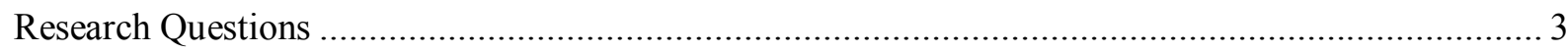

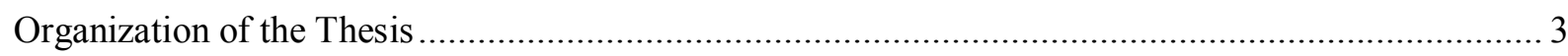

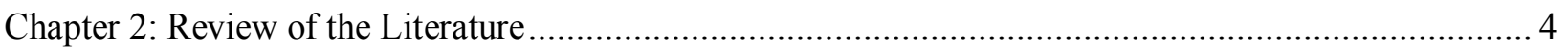

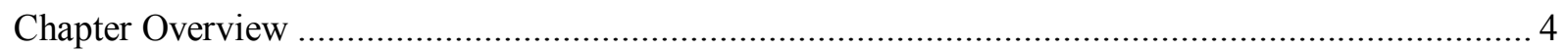

Recovery from Mental Illness: How is it Defined? ............................................................... 5

Recovery from Mental Illness: Situating the Concept Historically ........................................... 8

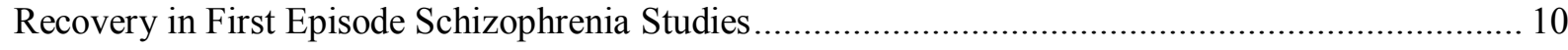

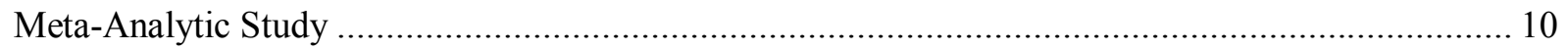

Studies of Symptomatic and Functional Recovery in FES …..................................................... 11

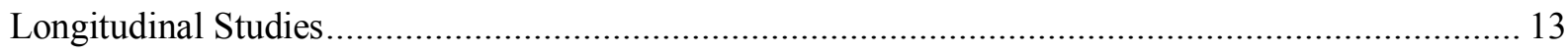

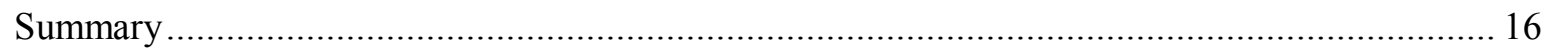

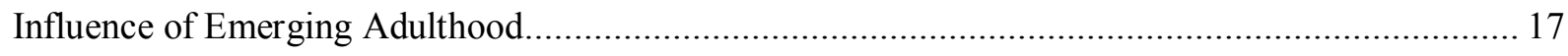

Recovery from Schizophrenia: Long-term Studies .......................................................... 19

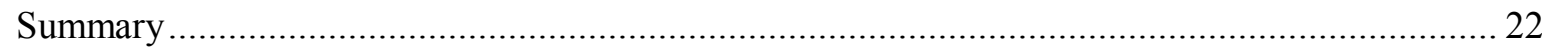




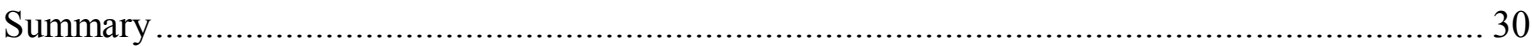

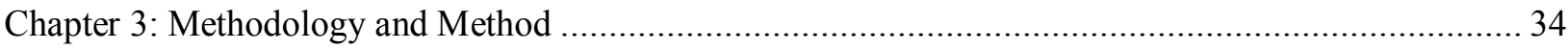

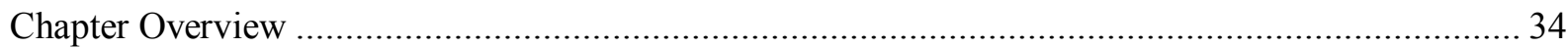

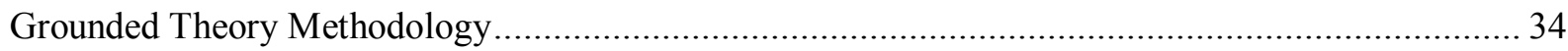

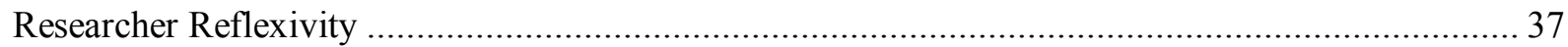

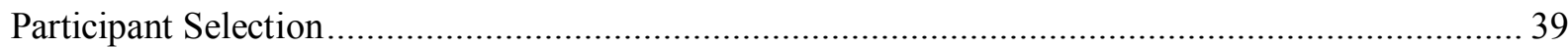

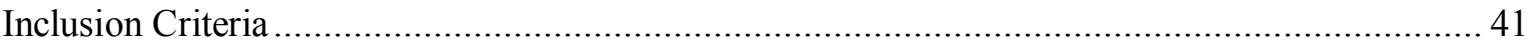

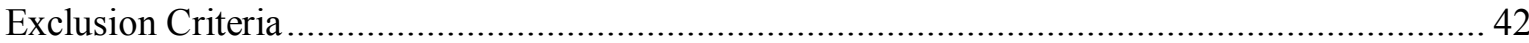

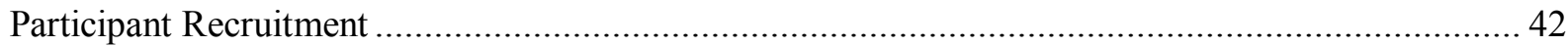

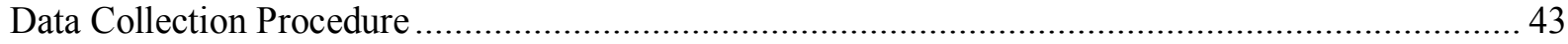

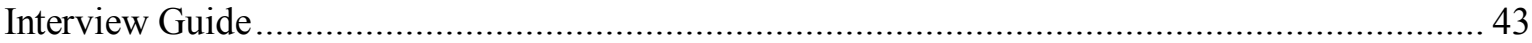

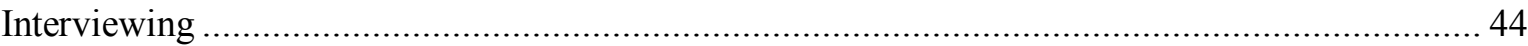

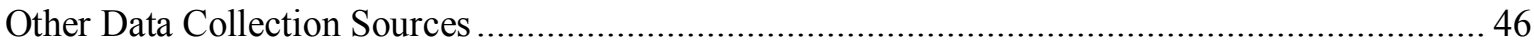

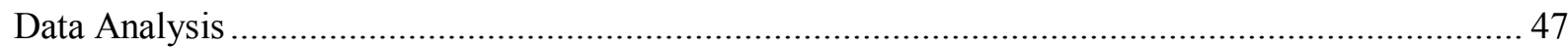

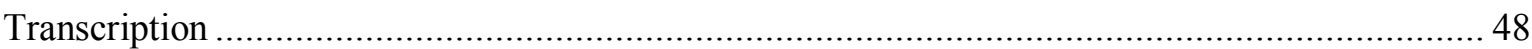

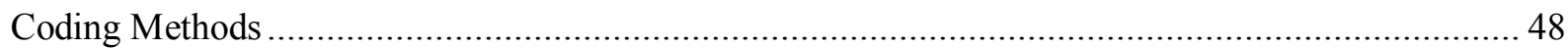

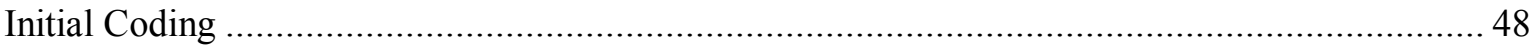

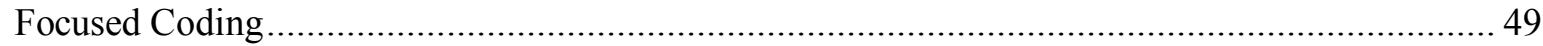

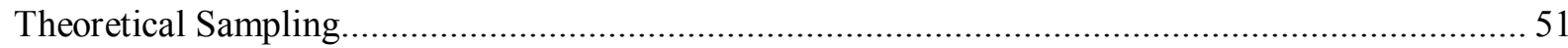

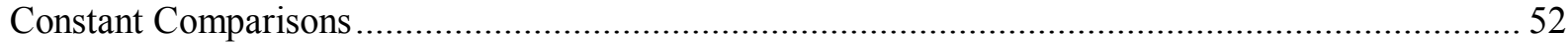

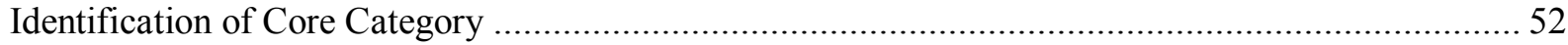




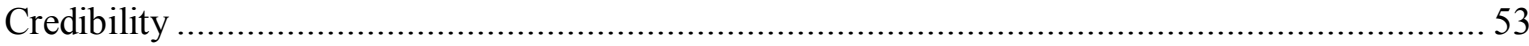

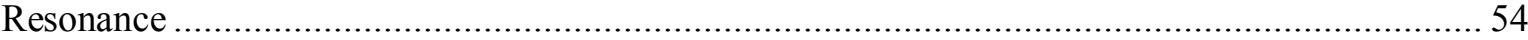

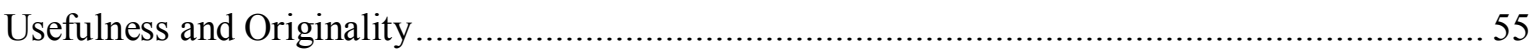

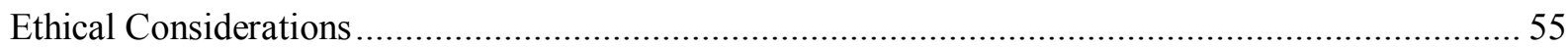

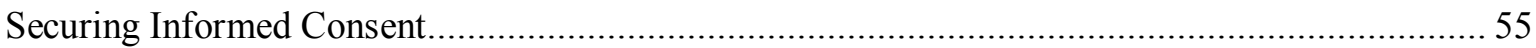

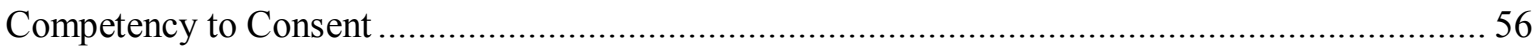

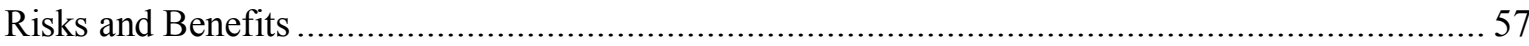

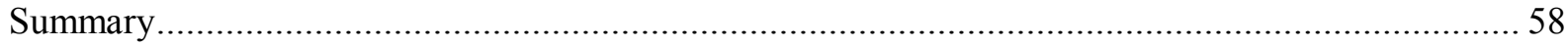

Chapter 4: Contextualizing the Participants: Who Were They? ......................................................... 59

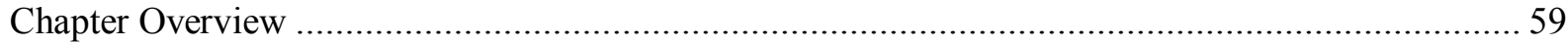

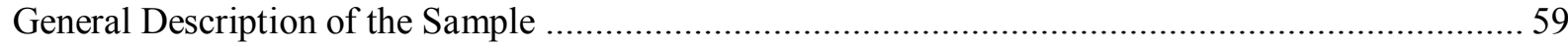

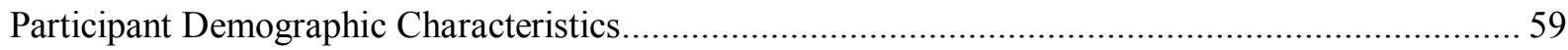

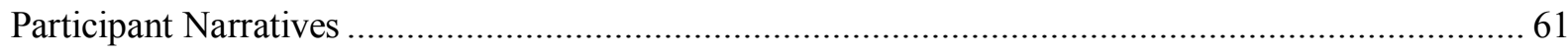

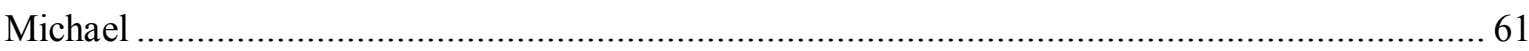

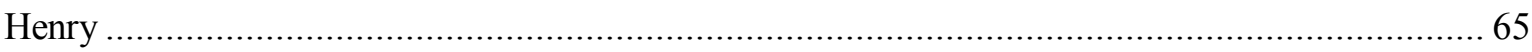

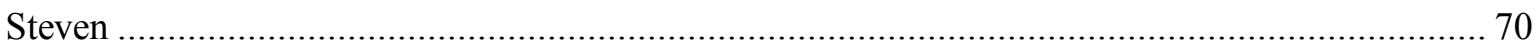

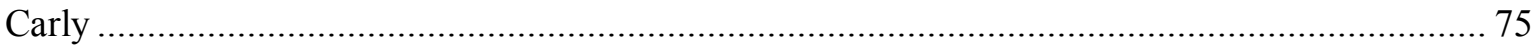

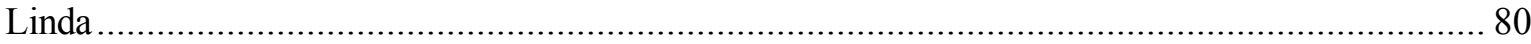

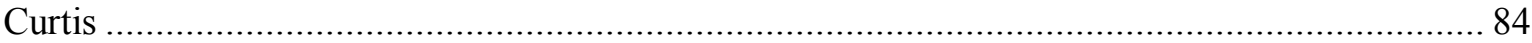

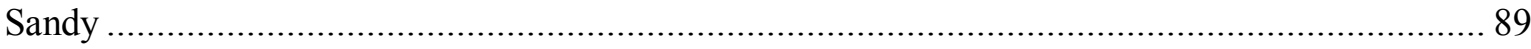

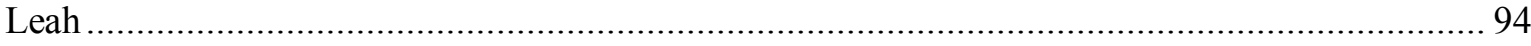


Laura

John

Summary.

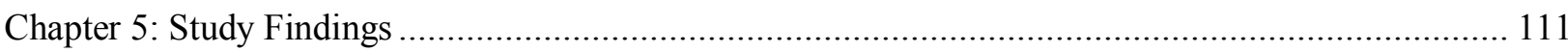

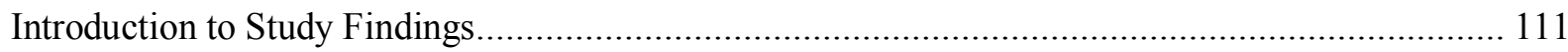

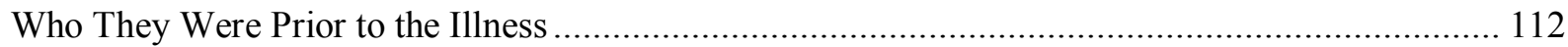

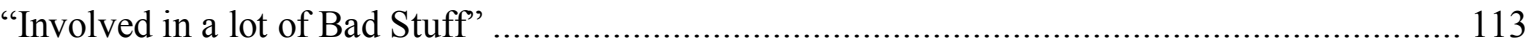

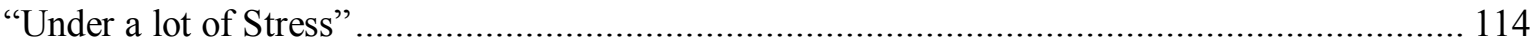

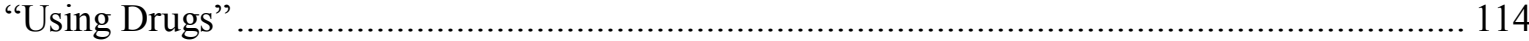

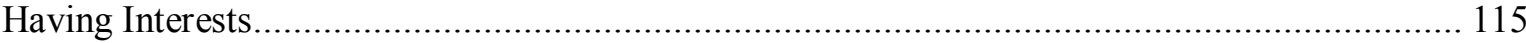

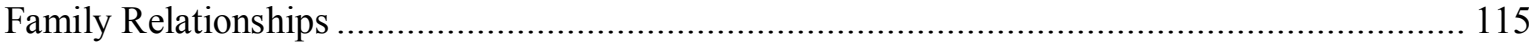

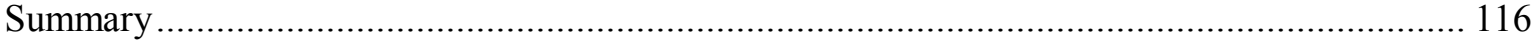

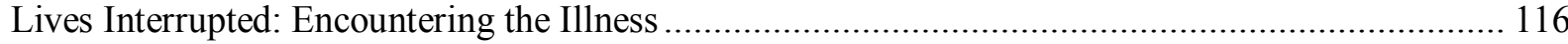

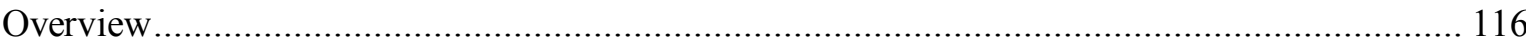

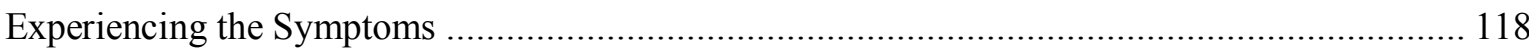

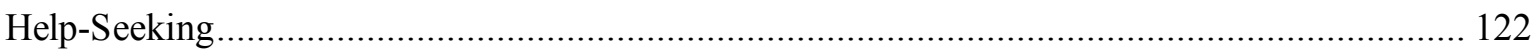

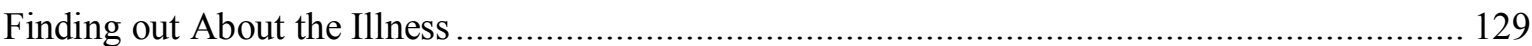

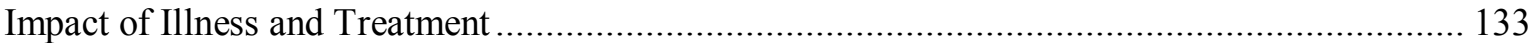

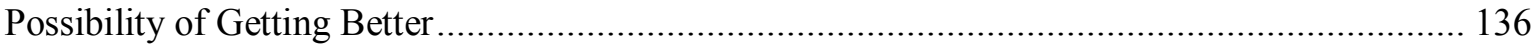

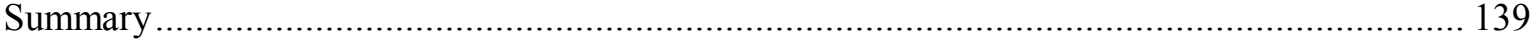

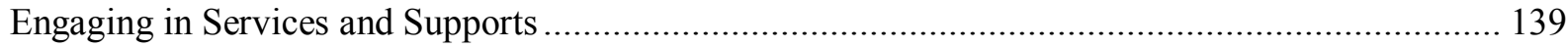

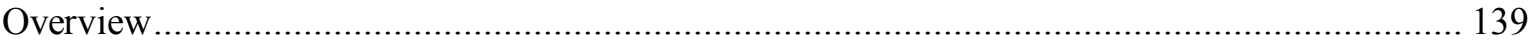




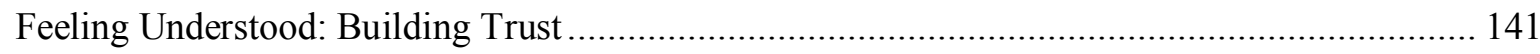

Striving to Get Better: The Role of Medication ................................................................... 145

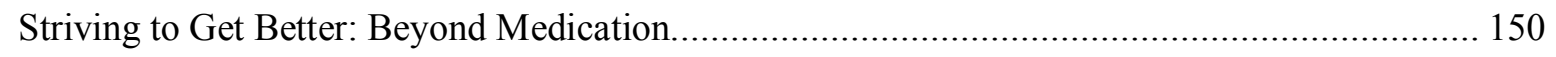

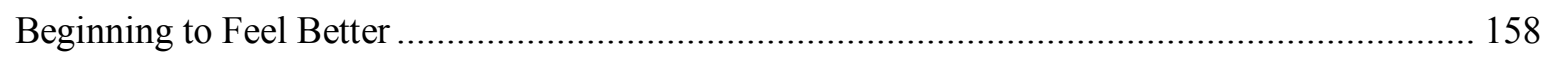

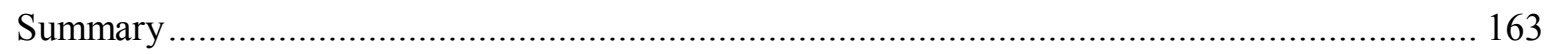

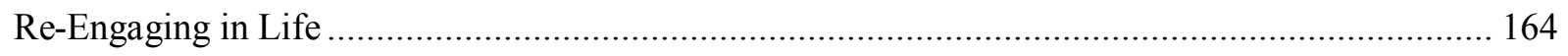

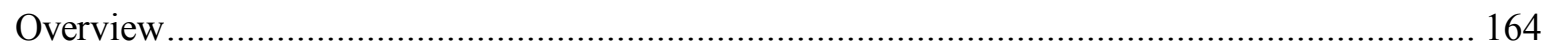

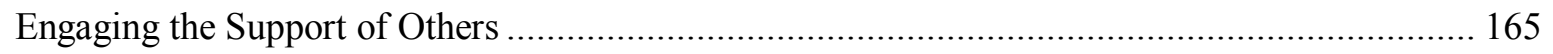

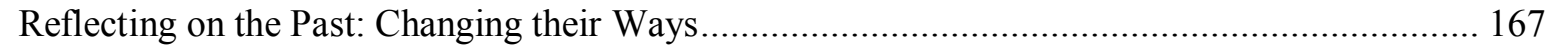

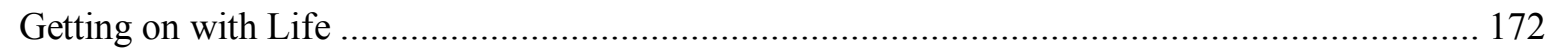

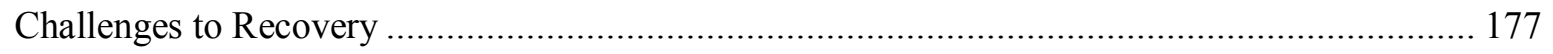

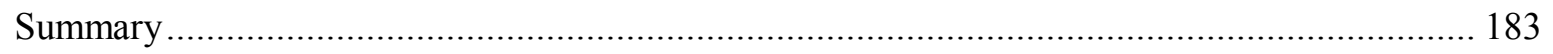

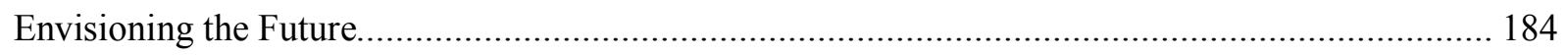

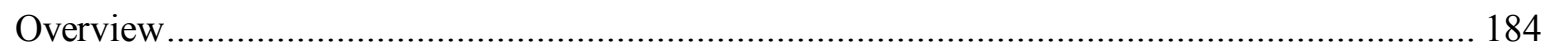

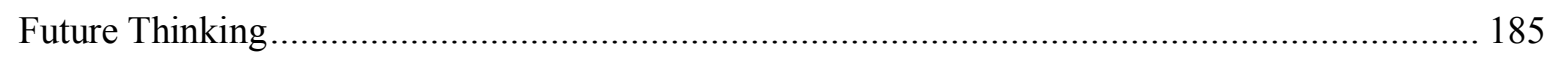

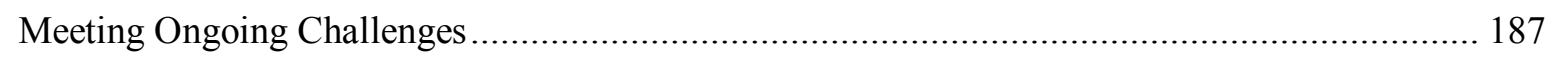

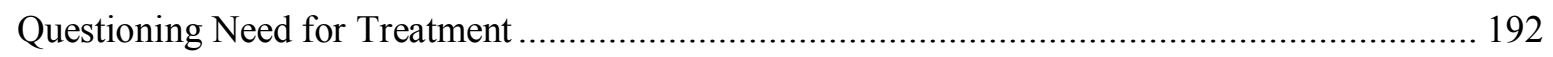

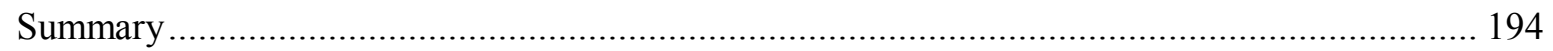

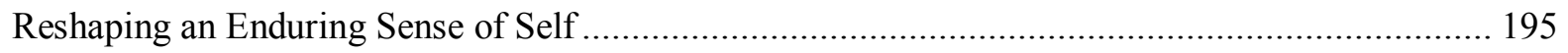

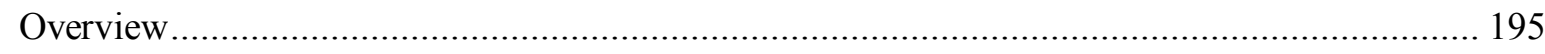

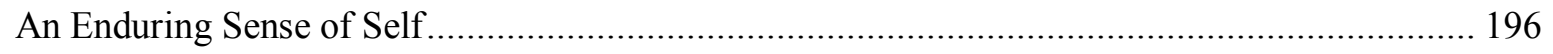

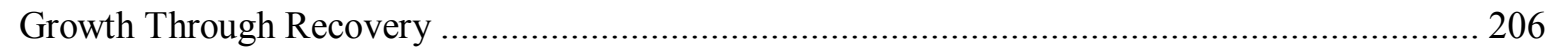




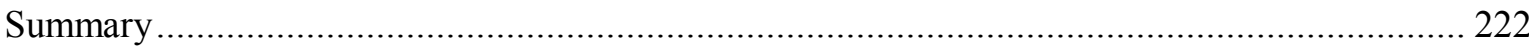

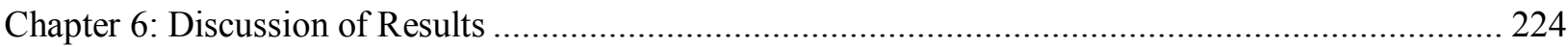

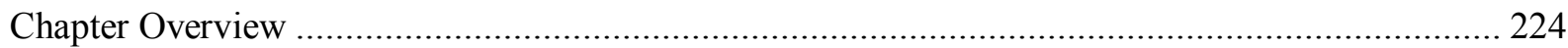

Discussion of Emergent Model ............................................................................................... 224

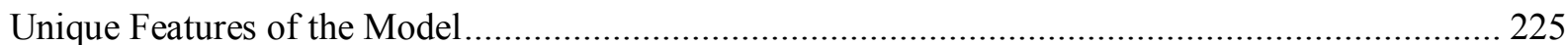

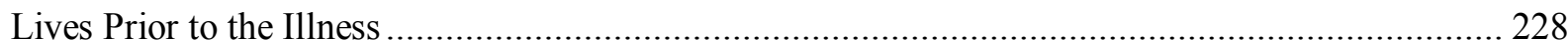

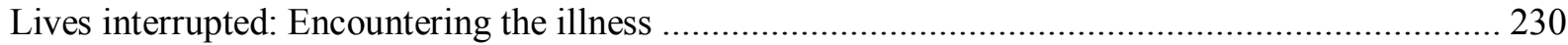

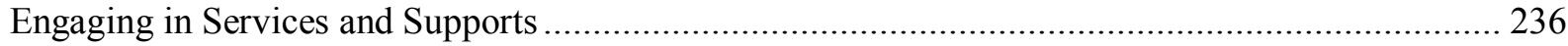

Re-engaging in Life

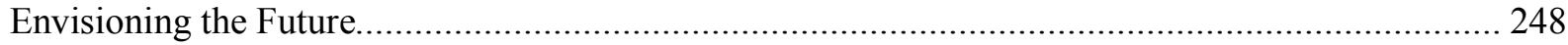

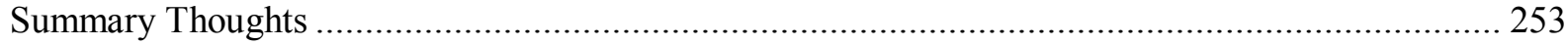

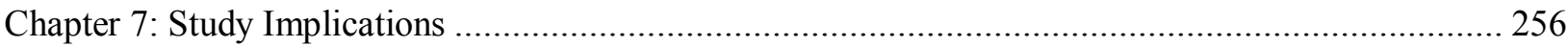

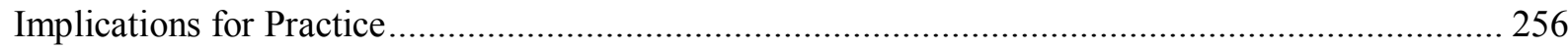

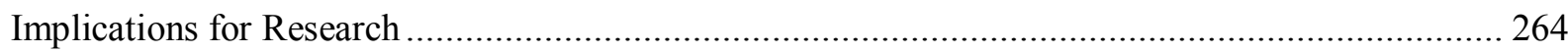

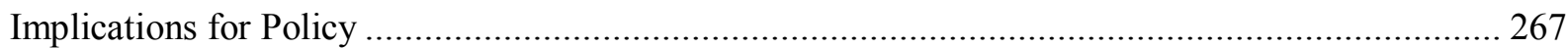

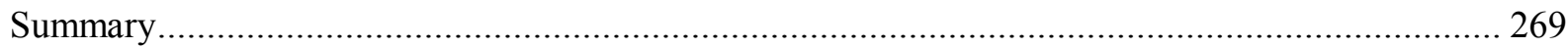

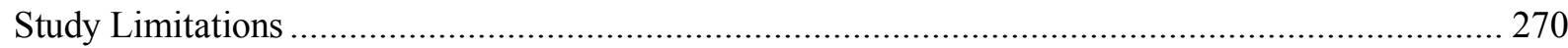

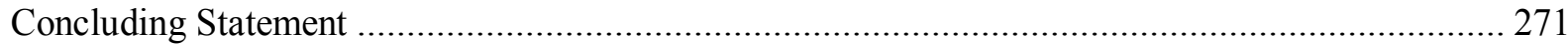

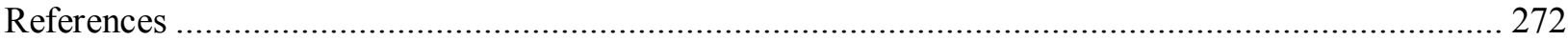




\section{List of Tables}

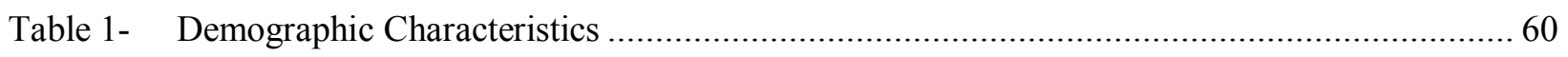

Table 2a- Summary of initial codes (primary participant interviews) ........................................... 297

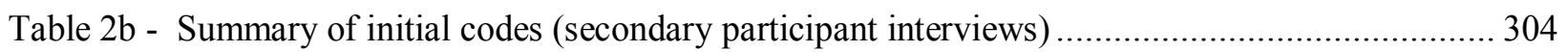




\section{List of Figures}

Figure 1 - Recovery as a Process - Categorization of Focused Codes that Subsume Initial Codes... 307

Figure 2 - Reshaping an Enduring Sense of Self: The Process of Recovery From a First Episode

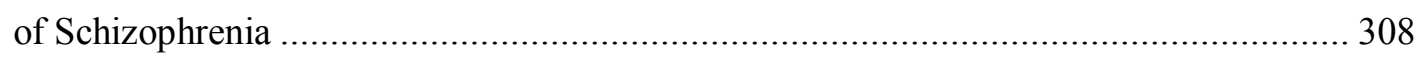




\section{Appendicies}

Appendix A1 - Letter of Invitation to the Potential Participants by the Intake Coordinator .................. 284

Appendix A2- Letter of Invitation to the Participant by the Researcher ........................................... 285

Appendix B - Informed Consent Letter to Participate in a Research Study .................................... 286

Appendix C (a) - Primary Participant Interview Guide Questions ................................................. 289

Appendix C (b) - Secondary Participant Interview Guide Questions ................................................. 290

Appendix D - Informed Consent Letter for Secondary Participant to Participate in a Research Study ... 291

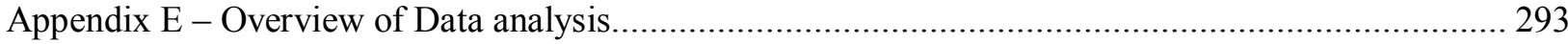

Appendix F - Initial codes that Emerged from Primary Participant Interview Guide Questions ............ 294 


\section{Chapter: 1: Introduction and Background}

Mental illness is a significant health problem that affects Canadian people of all ages, cultures, educational, and income levels (Health Canada, 2002). Schizophrenia affects approximately $1 \%$ of the Canadian population over the course of their lifetime (Public Heath Agency of Canada, 2002), and accounts for over 6.85 billion dollars of direct and indirect Canadian health care costs and productivity loss annually (Goeree et al., 2005). The onset of schizophrenia typically occurs during late adolescence or young adulthood. The symptoms encountered during a first episode of schizophrenia (FES) can affect the individual's thoughts, perceptions, and social functioning (Addington et al., 2005). As a result, this illness can influence educational achievement, occupational or career opportunities, the formation and nature of personal relationships, and a young person's sense of self.

Despite the significant challenges associated with schizophrenia, there is a new optimism about recovery, particularly related to improved pharmacotherapy (TauscherWiniewski \& Zipursky, 2002; Whitehorn et al., 2002). However, while many advances in understanding the treatment of schizophrenia have occurred over the past decade, little is known about the process of recovery from a FES. To date, the study of recovery in the field of mental health has focused on chronic mental illness. Therefore, exploring this topic in the earliest phases of illness provides an opportunity to gain a greater understanding of recovery that may be achieved for these young adults. 


\section{Study Purpose}

The need to explore the process of recovery has been identified by Anthony and his colleagues (2003), who state that there is a need to understand common dimensions of recovery that occur amongst individuals. However, a review of the literature indicated that very little scientific knowledge has been generated regarding recovering from a FES. Given the subjective nature of the recovery process, constructivist grounded theory was selected as the study methodology, since a strong focus is placed on a theoretical understanding of the socially constructed meanings that form the realities of people's lives concerning their recovery process. Grounded theory studies allow researchers to build theories in previously unexplored or under explored areas, through a rigorous system of data collection and analysis. This in turn leads to the discovery of a theoretical understanding about a particular social process.

Through the rigorous application of constructivist grounded theory, the aim of this qualitative study was to develop a substantive theory that describes the process of recovery from a FES. A substantive theory is one that emerges from one specific content area (e.g., FES) (Strauss \& Corbin, 1990). The knowledge derived from this research was intended to assist others who are recovering from FES and also inform clinicians, researchers, and policy makers of the needs identified by these individuals. Furthermore, this study allowed the voices of individuals with a FES to be heard. These individuals can offer an essential perspective with which to understand their recovery process. 


\section{Research Questions}

The research questions that guided this study were:

1) How do individuals who have experienced a first episode of schizophrenia describe their process of recovery?

2) How does an identified individual (e.g., friend, family member, teacher, clinician) describe their role during the participant's process of recovery, and their perception of the recovery process?

\section{Organization of the Thesis}

This thesis is comprised of seven chapters. Chapter 1 serves to introduce the research topic, study purpose, and research questions to be addressed in this study. Chapter 2 defines what is meant by recovery, (including objective and subjective perspectives), reviews the literature on recovery in FES, long-term studies of recovery from schizophrenia, and conceptual models that describe the recovery process in long-term mental illness. Chapter 3 outlines the methodology used in the study, and the specific methods implemented. Chapter 4 serves to introduce the study participants to the reader. The purpose of this descriptive chapter is to provide an overall picture of the participants and to give the reader an appreciation of the extent and variation of the sample by providing a narrative summary for each participant. Chapter 5 discusses the findings in detail. Specifically, the phases that comprise this emergent model from a FES are explored. Chapter 6 focuses on the discussion and inherent interpretation of the study findings that led to the development of a substantive theory of the process of recovery from a FES. Chapter 7 provides the implications of the study findings as they relate to practice, research, and policy development, followed by study limitations and concluding statement. 


\section{Chapter 2: Review of the Literature}

\section{Chapter Overview}

The purpose of this chapter is to review the literature regarding recovery, with a specific focus on the recovery process in first episode schizophrenia (FES). As the purpose of this study is to understand the subjective experience of recovering from a FES, I will identify the current definitions (including objective and subjective perspectives) of recovery. I will also historically situate the term recovery, highlighting its evolution. An overview of the literature that examines recovery from a FES will be provided. Given the paucity of literature in this area, long-term studies as they relate to understanding recovery from schizophrenia will also be reviewed. Finally, a review of the existing conceptual models in the literature that describe the processes of recovery from long-term mental illness will be conducted in order to assess their relevance to a FES. Chovil (2005), in his personal account, reflects that a FES occurs at a time in an individual's life "when career and romance choices are being evaluated and chosen, when one's place in the world is being defined...at a key developmental period during the transition from dependent adolescent to independent adult..."(p. 408). Therefore, given that the illness onset and subsequent recovery occurs in adolescence and/or early adulthood, I will provide an overview of Arnett's (2000) emerging adulthood theory of development. This approach to the literature review is aligned with Charmaz's (2006) assertion that in the literature review it is important to analyze the most significant works in relation to what will be addressed in the grounded theory.

The relevant literature related to the following key words was explored: first episode schizophrenia, first episode psychosis, schizophrenia, outcome assessment, recovery of function, recovery, symptomatic and functional recovery, phases, and/or recovery process, in addition to literature on emerging adulthood. Given the nature of the key words the following 
data bases were searched: Medline, Cinahl, PsychInfo, Embase, and Cochrane Review. Reference lists from articles were examined to ensure that the review was complete. Web of Science and Pub Med was also used to locate additional articles that were identified on reference lists.

\section{Recovery from Mental Illness: How is it Defined?}

The concept of recovery in mental health has been defined in many different ways. In my review of the literature on recovery, it is apparent that there have been two major approaches to understanding recovery. Specifically, one approach involves the assessment of recovery using objective/quantitative indicators of outcome, such as symptom severity and level of functioning, and will be referred to as the objective approach. Whereas, a second approach, focuses on understanding the subjective experience of recovery; specifically the processes involved in growing beyond the illness experience to create satisfying meaningful lives. This approach will be referred to as the subjective approach. As this is a qualitative study, an emphasis will be on reviewing the subjective definitions of recovery. Authors such as Bellack (2006) and Lieberman et al. (2008) recommend moving toward a synthesis of both approaches; acknowledging that a combination of both these dimensions is important to further understand recovery.

It is important to examine how the term of recovery is currently defined according to both objective and subjective approaches, in order to understand the application of the recovery concept to FES. Until the 1970's, the definition of recovery was influenced by the medical model and was defined from an objective perspective in terms of the elimination of symptoms caused by mental illness. Bellack (2006) asserts that objectively, recovery is defined as an outcome with an emphasis on symptom reduction or elimination, and a return to pre-morbid levels of function. 
Subjective definitions of recovery include the lived experiences of mental health consumers (i.e., those who have experienced a mental illness) (Deegan, 1996). There have also been numerous seminal recovery narratives written by consumers (Deegan, 1988, 1996; Fisher, 1994; Leete, 1989; Unzicker, 1989) on what recovery means to them. First person accounts of recovery from mental illness have defined recovery as a transformational and incremental process of change (Gagne, White \& Anthony, 2007). Consumer definitions of recovery also describe recovery as a non-linear longitudinal process that occurs over time, furthermore that the degree of recovery varies for each individual (Bellack, 2006). Patricia Deegan (1988) a mental health consumer/psychologist and well known contributor to literature in the recovery field describes recovery "as a process, a way of life, an attitude, and a way of approaching the day's challenges. It is not a perfectly linear process. At times our course is erratic and we falter, slide back, regroup and start again..." (p. 15).

In addition to the subjective definitions of recovery provided by mental health consumers, key authors in the field provide definitions that also highlight the subjective nature of recovery. In Onken's et al. (2007) review paper, an ecological framework was used to provide a dimensional analysis of the recovery literature (drawn from subjective perspectives) that assesses the growing consensus of what recovery is or what its definition should entail. Key definitional elements identified include individual attributes such as hope, self-determination, self-agency, meaning/purpose, and awareness/potential. Additional elements include interactions with others such as family, friends, and/or mental health professionals. These authors conclude that individuals seem to use their internal resources (e.g., hope) and their external resources (e.g., family and/or friends) as they move through their recovery. 
Davidson, O’Connell, Tondora, Lawless and Evans (2005) put forward nine common elements of recovery (as applied to long term and persistent mental illness) that were derived from consumer/survivor and psychiatric rehabilitation literature. Their definition of recovery includes: renewing hope and commitment, redefining self, incorporating illness, involvement in meaningful activities, overcoming stigma, assuming control, becoming empowered and exercising citizenship, managing symptoms and being supported by others. Many of the references that were reviewed when establishing these common elements of recovery were drawn from the process of recovery models (not specific to FES) that are described later in this chapter.

William Anthony (1993), a researcher who has written extensively on recovery, defines recovery as "the development of new meaning and purpose in one's life as one grows beyond the catastrophic effects of mental illness" (p. 15). He further adds that recovery is " $a$ deeply personal, unique process of changing one's attitudes, values, feelings, goals, skills and/or roles. It is a way of living a satisfying, hopeful, and contributing life even with limitations caused by illness" (p. 15).

In an attempt to address the inconsistencies regarding the definitions of recovery found in the literature, Liberman et al. (2002) focused on both objective and subjective recovery criteria in order to derive a comprehensive and consistent definition of recovery. According to these authors, recovery from schizophrenia involves not only resolution of the symptoms, but also gains in vocational functioning, independent living, and social relationships. Their operational definition of recovery from schizophrenia includes: “symptom remission, full- or part-time involvement in work or school, independent living without supervision by family or surrogate caregivers, not fully dependent on financial support from disability insurance, and having friends with whom activities are shared on a 
regular basis" (p. 256). For an individual to be identified as in recovery from the long-term illness of schizophrenia, each of the above criteria should be sustained for at least two consecutive years. Although these operational criteria were submitted for validation to focus groups of clients, family members, practitioners, and researchers (Liberman et al., 2002), this definition has not been validated with FES clients and does not include the subjective perspective of recovery.

\section{Recovery from Mental Illness: Situating the Concept Historically}

In my review of the definitions of recovery, the limited application of the concept of recovery to FES was apparent. Therefore, I found it necessary to examine the concept of recovery historically. Despite the tendency to view recovery as a recent concept within the field of mental health services, the origin of the term can be traced back to the 1800's. The term recovery was used by hospital "asylum" superintendents who tracked treatment outcomes (e.g., discharges) as either recovered or improved (Loveland, Weaver Randall, \& Corrigan, 2005). Their definition of recovery usually referred to elimination of observed symptoms, at least during the hospital stay. An apparent flaw in this methodology was that it did not account for patients who were never discharged from hospital and those cycling back through hospitals. Of interest is that Worcester State Hospital, the first ever state-operated psychiatric "asylum" in America, had recovery rates of almost 70\% during the period of 1833-1852 (Bockoven, 1972; Deutsch, 1949 as cited in Loveland et al., 2005). However, the publication of The Curability of Insanity in 1885 by Dr. P. Earles uncovered the invalid method for calculating recovery rates and re-calculated rates to be at or below $30 \%$ for the major "asylums" in America. This finding was coupled with the pessimistic view held by Kraepelin (1919) regarding the deteriorating course of schizophrenia which he termed 
"dementia praecox", and which contributed to the historical view that individuals with mental illness were almost always incapable of recovering.

During the first half of the $20^{\text {th }}$ century, the use of somatic interventions such as Electroconvulsive Therapy (ECT), insulin shock therapy, psychosurgery, as well as the early use of psychopharmacology, reintroduced what was termed the "revived cult of curability" (Pressman 1998, p. 159 as cited in Loveland et al., 2005). The use of the term recovery during this time referred to eliminating the symptoms associated with mental illness, which is consistent with the medical model where clinicians rather than the individuals experiencing mental illness defined recovery.

The emergence of the bio-psychosocial model of mental illness occurred during the late 1970's. This model suggested that research related to recovery and its course needed to account for the multidimensional nature of the process. Specifically, the changes in biological (e.g., symptoms), psychological (e.g., use of coping strategies), environmental (e.g., access to programs), and sociopolitical factors (e.g., impact of stigma from the community) need to be captured over time (Loveland et al., 2005). This is in sharp contrast to the historical field of mental health where in its "dark past...each disorder was considered to be intractable and stories of recovery were rare...people living with [psychiatric] disorders were expected to end up in the least favorable places in society, the gutter, prisons, asylums, or morgues" (Gagne et al., 2007 p. 33).

The most recent understanding of recovery arose out of the consumer advocacy movement in the United States during the 1970's (Loveland et al., 2005). This view of recovery is not based on the medical model but rather based on the subjective lived experience of those individuals "living with and trying to recover from a mental illness and 
the iatrogenic effects of institutional and other medically based treatment interventions"(Frese, 1998; Mead \& Copeland, 2000 as cited in Loveland et al., 2005 p. 27).

In reviewing the historical evolution of recovery over time, it is clear that the concept of recovery has evolved in the general mental health literature. Bellack (2006) applies current thinking about recovery to schizophrenia:

...in contrast to earlier views of schizophrenia as a debilitating condition with a very poor prognosis, the recovery model assumes that all consumers have the capacity to improve and develop a life distinct from their illness. In a sense schizophrenia is seen as more akin to chronic medical conditions like diabetes or heart disease which may interfere with functioning but which do not define the person in his or her own eyes or in the eyes of society. (p. 440)

\section{Recovery in First Episode Schizophrenia Studies}

Despite the many advances in understanding and treating FES, little examination has occurred regarding the process of recovery from it. Although the literature provides some conceptual understanding regarding recovery styles, a review of the literature did not reveal any studies that provided a conceptual understanding of the process of recovery from FES. The studies that have been conducted are primarily quantitative and predominately address recovery in the context of symptom remission, outcome measurement, and to a much lesser extent functional recovery. In addition, the perspectives of consumers are notably absent. Clearly, there is a gap in the literature which this current study serves to address. In summarizing the outcome literature, I will address and distinguish between meta-analytic and individual studies of recovery. The studies are grouped according to a meta-analytic study, symptomatic and functional recovery, and longitudinal studies all of which include both prospective and retrospective designs.

\section{Meta-Analytic Study}

In a salient review article, Menezes, Arenovich, and Zipursky (2006) conducted a systematic review of longitudinal outcomes studies of first episode psychosis (FEP). These 
authors conducted a literature search (1966-2003) for prospective studies examining

outcome in first-episode non-affective psychosis. Their review included thirty-seven studies, representing 4,100 patients. The reviewed studies varied in the categories of outcome used, the most common being 'good' (54\% of studies) and 'poor' ( $34 \%$ of studies). In studies that had these categories, good outcomes were reported in $42.2 \%(3.5 \%)$ of the cases, and poor outcomes in $27.1 \%(2.8 \%)$ of the cases. Specific predictors that were associated with better outcome domains were: "combination of pharmacotherapy and psychosocial therapy, lack of epidemiologic representativeness of the sample, and a developing country of origin. Use of typical neuroleptics was associated with worse outcome" (p. 1349). The authors concluded that outcome from FEP may be more favorable than previously described and both methodological variables and treatment may be important contributors to outcome. They recommend that a multi-dimensional, globally used definition of outcome is required for future research. This model would include a combination of symptomatic/functional and personal elements that would be measured at different points in time. Limitations of this review included variability of study parameters and definitions, and an absence of baseline and pre-morbid measures.

\section{Studies of Symptomatic and Functional Recovery in FES}

The following individual studies are grouped according to symptomatic and functional recovery, recovery style, and longitudinal studies which include both prospective and retrospective designs. A number of studies that have focused on recovery have been conducted in various treatment contexts focusing on mainly symptomatic and/or functional recovery. For example, a study by Whitehorn, Lazier, and Kopala (1998) focused on recovery in the context of a psychosocial rehabilitation program after the onset of psychosis. Findings indicated that fewer than $20 \%$ of patients per year who participated in this program 
required hospital readmission. Also, functional outcomes were found to be strongly influenced by age and level of functioning of the client prior to the onset of psychosis. For example, clients under the age of 19 years demonstrated an ability to continue with their education and improved function at home. Those clients over 27 years were also able to resume a degree of social and occupational independence. However, there were clients between 19-27 years who appeared to achieve less recovery success in social and occupational functioning and required more intensive psychosocial rehabilitation. The authors suggested that this is attributed to not yet leaving home or developing a consistent work situation, "often due to prodromal dysfunction or an extended period of untreated psychosis" (p. 1140).

A study by Whitehorn, Brown, Richard, Rui, and Kopala, (2002), that focused on understanding the dimensions of recovery in early psychosis, found that after one year, of 103 clients treated for early schizophrenia or related psychotic disorder, $67 \%$ met criteria for symptomatic recovery (no relevant Positive and Negative Syndrome Scale (PANSS) item greater than mild) and 50\% met criteria for overall functional recovery using the Social and Occupational Functional Assessment scale (SOFA >than 60).

Malla and Payne (2005) reviewed the literature in first episode schizophrenia and related disorders to understand the heterogeneity of the psychopathology of schizophrenia, as well as the trajectories of its outcome. With respect to outcome, their review found that short term functional outcome improves after treatment for the first episode, however longer term outcome remains "poor for a substantial proportion of patients" (p. 650). This level of longterm outcome was associated with pre-adolescent onset, poor premorbid adjustment, cognitive functioning and cerebral asymmetry, as well as negative symptoms during 
prodromal and post onset phases. They also noted the potential effects of early intervention on functional outcome and quality of life have not been well studied.

Thompson, McGorry, and Harrigan (2003) studied recovery style and clinical outcome in first-episode psychosis. 196 first-episode psychosis patients (aged between 16-30 years) participated in the study. Several symptom severity and outcome measures were used. Results found that more patients with schizophrenia spectrum disorders as opposed to patients in other diagnostic groups (e.g., affective disorders) tended to use a "sealing over approach" to recovery (e.g., isolating the psychotic experience). Furthermore, patients who integrated rather than seal over their illness experience during their recovery phase had "better functioning and outcome at 12 months" (p. 34). The study highlights that recovery style changes over time, noting that some of the schizophrenia spectrum patients who initially "sealed over" changed to a more integrated recovery style at 12 month follow-up. The authors therefore recommend the use of therapeutic strategies that can influence recovery style and improve long-term clinical outcome. It is important to be clear that in reviewing these findings it is not possible to make any conclusions about causality. Specifically, that those individuals who seal over are less likely to do well does not imply that other approaches for these individuals would necessarily lead to a better outcome. Sealing over could be considered a marker of poor outcome rather than a mechanism.

\section{Longitudinal Studies}

The International Study of Schizophrenia (Harrison et al., 2001 as cited in Bellack, 2006), conducted 15 and 25 year follow-ups with participants originally recruited from earlier international studies. The definition of recovery included having employment, resuming former role functioning, not seen as mentally ill by family, and no overt psychotic symptoms. Data was collected using standardized assessments of course and outcome. 
Findings revealed that $48.1 \%$ of participants were rated as recovered. Furthermore, $37.8 \%$ were rated as recovered using the same criteria in addition to a Global Assessment of Functioning score greater than 60 . The authors draw attention to the overarching message that their findings reflect, specifically that "schizophrenia and related psychoses are best seen developmentally as episodic disorders with a rather favorable outcome for a significant amount of patients" (p. 515). However, the authors caution that the hope that these findings represent should not be overestimated, highlighting that participants with "poor prognostic indicators" (p. 515) were not captured in follow-up, and mortality was elevated throughout the study. The authors also identify the need for future studies to explore environmental attributes that promote recovery.

Robinson et al. (2004) conducted a prospective study that focused on symptomatic and functional recovery. 118 young adults (average age was 25 years) with a diagnosis of schizophrenia or schizoaffective disorder were recruited. Results indicated that although most patients improve significantly after their first episode was treated, the majority experience subsequent episodes, with only a few patients able to regain pre-morbid levels of functionality. Specifically, there was a low rate of recovery with $47 \%$ of participants achieving symptom remission after five years, and 25\% achieving adequate social functioning for two years or more. Factors associated with recovery were enhanced cognitive functioning, and shorter DUP (duration of untreated psychosis) before entrance to the study.

In a prospective follow-up study conducted by Harrow et al. (2005), 274 early young psychiatric patients were first assessed as inpatients and then over a course of 15 years reassessed five times. Diagnoses included 64 patients with schizophrenia, 12 with schizophreniform disorder, 81 patients with psychosis, and 117 non-psychotic patients. Using an operational definition of recovery these patients were evaluated for recovery for one or 
more years. This definition of recovery was described as the absence of major symptoms throughout the follow-up year, adequate psychosocial functioning including working halftime or more during the follow-up year, the absence of "a very poor social activity level" [as measured on] the 5-point S-C Social Activity Scale... and no psychiatric re-hospitalizations during the follow-up year" (p. 725). Over the 15 -year period slightly over $40 \%$ of patients with schizophrenia showed 1 or more periods of recovery.

The results by Harrow et al. (2005) found that schizophrenia remains a disorder with a relatively poor outcome, with having poorer courses than other types of psychotic and non psychotic disorders $(\mathrm{p}<.001)$. The study did not describe the process of recovery for participants who showed periods of recovery. However, the authors state that over $50 \%$ of patients with schizophrenia did not have a disorder that was chronic and continuous, but instead episodic. For other participants the episodes were more frequent and severe, with slower recovery. Another finding was that $40 \%$ who were in recovery at the 15 year mark were not taking antipsychotic medication. Bellack (2006) draws attention to this study finding suggesting that some patients are in recovery without maintenance medications.

Rosen and Garety (2005), in their retrospective study comment that it is difficult to predict which patients "will do best... who will have a single episode, recover well and not relapse" (p. 737). Following extensive chart review of a sample of 436 individuals with schizophrenia spectrum disorder with minimum follow-up period for at least 6 years, $15.6 \%$ of these individuals had a single episode of schizophrenia. Methods involved chart review for patterns of illness course at six years, socio-demographic and clinical variables (e.g., symptoms, duration of the prodrome) at first presentation. The authors conclude that working on insight, promoting close and supportive relationships, changing habits of drug use in the context of providing early and effective medication, and psychological and social 
interventions (e.g., promoting return to work) may improve the prevention of relapse from a FES. It is however, important to acknowledge in light of these findings that medication non adherence is the major factor which predicts relapse and that it is likely that these other factors contribute through adherence. Addington (2007) indicates that improved rates of relapse have been reported in specialized first episode psychosis programs. For example, The Lambeth Early Onset (LEO) study reported that 30\% of clients relapsed by 18 months (Craig et al., 2004), while the Calgary first episode program reported that $29.5 \%$ of their clients experienced relapse at 2 years (Addington, Addington, \& Patten, 2007).

\section{Summary}

A review of the studies that focus on the concept of recovery from a FES highlight certain features. To begin with, the perspective of young adults who are recovering from a FES, as well as the attention to developmental phase of emergent adulthood is notably absent. Further, the majority of studies focus on symptomatic and functional attributes of recovery rather than the actual process of recovery. Generally these results indicate that the outcomes of FES studies are more favorable than past schizophrenia outcome studies, thereby influencing how recovery is currently perceived. However, results of some of the studies indicate that challenges exist related to sustained recovery for FES over a period of time. Finally, given the major thrust within health care reform to incorporate recovery oriented care, research addressing this type of care for young people who have experienced a FES is also not apparent. The gaps in the existing literature suggest the need for a qualitative grounded theory study to illuminate our understanding of the process of recovery in FES and to identify those conditions which support recovery in FES over time. 


\section{Influence of Emerging Adulthood}

Given that illness onset and subsequent recovery occurs in adolescence and/or early adulthood with the majority of participant ages in the current study being between 18-25 years, an overview of literature on emerging adulthood theory of development will be provided as outlined by Arnett (2000). The onset of schizophrenia and its emotional sequelae has the capacity to significantly interfere with the developmental trajectory of young adults (McCay, Beansland, Leszcz, Goering, Seeman, Ryan, Johnston, \& Vishnevsky, 2006). These individuals are left to negotiate the challenges of this illness in the context of this developmental phase.

According to Arnett (2000) the term emerging adulthood captures the "dynamic, changeable, fluid quality of this period" (p. 477). This phase of development is drawn from studies of young people in the West especially in the United States and from countries that are highly industrialized. Arnett (2000) suggests that emerging adulthood is not a universal period, but rather only exists in cultures that "postpone the entry into adult roles and responsibilities until well past the late teens" (p. 478).

Emerging adulthood is a distinct developmental period from the late teens through twenties, with a focus on the ages of 18-25 years. Arnett (2000) proposes that it is a unique period demographically, and subjectively, in terms of identity exploration. According to Arnett (2000) during emerging adulthood, individuals explore a variety of possible life directions in the areas of love, work and worldviews. He describes that it is "a time of life when many directions remain possible, when little about the future has been decided for certain, when the scope of independent exploration of life's possibilities is greater for most people than it will be at any other period of the life course" (p. 469). 
In highlighting the identity formation issues within this phase of development Arnett (2000) proposes three main areas of love, work, and worldviews. In emerging adulthood, explorations focused on love relate to questions such as: "given the kind of person I am, what kind of person do I wish to have as a partner through life"? (p. 473). With respect to work experiences the questions tend to be focused on preparation for adult work roles. In exploring work possibilities, individuals within this phase may ask: "What kind of work am I good at? What kind of work would I find satisfying for the long-term? What are my chances of getting a job in the field that seems to suit me best?" (p. 474). In addressing changes in worldviews during this developmental phase, emerging adults consider it important to re-examine the religious beliefs that they have been brought up with in order to "form a set of beliefs that are a product of their own independent reflections" (p. 474).

Arnett (2000) proposes that there is a great degree of variability during this phase of life with an emphasis on change and exploration. Individuals at this stage have a wider scope of life activities to choose and therefore, are less likely to be constrained by role requirements. For example, Arnett cites that emerging adults have the highest rates of residential change of any age group, and that school attendance is pursued in a nonlinear way, at times combined with work and non attendance. In addition, Arnett (1998) has found that the capacity to attain individualistic qualities of character is instrumental in this phase. For example, these include: accepting responsibility for one's self, becoming a selfsufficient person, and making independent decisions (Arnett, 1997, 1998; Green et al., 1992; Scher et al., 1994, as cited in Arnett, 2000).

Not all of the explorations in this phase of development can be viewed as enjoyable as emerging adults can be met with rejection, or failure to achieve desired occupation. Emerging adulthood is characterized by high rates of risk behavior such as substance abuse 
which peak during this phase of development. One possible explanation for the increased risk behavior at this phase is the fact that these youth are "less likely to be monitored by parents" (p. 475), and are less constrained by roles such as marriage and parenting. However, despite these challenges, emerging adults tend to be highly optimistic about achieving their identified goals.

In summary, the illness for these participants occurred during their "emerging adulthood", a phase unique to the West and other highly industrialized Nations that normally focuses on people ages 18 to 25. During this highly fluid period in a person's life individuals explore a variety of life directions and establish an identity in the areas of love, work, and worldviews. The capacity to attain individualistic qualities such as accepting responsibility for one's self, and becoming self sufficient are instrumental in this phase. Change and exploration are also prevalent during this phase often times including high rates of risk behavior such as substance abuse. These individuals are typically highly optimistic about achieving their goals.

\section{Recovery from Schizophrenia: Long-term Studies}

It is important to highlight that the use of the term recovery in these long-term studies is focused on outcome over time and is keeping with the objective definition of recovery (p. 5). The studies that have been conducted are primarily quantitative and predominately address recovery in the context of symptom improvement, outcome measurement, and functional recovery. In reviewing these studies, it is important to recognize that there are diagnostic issues that have changed over time that likely impact the study results. In summarizing this outcome literature, I will outline a classic meta-analytic study by Hegarty et al. (1994), followed by individual long-term studies. 
Hegarty et al. (1994) in their meta-analysis of the schizophrenia outcome literature identified 821 studies from 1895 to 1992 with close to $50 \%$ of them occurring between the 1950's and 1994. The authors note that the development of antipsychotic medications in the 1950 's introduced a new era of treatment with hopes of improved outcomes. Overall, 320 studies were reviewed, representing 51,800 subjects. Given the varied criteria used in these studies to describe outcome, the authors used a generalized standard. The authors developed a broad definition of outcome which included having been described "as recovered, in remission, well without residual symptoms, minimally or mildly symptomatic, improved without significant deficit, socially recovered, or working or living independently" (p. 1410). These authors reported that only $40 \%$ of patients were improved after follow-up averaging 5.6 years. It is important to note that data was analyzed by decade with outcome rates generally improving over time. Limitations of this review included limited inclusion criteria, such as, only studies with biological treatments, and no attempt to assess psychosocial or community based aspects of comprehensive care. It also included studies with potentially unreliable diagnostic or outcome criteria, and those that rarely provided information about baseline clinical status. Menezes et al. (2006) cite significant differences between Hegarty et al.'s (1994) meta-analysis and their review of outcome studies in FEP. For example, compared to Menezes et al. (2006), Hegarty et al.’s (1994) review included a longer mean follow-up (6 years), a larger percentage of chronic patients, and calculation of percentage improvement (which itself was broadly defined) that may have contributed to lower rates of improvement.

Jobe and Harrow (2005) reviewed ten long-term studies that assessed outcome as it related to recovery for patients with schizophrenia. Their definition of outcome included the absence of major symptoms and adequate psychosocial functioning assessed by varied 
quantitative measures and included controlled studies with a ten year follow up period or more. Their results found that the natural course of schizophrenia can be divided into mild, moderate, and severe. Variance in outcome occurred across the studies reviewed, however, schizophrenia remains an illness with a relatively poor course and outcome, compared to other psychotic and non-psychotic psychiatric disorders. However, "subgroups of schizophrenia patients had extended periods of recovery, some without the benefit of extensive mental health aftercare treatment, and generally patients with schizophrenia did not show a progressive downhill course" (p. 892). Overall, their review demonstrated that 21\%$57 \%$ of patients with schizophrenia showed good outcomes (based on various quantitative scales).

In the Vermont study, one of the well known long-term studies of individuals with schizophrenia, Harding and colleagues (1987a) conducted a retrospective study of 269 psychiatric patients diagnosed according to DSM-I criteria, 168 of whom received a diagnosis of schizophrenia. The purpose of this study was to provide a comprehensive clinical picture of the long-term course of schizophrenia (and other severe psychiatric disorders) through the use of a variety of structured measurement tools that assessed participant functioning in a wide variety of areas (e.g., social support, use of services, psychopathology) over time. These patients were treated with medication and intensive community outpatient rehabilitation. Findings revealed that after 20 years, $60 \%$ of the schizophrenia cohort scored over 61 on the GAF (Global Assessment of Functioning). This GAF score indicates "some mild symptoms or some difficulty in social, occupational, or school functioning, but generally functioning well, [and] has some meaningful interpersonal relationships" (DSM-IV-TR, p. 32). The individuals with schizophrenia scored very well on the Strauss and Carpenter (1972) outcome dimensions (e.g., symptoms improvement, 
employment status), with $68 \%$ of individuals showing minimal or no symptoms, and $61 \%$ employed in the last year of the study, although the criteria for employment status were not reported. The authors also highlight that this sampling of patients with schizophrenia in their 60 's reflects the possibility of some gradual improvement as patients with schizophrenia age (Harding et al., 1987a as cited in Jobe \& Harrow, 2005).

In their review of long-term recovery studies for schizophrenia, Kelly and Gamble (2005) draw attention to other long-term studies (Bleuler 1968; Ciompi 1980; Huber, Gross, \& Schuttler, 1980; and Ogawa, Miya, Watara, Nakazawa, Yuasa, \& Utena, 1987) that have yielded similar conclusions to Harding and colleagues (1987b) highlighting that over half the participants in these studies showed improvement or recovery across their life time. Again, recovery in these studies was based on the scores of a variety outcome measurement scores.

A classic study by McGlashan (1987) focused on recovery style from mental illness and long-term outcome. Recovery style was defined as either being integrative or sealed over. An integrative recovery style is "characterized by the patients' awareness of the continuity in their mental activity and personality prior to the psychotic experience, during psychosis and through recovery" (p. 681) and sealing over (i.e., isolating the psychotic experience) were identified as recovery styles from schizophrenia, with both being associated with good functional outcome. However, patients who had an integrated recovery style scored functionally better. Both of these recovery styles were correlated with motivation, premorbid social and work capacities, and baseline intelligence suggesting that these styles can be relatively enduring personality traits.

\section{Summary}

In reviewing these long-term outcome studies (all of which use varied quantitative methodologies) it is apparent that recovery has been assessed through the use of various 
objective outcome measures (e.g., quantitative symptom and functional instruments). Most studies focused on symptom reduction as the main component of recovery status, rather than including any indication of the subjective perspective. The study by McGlashan (1987) examined the recovery style from mental illness and long-term outcome, whereby there was some effort made to assess how patients viewed their illness experience. However, it is noteworthy that recovery was assessed using objective measures rather than gathering subjective perspectives. Finally, the terms recovery, remission, and outcome are used interchangeably making it difficult to compare findings across studies.

\section{The Process of Recovery in Long-Term Mental Illness: Conceptual Models}

Having reviewed the outcome literature from FES and long-term studies, I will now review conceptual models of recovery from long-term mental illness. These models have been developed based on the perspectives of individuals experiencing mental illnesses; such a perspective is consistent with the subjective definition of recovery (p. 5). These process oriented conceptual models have evolved from qualitative studies and as such have served as points of comparison with the theoretical model of recovery from a FES in this study.

Andresen, Oades and Caputi (2003) reviewed five qualitative studies of recovery accounts (Baxter \& Diehl, 1998; Davidson \& Strauss, 1992; Pettie \& Triolo, 1999; Spaniol et al., 2002; Young \& Ensing, 1999) of individuals with schizophrenia or other serious mental illnesses to develop a model of recovery. From their review, they identified a five stage model of recovery: 1) moratorium, "characterized by denial, confusion, hopelessness, identity confusion, and self-protective withdrawal" (p. 591); 2) awareness, when the individual realizes recovery is possible, this occurs as an internal process or may be identified by a significant other; 3) preparation, which involves working towards recovery by identifying values, strengths and weaknesses, and also becoming involved with groups 
and identifying with peers; 4) rebuilding, which occurs when a person works towards forging a new identity, along with goal development and reassessment. Risks are taken and set-backs occur along with the willingness to try again; and, 5) growth, which is the final stage and considered the outcome of the recovery process. During this final stage, the person is able to manage their illness, however may still experience symptoms, is able to maintain a positive outlook, is resilient when experiencing setbacks, and is able to live a full and meaningful life as they look towards the future. Furthermore, the person has a positive sense of self and realizes they are a better person because of this experience.

The emotional stages of recovery model (Diehl, 1995) was described and implemented in a peer taught program to support the process of recovery for individuals with severe mental illness (Baxter \& Diehl, 1998). This model is comprised of three psychological events; each accompanied by a stage, with corresponding emotions and needs. This model was developed by initially reviewing constructs in the recovery literature. Following this, a questionnaire was developed based on the literature review which was then used to interview 40 consumers. A content analysis of participant responses was conducted which ultimately led to the development of the model.

In this model, the first psychological event is identified as a crisis which is caused by an episode of mental illness, such as psychosis. As an individual emerges from the crisis they may feel exhausted with a need to recuperate. Feelings of denial, confusion, and despair may also prevail. In addition, individuals may have needs related to shelter, sleep and/or medications. The second event may not occur immediately following the initial crisis but may take anywhere from a few days to a few years. The individual's decision to "get going again" constitutes the second event which is then followed by efforts to care for oneself and to assume normal roles. The individual may also experience setbacks as well as success. 
Through this rebuilding, the individual may come to a more integrated sense of self. Varied emotions such as hope, frustration, and grief may also be experienced during this stage. Individual needs at this time may involve learning about mental illness, and life skill development. The third event in this model involves "an awakening to one's restructured personhood" (p. 352). As recovery progresses the individual focuses on reconnecting with life. During this stage, the individual may experience anger at injustice, helpfulness to others, and a sense confidence and acceptance of self and others. Needs for the individual may include having future dreams to strive for, meaningful work, and having an intimate partner. Although this model shares similarities with the model proposed by Andresen and colleagues (2003) (e.g., engaging the support of others, importance of goals), there is more of an emphasis on the emotional aspects of recovery.

A study by Young and Ensing (1999) also explored the meaning of recovery from the perspective of mental health consumers with the aim of developing a conceptual model of recovery. The model was based on qualitative data from 18 participants (12 female and 6 male), ranging in age from 26-59 years, with a mean age of 41 years. The mean number of psychiatric hospitalizations was 9.7. Most of the participants reported having bipolar disorder, followed by schizophrenia. A grounded theory analysis led to the development of a recovery model. Categories of the model that defined recovery as a process were: "1) overcoming "stuckness", 2) discovering and fostering self-empowerment, 3) learning and self-redefinition, 4) returning to basic functioning, and 5) improving quality of life" (p. 219). The authors identified spirituality as a central aspect of their recovery model, since spirituality was seen as an important source of hope. Another aspect of the model was the importance for participants to be self-empowered which was comprised of attitudinal and action oriented components. For example, adopting coping strategies, learning to self- 
monitor, and making a commitment to discontinue self-destructive behavior were important steps towards recovery. Specific internal states that constituted recovery were also identified. Examples of internal states were increasing self esteem, feeling normal, feeling stable, and feeling at peace, all of which contributed to an overall sense of well-being for participants. Finally, the role of interpersonal relationships between consumers in fostering the recovery process was also highlighted as an important aspect of the model.

Ridgway (2001) examined four first person accounts of individuals (Deegan, 1988; Leete, 1989; Lovejoy 1982; Unzicker, 1989) who experienced prolonged psychiatric disability and recovered. These particular accounts were chosen because each provided rich details thereby serving as exemplary narratives. The study purpose was to learn from individual narratives but also and determine whether common patterns exist amongst the lived experiences of recovering individuals. Constant comparative method was used to analyze the narratives; Mishler's (1986) narrative analytic method was also used to enhance thematic analysis.

Study findings describe the recovery process as a series of journeys that were common across narratives. These journeys include: a reawakening of hope after despair; breaking through denial and achieving understanding and acceptance; moving from withdrawal to engagement and active participation in life; achieving recovery through active coping instead of passive adjustment; shifting from viewing oneself as primarily a person with a psychiatric disorder to reclaiming a positive sense of self; and moving from a sense of alienation to a sense of meaning and purpose. Findings suggest that a multifaceted recovery process exists for people who experience prolonged psychiatric disabilities. Recovery does not happen alone and involves the support and partnerships with others (e.g., family, peers). 
It demonstrates "that the recovery journey, while unique for each person, has many broad passages that are held in common" (p. 340).

Forchuk, Jewell, Tweedell, and Steinnagel (2003) conducted a qualitative study in order to understand the experience of recovery from psychosis from the perspective of mental health consumers who were living with psychosis. Ten participants ranging in ages from 26-51 years were selected from a tertiary care psychiatric hospital and a general hospital setting and interviewed before starting, and during the initial year of medication treatment with either clozapine or risperidone. Seven out of the ten participants were taking clozapine. Each participant had 9 interviews for a total of 90 interviews. Six participants had experienced psychosis for 8-15 years without symptom relief despite taking various types of anti psychotic medication. Four participants had experienced psychosis for 1-3 years. At the beginning of interviews, 9 out 10 participants were inpatients; at the end of 12 months two remained as inpatients.

Using an ethnographic method for data analysis, study findings revealed that the recovery process began with participants recognizing improvements in their thinking and feeling. This awareness was followed by an ability to move away from an internal focus on self to a reconnection with the external environment. Participants reflected on the lack of support from clinicians, specifically noting that staff did not appreciate the impact that treatment decisions had on their lives. Furthermore, participants experienced a power differential in their relationships with staff as evidenced by concerns about "getting into trouble" with staff. Most of the participants described superficial relationships with their families, however noted once they experienced symptom improvement they were able to participate in more family activities. The authors concluded that "a person's recovery from psychosis involves more than a reduction in symptoms. It involves the entire self, bringing all 
components of physical, emotional, mental, and spiritual aspects of themselves into experiences of life" (p. 149).

Jacobson (2001) reviewed thirty recovery narratives written by individuals who described their experience of recovery from a range of mental illnesses, and used dimensional analysis in order to develop a conceptual model that would reflect the uniqueness of the recovery process. Dimensional analysis is a technique for systematic investigation and has been adopted for use as a tool in analyzing textual data. Similar to the present study, the narratives were drawn from individuals who identify themselves as recovering or in recovery. Jacobson's findings supported the development of a model with four central dimensions involved in recovery: self (comprised of identity, attitude, knowledge, meaning, experience, responsibility, and health); others (e.g., family, friends, peers, coworkers, bosses, and society); the system, which refers to the mental health system; and the problem, which is what the narrator must recover from. The problem includes cause(s), effect(s), and solution(s). Jacobson (2001) further described the recovery process as made up of components that correspond to these dimensions, specifically, recognizing the problem, transforming the self, reconciling the system, and reaching out to others. Also, individuals in these narratives used their own explanatory models to understand the cause of their problem, its effects and what they must do to solve their problem or recover. Jacobson (2001) cites the various implications of her study. Namely, that practitioners need to understand how their clients conceptualize their problem and what is meaningful in their life, underscoring the ability of practitioners to create human connections with their clients. For policy makers, implications include establishing systems that are supportive of an individual's recovery process. 
Jacobson and Greenley (2001) also described a conceptual model of recovery from mental illness. The aim for the model development was largely for educational purposes. The goal of this initiative was to link abstract concepts that define recovery in order to facilitate the development of a recovery-oriented mental health system for agencies in an US state. Their model of recovery was comprised of internal and external factors experienced by individuals who describe themselves as being in recovery from long-term mental illness. Examples of internal factors include: hope, healing, empowerment, and connection. External factors were identified as implementation of a positive culture of healing characterized for example, by an environment of empathy, compassion, trust, and recovery-oriented services. The authors note that both types of factors are based on the principle of human rights.

To understand the process of recovery over time, Spaniol et al. (2002) conducted a qualitative longitudinal study that resulted in a conceptual model of the recovery process, including major dimensions, along with factors that seem to be related with the process. This was the only study found that examined the process of recovery from schizophrenia longitudinally. The model was based on qualitative data from 12 individuals ranging in age from 30-53 years with a diagnosis of schizophrenia or schizoaffective disorder who were followed over a period of four years. Each participant was involved in a semi-structured audio taped interview every four to eight months which focused on the opportunity to discuss their current life experiences.

In this study, recovery was conceptualized as a process of self-discovery, selfrenewal, and transformation involving the adjustment of the individual's attitudes, feelings, roles, and goals in life. As well, four specific phases of recovery were described: 1) feeling overwhelmed by the disability; 2) struggling with the disability; 3) living with the disability; and, 4) living beyond the disability. The authors acknowledged that none of their participants 
were in the fourth phase therefore they conceptualized it by reviewing descriptions in the self-help literature. As participants moved through the phases of recovery they worked on certain tasks. These tasks included: 1) "developing an explanatory framework for understanding the experience of schizophrenia" (p. 352); 2) gaining control over the illness itself; and 3) moving into roles that are meaningful, productive, and valued in society.

Challenges and supports to the process of recovery were also identified in this study. Supports included the support of others, use of effective medication, basic necessities such as food, clothing, shelter, access to therapeutic environments, and reliance on religious faith. Examples of particular challenges were age and life trajectory that were found to influence the process of recovery. Specifically, individuals who had some experience and success in adult roles prior to their illness were most prepared for the tasks of recovery. These participants in particular had experienced late onset schizophrenia and were able to draw on established resources, specifically, their level of education, satisfying adult relationships, as well as established work and career habits. The authors highlight that their study lends support for the continued need to understand the perspective of people who are experiencing recovery, as is the case of this current study.

\section{Summary}

It is evident that many authors have provided a range of conceptual models attempting to capture the many dimensions of the recovery process from long-term mental illness. These conceptual understandings are based on consumer perspectives (consistent with the subjective definition of recovery) that I view as an overall strength of these models. Common features inherent within these models that are aligned with common elements of recovery described by Davidson and colleagues (2005) and include: hope, personal responsibility, meaning in life, and the pursuit of individual goals. Overall, the processes 
described in these models are understood to be nonlinear as summarized by Bellack (2006) "the consumer model of recovery involves a nonlinear process in which the consumer gradually adapts to and moves beyond the illness" (p. 440).

There were certain limitations apparent in the qualitative studies reviewed that support the need for this current study. A number of these studies used existing recovery narratives to identify features of the recovery process. This retrospective methodology did not allow the researcher the opportunity to clarify or elaborate upon participant perspectives. Furthermore, the studies samples are reflective of a variety of diagnoses, leaving the reader questioning if various mental health conditions are totally homogeneous or have their own unique intricacies of recovery. Finally, the participants whose recovery narratives formed the basis of these models had lived with their illness over many years and as such their experience may not reflect recent advancements in clinical practice, thus limiting our current understanding of possible recovery from FES.

Gaps emerged as a result of the review of conceptual models. Specifically, additional qualitative studies that provide individual and family accounts of recovery from the onset of schizophrenia are needed. Although characteristics of the recovery definitions apparent in models of recovery in long-term mental illness can be applied to FES, their particular relevance to this population has not been identified. Furthermore, given the challenge related to the age of onset on recovery as identified by Spaniol et al. (2002), the interaction between the process of recovery and emerging adulthood needs to be better understood. To date, indepth qualitative studies of the recovery process in FES have not been undertaken; yet they are required in order to examine the evolution of the process of recovery. 


\section{Overall Summary Thoughts}

The literature was reviewed in order to establish an understanding of the concept of recovery from a FES. Recovery from schizophrenia is not the same as a cure (Liberman \& Kopelowicz, 2005), and has clearly evolved as a concept over time. Overall, two categories of literature were identified in the review that served to define recovery. One approach included studies that used objective quantitative methods and were largely outcome focused for both FES and long-term studies. The second approach, which included qualitative studies, focused on understanding the process as it relates to the subjective experience of recovery. It is noteworthy that there were no published studies that addressed the recovery process from a FES. Across these perspectives, there is also recognition that many dimensions contribute to an individual's recovery process which is especially evident within the conceptual models. The need for research to focus on the strengths and personal qualities of the individual during their recovery rather than primarily on symptoms is also becoming increasingly apparent.

Although outcomes across long-term studies have been relatively discouraging, recent reviews, including the one by Menezes, Arenovich, and Zipursky (2006) conclude that the outcome from FEP may be more favorable that previously reported. This provides the opportunity to be hopeful, in that a growing body of literature reflects improved outcomes for young adults experiencing psychosis. However, this "hopefulness" in recovery must be balanced with the findings of the literature that indicate that symptomatic recovery from schizophrenia may not always occur. The conceptual models of recovery, although not specific to a FES, addressed the barriers to recovery along with features that would promote its occurrence. Overall, it is quite clear that the outcomes of long-term studies are different from those of FES. This suggests that the process of recovery from a FES will also differ from the recovery models of the past. To date, a recovery model which describes the process 
of recovery from FES has not been developed. Such a model is needed in order to identify barriers to recovery and to understand those conditions which promote recovery for individuals experiencing this illness. 


\section{Chapter 3: Methodology and Method}

\section{Chapter Overview}

This chapter outlines the methodology used in the study, and the specific methods implemented. Researcher reflexivity, participant selection, data collection procedures, data analysis plan, including strategies for ensuring analytic rigor are described. Finally, ethical considerations are explored. Methodological congruency with study design will also be illustrated throughout this chapter.

\section{Grounded Theory Methodology}

This study used constructivist grounded theory methodology, as described by Charmaz (1990), to develop a theoretical understanding of the process of recovery from a FES. The evolution of constructivist grounded theory can be understood in the context of understanding constructivism as a paradigm of inquiry. A paradigm is a "basic set of beliefs that guides action" (Guba, 1990, p. 17), and reflects the researcher's ontological (what is the nature of reality), epistemological (what is the relationship between the inquirer and the known), and methodological stances (how do we know the world, or gain knowledge of it) (Denzin \& Lincoln, 2000). Constructivism is a type of paradigm which views the nature of reality as a specific mental construction developed by an individual, and that multiple mental constructions exist with respect to reality (relativism) (Guba \& Lincoln, 1994). As human beings, we not only construct knowledge to understand experience, but also modify these constructions as new experiences arise (Schwandt, 2000). In doing so, there is a subjective and interactive link with the knower and what can be known. From a methodological stance, the researcher's inquiry creates knowledge from interpreted constructions, in order to provide 
a reconstructed understanding of the phenomenon of interest, with an emphasis on subject's meanings (Guba \& Lincoln, 1994).

In order to understand the rationale for the use of a constructivist grounded theory in this study, an understanding of grounded theory methodology is needed. Grounded theory was developed in the late 1960's by two sociologists, Barney Glaser and the late Anselm Strauss to challenge the prominent positivistic quantitative paradigm of the time (Baker, Wuest, \& Stern, 1992). Glaser was trained within a positivistic paradigm, under the guidance of methodologist Paul F. Lazarsfeld and sociologist Robert K. Merton (Bryant \& Charmaz, 2007), while Strauss was trained in the Chicago school of sociology. Within this school of sociology, there was an emphasis on symbolic interactionism, whereby attention was drawn to the study of process, action, and meaning (Charmaz, 2003). The combined work of these two sociologists produced a type of qualitative research methodology known as grounded theory. This methodology emphasized process, action, and meaning, and yet incorporated a systematic detailed method of analysis that supported theory development.

Grounded theory was developed with the purpose of studying social phenomenon and is based on the theoretical underpinnings of symbolic interactionism (Glaser \& Strauss 1967). Specifically, symbolic interactionism holds that people are in a continual process of interpretation and definition as they move from one situation to another (Eaves, 2001). Jeon (2004) draws attention to Mead (1934/1959) and Blumer (1969) who assert that meaning is a social product made possible through social interaction with others. Blumer (1969) cited three basic premises of symbolic interactionism. The first premise is that "human beings act toward things on the basis of the meanings that the things have for them". Second, "the meaning of such things is derived from, or arises out of, the social interaction that one has 
with one's fellows". Third, that "these meanings are handled in, and modified through, an interpretative process used by the person in dealing with the things [she]/he encounters" (p. 2). Charmaz (2003) asserts that constructivist grounded theory reflects symbolic interactionism as both focus on the meaning and action that the participants and researcher collectively construct of the phenomenon of study.

Grounded theory allows researchers to build theories in previously unexplored or under explored areas from the data collected. This leads to the discovery of a theoretical understanding about a particular social process. (Charmaz, 2003). As Charmaz (2003) asserts, grounded theory is one that is inductively derived from the study of the phenomenon it represents. Namely, one does not begin with a theory, and then prove it. On the contrary, one begins with an area of study and what is relevant to that area is allowed to become apparent. Furthermore, grounded theorists "construct an image of a reality..." (Charmaz, 2000 , p. 523). In essence, grounded theory provides a systematic way to move from a description of what is happening by collecting and analyzing data to a way to understand the process by which it is happening (Artinian, 1998).

Charmaz (1983) holds that every researcher who uses the grounded theory method will tend to develop his or her own variations of technique. Accordingly, she has developed her own style of using grounded theory, based on the framework of the original objectivist methods put forth by Glaser and Strauss (1967) and Glaser (1978). Constructivist grounded theory differs from objectivist grounded theory whereby researchers are removed from the research process and are ascribed the role of a conduit for the research process, rather than that of a creator of it. Specifically, the objectivist grounded theory assumes that an external reality of the participant already exists and the role of the unbiased researcher is to record facts about it. Furthermore, that through careful application of prescribed and analytical 
steps, a theoretical understanding of the phenomenon arises (Charmaz, 2001). Charmaz (2000) asserts that the objectivist approach to grounded theory developed by Glaser and Strauss (1967) and Strauss and Corbin (1990) is too systematic in its procedures, recommending a need for more flexible strategies that she has developed. Charmaz (2003) captures the essence of a constructivist grounded theory approach:

A grounded theory interview can be viewed as an unfolding story. It is emergent although studied and shaped. It is open-ended but framed and focused. It is intense in content yet informal in execution - conversational in style but not casual in meaning. The relationship of the research participant to the studied phenomenon as well to the interviewer and the interview process also shapes the type, extent, and relative depth of the subsequent story. This unfolding story arises as interviewer and participant together explore the topic and imprint a human face upon it. (p. 326)

Charmaz describes a research process whereby a relationship of mutual respect evolves between the researcher and participant and is central to the evolving story. As a story is told by each of the participants there is an unraveling of poignant collective stories, that, when shared with others can touch and influence the lives of many by offering a theoretical understanding of the phenomenon of interest. Constructivist grounded theory is an ideal method to understand recovery from a FES as it emphasizes understanding a phenomenon's process of evolution. Constructivist grounded theory was chosen for this study versus an objectivist approach to grounded theory because there is a significant emphasis on the views and feelings of the participants in the study, rather than on an objectivist stance of factfinding and description of acts (Creswell, 2002).

\section{Researcher Reflexivity}

Constructivist grounded theory encourages researchers to be reflexive during all phases of their research and writing (Charmaz, 2001). Being reflexive is also supported by Hutchinson (1993) who asserts that "because grounded theory requires interpersonal interaction the researcher is inevitably part of his or her observations" (p. 187). This 
reflexive approach is in contrast to objectivist grounded theory whereby researchers are encouraged to minimize reflexivity (Charmaz, 2001). Reflexivity pertains to assumptions about knowledge, research, the relationship between participant and researcher, and the goals of the research inquiry.

I believe knowledge is achieved by understanding the experiences, feelings, and perceptions of individuals. Based on my belief that individuals construct their reality, I engaged participants and asked questions in pursuit of knowledge and understanding. I view the pursuit of knowledge as a creative process where the participants and I can learn from each other by co-creating knowledge in order to understand the process of recovery from a FES. I find the researcher/participant relationship to be an honored encounter, one built on trust, honesty, and mutual respect.

I experience research through the disciplinary lens of nursing and thus approach research with an attitude of inquiry, by seeking to identify questions raised in everyday practice. Questions raised during clinical practice provide a rich source of information for research inquiry and direct my pursuit of discovering knowledge. I believe emergent knowledge that reflects the experience of individuals has the capacity to influence clinical practices in order to help clinicians better understand the individual's perspective of the illness experience. I believe research is a way to understand a situation, a person, and/or context and agree with Neilsen (1998) who comments that the conduct of research is an opportunity to create and give back.

The term "Grounded Theory" means that the resultant theory is grounded or has its roots in the data from which it is derived (Glauser \& Strauss, 1967). As a researcher, this aspect methodology resonates with me because rather than attempting to start with my selection of a theory to explain a phenomenon, in grounded theory, the theory emerges from 
the data collected. Grounded theory is appropriate for my research inquiry because it discovers the processes inherent within a phenomenon of interest (e.g., the process of recovery from a FES).

By conducting research, I can explore my clinical passions. Having worked in mental health for 15 years, I continue to have a passion for establishing systems that improve access to help, de-mystifying the stigma attached to mental illness, and advocating and collaborating with individuals who have a mental illness. Goering, Boydell, and Pignatiello (2008), assert that the great strength of qualitative research is "its interest in understanding human beings in the course of their day to day lives" (p.146). Through my research, I want to understand recovery from a FES from individuals experiencing it.

I also wish to express that, consistent with Charmaz's grounded theory approach, no effort was made to bracket my biases. Therefore, in my reflections and analysis, I acknowledge that I have clinical knowledge about a FES and have had some exposure to individuals who have recovered from it prior to conducting this study. However, I have limited preconceived ideas of what their recovery process is like.

I believe that research data is needed to influence and inform practice. Therefore, I agree with Strauss and Corbin (1994) who assert that all theory carries implications for action, and caution against restricting the applicability of theory. In light of this, I believe this study's emergent theory can be used for program planning and policy development at a health care systems level. It may also be used within clinical settings to inform interprofessional care providers about recovery in FES.

\section{Participant Selection}

A strategy consistent with a constructivist grounded theory was employed in the selection of study participants. Specifically, purposeful sampling was used so that 
participants were not selected randomly, but were instead chosen on the basis of variations and relevant experience of the topic to be explored (Charmaz, 2003b). This sampling strategy also underscores the importance that, within grounded theory, variation is needed for theory development (Schreiber \& Stern, 2001). Ten primary participants diagnosed with a FES, and who identified themselves as recovering were recruited from a first episode psychosis program at two university affiliated psychiatric outpatient clinics in Ontario, Canada. The diagnosis of schizophrenia was confirmed by participants' psychiatrists. Recovery criteria examples were derived from seminal personal narratives (Deegan, 1988; Leete, 1989) which were then used as a guide for participants to identify whether they were in the process of recovery. These criteria were outlined in the letter of invitation to the participant (see Appendix A1).

The ten primary participants were interviewed twice within approximately a one month period. Given that a developed grounded theory accounts for broad variations in the experience and perspectives of the participants, I also sought varied sources related to the phenomenon of interest, by including secondary participants. According to Charmaz (2000), the constructivist approach not only calls for an active, reflective participant but also takes into account the impact of the social forces on the participant, and "what, if anything, the participant feels and does about them" (p. 531). Therefore, in addition to the interviews with ten young adults who were recovering, I also interviewed an individual (secondary participant) identified by each participant as having influenced their process of recovery within one to three months of the primary participant's initial interview. These individuals included six family members, three health care professionals and a participant's girlfriend. Accessing others connected to the participant was not intended to validate what the participant had said, but rather to provide another perspective (Cole \& Knowles, 2001); for 
recovery can be viewed as an active process that requires not only individual effort, but also can involve collaboration with friends, family, and professionals (Mead \& Copeland, 2000).

To summarize, each primary participant had two interviews. In addition, there was a one-time interview with a secondary participant. Although there is no one standard sample size for qualitative research, there were a total of thirty interviews in this research study. This final number of participant interviews was influenced by purposeful sampling and the determination that saturation of data had been reached. It is important to note that the goal of qualitative research is "not to produce generalizations, but rather in-depth understandings and knowledge about a particular phenomenon" (Leininger, 1994, p. 107). It light of this, as the researcher I made certain that there was sufficient descriptive data to ensure that there is enough information for the reader to make assessments concerning the credibility of this study's findings. As Stern (1994) asserts “a well-schooled grounded theorist never, ever makes excuses for its sample or its characteristics" (p. 218).

\section{Inclusion Criteria}

To be included in the study, participants identified themselves as recovering from a FES, and met the following criteria: DSM-IV Axis I diagnosis of schizophrenia, were between the ages of 19 and 30, were able to read, comprehend, and speak English, were able to provide informed consent and were within one to three years since their initial treatment for a FES. These inclusion criteria were based on the literature which indicates that age of onset occurs in young adulthood and that active recovery most likely occurs following the first year of treatment (Taktak et al., 1999) with the resolution of acute symptoms. Also, conducting the interviewing within a three year window optimized the capacity of the participants to recall events related to their recovery. In addition, based on the contact they 
had with potential participants, it was determined by the intake coordinators of the outpatient clinics that participants were able to engage in in-depth interviewing.

\section{Exclusion Criteria}

Exclusion criteria included drug related psychosis, significant medical illness, and/or organic brain syndrome. The exclusion criteria were used in order to obtain a sample of individuals within the schizophrenia spectrum whose symptoms were not related to the above conditions.

\section{Participant Recruitment}

Participants were invited to participate in the study using a letter of invitation (see Appendix A1) by the intake coordinators of two outpatient clinics who had extensive recruiting and interviewing experience for research studies. They used both the study criteria and knowledge of the patients from the outpatient clinics to select participants. The intake coordinators approached the potential participants and briefly described the purpose of the study and asked permission for the release of their names and contact numbers so that I could meet with them to further explain the study in detail. In this way, no direct health care providers of the participants were involved in the individual's decision to participate in the study.

I met with individuals to explain the study (Appendix A2) and obtained informed consent (Appendix B). I also answered any questions and sought permission to set up a date and time for the interviews. The invitation to participate and the consent form for this study were written in language appropriate to the age and reading level of this group of individuals, in order to maximize participant understanding. One of the secondary participants was not fluent in English therefore an interpreter was used. This interpreter provided translating services to this outpatient clinic. 


\section{Data Collection Procedure}

\section{Interview Guide}

During this study, data collection took place using in-depth, semi-structured interviews to elicit data regarding the participant's experience of recovery from a FES. According to Charmaz, (2001) "the unfolding story arises as the interviewer and participant together explore the topic and imprint a human face upon it" (p. 690). The interview guide [see Appendix C (a)] resulted from a template suggested by Charmaz (2001). The questions within the guide were designed to be consistent with a constructivist grounded theory approach, whereby there is a need to define and explore the process under study. Furthermore, there was an emphasis on questions that addressed the participant's assumptions and subjective meanings. Therefore, topics such as impact of illness on their life, support systems, and coping strategies that have influenced the participant's recovery process were covered in the interview guide questions. Assurance of confidentiality was provided. However, it was specified that if issues related to participant safety were reported during the interview, I would be obligated to contact the participant's case manager or psychiatrist.

The interview guide was submitted to members of my thesis committee who have experience working with individuals with a FES. The committee which includes clinical scientists, a research scientist, and a psychiatrist, offered advice regarding the wording/structure of the interview guide. Charmaz (2001) also recommends that the researcher be constantly reflexive about the nature of the interview questions. Consistent with constructivist grounded theory, the interview guide was revised based on the data collected. Theoretical sampling was used in order to ensure that enough depth was achieved as categories were emerging. As Charmaz (2006) asserts "when engaging in theoretical 
sampling, the researcher seeks people, events, or information to illuminate and define the boundaries and relevance of the categories" (p. 189). This type of sampling was used to ask additional questions during the interview guide based on the responses received from previous participants. Specifically, it became apparent that additional questions were required related to who the participants were prior to the illness and understanding their struggles involving accessing help within the health care system.

\section{Interviewing}

As noted earlier, the interviews conducted in this study were in-depth semi-structured and allowed for flexibility. This style of interviewing is a well-established and accepted method for a constructivist grounded theory approach (Charmaz, 2003). Interviews were scheduled for approximately one hour and a half and were audio taped. The location of the interviews was determined by the participants. All primary participants chose to have their interviews take place in offices at their outpatient clinic. One secondary participant elected to have the interview take place in her home. Allowing participants to select the interview location is supportive of constructivist grounded theory whereby participants are interviewed in their natural setting if they so choose (Charmaz, 2000). I also wrote field notes during interviews in order to record any impressions. I later referred to these notes to aid in my analysis of the study findings.

Participants were informed of the nature of the interview process and were made aware of the topics to be covered in the interview guide before they consented to participate. Specifically, participants were given a copy of the interview guide to ensure transparency of process. They were also told that they could stop the interview at any time and continue at a later date if they so desired. The participant's clinical case manager was informed of this 
study and the nature of the material to be discussed in the interviews prior to their commencement.

Interviews were conducted using the interview guides previously described while consciously attempting to maintain flexibility and allowing the participant to lead the interview as much as possible. Probes were used to assist the participants in answering when necessary. Constructivist grounded theory supports the use of sequential interviews as they allow for a stronger basis for understanding social processes (Charmaz, 2001). In order to accomplish this participants were interviewed again approximately within one month period of the initial interview, although for some participants the time between interviews was longer depending on their availability. The second interview allowed me to reflect back to the participant what I learned from their first interview. In addition, it allowed the opportunity to further explore any issues that I or the participant may have wanted to expand upon or add. It also allowed for additional questions to be addressed which developed as a result of theoretical sampling. Furthermore, it provided the opportunity for the participants to describe their artifact (i.e., personal object) which symbolized for them their process of recovery. The use of artifacts/personal objects will be further discussed in subsequent pages; both terms are used interchangeably.

Within approximately one month of the participant's initial interview, the secondary participant, whom the primary participants identified as having influenced their process of recovery, was interviewed once for approximately one hour and a half. The secondary participant's interview guide captured information concerning their influence in the participant's recovery process (see Appendix C (b)). Having varied interviews supports the view that constructivist grounded theory interviews are used to tell a collective story through 
the interpretative lens of the researcher, rather than an individual story told in a single interview (Charmaz, 2001).

\section{Other Data Collection Sources}

Data not only involved transcribed interviews, but also included my memos, a description of artifacts (i.e., personal objects), field notes, and a review of the participant's clinical record. The clinical record was reviewed in order to obtain general information like the kind of treatment they were involved in, and descriptive information such as their age, marital status, level of education, and employment status in order to add to the description of participants. Memo writing has been described by Charmaz (2004) as a way to record what the researcher sees happening in the data, and to chart relationships in data, between emerging categories, and to elaborate on processes. Charmaz (1983) further asserts that grounded theorists use memos to explore ideas about the data, codes, categories, or generation of theory.

The use of artifacts as a way to capture and understand an individual's life is valued for the role they may have in enriching insights, and clarifying questions (Cole \& Knowles, 2001). Furthermore, "they have the capacity to illuminate a life in unanticipated ways" (Cole \& Knowles, 2001, p. 88). I asked participants to share and describe an artifact (i.e., personal object) that symbolized their recovery process. In doing so, I hoped to uncover as Cole and Knowles (2001) state the "meaning at the times of their importance or significance in a life" (p. 87). I chose to take photographs of the objects versus only a verbal description because I believe, as Harrison (2002) asserts, that until recently, the visual has been a neglected dimension in our understanding of social life (p. 856). I realized, as Pink (2004) states, "we should not treat the visual as an add-on, but as an integrated aspect of the experience of interviewing or interacting with participants" (p. 395). With the participant's permission, I 
took a photograph of the individual's hands holding the artifact so as to maintain his/her confidentiality. I felt a particular connection with participants when I took these photographs. Specifically, taking the photographs gave us an additional opportunity to collaborate and cocreate the depiction of an image that symbolized their recovery. The participants chose how they wanted to feature their object, and I attempted to capture it on film. The experience of working with the participant to take the photographs also increased my awareness and provided a visual representation of the many dimensions that reflect the subjective nature of recovery. A lesson I learned from this process from a technical point of view is related to the quality of the photographs of the participants' personal objects. Specifically, at the time when I took these photos I did not have access to a digital camera and used a disposable camera instead; this influenced the clarity of the photographs. The ability to focus in on the object I believe would have improved with a better quality camera. The photographs of these personal objects can be found with the corresponding participant narratives in Chapter 4.

\section{Data Analysis}

Grounded theory is characterized by a rigorous process of data collection and analysis that supports validity and trustworthiness of the data. Specifically, in the initial phases of research, data was collected and analyzed. In doing so, the analysis informs further data collection (Charmaz, 2003). The qualitative analysis not only drew from data collected from the transcribed interviews, but also included my memos, and description of personal objects. I used methods of qualitative data analysis described by Charmaz (1983) such as coding and constant comparisons. Consistent with a grounded theory study, I looked for processes occurring within the rich data I collected. This rich data allowed me to "trace events, delineate processes, and make comparisons" (Charmaz, 2003b, p. 89). 


\section{Transcription}

Verbatim transcription of the audio taped interviews was conducted in keeping with the approach proposed by Charmaz. Charmaz (2003b) advocates for interviews to be transcribed as it provides details for nuanced views and data reviews. Various transcription strategies were used (e.g., depicting interruptions, background noise, voice overlaps) during transcription. All 30 interviews were transcribed by transcriptionists. Once the interviews were transcribed I listened to them again to ensure that they were transcribed correctly from the audio tape. They were then entered into NVivo ${ }^{\mathrm{TM}}$ (version 7.0), a computer software program that facilitated organization and retrieval of qualitative data (QSR, 2006).

\section{Coding Methods}

Coding was used as the first analytical step to allow me to move away from description towards the conceptualization of the description (Charmaz, 2003). According to Charmaz (1990), codes and categories reflect emerging ideas that help the researcher examine the data and ask analytic questions about them. In doing so, codes and categories help the researcher to construct an analysis of the data rather than merely a description. Data analysis began with initial or open coding, and then moved to focused or selective coding (Charmaz, 2003). By creating codes the researcher defines what is seen in the data by trying to understand the participant's statements and re-envisioning the scenes in which we know them (Charmaz, 2006).

\section{Initial Coding}

Initial coding involved me reading and studying the transcript line by line and naming each segment of data. By utilizing initial coding, I remained attuned to the participant's realities by reviewing key phrases in their own words. This helped to identify the formation of defining actions or events within the data. Action codes describe what is happening and 
what the participants are doing (Charmaz, 2003). A list of initial codes that emerged from the interview guide questions were developed, for example see Appendix F. I met with my cosupervisor who also reviewed each interview to ensure that I was coding appropriately. A second committee member also agreed with the compilation of initial codes for three randomly selected interviews. Using NVivo ${ }^{\mathrm{T} м}$ (version 7.0), which assisted with data retrieval, I developed a list of initial codes for each participant interview by counting and noting their frequency across interviews in order to make comparisons amongst data. This analytic strategy is aligned with Seale (1999) who asserts that "counting [in qualitative research] is an important way of showing data to the reader as fully as possible, enabling readers to judge whether the writer has relied excessively on rare events, to the exclusion of more common ones that might contradict the general line of argument" (p. 128). For the summary table of initial codes developed from the primary and secondary interviews see Table $2 \mathrm{a}$ and $2 \mathrm{~b}$.

\section{Focused Coding}

In selective or focused coding, I utilized frequently used initial codes in order to synthesize the large amount of data gathered. During focused coding, movement moved away from using a code as a descriptive tool (as in initial coding) to using coding as a way to view and synthesize data. Focused codes can be described as abstract and categorize most of the data across the interviews, leading to the development of analytic categories that subsume groupings of similar initial codes (Charmaz, 2003) (See Figure 1). Charmaz (2003b) asserts that by making focused codes active (to reflect what the participant is doing or what is happening) and brief, processes gain visibility. Specifically, "grounded theorists look for substantive processes that develop from their codes" (p. 99). Charmaz (2006) describes engaging with focused codes as a way to begin to treat them as categories. In order to do so 
she further describes that "you begin to write narrative statements in memos that define the category, explicate the properties, specify the conditions under which the category arises, is maintained and changes, describe the consequences and show how this category relates to other categories" (p. 92). Therefore, when developing focused codes for consideration as categories, I referred to my memos as I defined categories, I clarified what the categories consisted of that is, their subcategories, I described how the category emerged and changed and specified in my description of the model the relationships between the categories.

As I was raising my codes to categories it became apparent that particular areas needed further data. For example, I further asked participants to describe who they were prior to their illness and about gaps in the health care system that may have influenced their recovery as it was apparent during the interviews that this was an issue that some of them struggled with. The ability to do simultaneous data collection and analysis is an advantage of grounded theory strategy as the researcher can identify gaps in the data and then locate sources of data to address the gaps as needed (Charmaz, 2006).

As interviews progressed, the emergent categories from the analysis of the interviews informed future interviews with the aim of developing the categories to the point of "saturation". This occurs when no new data leads to new insights, and marks the end of data to be collected for analysis (Charmaz, 2003). At this stage, model development involved refinement of category categorizations through the use of sub-categories. A meeting was then held with my thesis committee where I described the emerging categories characterized by subcategories which were grounded in the data from participant narratives.

Revisions to the model continued as relationships between categories developed. What assisted this was the use of theoretical coding which outlined phases that reflected the emergent process of recovery. Charmaz (2006) describes theoretical coding as "as a 
sophisticated level of coding that follows the codes you have selected during focused coding. In short, theoretical codes specify possible relationships between categories you have developed in your focused coding” (p. 63). As a temporal ordering of relationship amongst categories arose reflective of phases, I included in my model, as Charmaz (2006) describes, "an analysis of process" (p. 63). That is, in my analysis of findings, I identify and characterize how these categories are related to each other as phases in describing this study's process of recovery model. Inherent in this characterization is a definition of the phase, which is characterized through its subcategories. Within each phase are the conditions within it arises, is maintained and changes along with its consequence. In my model, I suggest the temporal ordering of these phases in supporting the notion of recovery as a process occurring over time. (see Figure 2).

In addition to the above coding techniques, narratives of the participants were written in order to capture features of their recovery story and to prevent fracturing of the stories so as not to lose the essence of the narratives. This allowed me to articulate the 'facts' of the cases as I interpreted them, and to also illustrate the emergent categories in each of the narratives and across narratives.

\section{Theoretical Sampling}

Theoretical sampling occurs when, during analysis, codes are raised to categories, and there is a realization that the category is incomplete, and lacks sufficient evidence (Charmaz, 2003). When this occurs, the researcher can select further individuals, places, and information to check and further elaborate on those categories that need additional explanation (Charmaz, 2006). This type of sampling was used to ask additional questions during interviews based on the responses received from previous participants. Specifically, it became apparent that additional information was required. I therefore included interview 
questions related to who the participants were prior to the illness and to their struggles accessing help in the health care system.

\section{Constant Comparisons}

The way to reach a grounded theory is through the constant comparative method of data analysis. According to Charmaz (2006) grounded theory depends on constant comparative methods and engagement of the researcher. Charmaz (2006) further asserts that making comparisons between data, codes, and categories advances your conceptual understanding because as the researcher you define analytic properties of your categories and then begin to scrutinize the properties rigorously. It was during data analysis that I worked with comparisons (like with like), and began to see patterns amongst categories and subcategories that guided the development of the emergent theory of the process of recovery. I also explored negative cases when they arose. Negative cases are those that do not fit within the pattern (Patton, 2002). Charmaz (2006) asserts that negative cases allow new variables to be found or alternative explanations to be sought from the developing theory.

\section{Identification of Core Category}

Data analysis continued until I was able to adequately corroborate explanations and provide a substantive theory that fully explained and interpreted emerging categories and subcategories within the data. This was accomplished through the development and integration of categories through which the construction of a theoretical framework emerges (Charmaz, 2003). Following the selection of categories that best explained what was happening in the data, an identification of a core category emerged. Charmaz (personal communication, Sept 14, 2008) asserts that a core category may be a process or an idea. Glaser (1978) describes the core category as one which "most other categories and their properties are related to...” (p. 35). The core category reoccurs frequently in the data and 
relates meaningfully and easily with other categories (Holton, 2007). Reshaping an enduring sense of self was the core category identified in this study, and will be explored in detail in the findings chapter.

\section{Methodological Rigor}

For my study, I used the criteria for evaluating qualitative studies proposed by Charmaz (2004). Rigor as a means to evaluate grounded theory is addressed within four areas: credibility, resonance, usefulness, and originality.

\section{Credibility}

Credibility involves providing enough evidence for the research claims to allow the reader to form an independent assessment and to agree with the claims (Charmaz, 2006). During my study, I used a number of strategies to enhance the credibility of my research. To ensure credibility, participants selected had experienced the phenomenon under study and were able to provide a credible source of information. In addition, I reported the audit trail

(see Appendix E), specifically, the process involved in the transformation of data that lead to the study findings. This included describing initial and focused coding practice, theoretical sampling, use of memos, and field notes. I met with my co-supervisor who also reviewed each interview to ensure that I was coding appropriately. A second committee member with expertise in qualitative research also agreed with the compilation of initial codes for three randomly selected interviews.

I also used various analytic devices such as coding and constant comparisons. Consistent with a grounded theory study, I looked for processes occurring within the rich data. This rich data allowed me to "trace events, delineate processes, and make comparisons" (Charmaz, 2003b, p. 89). During data analysis, I asked myself: "What process is at issue here? Under which conditions do these processes occur? How does the research 
participant(s) think, feel, and act while involved in this process? When, why, and how does the process change? What are the consequences of the process? (Charmaz, 2004). Answers to these questions contributed to my analysis of the findings. Excerpts from the participant interviews were also provided so that the reader can follow my decision trail in the development of the substantive theory. Consistent with grounded theory, a thorough review of literature was conducted at the end of data analysis in order to ensure the theory emerges from the data itself (Cutcliffe, 2000). As Charmaz (2000) states, "grounded theorists cannot shop their disciplinary stores for preconceived concepts and dress their data in them" ( $\mathrm{p}$. $511)$.

\section{Resonance}

A strong combination of originality and credibility increases resonance (Charmaz, 2006). In order to ensure resonance, I describe the process involved in the transformation of data that lead to the study findings. This practice is consistent with what Kilbourn (1999) describes as a hallmark of qualitative research, whereby, the researcher makes a clear connection between method and meaning. This included a description of the methodology, while also highlighting the congruency it has with the strategies used to collect, analyze, and interpret the data. I discussed each of the phases that comprise this model, (comparing their differences and similarities to existing literature), how the phases are interrelated, along with discussing how the core category is evident in each of these phases. I also clearly outlined the unique features that comprise this FES model of recovery.

Another strategy to ensure resonance occurred when participants were invited back for a second interview. This allowed me to reflect back to the participant what I learned from their first interview. In addition, it also allowed the opportunity to further explore any issues that the participant or I may want to expand upon or add. Also, in order to be true to the data, 
I engaged in my own "personal checks" during my research study. For example, I asked myself: "Does that thought originate from my own knowledge, experience or beliefs or does it come from the data collected?"

\section{Usefulness and Originality}

To demonstrate usefulness and originality, I provided a substantive theoretical understanding of the process of recovery so that the reader can determine on her/his own accord, whether the findings are applicable to his or her setting. The development of this theory took into account varied sources of data, such as interviews with primary and secondary participants, the use of memos, and personal objects, and the primary participant's clinical records. In my discussion of findings, I clearly outline how this study's model is unique from recovery models of long-term mental illness. Finally, the study findings have resulted in numerous implications for clinical practice, future research, and policy development that are outlined in Chapter 7.

\section{Ethical Considerations}

\section{Securing Informed Consent}

Ethical approval to conduct this study was sought and obtained from both the Health Sciences Research Ethics Review Committee of [name of University], and [the study institution] Ethics Board. All participants signed a detailed informed consent form prior to commencing the interviews (Appendix B \& D). Privacy and confidentiality of participants was ensured through a variety of means. For example, participants were not contacted by their clinical case manager to participate in the study. Data will be kept in a locked cabinet in a secure location for five years. Tape recordings of the interviews will be erased upon completion of the study. Other than me, only members of my thesis committee and transcriptionists (at the time of transcription) had access to the transcripts. No one involved 
in providing treatment to the participants had access to the transcripts. If names or other identifying information were mentioned in the interview or photograph, I altered identifiable information prior to any presentation of the results. These measures were explained to participants before they consented to participate.

\section{Competency to Consent}

Competency to consent to research was determined by completion of the MacArthur Competence Assessment Tool for Clinical Research (MacCat-CR) (Appelbaum \& Grisso, 2001). It was administered by the researcher. The MacArthur Competence Assessment Tool for Clinical Research (MacCAT-CR) is used to assess the competency of potential study participants to consent to research. The MacCAT-CR is administered in a semi structured interview assessing potential participant abilities in the following four areas: (1) understanding of disclosed information about the nature of the research project and its procedures, (2) appreciation of the effects of research participation (or failure to participate) on subjects' own situation, (3) reasoning in the process of deciding about participation, focusing on subjects' abilities to compare alternatives in light of their consequences and (4) expressing a choice about research participation. In addition, it was required that participants be able to engage in in-depth interviewing (determined by the intake coordinator).

The individuals who agreed to participate in the study signed a consent form. Participants were assured that their participation would be voluntary, and that refusal to participate would not affect their clinical outpatient care in anyway. They were also informed that the interview would be held at a location of their choice, would be taperecorded, and that they had the right to stop the tape recorder at any time. In addition, they were informed that a picture would be taken of them holding the artifact. Only their hands would be shown to ensure their confidentiality. Participants were asked to give their 
permission to allow me to access their clinical record from [name of mental health facility]. They were made aware in the consent form that their medical record would be reviewed to obtain general information required for the study, including the kind of treatment they were involved in, and descriptive information, such as their age, marital status, level of education, and employment status.

Participants were made aware of their right to refuse disclosure of any information that may create discomfort, and the right to withdraw at anytime during the study without any impact on their clinical treatment. Participants were informed that the information they shared would be used for research purposes, with the results being published and disseminated within academic, health care and community settings. They were made aware that their name would not appear on any written recordings of the interview(s), photographs, or publications of research findings, and that they would not be identifiable in any reports or communication of the study findings.

\section{Risks and Benefits}

With respect to benefits of participating in the study, participants felt that given the sparse amount of knowledge related to recovery from a FES, their stories may enlighten and offer hope to others newly diagnosed with schizophrenia. Also, by participating, individuals gained insights into their recovery.

With respect to risks, given the sensitive nature of the subject matter to be discussed, participants may have felt distressed during interviews. If this had occurred, they would have been given the option to stop the interview and would have been asked if they needed additional support such as contacting their clinical case manager or psychiatrist. In a crisis situation, if safety was an issue, I would have contacted the participant's case manager or 
psychiatrist. Participants were advised of this possibility before consenting to participate in the study.

\section{Summary}

In this chapter an overview of constructivist grounded theory was presented along with the rationale for selecting this type of methodology for my study. Wherever possible, I have attempted to be transparent through my reflexive comments and description of the analytic choices I have made. It is hoped that this chapter has given the reader an appreciation of how this study design is congruent with constructivist grounded theory methodology. 


\section{Chapter 4: Contextualizing the Participants: Who Were They?}

\section{Chapter Overview}

This chapter serves to introduce the study participants to the reader. The purpose of this descriptive chapter is to provide an overall picture of the participants and to give the reader an appreciation of the extent and variation of the sample by providing a narrative summary for each participant. The names and other identifiable participant information have been changed to protect the anonymity of participants and their family members.

\section{General Description of the Sample}

Table 1 describes the demographic characteristics of the sample. The sampling strategy was purposely focused on attaining heterogeneity of demographic characteristics. The resultant strategy was therefore mixed in terms of gender, age, marital, and vocational status, and living arrangements. Given the multicultural nature of the community immediately surrounding the recruiting hospital sites, a mixture of cultural backgrounds was also possible.

\section{Participant Demographic Characteristics}

Eighteen individuals were approached to participate in the study; eight potential participants declined. Reasons for declining included competing family obligations, and over involvement in research studies. The average age of all participants was 23 years $(\mathrm{M}=22$ years, $F=25$ years). This average age was consistent with the findings in the literature which state that illness onset is most common in young adults (Addington et al., 2005). All participants were interviewed in an outpatient clinic with the exception of one, a secondary participant, who was interviewed in her home. Of the participants interviewed, six were employed. Specifically, four participants were actively going to school and working parttime at the time of the interview, one was employed part-time, and one had temporary work. 
Another participant was actively looking for employment. All participants lived in large urban areas. Two participants had a family history of mental illness. All participants had diverse interests ranging from the arts, writing, sports, and socializing with friends prior to and during their recovery. Two stated that they had only a few friends prior to the illness occurring. Two of the male participants were involved in gang activity and had spent time in jail prior to seeking help for their illness. For one of these participants his brief incarceration occurred during the active treatment of his illness, after he had stopped taking his medication.

\begin{tabular}{|c|c|c|}
\hline \multicolumn{3}{|c|}{ Table 1: Demographic Characteristics $(n=10)$} \\
\hline \multicolumn{2}{|c|}{ Characteristics } & Frequency \\
\hline \multirow{2}{*}{ Gender: } & Female & 5 \\
\hline & Male & 5 \\
\hline \multicolumn{3}{|c|}{ Ethnic/Cultural background: } \\
\hline & Caribbean & 4 \\
\hline & Caucasian & 4 \\
\hline & South Asian & 2 \\
\hline \multirow[t]{3}{*}{ Education: } & Process of completing secondary & 2 \\
\hline & Completed secondary & 3 \\
\hline & $\begin{array}{l}\text { Process of completing post } \\
\text { secondary }\end{array}$ & 5 \\
\hline \multicolumn{3}{|c|}{ Marital status: } \\
\hline & Married & 1 \\
\hline & Single & 9 \\
\hline \multicolumn{3}{|c|}{ Living arrangements: } \\
\hline & With family & 8 \\
\hline & Alone & 2 \\
\hline \multicolumn{3}{|c|}{ History of drug use: } \\
\hline & Yes (4 males and 2 females) & 6 \\
\hline & No & 4 \\
\hline \multicolumn{3}{|c|}{ Individuals that influenced recovery: } \\
\hline & Parent & 6 \\
\hline & Girlfriend/boyfriend & 1 \\
\hline & $\begin{array}{l}\text { Healthcare professional ( } 1 \text { nurse, } 1 \\
\text { art therapist and } 1 \text { psychiatrist }\end{array}$ & 3 \\
\hline
\end{tabular}




\section{Participant Narratives}

Brief narratives that describe each participant prior to illness, how the illness entered their lives, and how recovery was enabled, challenged and sustained are provided below. Below the name of each of the narratives is a photograph and description of their personal object which they selected in symbolizing their recovery. The photographs also serve to provide a visual representation of the many dimensions that reflect the subjective nature of recovery. Capturing an image of only their hands also serves to ensure anonymity. By selecting this type of placement for the photo, I hope to further personalize their narrative.

\section{Michael}

"Well knowing that I am schizophrenic and like and like not hearing voices anymore like sort of getting better from it..."

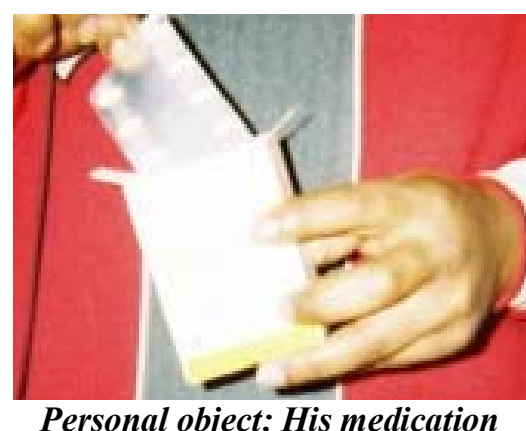

Michael is male, of Caribbean descent, and is in his early twenties. Michael was a young boy when he learned that his mother died unexpectedly. His grandmother (a secondary participant) recalls that Michael had "a hard time dealing with his mother's death." She wondered whether an episode, that she observed when Michael was young, where "he was beating up on his little [sibling]," was due to the stress of his mother's death or was because of an illness. "I don't know if that was part of the illness, or whether that was part of his grieving for the mom or what, I don't know." Michael did not have regular contact with his father growing up. From his teenage years, Michael has always taken pride in his artistic ability. Until his late teens he moved between his relative's homes. Michael's early to mid 
teen years were troublesome marked by repeated confrontations with authority (police and educators) and time spent doing community service.

After completing high-school, Michael's grandmother repeatedly tried to help him find work however, Michael was never able to stay employed. His grandmother describes that none of the jobs worked out because Michael often had some complaint about other people "looking at him." During that period, he also had turbulent relationships with his relatives. The repeated clashes with them resulted in his relative evicting Michael from her home. Afterward, Michael had unstable living arrangements moving between shelters and rented rooms. He earned a living working in the arts.

Michael first noticed changes in his behavior, namely, the emergence of paranoid thinking in his early twenties when he was traveling. He suspects the onset of his schizophrenia occurred after he had contact with a substance that his friend gave him. He was so distressed following this incident that he flew home and sought financial and housing assistance from his grandmother. After arriving home, Michael became increasingly delusional and was subsequently evicted from his relative's home, living in shelters and receiving social assistance for a period of time. In retrospect, it became clear to Michael that his illness remained untreated for two years. He describes that both he and his family felt uncertain, during this period. He recalls changes in his behavior such as isolating himself from others, hearing voices, and feeling as though he was on "a spiritual plane." He also describes this period as a "crazy time" in his life. His grandmother describes managing Michael's behavior in the early stages of the illness as a very challenging time. She further describes that there were ongoing changes in his behavior that continued from his teens through to his early 20's. At the time, Michael's grandmother was not sure what was causing these changes. 
While he was at a homeless shelter, a case manager recognized his symptoms and brought him to a hospital emergency where he was diagnosed with a FES. Since then Michael has been treated as an out-patient by a community first episode psychosis team, and has required an inpatient hospitalization following his initial treatment. Michael does acknowledge that he has schizophrenia and as a result feels the need to fight it. He occasionally refers to himself and his behavior as "schizophrenic". As he describes:

...you know when I wasn't schizophrenic, um I never even heard about schizophrenia I didn't even know what it was so, it just like, just getting it just makes me, makes me think you know I shouldn't have this...You know I'm not, I'm not saying that like cause, cause it's a bad thing, but I'm just saying that I shouldn't have this, but um, and then that just makes you wanna like, it just made me wanna fight it you know.

Michael realized that he was recovering when his symptoms began to improve, specifically "that the voices slowly were like slowly they were going away." Although he identifies himself as recovering he experiences symptoms sporadically. Michael describes his recovery as a slow process stating that his schizophrenia used to be worse, but is now improving. Medications have helped him deal with the voices. Family, friends, and others who share a similar illness experience have given him the comfort and support he needs to persevere. Furthermore, being involved in a number of his artistic interests gives him the proof that he is recovering. He also describes the need to "constantly battle my thinking", because "if you let it [schizophrenia] take over your mind and stuff then, if you let the disease take over, like take over you, then you'll never ah you'll never get better."

Michael describes the challenges of managing his symptoms, and in light of this, recognizes the need to take his medications. This was highlighted by an incident when he stopped taking his medication and became delusional. At the time, he wanted to improve his mood and thus began to drink; a solution that had used in the past. He subsequently forgot to take his medication for a few days. This resulted in Michael being involved in an altercation, 
and spending a short amount of time in jail prior to his brief hospitalization. Upon reflection on this incident, he recalled "I was taking my pills everyday [in hospital] and then I got let back like I got back to getting better." This example served to highlight that Michael was able to draw on the support provided during his hospitalization to help him resume taking his medication. Taking medications also helps to manage his fear of relapse. Michael chose a pill bottle as the meaningful object that symbolized his recovery stating that "...everytime I see it, it's like, I don't like smile like you know. I see it and I'm just like, yeah, I'm gonna get better, you know. Like I'm gonna pop a pill.” Michael continuously challenges his thinking and is also very determined to fight the illness and to not let it take over.

Michael also recognizes the importance that support from family, health care providers, and friends plays in his recovery. One of his childhood friends often encourages him by telling him that he will get better from his illness, and supporting the need for Michael to continue to take his medications. Michael also stresses the invaluable support he continues to receive from his grandmother and relative stating that "I know I'd have my doctors and stuff and my friends and stuff but if I didn't have them I would feel lonely so with this, with them calling me, it just makes me feel more loved and with the love it helps me with my schizophrenia." They also provide support to Michael during telephone conversations and encourage him to take his medications. He also conveys the comfort and support he receives from others who share a similar illness experience, stating, "I feel that I'm not the only one going through the problems."

Michael's recovery has been marked by an increased interest in other activities like school. He states “things are getting better...I wouldn't be going to school...I wouldn't be doing that stuff if I wasn't getting better. " Michael attends a specialized vocational/educational program as he describes: “... it's a school for schizophrenic people 
and I go there um for class..." He also listens to music as a way of taking him "away from the reality of schizophrenia...so when I listen to music it takes me to another place, meaning that it just, it's ah, it lets me think about something else."

Michael currently lives by himself and has an active social network of friends. He has expressed interest in applying to college and believes that having future goals of continuing with his education and exploring a career in the arts has been helpful to his recovery process. He would also like to find a job in the near future, but worries he might start to hear voices and get distracted if he were to be working, stating "now's not a good time. But uh soon in the future." He is hopeful that over time his mind is getting stronger.

His words of wisdom for others recovering from a FES are "making sure you take your pills and listen to your doctor and what they have to say and let them help you..." Furthermore, he stresses the need for individuals who may be experiencing schizophrenia to talk about it with someone and to get help, as he describes "they should pay attention that sort of stuff and just let someone know about it because...you could get a cure for all that stuff and you could be better..."

\section{Henry}

... they [clinicians] don't make you feel like you're crazy, they make you feel like you're a somebody you know they make you, they give you hope that you can carry on after this... they just guarantee you that you will recover; you know they're positive in that ... as long as you take medication you will recover basically.

[No photograph of personal object rather a verbal description of song lyrics is in the text]

Henry is a male of Caribbean descent and is in his late teens. He lives with his parents and has siblings. He describes himself as being a funny child with many friends who enjoyed being around others in school. Immediately prior to his illness, Henry was in the process of completing high school. He was expelled a few months prior to his hospitalization because he got into trouble. He vaguely describes associating with "negative company" that led him 
to do the wrong things all time. He recalls, "I wasn't really doing anything productive with myself." Henry relates a history of drug use.

As a young teen, Henry recalls beginning to hear unexplained voices stating, “...things started happening to me, it wasn't good at all, there was like the worst of the worst eh, I was like I had voices telling me that I shouldn't be living stuff like that, like I went to [name of the country] and I was gonna jump out of a car, because I thought I was gonna die..." The voices Henry heard continued over the next few months, and led to an altercation with an individual in the community. As a result of the events concerning the altercation, Henry spent over three weeks in prison

Following his release from prison, Henry's mother noticed changes in his behavior and recognized that he needed help. She brought him to the hospital, where he stayed overnight. As he describes: "I didn't want them to think anything was wrong with me," because in his mind there was nothing wrong. He adds, "it's not like I talked to myself or anything like that so like there was no way to tell." Following his assessment in the emergency department, and in spite of his mother's concerns, he was discharged because as he states staff said "there is nothing wrong with you." A month later his mother accompanied him to the hospital again. He recalled that he was frightened by his behavior, stating "it was like the worst time that I've had but basically it would still be going on if I didn't deal with it." After his assessment in the emergency for the second time, Henry was hospitalized as an inpatient for over two weeks. He continues to be followed by an outpatient first episode psychosis team.

Henry realized that he was beginning to recover when he noticed an improvement in how he was feeling. “...at first I wasn't trusting anybody and things like that...I thought they were poisoning my food, trying to kill me like... but then slowly I started out trusting more people, I started taking my medication... and that's a big part of it taking medication cause it 
helps." Henry describes recovery as "going through steps, processes to get to the best shape you can get." He adds, "Like you never know what could happen the next day, you know. So basically, I would think in my mind that I'm always recovering...Constantly recovering. " $\mathrm{He}$ is pleased with his recovery and yet expresses fears of relapse. As a result he is a firm believer in continually taking medication and maintaining an optimistic outlook to sustain his recovery. As he describes, "You just need to reassure yourself and you will get better. Take your medication and you will get better." He reflects upon his recovery saying, "Like everyday it just gets better and better your closer to the... end of like all the symptoms." “...Because like everyday is just a step closer cause you can't you can't get worse from this point, cause like you know how it was..."

Obtaining support from various people has been a source of strength for Henry. He says “...going to to the [name of] First Episode Program was really important to my recovery cause there they don't only offer, like give you treatment and stuff but they don't lock you up in your room..." When dealing with difficult feelings that arose because of symptoms Henry found it helpful to be told by staff “...don't worry about it you know, like that's in the past, not what you did before... like your getting better now and that's all that matters."

Henry identifies his girlfriend as someone who has helped him to get better through her ongoing presence and support; and also added that the support of his parents has been beneficial. Simply knowing that they were there for him was tremendously important. Henry has also found support from his friends during his recovery and while he continues to associate with his old friends, he no longer uses drugs or drinks with them. He has also made new friends from the hospital with whom he shares common experiences. These friends provide assurance that he is not alone and that with the help of others he can get through this. 
Other important contributors to Henry's recovery were having structure to his day, having hope and spirituality. Henry found having daily structure helpful stating: "So like school helps a lot cause it kept me focused and busy. " Currently Henry has nearly completed his high school credits by attending a school which is located at the outpatient centre where he receives follow up care. Henry reinforced that hope and spirituality played important roles during his recovery when he states, "Well hope is big. If you don't have hope then they say you're not gonna recover," and "Well, um, since then like I've started to read my bible and stuff, that helped me a lot because like Ifound when I was reading my bible like everything calmed down."

Henry feels that this illness experience and ongoing recovery has changed his life for the better:

My life is... gonna be like better than it was looking before like cause before cause who knows, I wasn't even I wasn't even thinking about going back to school and stuff like that I was...I was just gonna drop out or something. And now I can actually have like I actually respect for myself for what I've done, the accomplishments that I've made and before I was just like you know I wasn't too thrilled about stuff that I did like all I did, was like sell drugs to people and stuff and no one knows where that's gonna lead you. You can get caught up somewhere and get going and walking in the alley and you get shot or something you know now I don't, I don't have those risks to take anymore.

The meaningful object he chose to symbolize his recovery was a song with religious overtones. The message of this song is redemption and turning away from situations that bring about harm. Henry described the relevance of this song when he said: “...you never know why schizophrenia or anything will happen to you like it might happen for a reason cause maybe for me cause like the wrong life I was leading and I would still be doing if it wasn't for the fact I got schizophrenia." An additional example Henry uses to demonstrate how he has changed for the better, since his illness experience, is by his increased desire to help others. Specifically, because he has been very effective at encouraging others at school 
to believe in themselves, he has been presented with a school award for his contributions to the well being of others. He does not view schizophrenia as an excuse for not trying hard in life, and he strives to instill this belief in others.

His positive attitude and belief in himself is clearly evident. Henry looks forward to a bright future, saying that he has new possibilities in his life that may not have been there, if it were not for his illness experience. He is determined to move forward, stating:

...especially knowing what could happen, or will happen, it's like now what should happen...Now I just think that like I should continue doing what I'm doing, like I have a bright future ahead of me now, like doing my life before, who knows what I could've became, some drug dealer or something like that.

On the topic of future plans he recalls that when he used to help his mother at work "...I used to play my instruments for the kids used to love that..." Henry would also like to explore his interest in cooking.

His words of wisdom for others recovering from a FES are, "Basically, I would just say don't give up hope... make the best of [life] and try and push forward and do the best you can do." He further states: “... I know how hard it is to face it but it's something that just has to be done, you have to overcome it and lookfor a better for the future." An overall striking feature seen throughout Henry's interviews is his enduring optimistic outlook toward his recovery, which is highlighted in his concluding statement from his second interview:

Like don't give up cause like your life is something worst could have happened to, you know and there are people who are paralyzed and still don't give up hope you know they still try and try and some of them even come back from being paralyzed. To having recovery with all their limbs and like if they can do it with such a terrible time and like what they've been through you can do it you can do it with schizophrenia. Don't let it [schizophrenia] overcome you and like cause like that's not the worst there's plenty of other things out there that can happen to you like don't don't make it take over you and don't make it control you because like you can fight it and you can control it. 


\section{Steven}

"I feel like I'm just growing and growing more and more and I'm getting better and better at everything that I do, because I'm more careful and more persistent."

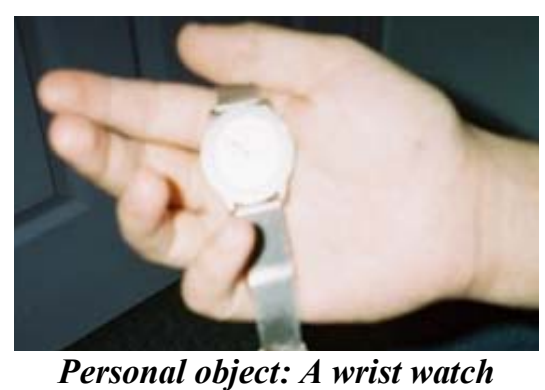

Steven is a Caucasian male in his twenties. He describes himself as very popular in high-school. He is a college student who lives at home with his parents and siblings. Prior to his illness, Steven had a wide circle of friends that he both socialized and smoked marijuana with. As he describes, I had "parties every weekend, and girlfriends all the time, and, you know friends doing drugs all the time." His mother describes Steven as "the wilder one, he did like to party, come in late." Steven recalls that having those friends resulted in him almost getting kicked out of his house and being involved in "... a lot of bad stuff like that and trouble with school and getting sent to the office [frequently]."

Steven first began to hear voices and experience delusional thinking while he was attending school. He recalls believing that his suspicious symptoms were inter-connected and involved the media. Steven recalls, "I was just, just completely bombarded I felt like there's, there's no escaping and I kept thinking like you know next day I'm gonna wake up and it's gonna be gone." He adds, "I wasn't getting any rest, I lost my job...I was in a state of mind where I could barely even think." "It's like your dreaming in real life but it's like a nightmare." His mother was also aware that Steven was not feeling well, stating "you could see that he was trouble..." 
It was over 12 months before Steven finally obtained the help that he required. In the early phase of his illness he described wanting "to solve it [the illness].... So what I originally wanted to do, I was like I want to join the [military]; I want to move out on my own. I want to be by myself.... and just get away from all of this cause I thought I [was]harming people around me." Subsequently, his parents brought him to his family doctor which as he described "made things a lot worse." His family doctor diagnosed him with depression, and prescribed an antidepressant that did not provide him with any relief of his symptoms. Recognizing that this course of action was not helping, Steven made the decision to obtain help elsewhere. Steven states, "I think the big move that I made was I got in the car and I said mom take me to the hospital... I was pretty desperate, so I went there they hooked me up with a psychiatrist almost right away..." Upon diagnosis, Steven states that he "was actually happy" and felt "a lot relief" about his diagnosis because he was told 'this is what you have and we could treat it.' Steven has since required a brief hospitalization for medication re-adjustment. Following this admission, he continued to be followed by a community first episode psychosis team.

Steven referenced many emotions and feelings when discussing the impact of his illness:

...well I went from you know kind of a popular kid in high school, drinking, partying and all that kind of stuff to uhm complete psychosis. And then after like when you go through a psychosis you feel like you lose a lot of yourself, like you lose a lot of, it's very energy consuming and your mind is constantly working and a lot of negativity.

Furthermore he described that when he was acutely symptomatic, "like I didn't feel like this was normal you know." When asked to describe in what ways he changed, Steven states, “Well just, just, I was completely like different. Like I didn't think that could happen you know. It's like your dreaming in real life but it's like a nightmare you know, just it's really intense." In knowing about his illness he felt his parents "weren't like ashamed or anything 
they were completely pretty supportive." He acknowledges the impact stigma has had on his relationships. As he describes, "people are treating me like I got [name of disease]." When asked about the challenge of disclosing his illness to others he states:

There is a huge difference telling people about yeah I have cancer rather than have a mental illness. Uhm people seem to think like ok, if you have a mental illness all it means that you can't like handle yourself or you're not like a strong person... if you have cancer people are like you know they always try to raise money for you or try to help you like that...People feel a lot more sorrow if you have cancer...

Steven identifies the time when his medication was changed, one year after the onset of his symptoms, as the point when he believes he was starting to recover stating, “...right when I switched meds. I got on the right medication and almost right away I started like you know, everything kinda just like disappeared...You know just totally cleared my head and it allowed me to focus on things that are better." He identifies several activities as evidence of his recovery, including being in school, and taking demanding courses that he did well in. He also states that he has become more productive with his time. In addition, he states that he is no longer consumed by his illness:

...the illness is like in most people's lives is like 90\% of their life and only like only $10 \%$ is like family, school all that. But with me the illness is actually only like maybe $5 \%$, like oh so it's not something that I really think about, and now that I'm being distracted as much and I focus on like the right things.

Steven's mother also attributes his recovery to the medication, stating that "now the medicine that he is on is doing what it's supposed to do and uh he's just a much happier person you know he's much more comfortable with himself uhm I wouldn't say 100\% but much better than you know a year ago." Steven's mother describes Steven's recovery as a gradual process stating “initially, during psychosis... they can't absorb, they can't remember, they don't know whether they're coming or going. But slowly they are able to learn and absorb and keep that because they don't have the distractions in their brain." 
Steven acknowledges that after going through his "psychotic episode" he re-evaluated his life's activities. In the process of self-reflection, he took inventory of things that he did not want to go back to, and did not want to have anything to do with. He describes that his recovery was like a growth experience within him. Steven is able to recount the period of time when he was still focused primarily on recovery, in contrast to the present where he is close to being discharged from his outpatient team stating that "I'm kind of past the recovery stages."

He identifies that the support of his parents, friends, the health care team, eliminating the use of marijuana, taking the proper medications, and working hard at his goals have all played an important role in his recovery. Following his illness experience, and during his recovery, Steven found a new set of friends. As he describes: “...you know the people that I surround myself now with, you know they don't try to bring me down. " He also values the company of one of his best friends whom he met while he was in hospital. As he states: “...he's actually been a huge support, not really support but just being able to communicate with somebody and get along with somebody. That's in the exact same situation."

Steven also described that his relationship with his parents has improved during his recovery specifically stating “...my relationship with my parents now has been better than ever." He feels that he now has an added appreciation of his parents and his home life. In fact, Steven identified his mother as someone who has influenced his recovery. He also mentions how helpful health care professionals have been. He states that his case manger is encouraging and when describing his doctor he recalls 'you know he's honest and he'll say... 'that's not a good idea to do that... why don't you try doing this.' And he's always been really good with monitoring my medications." 
Steven no longer uses drugs and continues with his studies with a continued interest in wanting to establish himself in the field of art; he also works part-time. He aspires to get married and buy a house, one day. Steven states that as he recovers he has changed his ways [that did not support his recovery], and has grown as a person by acknowledging that he has “developed thicker skin or more confidence I guess." Upon reflection, he is able to realize where he was in his life, and where he wants to go in the future. He clearly has the ability to motivate himself and is determined to earn his own living. He also has noticed a change in his daily routine in that he now feels inclined to either be working or studying. Steven hopes to reduce his medication dose as much as possible stating that he "wants to reduce the medication though. I want to see if I can handle without it." He worries that his illness will affect his capacity to have an intimate relationship in the future, stating:

I used to be so, so good with girls and now it's like I'm really, you know, nervous cause I'm always thinking like in the back of mind like you know, what kind of girl would wanna, you know, to be with somebody who has an illness?"

Steven chose a wrist watch as the personal object which symbolizes his recovery stating that "time heals all wounds." His words of wisdom for others who have experienced a FES are to "just get out there... get back, get back in the system ...be employed...go to school. You know don't feel discouraged cause you know, there's other people out there and they've gone through it." 


\section{Carly}

"I think I learned a lot more about myself where I was like you know, just started to focus on that I do want to recover you know like, that it's... important to me to... get back to the place where I was but...do it properly like do it in a way that I can keep up that balance..."

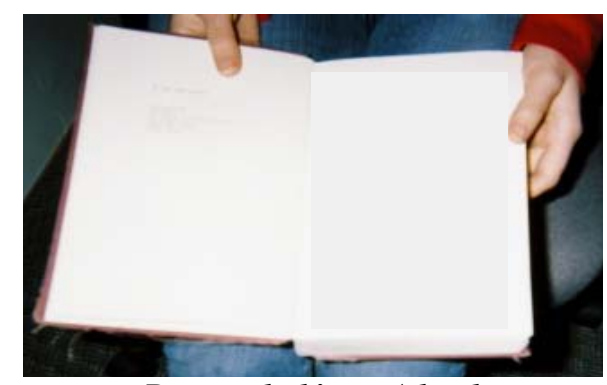

Personal object: A book

Carly is a Caucasian female in her twenties. Her mother describes her as very extroverted and mature for her age. She is a university student who is working towards her undergraduate degree. Carly describes herself as a member of a close family. She has a family history of mental illness. Carly's has not seen her father since she was young. Carly's mother feels her re-marriage ending was "a shock" for Carly. Before the onset of her illness Carly was working alot, had an active social life with friends, and attended school. Her mother describes that Carly “...was using drugs to help her stay awake, she was working at night, and going to school during the day."

Carly's mother recalls that her daughter "had this crash" following an intense ongoing cycle of continuous work and school, as she describes "...we were all in family alert monitoring her, all I remember at the time was it was so frightening watching her... She'd be smiling to herself in her own little world all the time and we didn't know what was wrong with her." Carly recalls that she began to experience changes in her behavior. As she describes: "When I was going to school... I started having weird experiences, where I was like, you know hearing voices and things like that... I went through a period where I was just so distracted and out of it...I ended up staying home for [a few] days." At that time Carly 
was living by herself in an apartment and could not manage to take care of herself. She recalls her friends were worried about her because she did not answer her door. During that time, her mother came to her apartment as Carly recalls: "she was just like you know 'what's going on with you' and I think I was obviously very out of it."

Carly was brought to hospital by police upon the request of her mother early in the course of the illness. She was concerned that something had happened to Carly as she was unable to reach her. As Carly describes "I had some drama going on in my life, I had a really bad relationship that I'd just gotten out of, that was one major thing and also the financial stress and stuff like that." She willingly went to the hospital with police as she recalls "to have them look at me". She was first assessed in a general hospital then transferred to a psychiatric emergency as she describes:

I ended up staying over night ... [there wasn't enough beds...I think I slept in an interview room]... and I had about 3 interviews with 3 different doctors and they didn't know what to do with me, like, they were like, you know she seems fine and she seems happy but she's also you know out of it and then you know she seems confused...one doctor was sort of harsh and she actually said a few things to me that upset me...

She was discharged from emergency and was referred to a psychiatric crisis clinic at a general hospital. Carly describes the care she received at this clinic as: "probably the worst thing that happened to me during my illness that she [the psychiatrist] suggested that everything was probably okay and it was better... now that I was staying with my parents...she thought that I should go back to school." Taking the advice of this clinician, Carly went back to school however, did not make it to school and instead wandered "and sat in the [name of the building] overnight...I think I didn't make it home till... the following night I called my mom who came to pick me up."

One month later, Carly went back to the clinician in the crisis clinic who then started her on antipsychotic medication. After being seen in the crisis clinic, Carly continues to have 
follow-up in an outpatient first episode psychosis clinic. Carly reflects on her help-seeking experience:

It's a big deal I think with something...really bad had to happen for me to...really get down to it to go and, and get proper help and I needed a lot of support from my family...in order to do that... it took a little while like there was a little bit of trial and error involved with seeing doctors and stuff like that to sort of find that right help that I was looking for...

Carly strove to understand her illness experience as she recalls "it can be a really really scary thing you know and you think, well what caused this or what, what is it that I can do, or what's within my power that can help me, you know? That can help me get better." In conversations with her psychiatrist, Carly clearly sees the relationship between unmanaged stress and her illness onset, stating "that's how I react to um, you know to that kind of pressure I have, I go you know psychotic..." As she reflects on the occurrence of her delusions she recalls how strange it was “... I really thought all this stuff was going on, and, and it's not true, but it's not you know, it's not your fault, it's not anyone's fault, for sure." Carly's mother is struggling with the thought of Carly having schizophrenia, making her feel very uncertain about the implications of this illness on her daughter's life.

Carly describes her recovery as an ongoing process that requires her to stay healthy and focused, take medication, and to control her symptoms with the regular help of health care professionals, in doing so "that potentially that this [the illness] may not ever happen again right?" She describes feeling shaken and fragile during her early recovery. “...I wasn't very clear headed and I think I had a lot of physical reactions from the whole psychosis experience...so I think when I first started my recovery process it was like just taking cues from that and talking to the doctor about it." She was unsure if she would "ever get back on track." However, when she began to take medication she recalls: "like all that sort of the ups, the highs and lows and the confusions sort of like all cleared at once. So all of a sudden it 
was just like you know, it was almost like cold water on the face you know." Carly recalls that once the medications started to take effect almost all of her symptoms went away stating that "it wasn't a very long period." She also describes it as a down period given that she was not working or going to school. Looking back, although it was a nice change to move back with her parents, she felt lonely, at times. Carly states that managing stress has been the key to her recovery and identifies the recommendation by her psychiatrist to take time off school in order to recover as a significant event.

She described herself as recovering three months after observing changes in her behavior and has noted a marked improvement in her symptoms. A few months later she was able to go back to school, work part time, and re-engage in her friendships. Through her recovery she describes her mind as "becoming clearer" and that she has become increasingly aware of how to manage stress in her life by taking cues from her physical symptoms, such as changes in sleep. She now enjoys reading again and has new interests such as cooking. Carly chose a book as the object that symbolizes her recovery. The "hopefulness" represented in this book has helped Carly to better understand her experience, and reflects her love of reading, which she has regained and that she has used to monitor symptom improvement.

Through her recovery process Carly has found and now appreciates having time for herself and has re-established her priorities in life. She clearly has a strong support network including, health care professionals, the family pet, and a few close friends. Carly also commented on the importance of her family's support during her recovery, especially from her mother. Carly's words of wisdom for others recovering center around an openness to receiving help. 
Carly feels that she has almost recovered because she has not experienced symptoms for almost two years, is able to deal with the stress of life, and has engaged in activities that she would have not engaged in earlier. She believes the use of strategies such as exercise, cooking, and engaging with friends has enabled her to take better care of herself. She is able to progress with her life "after recovering" by initially going back to school on a part-time basis. She has a potential job opportunity following graduation. Overall, she feels that her physical, mental, and emotional health is now being balanced. Carly's mother states that Carly is recovering “... she's back, she's a part of the family... she's more caring about others around her, where she wasn't before..." Carly is concerned that her symptoms may re-surface in the future. She knows if this were to happen her medications may have to be adjusted. Carly describes being able to monitor her symptoms, a skill that she has learned from her health care professionals. She is also concerned about her friends' reactions when she was acutely ill.

Carly identifies that she has discovered insights concerning loyalty and support about herself and others through her recovery. She also values her resiliency: "I think...I'm pretty resilient which is good because I think I can you now deal with challenges...over the last two years... Ifeel definitely clear and my emotions are balanced which is you know a good thing and generally up feeling." 


\section{Linda}

"I am doing well step by step"

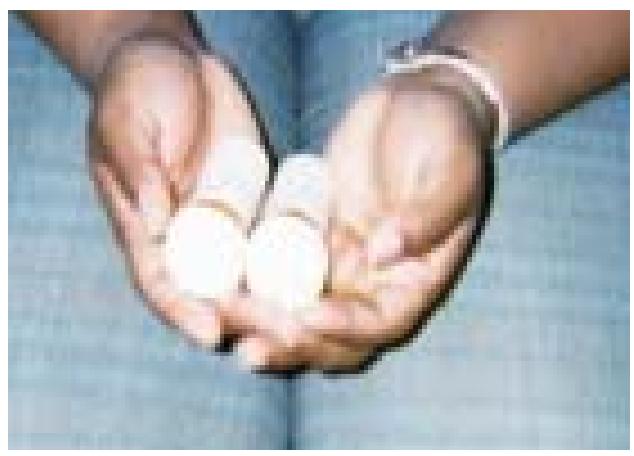

Personal object: Her medication

Linda is a married female of South Asian descent who came to Canada in her twenties. She has a large family, and is the only child residing in Canada. She lives with both parents, while her husband lives a distance away. Linda is a full-time student who works part-time in order to earn enough money to meet her needs. She is actively involved in her religious community. Linda describes that prior to her illness she was busy in school and work. She considers herself the type of person who will work very hard to complete what ever she starts. Linda's father describes her as someone who is very intelligent, did well in school, and is brave. He stated that before coming to Canada she was involved in education.

Linda described what she believed contributed to her illness: "I studied from books, I went to classes too...that is more stress for me because working full time and at the same time I have to go to the class. And I couldn't sleep 3 or 4 days continuously, because I was always studying...that's why I got sick.” According to Linda's father, he and his wife noticed behavioral changes at that time which included sleeplessness. They also noted that she wanted to visit her religious centre more frequently, which was not her usual behavior. As a result Linda's parents took her to their family doctor. Linda's father voiced frustration with the family doctor because, as he described, this doctor did not see anything wrong with Linda however he did prescribe sleeping tablets. Linda's parents noticed that the medication did 
very little to improve her sleeplessness. Linda also recalls that she was not sleeping and that she was shouting to her parents about religious ideas. It became increasingly difficult for her parents to manage her delusional thinking which prompted them to phone for help.

After her parents called 911, she was brought to a general hospital emergency department by ambulance accompanied by the police, where she remained an inpatient for several weeks. Her father recalls that there was always a family member present with Linda in hospital. Looking back on this experience, Linda felt that she needed to go to hospital. Following her hospitalization, she recalls that the psychiatrist who made the referral to a specialized mental health facility said she "would recover quickly there." She continues her outpatient care at this facility.

Linda feels that she is different from others because she has a mental illness and describes it as "a bad thing." The consequence of this illness is that "we can't share our things... with other people because my [relatives], many people don't know I get illness. Only close friends, my [relatives] they know." When asked if it was important that other people know about her illness Linda stated, "No, that's not important but we can't tell because my parents don't like to tell others, I got illness." She also concurs that she does not like to tell other people too, as she describes, "Maybe they...maybe they think like I have mental problem...Now I feel normal, [I] don't like to tell them." When asked if her husband knows about her illness, Linda states that he is aware of it but treats her as though she does not have an illness at all.

Linda believes that telling people about her illness could affect her future. Linda has not yet talked to her counselor about the issue of disclosing to others because, as she states, "this is not a normal disease, this is different...back home no people normally get like this. Here when I go to family doctor, he says don't worry about this because it is normal here", 
which according to Linda is quite different from how mental illness would be perceived in her country of origin.

She began to think about recovery immediately after she got sick. She went back to her birth place and stayed there for a few months to recover. While there she was able to spend time with her family and attend religious ceremonies. She believes that taking medications and keeping busy have been important elements of her recovery. Linda chose her medication as the object that symbolizes her recovery, as she states it "helped me a lot to my recovery." Specifically, the medication has helped her worry less and improved her sleep.

As evidence of her recovery, Linda indicates that she has seen an improvement in her symptoms stating, "if you know my illness symptoms it is easy, it is easy to know my recovery because I was too sick at that time." She also states that she is no longer receiving messages from God. Linda also points out that she has noticed an increase in her level of participation in activities, for example, sharing relaxation exercises, and cooking at home. She also enjoys being involved in a program for mental health consumers. Linda states that she can think clearly, her sleep has improved, and she is working part-time while she continues to go to school. She has attempted to reduce the level of stress in her life by making one day a week her day of rest. Linda also believes that she can help to minimize the level of distress for people who are in similar situations, by sharing her illness experience, and by providing hope that recovery is possible.

During her illness, Linda noticed that she was unable to help her mother with activities around the house which she believes resulted from not feeling well. However, now that she is feeling better, she keeps busy and is able to help her mother with household duties. Linda states that her mother says that she is "75\% ok", which she agrees with. When asked what she plans on doing to gain the remaining $25 \%$, Linda states that her plan includes 
continued improvements in her sleep, decreasing some of her weight gain by getting more active, and then starting to get back into a daily routine. Linda's father concurs that she is "70-80\% recovered because he has noticed memory improvements, she continues to go to school, her engagement with the family is evident, but the $20 \%$ is still like...the being more active perhaps, exercising more." According to Linda's father, recovery for his daughter would mean that she lead a very happy life.

Her parents are also supportive in reminding her to take her medications. Linda identified her father as someone who has influenced her recovery. Linda emphasizes the importance of talking and being around other people as being helpful to her recovery. She adds 'if I'm all alone I would worry too much, if there are people around me I don't worry as much." Linda's father reinforced the importance of family supports. Linda also feels that the life/leisure skills program that she has been involved in has also been helpful. As she states, "Cause all patients there they teach like our illness... and what food we have to eat, sleeping and...medication." Linda takes pride in academics, noting that one of her accomplishments during her recovery has been to persevere and complete courses, even though she was not feeling as well as she would have liked. Linda recognized that others around her value her smile, her spirit, and determination which she describes as a personal strength. Her main support is her family. She continues to be active in her religious community. When asked to offer words of wisdom, Linda highlighted the importance of taking medication on an ongoing basis, and sharing recovery stories in order to give hope to other individuals in the process of recovery.

Linda is concerned about the impact of her illness experience on her finding a job when she has completed school. She has identified that she has supports in place, such as her case manager and psychiatrist to assist her in working through this. She also identified 
struggles she has encountered during her recovery process. Specifically, she has noted physical changes related to weight gain, changes to her menstrual cycle, her ability to concentrate, and sleep cycle all of which she discusses with her clinicians. Linda also reveals that she would like to know more about her illness. An additional concern for Linda (that she would be discussing with her clinicians), is her uncertainty regarding her follow-up once she is discharged from the outpatient clinic at the specialized mental health hospital. Linda describes the need to want to recover more and soon stating “... I'm not fully comfortable because I want to recover more. That's not enough, I want to become a normal person like everything in my health and my studies and my work."

\section{Curtis}

"I think I'm doing so well and not letting anything impede my progression or performance...stay on point I would say and I could be successful."
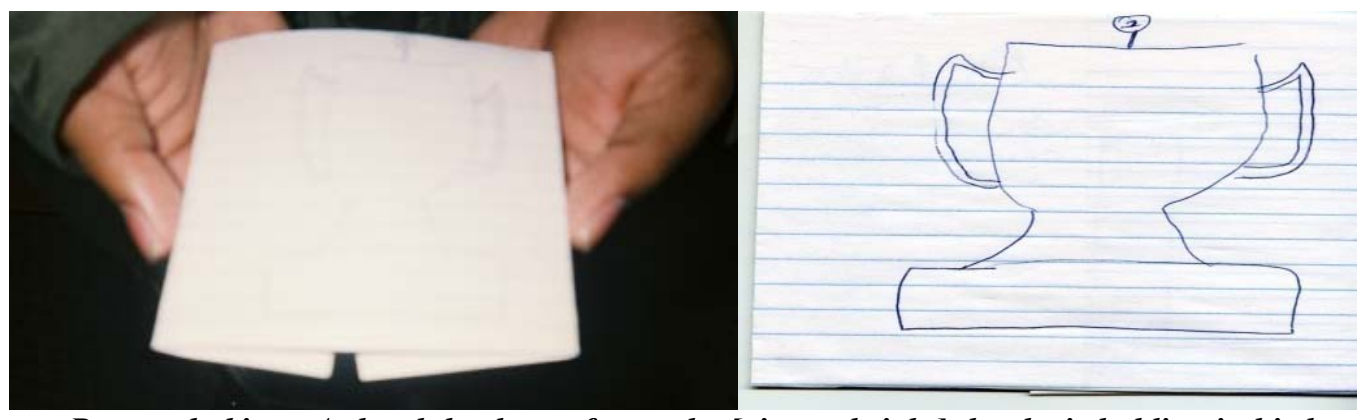

Personal object: A sketch he drew of a trophy [pictured right] that he is holding in his hands

Curtis is a male of Caribbean descent, in his late teens, and a member of a small family. Curtis has a strong interest in academics, prides himself in achieving good grades at school, and enjoys interacting with others. He also describes himself as a person of faith. His personal interests include exercise, attending school, and reading. His parents are separated and he lives with his father. He describes a turbulent relationship with his father who can be over-bearing at times. His mother is not well and does not live at home. There is a family history of mental illness. He describes his relationship with his siblings as "buddy, 
buddy now" stating "They are trying to be on good footing with their... brother now because I guess they see where he is going in life..."

He recalls that even though he achieved high grades and was an award winning student, no one knew about his fear of public speaking. He recounts feeling so anxious and worried about participating in class, that he often could not focus on what the teacher was saying but rather just tried "to get through the school day." During high school, his grades began to slip; he describes himself as feeling drained, "knowing that something was not right," and noticing changes in his thinking. He also described that he had issues with anxiety in school. As he recalls: "when I was kind of anxious and worried, it wasn't affecting my academics, I was still focused on my classes... I was still getting good marks and when high school came it was different really affected me..."

His family also noticed changes in him. As Curtis recalls there was a time when "like just my mind set like wasn't really clear. I was like uh obsessing over stuff it was crazy...” His father accompanied him to a general hospital emergency for assessment that resulted in a brief hospitalization during which he was started on medications. After his hospitalization, he was referred to an outpatient clinic that specializes in first episode psychosis where he continues to be followed. His psychiatrist described helping Curtis improve his low energy, and difficulty with focusing.

Curtis remembered not knowing that there was a term that described his illness. As he recalls:

I didn't even know there was a name for it [his illness], I only knew that because I was applying for [name of government assistance program], they actually have a grant if you have a permanent disability. So the way I look at it, for the purpose of school and [name of government assistance program] I have a disability. Anything else, no I don't. It's kind of weird. 
Curtis feels that the term schizophrenia does not define who he is, nor does he allow himself to be restricted by the illness label. He affirms that he is able to get on with his life because he is ambitious in school, has goals, and interests.

Curtis prefers not to discuss his past illness experience, only recalling that at one point his relatives were concerned about him. He describes feeling "stung” by this. He preferred not to elaborate on this stating "I don't know, I'd rather not talk about it, we can talk about other things," suggesting a desire to put it in his past. He states that positive things have arisen out of acknowledging his illness. Specifically, the financial assistance he receives in the form of a renewable grant, and the extra time he is given to complete exams in school. He does however highlight the importance of other students not knowing that he has this arrangement.

He first began to think about recovery when he was asked to participate in this study. He describes himself as recovering because his "symptoms don't really appear," and he doesn't talk to his psychiatrist "about crisis anymore." He adds that symptoms are not the focus of their discussion but rather on others things in his life. During his recovery, he describes receiving emotional support from certain relatives and financial support (e.g., paying for his medications) from his father. Recovery for Curtis consists of living with an illness whose symptoms do not affect his daily life (e.g., progress in school). As additional evidence of his recovery he suggests that he has been able to get on with his life.

Curtis noticed that his mind has become clearer approximately two years from the time when he first noticed changes in his thinking stating "I was enjoying my life more I was doing better in school, I was feeling a lot better." Curtis identifies a combination of things that have contributed to his recovery. He has learned about the value of positive thinking, and setting goals in his life during his recovery stating that: "I was able to do all all the things I 
wanted to do. Like I'm able to go to work, fully function to be the best that I can be..." $\mathrm{He}$ also feels that taking medications, talking to others, along with his inner drive, motivation, and his focus on the future have all helped tremendously in his recovery. He is able to selfreflect and has used strategies to help him deal with his thinking, and through this has learned “that once a thought's been forgotten that's it... you don't have to worry about it anymore..." He is $100 \%$ immersed in whatever he does, and tries to do the best he can in areas of his life. He also feels that exercising and having a routine at school helps him to recover, as did the reading of a book that helped him challenge his thoughts, think positively, and not to jump to quick decisions. He comments that prayer has been helpful "definitely pray at night, it definitely helps me."

Curtis also described the support that he received from the first episode psychosis outpatient clinic staff and his psychiatrist as important to his recovery. He states that they know him well and made him think differently pointing out the importance of giving himself a pat on the back. Curtis' psychiatrist describes him as resilient and "a poster child" for individuals who are recovering from mental illness. Curtis also reflected on the supportive role of his guidance counselor and his psychiatrist in helping him to regain momentum with his studies. He recalls that having gone to summer school was a new beginning for him a “new start ah my mind was much clearer...I don't know if that was possible with medication..." He describes the importance of others not noticing anything is wrong, disclosing that he has only told one friend about his illness.

Curtis is clear that he will not allow the illness to control him, but rather he is going to control what is going on in his life. He also mentioned that he previously internalized everything, noting now he has changed because he is able to share his feelings and is more mature. He notices an improvement in his interpersonal skills stating that he is "definitely 
better with people now." adding that others value his ability to engage. Curtis is committed to establishing goals for himself, which are mainly focused on school and being a university student. Curtis recognizes the drive that he has and the progress it helps him make. He sees himself as very engageable, enjoys talking with others, and making them feel comfortable, and prides himself in bringing out the best in others. He believes that his positive thinking, faith, and the supports that he has identified have helped him to do this.

The strengths Curtis processes are his self-awareness and his high level of ambition. When asked, he states that he values his intelligence, although acknowledging that at times his relative jokingly calls him a "dummy," and further states that "he thinks his dad thinks he is a fool. "However, views such as these do not hinder him, as he hopes that in the upcoming years he will be graduating from university. His future ambitions include working with young people, and marriage. Curtis' words of wisdom for others recovering are:

You have to set goals you gotta know where where you wanna go but then you also have to evaluate how you're gonna get there to get to achieve those goals. Once you figure that out you gotta stick to it and stay focused. And...then you also gotta shut out all the all the negativity.

Curtis drew a picture of a trophy with a number one on it when asked about an object that symbolized his recovery. He described that it also represented his strong ability to continue with his aspirations. By drawing this trophy it symbolized giving himself a visual award. He recalls that he has always earned awards in school by being determined and working hard, qualities he believes will help him now. Curtis continues to describe himself as number one, the number which he placed on the top of the trophy he drew. 


\section{Sandy}

"I think that I've come a long way from like when I was sick."

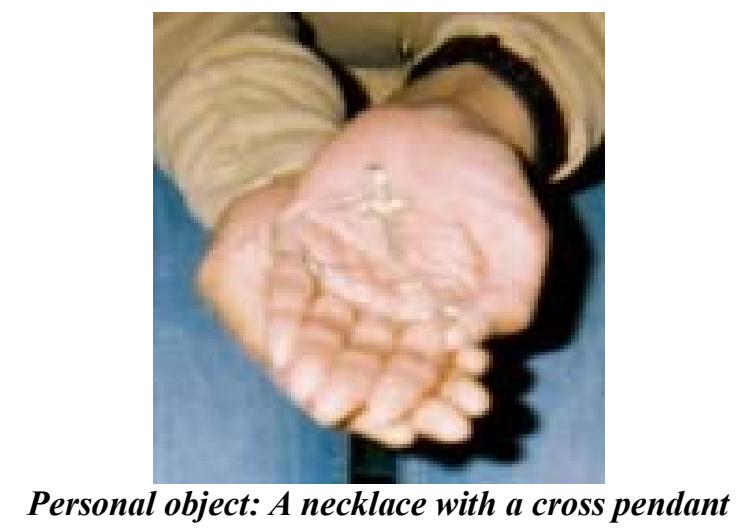

Sandy is female of Caribbean descent who is in her twenties. Prior to her illness she was enrolled in University. Her parents are separated and she lives with one of her parents. Her religious faith, which includes prayer and participating in church activities, is important to her. She takes pride in her academics acknowledging that it's something that she has always done well.

Sandy acknowledged that she did not recognize she was ill until well into the helpseeking process. She recalls an incident where she was displaying odd behavior in public. Her parents were subsequently contacted and arranged for her to be taken home. Her mother also recalls receiving copies of notes that Sandy wrote to others about wanting to harm herself.

Sandy's parents took her to their family doctor because, as her mother described, they were concerned Sandy “does not socialize...she’s introverted ...critical of herself.” Sandy recalled the experiences of seeing her family doctor as "bewildering" because as she recalled "I didn't think there was anything wrong with me." Her mother recalled that the family doctor referred her to a psychiatrist who stopped the meetings after a few appointments because the doctor did "not see any problems" with Sandy. She continued to see her family 
doctor for several months. Subsequently, the following year, in response to the changes her family was noticing, Sandy's family brought her to a general hospital emergency department, where she was assessed and discharged. Two weeks after the discharge her behavior continued to worsen.

After that, her mother recalls an incident when Sandy was not sleeping because she reported that she was seeing things and hearing voices. Later that same day, Sandy recalled feeling that her family wanted to harm her. Her family had her assessed by her family doctor, who then arranged to have her admitted into hospital where she stayed briefly, and was started on an antipsychotic. Sandy recalls that she was feeling very energetic and would go days without sleeping before her hospitalization. Sandy believes her hospitalization was helpful because it gave her a break away from everyone, and that once on medication, she had the opportunity to reflect on everything happening in her life. She also stated that after a while, she wanted to leave the hospital, because she felt at times that the nurses and doctors could not understand what she was going through.

After Sandy's hospital discharge her parents began looking for a psychiatrist whom her mother found approximately three years after her initial symptoms. According to Sandy, this psychiatrist diagnosed her with schizophrenia and he continues to follow her as an outpatient. She also began to see a psychotherapist who later referred her to a program that focused on helping people who had been hospitalized for mental health reasons re-enter work, and school life. Sandy remembers having a positive experience and participated in the program because it was fun, allowed her to make good friends, and combined academic and recreational work, all of which allowed her to build her confidence.

Sandy talked about feeling frightened about her illness because of how the media has portrayed others with schizophrenia. She also expresses a strong desire to help change 
people's negative perceptions by “creating awareness of the facts of schizophrenia” and making people aware that in spite of it, people with mental illness still contribute to society.

She adds:

I've gone through it, I want to be able to say that schizophrenia...like it's scary to the person who has been through it and to my family, those are the people that I'm around most of the time who saw me go through this... but you don't have to treat people badly because it is scary...

She believes that she experienced the effects of stigma associated with mental illness when some of her relatives did not visit her while she was in hospital. Sandy has been reading to increase her knowledge of mental illnesses. As she recalls "I read that there's a link between depression and schizophrenia... as more people... go through depression ...they are at risk for schizophrenia..."

Reflecting on her process of recovery Sandy recalls that she initially found it difficult, and sometimes cried herself to sleep because she was in denial, not being able to accept "or embrace" that she had an illness. She also felt angry with herself and thought about ending her life. Sandy believes that accepting that she had an illness was important to her recovery. As she described:

Beginning the recovery process is taking that difficult [first] step in um, in um being in denial to um to um starting medication...Because um like um like you start because you admit to yourself okay I am sick, I am not well,... and then like the struggles do begin but I think...maybe every step to recovery could be difficult to handle, in some way, whether it is a positive... well I recall the step...it's um a difficult demanding step...denial to acceptance.

She adds that "having inner harmony, inner peace like made me calm down and um also let me have a little hope."

Sandy states that the first time she thought about recovery was when she was accepted into a work program (approximately three years after her initial symptoms) because it was a professional work accomplishment. She recalls her life prior to applying: 
...the summer of [year] I tried to do a class in university and then I found it to tough and then I decided you know what, I'm not going to do anything with this program, take it easy, just relax and uhm just sleep...so that meant from [month]l to [month] I did nothing and then ... that was [year]...I think it was the summer of [year], I decided okay, I'm going to do this [name of] program...

Sandy believes she is now more confident and happy. Her family members are noticing, and commenting on the changes in her as she recovers. As she describes: "I was on medication ...one of their families... told my mom that they think I've changed." When asked in what ways she has changed Sandy acknowledges: "I think that... I look look more confident than I look more happy, that I've become more happy." The changes in behavior her mother has noticed include Sandy sleeping less, an increase in her energy level, and interest in her surroundings, and that she is happier.

Sandy describes her mother as someone who has dedicated a lot of her time to making sure she receives the care she needs to recover, this included finding Sandy her psychiatrist. She has also provided important practical and emotional support. As she describes: "I had been through a lot of psychologists and psychotherapists and all of these professionals, and I still wasn't getting help, if it wasn't for my mom I wouldn't be where I am today, she is the one that went and got the help. "Sandy recognizes that taking medication has been helpful because it makes her feel more alert. Sandy also highlights the importance of having friends during recover stating "Like I've been around my family for my whole life and uhm I haven't had that many friends [stating earlier that she could not really relate to people] and as I grew older, my family got more protective, and I got more friends, also I got more friends that went through the same thing as me with schizophrenia." A hindrance to her recovery has been at times feeling smothered and overly protected by her parents. 
Sandy's desire to become more independent, including managing her finances is reflected by her life approach, specifically "taking it one day at a time, one goal at a time, one action at a time." This also reflects her approach to recovery. Sandy recognizes that she is becoming more independent as evidenced by her ability to do things for herself (including taking public transportation) however; she fears that she may fail at becoming increasingly independent. Sandy reflects on the importance of independence in describing what recovery means to her:

...after you're hospitalized and you go on medication and that medication leaves you like...like leaves you feeling depressed after a while and you sleep more and you don't want to do anything. I think recovery, recovering from that, your recovering from not being there, to do things for yourself and when you can do things for yourself that makes you feel confident and being able to do things for yourself and that raises your self- esteem.

When asked what she values about herself she states "I think I value integrity... I try to say what I mean and mean what I say." She also mentioned the central role of inner peace and harmony, the role of God, prayer, spirituality, and the importance of hope as essential elements of her recovery. "I think um to recover you should be happy with everything that you have..." "I am thankful and the one who I thank for all these things is God and when I pray every night I thank him for everything that I have." Sandy describes that hope has boosted her "desire to become a better person." She also mentions that her friends value her intelligence.

Sandy's future goals include having a relationship, completing her schooling, becoming more independent, and living on her own. Sandy has a positive outlook on life and thanks God for things in her life such as housing, and food. The personal object she chose to symbolize her recovery was a necklace with a cross pendant. She stated that the object symbolized her struggles and hope through her illness experience. However, she now is looking forward to the future, and has clear hopes for world peace. Sandy describes: "I do 
believe in world peace and my purpose will be...um I think that somehow doing little things like I've contributed to would peace or peace in society... like the little things do add up to big things." Her words of wisdom for others recovering from a FES are to "try to do something that raises your self esteem, builds self confidence, try be more independent anyway you can."

\section{Leah}

"I used to be like really temperamental and stuff like that, not temperamental but I was kind of like an angry person. So, now I try to be nicer because I want to ah be more positive."

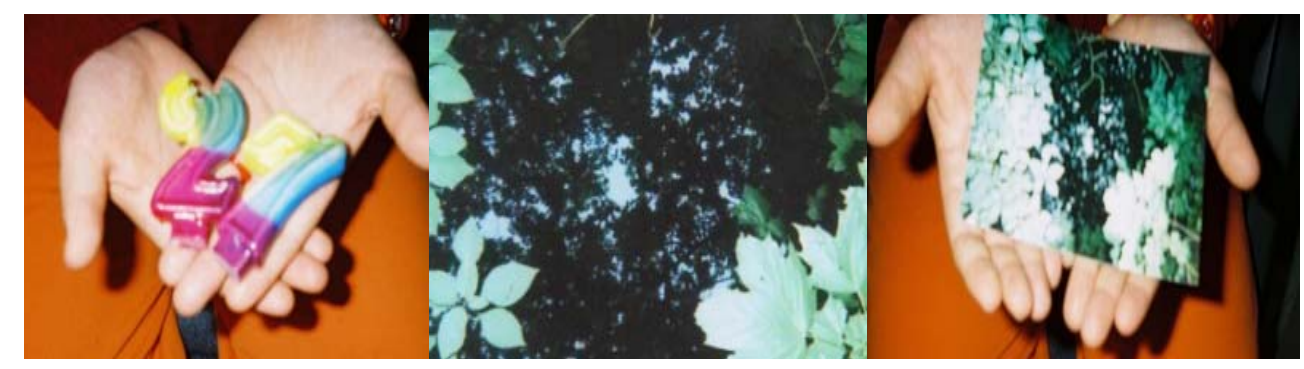

Personal objects: A photograph of trees, and birthday candles

Leah is a Caucasian female in her late twenties. She is the only child in her family. Leah lives by herself; and has a close relationship with her mother. She does not have a relationship with her biological father, and her relationship with her mother has been turbulent during her early twenties. Prior to her illness, Leah describes herself as not very pleasant to be around because she was under a lot of stress. She had a boyfriend whom she no longer is seeing. Prior to her illness, Leah had history of drug use stating "I just thought psychedelics are okay as long as you're not doing cocaine or whatever."

Leah describes hearing voices for the first time while experimenting with drugs. Thinking it was the drugs, Leah stopped taking them for several months but continued to feel symptoms that she thought was a chemical imbalance resulting from the drug use. Leah recalls that at the end of this period she had not bathed or eaten for a short period of time. 
Her mother encouraged her see a doctor when she noticed these changes in Leah. On her way to the doctor, Leah became confused when she was spotted by someone she knew. This individual, recognizing something was wrong convinced Leah to go with her to get help. Subsequently, she was taken to an emergency department, her mother was contacted and she was admitted to the inpatient psychiatry unit. After a brief admission, during which she refused to eat, Leah was transferred to a specialized psychiatric facility where she was admitted to their first episode psychosis unit for over four months. She remembers feeling paranoid during the early stages of her hospitalization when she believed nurses and doctors were part of a conspiracy.

Early in her illness, Leah did not believe she had schizophrenia, or that there was anything wrong with her as she was convinced that the voices she was hearing were being transmitted to her. A book given to her by her mother on schizophrenia helped her to begin to understand the illness. As she recalls: 'Like, just since I've had time to uhm sort of heal a bit, now I can look back at how ill I was, and it's like okay maybe there was something wrong with me." She recalls when she acknowledged to herself that "maybe I was schizophrenic..." She adds that having this acknowledgment helped her feel "a little bit better I guess like it sort of explain things...like what my doctor had to say he said that schizophrenia is not a diagnosis it's more like a description of symptoms that people have." As a result of conversations Leah has had with her psychiatrist she realized "there's plenty of people [with mental illnesses] that... have jobs and they have families and everything like that and they're on medication. And people won't even know it, a lot of people keep it to themselves, I guess cause of the stigma around it. But, me I'm totally open about it." Leah continues to see her outpatient psychiatrist once a month, her art therapist occasionally, and may also explore the possibility of seeing a psychotherapist in the future. 
Leah describes her recovery occurring in stages. She recalls transitioning from her illness onset which hit her all at once, "I was too paranoid and disturbed and absorbed in my own little world to understand that people were trying to help me, " to eventually reaching a point when she was able to talk to the doctors and nurses and was able to start "... thinking about my behaviour I was like I can see why they think I'm crazy." She states that medications didn't work at first and made her feel extremely tired. She also described being very troubled by the side effects of the medication specifically significant weight gain, body aches, exhaustion, and drooling.

She described feeling "normal again" and could carry on a conversation when she was switched to another type of medication [as part of a research study]; she also experienced weight loss. She also commented that her doctor noticed that she was suddenly "awake and more lively". "So I basically, I started feeling like myself again and I haven't felt like myself in two years." Even though she supports the importance of taking medication, Leah feels that she is more than just medications. As an example, Leah mentions that at times she gets annoyed with her mother who quickly assumes she's stopped taking mediation when Leah gets emotional. As Leah describes, “...sometimes when I'm emotionally a wreck, it's just like it's not just that [I]didn't take my medication or something, it's also like something's in my system that I need to get out."

Leah describes herself as recovering because she notes a marked change in her appearance "when I was ill I was like I've come a long way like I was really skinny and I didn't bathe and like I [shouted] a lot and I don't do that anymore..." She believes that her illness has changed her for the better. Prior to her illness, she describes feeling "trapped in her life" and "hoping and praying that something was going to happen. And something did happen and it wasn't great that I went crazy but it's it's pretty much changed my whole life 
around. And so things are like a lot better now." Events that were also important during her recovery was the break up with her partner which provided her with a sense of liberation, and going back to work, which allowed her to have money and provide her with a means to live on her own. Leah is also getting better at managing her stress. She highlights the importance of keeping busy doing hobbies, and using resources at a psychiatric facility.

She articulated very clearly the importance of being open to receiving help. An important insight that Leah has learned as she recovers is that “... when ever you do need help you'll get it eventually. Like sometimes you have to be patient." She believes that having gone through her illness experience has changed her perceptions of mental illness as she states: “I don't find mentally people scary at all." Leah uses a number of strategies for her recovery, such as journal writing, and talking with others. She further states “...it helps to go over things. I mean not like obsessing like I usually do...But, yeah it really helps to go over things and like get a different perspective on them."

Leah recognizes how supportive her mother and more recently her sibling have been during her recovery. Leah also values the support provided by her health care team. She also has identified her art therapist and primary inpatient nurse as individuals who have influenced her recovery. Both have commented how pleased they are with Leah's recovery given how ill she was when they first met her. Leah describes herself as a "pretty sensitive person" who worries at times how she will be perceived by others. She also states that she is more likeable now and having friends is good for her self-esteem. She mentioned that at one point she did not have many friends because she "wasn't very social" due to the medications she was taking, but now has "lots of friends." 
Leah values her coping skills noting that she does not get upset about things anymore. She recently got her first apartment, and would like to learn how to budget her finances. Leah describes changes in her demeanor as she is recovering indicating that she is a lot better emotionally. She has resumed her part-time job which keeps her busy and also takes an interest in educating the public regarding mental illness. It is apparent to Leah that she is able to use available resources depending on her needs at the time. As she described:

...my [relative] pointed out to me, you know it's terrible that you had to spend so much time in the hospital, and like, you were really drugged for a while you know but she said look at what happened, now you've got all these benefits you can go to school for cheap or like for free like I'm doing now, and maybe I can get into public housing, like lots of good things have come out of it...

Leah is focused on developing her own interests and hopes to one day resume dating. She no longer uses drugs stating "the longer I've stayed away from it the better I feel." and on the advice of her psychiatrist she has found new friends that do not use drugs. Leah attends a program for mental health consumer survivors. Even though Leah sees herself as recovering, she still worries that her illness will return. For instance, she describes having "glitches" meaning symptom reoccurrence, when she is under stress. However, she hopes to stop taking medications in the future and hopes she will not be paranoid, irritable, or psychotic, but instead feel as good as she does now. She chose two personal objects to symbolize her recovery. The first was a photograph she took of a tree because it reminded her of mother earth; an entity that can assist in healing. She also acknowledged that time has helped her healing, symbolized in her second object which were birthday candles. Her words of wisdom for others recovering from a FES includes listening to their doctors, and to realize that things are going to get better eventually. 


\section{Laura}

"Recovery means a working able mind and body"

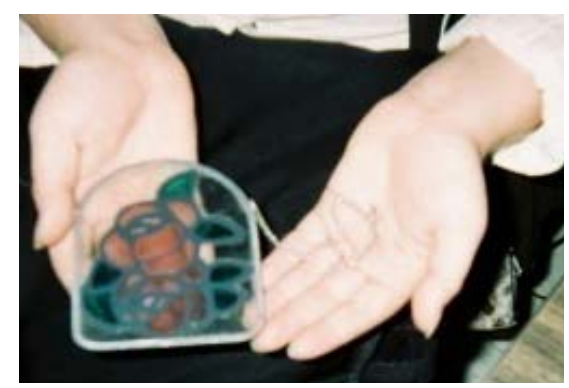

Personal object: A piece of stain glass

Laura is a Caucasian female, in her twenties, with a family history of schizophrenia.

She lives with her mother and other relatives. She is an avid reader, enjoys the arts, and athletics. Before her illness she describes herself as being "a major [type of athlete].” She was very active and "really healthy." She described herself as a "party person" who "would go out every night with my friend, we would have a drink and stay up until...the morning, just talking and being goofy..." Laura remembers writing as a way to cope with depression during high school and also mentioned associating with the "wrong crowd." She recalls doing well in [name of language course] and was considering pursuing this area as part of her post secondary studies until she became ill. Laura has no history of drug use but drinks socially.

Laura recalls the onset of her symptoms while she was finishing high school, "I was at school one day and I started hearing voices. I got sick and ...that world was lost to me, like I couldn't function like I couldn't do anything." She also was fearful and struggled to understand what was happening. She adds “...I just had this Ifeel like pressure in my stomach and I said... I'm not I'm not feeling very well." Laura states that she was also hallucinating at this time. 
At her request, when Laura was in her late teens, her parents took her to a general hospital emergency department. She was admitted to hospital for a period of months and according to Laura was diagnosed with "mild psychosis." While in hospital she felt that she had lost her ability "to do anything, I couldn't write, I was still in the middle of school and, I wanted to finish my year, so I participated in class at the hospital... and I got my report card at the end of the year." Laura describes being in hospital as one of the worst experiences she has ever had. She was subsequently transferred to a specialized psychiatric facility as an inpatient and continues to be followed as an outpatient by a community first episode psychosis team.

Laura recalls that approximately a year after she had been sick she was excited to be in college. However, while Laura was seeing her outpatient psychiatrist with her parents, it was felt that she needed to go back into the hospital. As she recalls:

I just burst out crying I was so upset and so like just stricken with fear, like why are you doing this? You know, everything is fine...they had to get security because I wouldn't leave... It was kind of one of those situations where it was just so heartbreaking for me. I said I don't want to go back, and I was kind of angry at my dad uhm and my mom for you know not taking my word that things were fine.

Laura recalls feeling that returning to hospital would be detrimental and responded to this event saying, "if I had to go back to the hospital I'm going to become like this weird person...I'm not going help, my recovery...it was more like that I was just...I was angry at my parents for bringing me back." She also mentions that she lost some of her friends because she was always in the hospital.

Laura's case manager describes that Laura's illness experience has not been easy for her as she has had a few hospitalizations, including one related to a reaction that she experienced to the antipsychotic medication she was taking. He adds that because of her fluctuating mental status, medication adherence, and safety concerns, Laura needed increased 
support. Laura recalls that during the first year of her illness "the illness kinda of swamped me and I didn't do anything, I stayed on the couch all day, I watched a lot of TV." She also describes feeling overwhelmed and nervous around people and felt embarrassed by her illness especially around her friends.

Laura presently describes herself as "suffering from schizophrenia for 3 years now." She states that her relative also has schizophrenia and although she does not know him that well, "I know him enough to be like oh my God, if that's what I have." Laura believes strongly that the illness is only a part of her and does not make up all of her. As she describes "...I find that people, talk to me as though there talking to the illness and not who I am as a person cause the illness is only a part of me." Laura recalls telling her mother that:

...I'm allowed to get angry without you calling it a symptom of the illness and putting me in the hospital for a couple of more months... because I find that after I got sick if I got angry or and I felt upset, I was immediately returned to the hospital, and I'd leave very quickly because what happened is that I wasn 't sick, I was just having, I was just being emotional.

Laura described being diagnosed with schizophrenia as a profound trauma that she never expected to happen to her:

...it's like one of those things that you just go it's never going to happen to me and then it did ...you don't like you don't begin life going you know when I'm [in my late teens], I'm going to get schizophrenia you know you don't, it's like a huge trauma...you find out that while you're in the midst of your life and your surroundings, you go oh my god I've been diagnosed as schizophrenic, like why is this happening to me?

Laura's case manager describes how difficult the early phase of illness was for her.

He recalls "a period where she would not just talk about it. She was angry, hostile, ah disappointed that she had to be involved with this whole system..." He also describes that she "was very symptomatic, I think she was a very mistrusting person, very very bottled up."

Laura recalls that the treatment for her illness was also difficult. Initially, some of her medications had "really bad" side effects that sometimes made her symptoms worse 
however "now that they've found the right like medication for me, so I'm doing a lot better than I was..." She now perceives the medications as very helpful stating that "as long as I take the medication I will be okay." According to Laura's case manager she has "evolved" during her illness experience "to a point where she is able to kind of talk about her conflicts, her her turmoil, things that she would like to change." He further states that over time "I think a lot of self awareness is like you know okay this is happening to me, but what am I going to do now." Laura recalls that because she found it physically demanding to write she began to use the computer to do free style writing, "just to get my mind off my illness and the symptoms that I was feeling. ”

Laura recalls a time where she gained a lot of weight and therefore wanted to change her lifestyle as she describes: 'I spent a lot of my kind of eating and I decided that I wasn't going to let that take over like it wasn't going to substitute for my illness. So I started like reading lots." Laura recalls acknowledging to herself "I can't go through life living like this...I have to find things to do, I have to get out of the house, I have to you know monitor my you know intake of caffeine and cigarettes and it's no way to live and that is when I started to think about recovery..."

She describes herself as recovering "because I no longer consider myself ill, cause ever since...like during family holidays, my [relative] sometimes would go off his medication and he would have these breakdowns and it's was so hard to see him that way, and so I made a promise to myself never to go off my medication so I think in that sense... I am recovering; as long as I am on my medication I'm not sick." Being productive is also important to her recovery because it took her mind off the symptoms adding "....if I don't be productive I fall into a slump and I don 't want to do that." A strategy that she used to provide structure to her day was participating in different activities. She began volunteering in activities that were of 
interest to her, tutoring [a language], and working on goals stating, “...just being on my own and doing things that helps the community and trying to get jobs..." adding "getting things accomplished every single day and that's a huge part to my recovery that I'm not kind of at home all the time just dwelling on you know either depression or illness stuff...I'm out in the world doing stuff."

Laura states that while she has remained close with some friends who have helped her during her recovery she "lost touch with a lot of my good friends when I was trying to recover uhm which I totally regret more than anything." A fear identified by Laura is that she will "have another attack again" and will have to go back to hospital. However she believes that this will not happen any time soon because as she states "I'm recovering...I've just I've gone through huge transformations and I'm recovering. "

Laura describes that some of her friends and family have played major roles in her recovery stating "they've always been there for me and they've done everything they can to make sure that, that I've you know, that the best is wanted for me." She identified her case manager as one of the individuals who has also influenced her recovery. Although her parents have been supportive she feels her sibling has not because "she's doing her own thing...” She describes the support that her mother and her boyfriend provide by sharing accommodation with her, reminding her to take her medications, and monitoring her cigarettes. She also mentions the supports from various clinicians as helpful "... I guess that they're focus is the same as my focus, that I do recover...that I am recovering... so that combination of like my family, clinicians, me, and my friends, all wanting the same thing that is like a huge boost..."

When commenting on if she has grown during her recovery Laura states "it is basically like getting back on the horse... I'm just like going back to what I was like before I 
got sick and not making the same mistakes that I did the first time. Well, not mistakes but just being aware and...conscious that I have been diagnosed and it's not going to spring up on me again." In describing what she values about herself, Laura lists her family, her love of literature, and her ambitions. She further states that others have noticed that she is "very good at expressing herself" $a$ strength that she notes she has acquired since she has been sick. Reflecting on what others value about her she states 'I'm easy to talk to. That's what like a lot like that's what all my friends say...I think that's I mean like a really big achievement..."

Laura's case manager describes her as a "pretty strong...intelligent, articulate person who has goals... has hopes and dreams..." Laura's ambitions for the future are captured as she states: "Even though I was diagnosed when I was [in my late teens] and...now... my goals and my efforts are still...still gonna to be pursued. Like the illness is not going to conflict with them...like for school and volunteering and trying to you know be a better person and not let the illness take over." Laura has been attending school and is near completion of a pre-requisite course for college. She continues to socialize with friends, however she volunteers less, as she is focused on finding a job, and would like to attend school full-time. Laura has the goal of exploring a career in the Arts. She has written about her illness experience.

Her words of wisdom for others recovering is to understand "that you are more than...just the illness...continue and to find other qualities in yourself that will help you let the bad die...meaning let the illness fade" and not to "get caught up it [the illness]." Laura chose a stain glass image as the object that symbolizes her recovery. The object inspired her to continue on with life and her recovery. 


\section{John}

"I think I can be cured...it's not ...you know right now I would say from 100\% - 65\% is cured. The last 35\% I have to be cured".

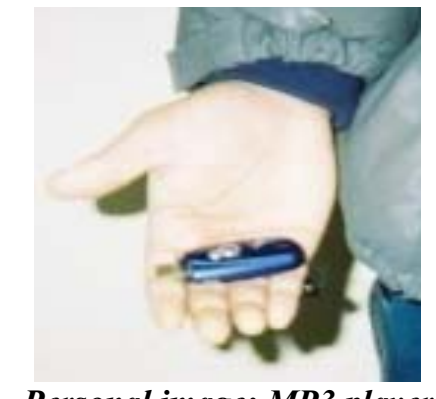

Personal image: MP3 player

John is a male of South Asian descent. He is the eldest of his siblings, and has completed his high school education. John lives with his family and has good relations with his parents. He states that his mother makes him happy. Prior to his illness his daily routine consisted of going to school in the morning, doing homework for a few hours and then as he describes "go outside and play sports, or do some kind of fun activity, socialize..." He also described a history of using marijuana 3-4 times a day, however, has since stopped following treatment for his illness.

John noticed changes in his behavior, when he was not feeling well, and had thoughts of suicide. He also reports experiencing audio and visual hallucinations. After experiencing the symptoms for three months, he asked his mother if she was seeing what he was to which she replied “...we don't see it right, you see it so you know you have some kind of illness.” His mother also noticed changes including ignoring his parents, no longer obeying them and coming and going as he pleased.

John was involved in situations, which he did not elaborate upon, that resulted in him being detained in prison. While in jail he was told by a doctor that he had schizophrenia and was prescribed medications. At first, John did not believe the doctor, as he recalls "she's just lying. I believed my mind, right, that is why I didn't take my medication at the beginning..." 
John describes “...she gave me medication, right and I didn't take it, uhm so she referred me to this place [a specialized first episode psychosis program], which will help my prescription because she can't write it all the time..." The doctor at this facility made him aware that if he did not take his medications his condition would worsen. Shortly after this, John began to take the medication while he was in the community first episode psychosis program.

John believes that his drug use not only caused his schizophrenia to occur, stating " $I$ brought this on my own" but has also contributed to a slower recovery. He says that peer pressure contributed to the start of his drug use stating, "everyone does it right...so I tried to do the thing and then after [a few months] months schizophrenia started happening, so I kept on doing it right. Then I saw the doctor and he scared me right, so after that I didn't do anything." When asked how his doctor scared him, John mentioned that his doctor described how symptoms could get worse if he continued to use drugs.

John also stated that it is important to him that others do not realize he has schizophrenia:

...they can't say that I have schizophrenia ...no one can say that I'm schizophrenic. But before I acted weird, like I used to do things that were like weird so back then they can say that I was schizophrenic but not any more... you can't say that I'm a schizophrenic. I'm like a normal person.

He adds that if people could tell he has an illness they might see him as person who is dumb saying "they will be like oh sorry in the beginning right, when they see someone else they'll be like this guy...he looks weird, he's awful you know...Plus if it's a mental illness, it just reduces your reputation."

John acknowledges that when he first learned from doctors that he had schizophrenia he did not want to believe them and did not take medication; he also continued to use drugs. However, he changed his mind after discussions with a one of the doctors because: 
Whatever he said was making sense. Like he was telling me, you know you see these imaginations and you see all these things and all that [indistinct] voices. You know that could be cured away, you don't have to be like...you don't have to feel the same way in the future, right. So you got to take the medication because it will help you a lot, right? I believed him, right. So I started to take the medication, if, I, if the voice and the hallucinations don't go away in 2 months I would stop taking the medication, but it went away right. Then I started believing the medication can help me. It was a risky choice you know.

John now describes himself as recovering because, as he states, "I can tell by myself that you know at a certain point at time, that I'm changing, my mind is changing..." He realized that he was recovering when, after taking the medications and seeing the doctor, he started noticing some gradual changes happening with respect to improvement in his symptoms by "taking away the voice in his head." John also describes that his mood has changed, suggesting he doesn't have "any more wild thoughts." He also mentions that his "mind is in one place" and that he is able to focus and do things on his own. John states that he feels better as he no longer has acute symptoms or acts "all weird."

However, John also states that even with these improvements "there is some discomfort in it, but I know that will change so I'm just hoping for it." For example, he mentions that before his illness he was fluent when he spoke and could "speak like without even thinking, right. And I have to think harder to say things." John acknowledges that schizophrenia is a dangerous illness because you cannot distinguish between what's real and not real. He describes a dullness he experienced over a year ago during which he had thoughts of harming himself and was taking marijuana a lot. This has since cleared and he is currently working on improving his concentration, memory, and his ability to think; he still describes his mind as weak.

John also notices a renewed interest in watching sports on television which makes him feel excited and as he states "it takes away my mind for 2 1/2 hours, 3 hours." He values his life, happiness, and his recovery for which he takes ownership. He adds that his family 
values his attitude, behavior, and leading support for his siblings to follow in his footsteps. John described his mother as an individual who has influenced his recovery saying that she is always there to encourage him.

John also describes that coming to a community first episode outpatient psychosis program on a monthly basis, talking to his case manager, and taking his medication as having been important to his recovery. John recalled a conversation he had with his case manager who stated that this illness is a 3 three year commitment which he agrees with. He recall his case manager's explanation, “The first year is the horrible time where you are depressed all the time, second year is like you feel happy, the third year is for the brain, the concentration, the memory and the thinking continues to be cleared away. "Now in his self-identified second year, he describes that he feels strongly about the ongoing need to take his medication stating "I want to keep the medication for a longer period, so I won't have to experience it [the illness] again...I know what I went through at the beginning right, and if I have to go through it again, I won't like it."

John enjoys watching sports on television, and listening to music from his homeland because he finds it inspiring in helping him to focus on future goals. John selected his MP3 player as the object that symbolized his recovery because it allows him to listen to music which has helped his recovery. He also notices that he is able to look after himself better, and do his own laundry. He continues to smoke a few cigarettes (although has reduced the amount) which helps him cope with his illness "when I have it [cigarette], it just lets me relax and think of things right." He has changed his circle of friends and has also made new friends which he describes as "clean". Reflecting on his friendships, he states, "Before I had bad friends, right. I cut them all off, now I am down to 3 of them, right, so I only share with 3 
people, before I used to chill with everybody right... but they left to be gangsters and thugs. I was involved to, but you know I changed, I don't want that any more."

While acknowledging his improvements, John continues to have struggles during his recovery "I have no feelings; I can't feel...like it's all blank.” He also still struggles with his ability to feel happy stating:

...right now I feel like I don't feel happy as when I was in the beginning, right when I was normal I felt like so happy...Now it's like everything is taken away from me. The feeling, emotion, the happiness, everything is gone... like I can feel it but I can't explain it how it is, it's it's something that you have to experience it for yourself.

John acknowledges the importance of staying away from drugs, and encourages

others to do so. He currently works as a general laborer. John sees himself as improving saying “You know I'm improving...I can't stop, I can't stop the medication now right. I

continue on and use it until I get better right. Like all my happiness revolves around the medication nothing else." His words of wisdom for others recovering from a FES is to "take care, and you will do well just stay on the medication, stay away from drugs, alcohol, and if you don't smoke it's even better cause you get recovered faster than if you smoke."

He also looks forward to his future stating: "I shouldn't do marijuana any more, no drinking till I get cured. Don't hang out with bad people, you know work, go to school, I mean yeah go to school [he is saving his money for this] but not right now till I'm recovered", while also stressing the need for his memory to improve. John outlines his future plans stating "I want to go back to school, I want to have a job, I want to get a car, I want to start my own family. But right now what I'm thinking is that I have to start from scratch, everything that I had is lost, right. I have to start from scratch" He states that he has to start from scratch because "I want to show everybody you know I'm better than [them]. Cause I know my mind is strong... "John's career aspirations include going to college and university, securing a job in the financial field, and having investments. 
John says that he has changed by having gone through his illness experience. He described that he respects his family more:

... when I was like you know young back then, right. So you know you all act like idiots back then right... when I got home like I hadn't had no respect for my family, right. I would just call them names and everything. I would hurt my feelings right. I had no thought about them, thinking that I would hurt their feelings. But now I think back and I say to myself, why did I do it? Now I respect them, right...

Over time, he has also matured stating "I'm not those things that I wanted to do when I was young, right. I have some responsibility, I have organized my life. ” John's has gained insights during his recovery as he describes: "I feel I'm more comfortable, I have confidence now a little bit. You know like I know my strengths and my weakness. What should I do and what shouldn't I do."

\section{Summary}

This chapter has served to introduce the participants to the reader and to provide a basis for the findings which will be the focus of the next chapter. It has been suggested that the process of open and focused coding can lead to a fracturing of participant stories. In addressing this, the intention of this chapter was to provide the reader with an appreciation of the participant's within the study sample, highlighting the various characteristics within their recovery stories as a whole. This information therefore serves as an important backdrop for the study findings contained within the next chapter. 


\section{Chapter 5: Study Findings}

\section{Introduction to Study Findings}

A constructivist approach to grounded theory acknowledges that the resultant theory is an interpretation (Charmaz, 2006). In light of this, the findings that unfold as phases in the subsequent sections of this chapter are my interpretations of the process of recovery from a FES. They have been developed as a result of the analytic devices I have utilized, outlined in my methodology chapter.

In my analysis of the findings, I have also raised questions as a way to assist in my interpretation of the findings and to, as Charmaz (2006) asserts, "engage my reader in a theoretical discussion" (p. 167). I raise these questions in my analysis for each of the phases and will provide possible answers during my discussion chapter. I have included a quote at the beginning of each phase in order to provide a glimpse of the emotional tone of participants in each of the phases. This, I believe, serves to highlight the subjective nature of the recovery process. As mentioned in my methodology chapter, Charmaz (2003b) asserts that insertion of detailed interview quotations keeps the human story in the forefront of the reader's mind. Furthermore, the inclusion of detailed participant quotes throughout this chapter, contributes to the richness of data, and reflects what Charmaz (2006) asserts, is the building of significant analysis. This chapter begins with a description of the participants' lives prior to the illness, followed by subsequent finding sections: 1) Lives interrupted: Encountering the illness, 2) Engaging in services and supports, 3) Re-engaging in life, 4) Envisioning the future, and 5) Reshaping an enduring sense of self. 


\section{Who They Were Prior to the Illness}

Having a glimpse of who the participants were prior to the illness allows for a foundation to be established in order for the reader to understand how participants' sense of self was reshaped through their recovery process. As the participant interviews progressed, it became increasingly apparent that they did not readily provide information about their lives prior to the illness, but rather engaged in a discussion about current issues in their lives. In addition, during review of the initial transcripts, by two thesis committee members and I, we realized that more information was needed about participant's history in order to further develop this area. As a result, I included in subsequent interviews more detailed questions about who they were as individuals prior to their illness, which constituted a form of theoretical sampling. In light of this, I have a better understanding and richer descriptions of participants' lives prior to their illness for those individuals who were interviewed later in the study as opposed to those who were interviewed earlier. Also, three of the secondary participants were clinicians who did not know the primary participant prior to the illness, thus their reflections start from the point of illness through to recovery.

At the time of the interviews, participants recalled significant features that occurred in their lives prior to the illness that reflect the following characteristics: 1) "Involved in a lot of bad stuff”, 2) “Under a lot of stress”, 3) “Using Drugs”, 4) Having Interests, and 5) Family Relationships. The phrases in italics are the words participants used to describe their situation. 


\section{"Involved in a lot of Bad Stuff"}

During the interviews, it became apparent that prior to illness some of the participants engaged in behavior that led them to drop out of school and/or spend time in jail. It is difficult to discern whether these behaviors were related to illness onset. Participants did not seem to connect these behaviors to illness onset. Henry characterized this period as unproductive stating "I wasn't really doing anything productive with myself”. He also described that he was into "negative company...doing the wrong things all time, ending up in the wrong places..." Steven described that when he was with his friends prior to the illness he was "almost getting kicked out of the house". He added "that he was involved in a lot of bad stuff and trouble with school and getting sent to the office... [frequently]". He also stated that he did not return to school after being expelled and subsequently spent his time going out with friends. Laura recalled her lifestyle of getting "really drunk" and "really high" with friends. She recounted an incident just prior to her illness, when she "got into a lot of trouble" because of a prank she and a friend participated in.

Three participants described encounters with law enforcement authorities. Michael's grandmother recalled that when he was in his early teens he "got in trouble few times and punched somebody for just looking at him and I couldn't understand why he would do something like that but I guess he had a lot of anger...he got charged and he had to do some community service..." A few years later, in his mid teens, after being attacked, he hit an individual that resulted in him being charged and put in prison. Following this, he was expelled and began at another school where he completed high school. John recalled that the company he socialized with prior to his illness was "gangsters and thugs." He entered the mental health system through the court support program, although he did not explicitly describe the events leading up to him being charged. Henry described going in and out of jail 
prior to seeking help for his illness, but again did not describe the events leading up to these occurrences. In summary, a common occurrence that emerged amongst interviews was that, prior to their illness some of the participants were involved in activities that could be viewed as harmful to themselves or others, and sometimes unlawful.

\section{“Under a lot of Stress"}

Many participants described circumstances that made life stressful for them. For example, Linda, a newcomer to Canada and married, recalled spending the majority of her time working in two jobs so that she could save enough money to meet her needs. Curtis recalled the extreme anxiety he experienced by participating in public speaking activities. He described that he "definitely internalized everything." Carly described having "some drama going on in [her] life" namely, the ending of a "really bad relationship" as well as "financial stress." Furthermore, she recalled this as a period that was stressful for her and a time where she neglected her own physical health. Lisa disclosed that before she "got sick" she "wasn't a very pleasant person to be around for a while..." She also suggested she was "under a lot of stress" but did not elaborate any further.

\section{“Using Drugs”}

In addition to being under stress, it is important to highlight that a majority of participants (6 out of 10) had a history of drug use prior to the illness. John believed it was peer pressure that led him to begin using marijuana. According to Carly's mother, her daughter used drugs to help her stay awake as she was working at night and going to school during the day. Henry "smoked weed" and alluded to selling drugs in the past. Steven described a lifestyle of being "Mr. Popularity" in high school, "parties every weekend, and girlfriends all the time...friends doing drugs all the time." He also recalled his own drug use. 
Leah recalled that she took drugs, thinking that "psychedelics are okay as long as you're not doing cocaine..." she also described "smoking pot" when she was bored.

\section{Having Interests}

All participants indicated that they were involved in varied activities and had many interests prior to the illness. Henry described that he grew up in the church; attending weekly services. He also mentioned enjoying spending time with young people, cooking, and playing musical instruments. Carly identified her love of literature and writing. John commented on his interests in playing sports and socializing with friends. He also would spend the majority of his time in school. Laura recalled that before she got sick she was "really active..." every single day and enjoyed reading. Steven prided himself in his artistic ability. Michael also had a number of artistic interests. Leah stated that she liked to write and has kept a journal since she was in her teens. Both Sandy and Curtis commented on their academic strengths, a strong area of interest for them.

\section{Family Relationships}

Participants described family relations that ranged from being supportive to smothering and overbearing. Henry stated that he had the support of his parents prior to illness. John's mother described their relationship as very good before the illness began. Sandy recalled feeling smothered by her parents and believed they were too protective of her. Leah described that prior to her illness she was not talking to her mother because she felt her mother did not care about what was going on in her life. Curtis described his father as overbearing and uncompromising. Carly described her family as supportive, however did not have enough time to spend with them due to her busy lifestyle. In recalling her relationship with her mother, she stated "we were like a little bit separated for a while because I was very much on to...get my career going and I live in the city..." In summary, participants had 
family relationships with a wide range of supports and emotions typical of developing young adults.

\section{Summary}

The intention of describing participants' lives prior to illness is to provide a glimpse of who they are as individuals and what lifestyles they had before becoming ill. Participants described being under stress and a majority used drugs while some had encounters with law enforcement. Participants also had particular strengths, a wide range of interests, and varying degrees of family support.

\section{Lives Interrupted: Encountering the Illness \\ "I was at school one day and uhm I started hearing voices" (Laura)}

\section{Overview}

Lives interrupted: Encountering the illness describes how and at what point in the participants' lives initial symptoms emerged, the process of help-seeking, finding out about the illness, and how clinicians communicated the possibility of getting better. The onset of illness interrupted participants' lives at a crucial developmental phase as the majority of them were transitioning into early adulthood. Five of the participants were in school when they first experienced their symptoms, two were working and going to school, two were working, and one was neither working nor attending school. Symptoms brought on emotional responses that were unsettling for them and their families. Over time, their symptoms intensified reaching a point where help was sought, and for some, the symptoms necessitated an urgent help-seeking response that was provoked by a crisis. Help-seeking was initiated by the participant or a family member. The amount of time from when a participant experienced first symptoms to when they sought help varied from several weeks to years. It was apparent 
during the interviews that participants did not dwell on their illness experience. In fact, it appeared as though they did not want to revisit that point in their lives.

The subcategories that characterized this phase were:

a) Experiencing the symptoms - physical and behavioral changes that were accompanied by strong emotional responses in both participants and family members.

b) Help-seeking - a period of time lasting weeks, months, and in some instances years during which time participants "self-managed" or sought help from numerous sources for increasingly unmanageable symptoms. In many instances, symptoms intensified until an urgent help-seeking response was required.

c) Finding out about the illness - the initial period immediately after diagnosis that for most participants was accompanied with strong feelings of fear, disbelief, anxiety, and uncertainty. It was a time when some participants questioned if recovery was possible.

d) Impact of illness and treatment - a time when participants made initial attempts at treatment and was characterized by significantly reduced participation in life activities and interests (e.g., school, work, etc), increased dependency on others, and a significant change to social circles.

e) Possibility of getting better - with the support of clinicians, participants began to feel increasingly optimistic as they began to understand their illness and were told about the possibility of getting better. 


\section{Experiencing the Symptoms}

Participants and family members recalled encountering "changes" when symptoms began. All participants noticed a surfacing of delusional thinking and/or onset of hallucinations that occurred over a period of weeks, months, and in some instances years. It was clear that experiencing these changes evoked a range of profound emotions for them including anxiety, fear, and uncertainty. Two participants felt so distressed that they experienced thoughts of suicide. Specifically, a participant's mother found emails sent by her daughter to another individual describing how she would kill herself, and a second participant stated when his illness first started it "was very dangerous to [him]," and that he had thoughts of "suiciding." In addition to experiencing changes, symptom onset was also accompanied by an increased difficulty in performing basic activities of daily life, and their ability to remain focused on their personal lives. Two participants noticed that it became gradually more difficult to care for themselves. Five reported changes in their sleep and eating patterns, and/or energy level. Participants' families and friends noticed and struggled with the changes. Initial symptoms began at a time when a sense of self was still developing. The following section outlines in greater detail the participants' initial experience with the illness and the range of delusional thinking and hallucinations that virtually all participants encountered.

Five participants noticed a surfacing of delusional thinking that was paranoid in nature. During his teenage years, expelled from school and not working, Henry described that "at first I wasn't trusting anybody and things like that like I wasn't sure like I thought they were poisoning my food, trying to kill me like I was having like [a] bad breakdown." This left him feeling fearful and out of control. He further stated "I used to feel like the world was mad at me or something." Steven first began to experience delusional thinking while he 
was attending school. He recalls believing he was part of an "initiation" program that involved the media. He described that he "... was just, just completely bombarded Ifelt like there's, there's no escaping..." He remembered, "I wasn't getting any rest, I lost my job." He also mentioned that he "was in a state of mind where I could barely even think...It's like you're dreaming in real life but it's like a nightmare...its really intense." Michael first noticed the emergence of paranoid thoughts in his twenties when he was traveling and had contact with a substance his friend gave him. He described that after that incident he "just felt like everything was out of place in my mind". After arriving home, he thought "something weird" was happening to him. He recalled changes in his behavior such as isolating himself from others and "being paranoid about everyone someone trying to get me or someone trying to kidnap..." He added that this period was a "crazy time" in his life. Sandy felt distressed because she believed her family was trying to hurt her. Before getting treatment she described that her life was "bewildering at times." She further recalled an incident where she was displaying odd behavior in public.

Three other participants experienced different types of delusions. Carly described that while attending school, she "started to get like really confused... wasn't paranoid or afraid..." In addition, she recalled that her doctor told her he believed she was having "delusions of grandeur." She remembered her feelings at this time:

I'd be sort of happy at the time but um, I think for me like that was really my mind really escaping from a lot of the stuff I was going through...I'm generally a happy person but I actually hadn't felt happy at all in a long time before that [the illness] happened to me so I think it was almost like a release or like, you know my mind sort of just rejecting what I was doing and saying. 
She recalled additional feelings with the emergence of her symptoms:

I had symptoms before I went into sort of a full psychotic episode and uhm it's really quite a scary experience to have because um I didn't know what was going on with me... and it's really quite frightening.

Her mother also described feelings of being frightened when she realized that Carly was delusional. As she recalled "she was really delusional [it was] very frightening to have a child who's delusional." Linda experienced religious delusions and her parents noticed that she was unusually religiously pre-occupied. Laura had fears and struggled to understand what was happening. She added "...I just had this I feel like pressure in my stomach and I said... I'm not I'm not feeling very well."

Seven of the participants experienced hallucinations. Henry recalled beginning to hear unexplained voices stating:

...things started happening to me, it wasn't good at all, there was like the worst of the worst eh, I was like I had voices telling me that I shouldn't be living stuff like that, like I went to [name of the country], and I was gonna jump out of a car, because I thought I was gonna die...

Carly recalled when she was going to school. "... I started having weird experiences, where I was like, you know hearing voices and things like that..." While finishing high school Laura recalled, "I was at school one day and I started hearing voices. I got sick and ...that world [school] was lost to me, like I couldn't function like I couldn't do anything. ' Leah described hearing voices for the first time while on [name of drug]. Thinking it was the drugs Leah stopped taking them for several months but continued to feel symptoms that she thought was a chemical imbalance resulting from the drug use. Curtis noticed a change in his thinking in his teens. While attending school his grades started to slip; he described himself as feeling drained, and "knowing that something was not right." His psychiatrist recalled that "one time he [Curtis] was hearing voices, but they were brief, they were manageable." John 
recalled that when he was at work he would "see all these things and my partner...is like where are you man, are you in another world right now?"

Family members commented on the challenges and feelings of uncertainty they encountered as they managed the behavior changes of their children prior to seeking help. Furthermore, they indicated that they witnessed these changes over time. Michael's grandmother described that there were ongoing changes in his behavior that continued from his teens through to his 20's. During this time he described feeling uncertain, as did his family, as he recalled everyone thought "I was just acting up." Steven's mother noticed that her son was not feeling well, stating "you could see that he was troubled." She remembered:

... the night that it all started was he first said to me 'I don't understand this new way of communication, this being able to read minds.' She replied to her son saying 'I can't read minds, I can't do this you know, I was like what the heck'?

Carly's mother recalled that her daughter "had a crash" following an intense cycle of continuous work and school, as she described:

...we were all in family alert monitoring her, all I remember at the time was it was so frightening watching her... She'd be smiling to herself in her own little world all the time and we didn't know what was wrong with her...

Reflecting on my field notes taken during the interviews, I noted that while participants did not dwell on their illness experience, the emotional intensity in describing their symptoms was still apparent. Some of the participants recalled being paranoid, some were delusional, and used words such as bewildering and frightening to describe their feelings at this time. In some instances, reactions to symptoms were so intense that two participants considered suicide. I wondered if the reason they did not richly describe their illness experience was related to what Baxter and Diehl, (1998) identify as the trauma associated with experiencing severe mental illness, or was it largely because the interview 
was focused on a discussion of their recovery. Regardless of the reason, participants were clearly not dwelling on their past illness experience.

\section{Help-Seeking}

The help-seeking subcategory summarizes the various ways participants used to cope with and seek help when their symptoms started and intensified. Most participants recalled that efforts to obtain help were, in most instances, initiated by themselves or a family member. Unfortunately, it would appear that few improvements have been made in the way of timely access to help since my last study which focused on help-seeking for a FES (Czuchta \& McCay, 2001). Many described periods of weeks, months, and in some cases, years during which time participants attempted to "self-manage" symptoms and sought, but failed, to obtain the help they required to manage their illness. Several described unsuccessful attempts to obtain treatment from their family physicians and from both general and specialized hospital settings. Ultimately, in many instances, participants described that symptoms continued untreated until an urgent help-seeking response akin to a crisis was required. As in my previous study, symptoms were accompanied with feelings of fear and uncertainty. The following paragraphs summarize some of their experiences.

About half of the participants sought help over a number of months while the remaining obtained help more urgently. Two of the participants approached their parent(s) stating that they needed help for symptoms, while six of the participant's families identified that their child needed help. For the remaining two participants, it was staff in community agencies that recognized the need for help. The amount of time it took to initiate help also varied amongst participants, as did the type of agency that was sought. As Carly reflected: “... it took a little while like there was a little bit of trial and error involved with seeing doctors and stuff like that to sort of find that right help that I was looking for..." 
Parents described a change in their children from their normal way of being. These changes, which were apparent in the child's mood and behavior, evoked feelings of uncertainty and prompted them to seek help as they struggled to understand what was happening. Participants and their families had sought help from a variety of agencies including family doctors, community agencies (e.g., shelters, court services), hospital emergency departments, and the police. For some participants, this resulted in delays before the necessary help was obtained. Furthermore, the time it took to secure the necessary help varied. Three participants repeatedly sought and were unsuccessful at obtaining help from their family doctors. Linda's father voiced frustration with the family doctor because, as he described, this doctor did not see anything wrong with Linda however, he did prescribe sleeping medication. Her parents noticed that the medication did very little to improve her sleeplessness, with her condition worsening over time. Seven of the participants required inpatient hospitalization for treatment of their unmanaged symptoms while the remaining three participants were managed as outpatients (noting that one of the participants later required inpatient hospitalization when he stopped taking his medications).

The following excerpts illustrate examples of the various agencies that provided help for the participants. They also highlight the elapsed time it took for most of the participants to secure the necessary help. While Michael was at a shelter, (after becoming increasingly delusional and subsequently kicked out of his relative's home) a case manager recognized his symptoms and brought him to a hospital emergency where he was diagnosed with a FES. He recalled that it was a period of 2 years from when he first noticed changes within himself to the time he received help for the symptoms he was experiencing. For John, it was a period of several months before he was diagnosed by a court support doctor and subsequently referred to a community first episode psychosis clinic for treatment. John's mother recalled how she 
sought help for her son, which she believed was further complicated because she could not approach anyone from her culture to help her:

I didn't want to go for help, because I was afraid sometimes if I go and tell... if I try to take advice from somebody else in our culture their ideas and the way they look at my son, sometimes would aggravate his situation so I avoided getting help from people of my culture. What I did, I sat alone, I used to sit alone for some time, and I used to think how I could help my son with his recovery. That is how I helped him, I did not go for any support from anybody in our culture.

Over twelve months passed before Steven finally received the help that he required.

In the early phase of his illness Steven described wanting:

...to solve it [the illness]...So what I originally wanted to do, I was like I want to join the [military]; I want to move out on my own. I want to be by myself.... and just get away from all of this cause I thought I [was] harming people around me.

Subsequently, his parents brought him to his family doctor which, as he described, "made things a lot worse." His family doctor diagnosed him with depression and prescribed an antidepressant that did not provide any symptom relief. Steven's mother recalled this experience:

...we went to the family doctor first and about a month, 6 to 8 weeks after, 3 or 4 weeks on this antidepressant and it made him into a zombie... he worked with his [sibling]... he would just stand there and was totally incapable of doing anything...

Recognizing that the help provided by his family doctor was not working, Steven made the decision to go to a hospital to obtain help. He stated that if he did not go to the hospital "we would've been spending thousands of dollars on a psychologist." He was admitted as an inpatient and discharged with follow-up outpatient care in a first episode psychosis clinic.

Laura recalled that in her late teens she "was at school one day and uhm I started hearing voices and my [relative] who suffers from schizophrenia and I knew that [was] one of the symptoms." As a result, she asked her parents to take her to a general hospital emergency department. She was admitted to hospital for several weeks where she was subsequently diagnosed with "mild psychosis". 
Curtis stated that his relative "... who was living with us at that time she noticed something that that was that was different... my dad didn't pick up on it because he wasn't around all the time." The relative shared her observation with Curtis' father who then brought him to the emergency department of a general hospital, which led to his hospitalization and subsequent follow-up in an outpatient first episode psychosis clinic.

Although one participant previously sought help, five participants recalled that an acute incident, akin to a crisis, prompted an urgent help-seeking response. Specifically, three participants were brought to hospital emergency departments, while the other two participant's families called 911. Henry recalled "hearing things in my head" after he smoked up at a friend's house following his release from jail. He further described what happened that day:

I went upstairs like I started hearing police sirens and I started thinking that the police were out to get me and all this stuff, I don't know why it just happened, and I wasn't too sure why...

At home the next day he recalled "I brought my mom into my room and I said I know what you're trying to do and I know that you guys are trying to get me killed and stuff and my mom was like 'what are you talking about' she was like in a very calm and soothing way." In retrospect, he recalled how helpful her calm approach was as he stated: "she wasn't getting upset or anything like that and that was really helpful because then I would've just like reacted on that and I probably would've gone crazy and started hitting her or something." Following this interaction, Henry was receptive to his mother bringing him to a general hospital emergency department to be assessed.

Following his assessment in the emergency department, and in spite of his mother's concerns, he was discharged because as he states staff said "there is nothing wrong with you." Henry described that "my mom was like she didn't know what to do cause she knew 
there was something wrong with me." A few weeks later his mother brought him to a specialized psychiatric emergency department. As Henry recalled he was not sleeping and thought that "they put gas and stuff to kill me in the room." Upon reflection, he described that he was "like I was just out of my mind basically." After his assessment at the emergency department for the second time, Henry was hospitalized as an inpatient for over two weeks with subsequent follow-up at an outpatient first episode psychosis clinic.

Leah's mother encouraged her to see a doctor when she noticed changes in her daughter. Specifically, Leah kept going to mother's house and would not go home. Her mother was also worried because she was not looking after her pet. Leah recalled that "she [her mother] finally left me a note before she went to work one day saying go to the doctor..." Leah wandered around the city and was spotted by someone she knew. This individual recognized something was wrong, and convinced Leah to seek help. She was taken to an emergency department and her mother was contacted. She was subsequently admitted to an inpatient psychiatry unit.

Sandy's mother recalled an incident when her daughter was not sleeping because she was experiencing visual and auditory hallucinations. Later that day Sandy recalled feeling that her family wanted to harm her. Her family soon arranged to have her seen by her family doctor who then arranged to have her admitted into hospital for two weeks where she was started on an antipsychotic medication. During her daughter's hospitalization, Sandy's mother recalled, "I didn't know what to do, I was not informed by the hospital. The hospital was no help to me...All the hospital did was...then she was discharged, they gave me the name of [a family support group].” 
Carly recalled that "I went through a period where I was just so distracted and out of it...I ended up staying home for about 4 days. " At the time Carly was living by herself and could not manage to take care of herself. She recalled her friends were worried about her because she did not answer her door. Her mother came by her apartment as Carly recalled: "she was just like you know what's going on with you and I think I was obviously very out of it." After she was unable to contact Carly, her mother notified the police who subsequently found her in her apartment. Based on their conversation with her, they suggested, and she agreed, to accompany them to a general hospital emergency department where she could be assessed. Carly's mother also voiced her frustration with this experience because of the inability to secure the necessary help:

Well I had a bad experience with a young psychiatrist down at the hospital who uhm I'm sure meant well but there's a real thing with confidentiality and this stuff, where Carly would go in, she's delusional and I couldn't tell the psychiatrist anything about that because and she would tell Carly everything and then it was my...the relationship I had with her was like I was turning her in all the time. I was totally freaked out trying to get across to this woman that there was something wrong with her and of course there wasn 't any reassurances because they can't come out and say well this is what it is.

After this assessment, she was transferred to a psychiatric emergency department for further assessment. During Carly's assessment in this emergency department, her mother continued to feel frustrated with staff there as she recalled: "I was so angry at this woman because there was no sort of listening to me. I was with her every minute, I knew what she was capable of ..." Carly stayed in the emergency department overnight and then was discharged with follow-up at general hospital crisis clinic. After being seen at this clinic for several visits she was later referred to an outpatient first episode psychosis clinic for follow-up. Carly reflected on her experience which led to an urgent help-seeking response:

It's a big deal I think with something... really bad had to happen for me to... really get down to it to go and, and get proper help and I needed a lot of support from my family...in order to do that... 
Linda was attending school and was employed at two jobs; one of the jobs required a great deal of reading. At that time, Linda was sleeping poorly because of her extra studies and personal concerns. As she recalled:

I studied from books, I went to classes too...that is more stress for me because working full time and at the same time I have to go to the class. And I couldn't sleep 3 or 4 days continuously, because I was always studying that book, that's why I got sick...

Linda also recalled shouting to her parents about religious ideas. It became increasingly difficult for her parents to manage her delusional thinking which prompted them to phone 911 for help. Linda was subsequently accompanied by police to a general hospital emergency department via ambulance where she remained as an inpatient for over one month. She recalled that she first became sick one month prior to her being in hospital. Upon discharge she was transferred to an outpatient clinic at a psychiatric hospital.

As described in my earlier reflexive comments in the methodology chapter, as a result having worked in mental health for 15 years, one of my passions is to establish systems that improve access to help. In light of this, what struck me was the prevailing challenge participants faced when securing appropriate help. Specifically, for some, the only way they were able to secure help was by reaching a crisis where an emergency visit was warranted or by calling 911 . This is consistent with my previous research (Czuchta \& McCay, 2001) that indicated that the amount of time that passed before securing help was lengthy, arduous, and at times the type of help obtained was inappropriate. In this current study, for some participants numerous visits to the family doctor continued, with ineffective medication prescribed. The cultural barrier to accessing help was also evident. For example, as seen with John's mother not seeking help for him from members within her culture because of the prevailing impact of stigma related to mental health issues. 
As I reflected on my field notes later, what also struck me during the interviews with some of the secondary participants was that in recalling their help-seeking experience there appeared to be a sense of gratefulness that I, in my role as researcher, was interested in hearing their stories. This was especially evident when family members described their frustrations with accessing appropriate help for their children. As I listened to their "emotionally charged" stories, it appeared that they were not really heard or believed at times by clinicians.

\section{Finding out About the Illness}

Once participants and their families accessed the help they required, they described a variety of emotional responses to finding out about the illness; specifically in learning the diagnosis. In isolated instances, participants described a sense of relief, but in most instances feelings of fear, shock, disbelief, anger, sadness, and uncertainty accompanied knowing the diagnosis. The apparent effects of stigma and use of the term "schizophrenic" were also mentioned by some of the participants. Many questioned the possibility of recovery.

In two instances, participants described a feeling of relief accompanied with other emotions when they learned their diagnosis. When Steven was diagnosed he "was actually happy" and felt "a huge relief" about his diagnosis, because he was told "this is what you have and we could treat it." He also remembered that his parents "weren't ashamed, but were completely supportive." In contrast, Steven's mother recalled her thoughts in finding out the diagnosis:

Well I was upset for sure you know I was angry, I thought where is this coming from? Like why does this have to affect young people at this age, and going through life.

She went on to describe the support she provided to Steven and coming to accept that he had an illness which was confirmed by the diagnosis: 
You know at first you don't want to accept that it's an illness, you know cause drugs were involved before this too so you want to hope okay the drugs have triggered something, it may go away, give it 6 month period I forget what they call it but it's possible that it's... ...from street drugs. At that point you have to be open too that it is an illness and just to be there for him and being able to support him with... we spent hours with him...

Michael too recalled the feelings of relief followed by sadness when he first learned that he had schizophrenia from the doctor:

I couldn't believe it. But it made sense it made sense I was like augh I was kinda like (sighs) phew now I know what's wrong with me cause I thought I didn't know what was wrong with me the whole time.

He further elaborated:

So once they told me that it was schizophrenia...I was kinda sad but at the same time I was like phew (sighs)now I know what's wrong with me now I know now I could just take pills and stuff like that...

When asked what made him sad about the diagnosis he reflected 'Cause I didn't think I never thought in my whole life that I would get something like schizophrenia." When asked

how his grandmother and relative responded to his diagnosis Michael stated:

It's like my [relative] knew beforehand that I had schizophrenia she was giving me this tablet ...It's in this magazine... it [the magazine] just had something about schizophrenia in it that's why she gave it to me. It had something about schizophrenia in it and I started reading it. So she had always thought that I had schizophrenia. She like before I even went to the doctors and stuff like that. Cause the way I was acting was like a schizophrenic would act...Like hearing voices and walking around the house like taking like [many] showers in an hour I was taking [many] showers in an hour just feeling so uncomfortable...

Michael's grandmother discussed her feelings about learning of his illness, the subsequent treatment that was available, her concerns about relapse, and what that would possibly mean when she said:

Well I'm glad they found out that something was wrong with him and he can get help with the medication and treat him and he can have somewhat of a normal life... I am getting older I worry about if something happen to me you know, I know my daughter would be there, you know, to help him and I sometimes wonder if he would get a relapse, or if he would continue to improve and what not, all of these things I think about sometimes. 
In most instances, participants used powerful emotions to describe their reactions to their diagnosis. This was a period of uncertainty and fear for some participants, as they questioned if recovery was possible. As Henry described:

I wasn't even sure... if I could recover from it you know if it happened to me everyday like at first you don't even know if there's anything if there is any treatment for it. I never never knew if there was...

Furthermore, Carly's mother added that she remained uncertain as to what her daughter's diagnosis was:

Well I'm still kind of lost, you know. I sort have assumed it was drug related symptoms that were like like schizophrenia, I read all the brochures it struck me that schizophrenia was something that got worse and the symptoms were the same and this got better. I don't really understand if Carly [is] a schizophrenic? I don't even know that. Is she? Would you say she is?...I'm her mother and adult and she's a grown up and I never sit down with anyone and to have them say oh this is the diagnosis. I'm not sure if Carly has ever had it put so clearly I don't know. Symptomatically that must be the way it is.

She also felt uncertain about the possibility of recovery for her daughter, when she described: ...I guess it does worry me or freak me out a little to think that she is schizophrenic for sure. I mean, I don't think anyone wants their daughter to be schizophrenic. I like to know whether she is or not, or what would she look for, or what the implications of that are, like can [it] come back or what...?

Sandy described that when she first learned of her illness:

...it made me I'm not sure maybe nervous or apprehensive I'm trying to think of the right word... When schizophrenia comes to mind I think of the negative stigma, like the stories in the media...come up and that makes me feel scared.

Laura recalled that when she was 'first diagnosed... I couldn't speak, I was like in some kind of shock, I was in so much shock." Furthermore, she described that being diagnosed with schizophrenia was a "huge trauma" that she never expected to happen to her:

...it's like one of those things that you just go it's never going to happen to me and then it did ...you don't like you don't begin life going you know when I'm [in my late teens] I'm going to get schizophrenia you know you don't, it's like a huge trauma...you find out that while you're in the midst of your life and your 
surroundings, you go oh my god I've been diagnosed as schizophrenic, like why is this happening to me?

She added that her relative also had schizophrenia and although she did not know him that well, "I know him enough to be like oh my God, if that's what I have." John did not believe the doctor when he was first told he had schizophrenia. As he recalled "she's just lying. I believed my mind, right, that is why I didn't take my medication at the beginning... " Leah also described similar feelings of disbelief recalling that she was "completely in denial. I'm like I'm not schizophrenic" when she was first diagnosed.

To summarize, while in isolated instances diagnosis was accompanied with feelings of hope and relief, most participants found diagnosis to be unsettling and/or traumatic. In my own clinical observations, given the success specialized first episode psychosis clinics have had in providing the treatment and supports to individuals diagnosed with schizophrenia, I was surprised there were not more feelings of hope expressed by the participants. Upon reflection, I realized that participants did not initially arrive at these specialized clinics; they were first assessed in hospital settings or family doctor offices, where I believe more clinical education is needed regarding the onset and possibility of recovery from a FES.

I wondered about what barriers are preventing the public from learning about the advancements being made in the treatment of a FES. What information should be shared to educate the public? Who should deliver the message and what strategy should be used to make it most effective? Clearly, despite the advancements made in the treatment of schizophrenia, for the most part, individuals and their families encountering the illness for the first time, view this illness negatively. 


\section{Impact of Illness and Treatment}

When asked to describe their initial experience with treatment, it is not surprising that most participants described a reduced participation in what had made up the major activity of their lives prior to the illness, a significant reduction in social ties, and an increased dependency on others.

In reflecting how participant lives were interrupted in experiencing their illness, what I found striking is that the illness emerged at a critical time of development. Activities interrupted were reflective of young adults working at completing higher education, establishing careers, social networks, independence from their families, and beginning significant relationships, such as the case with Linda who had been married. As noted earlier, five of the participants were enrolled in school when they found out about their illness, one was working and going to school, two were working, and two were neither working or going to school. In essence, their lives were interrupted by this illness. That is, not only did they have to endure the illness but also had to temporarily remove themselves from their key life's activities. As a result, their independence was challenged (e.g., having to move back home, taking a leave of absence from work or school, becoming more dependent on others) at a time when they were aiming to assert themselves as young adults.

Most participants had to leave the school environment or program they were enrolled in to seek treatment. This represented a profound change to their daily routine. Laura described that being in hospital was one of the worst experiences she has ever had. As she described:

I wasn't allowed to go outside, and it was summertime and the people there were all very, very sick ...it was one of like the worst experiences of I've ever and being away from my family. 
She also stated that while in hospital seeking treatment she lost her ability "to do anything, I couldn't write, I was still in the middle of school and, I wanted to finish my year, so I participated in class at the hospital... and I got my report card at the end of the year." Carly recalled a conversation she had with her psychiatrist who suggested she take time off of school and work to recover. As she described: "When I first learned about my illness uhm there were you know the day they [her clinicians] told me that I should take my breakfrom everything and drop out of school." Carly recalled her feelings at this time:

...it was kind of a down period for a while because I was like you know I don't have school, I don't have work you know, I feel and like I was living with my parents it was a nice change because you know to have company there and to have your family around but they also both, like a big thing for me was like they also have full-time jobs... and their gone all the time and you know, so it's like, I'm in this... house by myself and I don't know...you're sort of alone in the house.

Having to leave school and move back home eventually posed a challenge for Carly. She remembered:

...it took me maybe probably like 3 or 4 months to really get used to that whole idea. Um, I was, it was, it was difficult. Like, you know there's at first I was dealing with boredom and I was doing a little bit, I was feeling anxious because I had this thing where I was like oh I'm not accomplishing anything, I'm not accomplishing anything...

After being in hospital, where she began her treatment, Linda left her job, took time away from school, and returned to her country of birth for two months so that she could recover. Sandy chose to drop out of her program at university as she described: "before I got sick I started ....... [name of] program at [name of] University...I want to go back there... and after I'm done at [name of] College, I'm going to go back there part time and finish my degree."

Leah had to take a leave of absence from work when she sought treatment. Her primary inpatient nurse recalled a number of activities that needed to be eventually resumed in Leah's life: 
I [primary nurse] was just trying to get her [Leah] back to, uhm, to activities daily living, you know, independent living skills, her plan was going back to school, uhm, going back to work. Cause she was on a leave of absence from her job at that time. Uhm You know, getting back to socializing with her friends at that time I think that, uhm, she was alienated from her friends.

John stated that his goal of finishing school has been put on hold until, as he described, he is "cured from his schizophrenia." This is in contrast to Steven, who was able to continue with school without having to take time off, which he found challenging.

As he described:

...going into second year [post secondary school] like I was ill in the summer and I decided just to go to school instead of taking time off. A lot of people didn't think I would be able to go back to school when I did. But I was very, I was still recovering, I was still in pretty bad shape. Like I still having the voices and the medications aren't really working, I was kind of lost in my own little world.

In addition to experiencing changes to their life activities, many described a change to their social circle as a result of the illness at a key developmental period in their lives. In some cases, this change may be reflective of the impact of stigma, while other participants believed they lost touch with friends because of the illness related symptoms they were experiencing. I question if this loss of social circle is a unique phenomenon to mental illness or common to the onset of other illnesses? Michael used to spend a lot of time with friends prior to his illness. He realized however that because of his symptoms, namely his paranoia, that "being young and around friends [I] can't do that anymore." Laura recalled a change in her daily activity and not being able to spend as much time with her friends:

I remember the first... year that I was sick, the illness kinda of swamped me and I didn't do anything, I stayed on the couch all day, I watched a lot of TV ...I didn't I wasn't myself and I was nervous around people... and it was an awful experience and I didn't like big crowds and my friends always inviting to parties and I would have to leave early because I would be so overwhelmed and they were all, they'd drink and I wasn't drinking at that time, because I was on medication and plus I was I was suffering you know from the illness and uhm so that was also also kind of embarrassing like not much that it was peer pressure like on their part, but it was more like we understand if you have to leave. 
Steven's mother acknowledged the change in her son's social circle from the start of his illness:

... it's unfortunate you know that even all his friends from school that he's known since kindergarten but none of them are there for him ...he would have friends from school, friends from work, friends from [post secondary school] then and he didn't actually have one good friend. You know going one from the phone ringing off the hook for him to nothing...

Leah also recalled a change with her social circle that she attributed to the effects of the medication that she was first started on stating "I didn't have any friends for a while cause I was still on [medication name] and I wasn't very social." Carly recalled that she did not see her friends as much after she got ill: "I sort of lost touch with people for a while, like I still, you know, made like minimal contact but I lost constant touch with my friends and their used to me living downtown and seeing them around all the time."

In summary, evidence appears to support that the onset of illness brought with it a new set of illness related challenges that included reduced participation in major day to day life activities, increased dependence on others, and reduced social circles.

\section{Possibility of Getting Better}

In contrast to their fears and uncertainties about the meaning of illness, participants were encouraged by having access to clinicians who shared optimistic and hopeful messages about the possibility of getting better. Furthermore, the way in which clinicians explained the illness, and the challenges they would face provided a foundation for a dialogue about the possibility of getting better and a means by which participants could begin to understand their illness.

Leah remembered “...like what my doctor had to say he said that schizophrenia is not a diagnosis it's more like a description of symptoms that people have... and that schizophrenia is really different for everybody. " From their conversation she understood 
individuals may have schizophrenia for years and are able to function in life but are at risk of relapse:

...some people are schizophrenic for years and years and they hear voices and they're functioning. Like on the surface they're functioning. Like, they go to work and things like that and then one day it just overwhelms them and they have a breakdown I guess.

As a result of conversations Leah had with her psychiatrist she realized that individuals with mental illnesses can lead fulfilling lives and that:

...there's plenty of people that are they have jobs and they have families and everything like that and they're on medication. And people won't even know it, a lot of people keep it to themselves, I guess cause of the stigma around it. But, me I'm totally open about it...

Similarly, in conversations with her psychiatrist Carly remembered the optimism he provided remembering "my doctor had said is that you can have an...episode of psychosis and many people do um, where they've had an episode and will never have another one again."

Following her hospitalization, Linda recalled that the psychiatrist who made the referral to a specialized mental health facility said she "would recover quickly there." Henry recalled “...the people at [name of the hospital] they're not even hopeful they just guarantee you that you will recover; you know they're positive in that at it, as long as you take medication you will recover basically." Curtis's psychiatrist described the messaging that he uses when individuals are first diagnosed:

Well we usually start with ah moderately optimistic tone, obviously we're not unrealistic, we don't talk about cures, but we do talk about people like Curtis. In other words, if people can have remarkable recoveries, that it takes a long time, it takes a year on medication before we see the full impact of medication, we see medication as a first step and then psychosocial strategies.

Although dialogues between the participants and their clinicians were optimistic they also presented the challenges that participants might experience. John recalled a conversation he had with his case manager: 
... [case manager name] told me. The first year is the horrible time where you are depressed all the time, second year is like you feel happy, the third year is for the brain, the concentration, the memory, and the thinking continues to be cleared away.

Not only was the messaging key in promoting the possibility of recovery, but most of the participants had access to staff that supported them early in their illness. When dealing with difficult feelings that arose because of symptoms Henry found it helpful to be told by staff “...don't worry about it you know, like that's in the past, not what you did before... like you're getting better now and that's all that matters." Leah's primary nurse offered the following perspective when she cared for her as an inpatient: "be supportive, uhm, spend time to hear, to hear what they have to say you know, and give them encouragement and let them know that there is nothing that they can't do."

I believe that a participant's willingness to accept the possibility of recovery was directly influenced by how clinicians communicated the possibility of the same. It appeared that the treatment philosophy that the clinicians operated from mirrored a recovery oriented perspective in that they conveyed the possibility of recovery to participants. Evidence of this lies in the description provided by Salyers, Tsai, and Stultz, (2007) who state that programs that are recovery oriented promote partnerships with consumers... and instill hope. 


\section{Summary}

In summary, this phase has served to describe the onset of participants' symptoms which included paranoia for some and hallucinations for others. It depicted how the illness entered their lives and the life activities that were interrupted when they encountered their illness. This period was accompanied with feelings of uncertainty, fear, and desperation. In two instances, participants considered ending their lives. All participants and their families made numerous attempts to seek help that, in some cases, resulted in a prolonged period of untreated illness. Some participants experienced a specific incident that necessitated urgent intervention in obtaining help. Participants described how they were diagnosed, how they felt about their diagnosis, and the supportive messages conveyed by clinicians about the possibility of getting better. While much has changed in the treatment of schizophrenia, these findings serve to highlight that many challenges regarding access to help and information, and the effects of stigma still remain in place. Having encountered their first episode of schizophrenia and received the message of the possibility of recovery, the phase to follow will describe how participants began to engage in services and supports by using a variety of strategies, which eventually enabled them to begin to feel better.

\section{Engaging in Services and Supports}

"Things started to change for me...like I no longer heard voices in my head and stuff like that...it was like better yeah I guess this stuff [medication] really works for me."(Henry)

\section{Overview}

As identified in the previous phase participants began to believe it was possible to get better. This initial belief in the possibility of getting better seemed to result in willingness to receive services and supports that gradually shifted to full engagement in services and supports. Features that contributed to full engagement were participants feeling understood and building trust with clinicians, experiencing the benefits of treatment such as medication, 
and engaging the support and encouragement of health care professionals \& others. As participants realized that they had an illness where the acute symptoms would resolve, they became more involved in their treatment in a variety of ways. These ways were deliberate and planned and, in addition to taking medication, involved other strategies that helped them manage their acute symptoms.

The subcategories that characterized this phase were:

a) Feeling understood: Building trust - a point in treatment when participants felt increasingly understood and began to trust health care providers resulting in a willingness to engage in treatment.

b) Striving to get better: The role of medication - highlights the role of participant's trust in their health-care team and their willingness to take medications as a way to alleviate symptoms. It also accounts for struggles experienced resulting from concerns over medications side-effects.

c) Striving to get better: Beyond medication - during this period of symptom stability participants began to use non-medication related strategies like making lifestyle changes, engaging the support of others, challenging their thoughts, and resuming participation in personal interests as ways to help manage their symptoms.

d) Beginning to feel better - a complex period where participants noticed changes in themselves indicative of improvement overtime and evidence that they were beginning to feel better. Participants also acknowledged feelings of sadness as they contemplated what they had experienced during the acute phase of their illness coupled with an awareness of the challenges ahead of them. 
It is important for the purposes of this phase to clarify the terms "recovery" and "getting better". When participants were introduced to the study by the intake coordinator, the term recovery was explained so that future participants could identify whether they perceived that they were recovering. For the purpose of the study information sheet, recovery was described as: possibly involving improvement in symptoms, ability to work or go to school, and to interact with others. Recovery was also described as a shift in attitude such as feeling more optimistic about the future. As the participants' stories of recovery unfolded it was difficult to ascertain how the participants adopted the term. Overall, improvements within the acute phase of their illness seem to be described as "getting better", whereas recovery was reserved for improvements in all aspects of life.

\section{Feeling Understood: Building Trust}

An important feature that emerged in the interviews was the role trust and feeling understood by health care providers played in a participant's willingness to engage in services and supports. This subcategory underscores young people's capacity to build trust with clinicians. It would appear that this ability was evident very early in participants' treatment and left the participants with valuable impressions of the clinicians. Henry emphasized the importance that trust played in helping him to begin to take medications:

....slowly I started out trusting more people, I started taking my medication stuff like that and that's a big part of it taking medication cause it helps... that's it cause if you don't trust anybody, there's no way your gonna get help... Their only trying to help you...And like you need to see that. The medications they help, they help the voices go away, if it's not, if it's not going away then your not taking enough medication. It's like that's just that's just the basics like, you may not think you have anything but you do...

The idea of being understood by clinicians was identified by participants as an important pre-requisite for full engagement in services and supports. Feeling understood allowed trust to build and in so doing allowed participants to engage in services and supports. 
When analyzing the interviews, it appeared that clinicians used a collaborative treatment approach, furthermore, that they genuinely cared for the participants. John recalled that it was the contact with his psychiatrist in a first episode psychosis outpatient clinic that was most helpful to his initial improvement. Inherent in this interaction was the notion of being understood by his psychiatrist. As he described:

When you're seeing something right, that no one believes you right, like they won't know what I'm talking about right. They won't be able to say something, but Dr. [name] right, he understands a lot right, I can explain it to him. I don't know if I can explain it to you [the interviewer], would you be able to understand it?

Leah also described how helpful it was to feel understood by her art therapist during her hospitalization. As she recalled:

...my art therapist she helped me a lot too like I used to talk to her about the transmitters and all like my delusions and stuff like that and she never denied that in they were wrong or anything like that [she] just like tried to, excuse me, she'd just listen and uh be interested.

Leah's art therapist described her approach to care as one that stems from the premise of empowering her clients as she described:

...there's a sense of empowerment...I can't tell them what to draw and I can't make them draw, so uhm it's very self directed...they have the pencil or the brush in their hand and it's entirely up to them ah what they do with it. And then as an art therapist I give them you know praise, encouragement, support, ah, and very non-judgemental.

Laura's case manager also stressed the importance of engaging in "rapport building" with Laura as a way to develop "trust in terms of a therapeutic alliance." Feeling understood was fostered by clinicians taking into account participants' individual needs. Curtis' psychiatrist underscored the importance of looking at the whole person as part of his treatment approach and acting on needs identified by the client as he described:

I think recovery has to look at the whole picture, otherwise you're just medicating and you'll turn off the patient client very, very quickly. And again we're meeting his needs, he clearly identified... he brought those to the table... 
Some of the participants recalled specific encounters with clinicians that contributed to them feeling better. I believe having trust in and feeling genuinely understood by clinicians seemed to enable participants to engage in services and supports. As Leah remembered when she was in hospital:

...it occurred to me one day that the staff was trying to help me. There was a meeting with Dr. [name], Dr. [name], and my mom where I flipped out. I accused them all as part of a government experiment the transmitter...Dr. [name] explained that they were just all doctors and nurses in the mental health field and that they didn't know about any experiment it didn't occur to me that maybe I was wrong and it was all occurred in my head and maybe I was delusional. But I did realize that they didn't know about the experiment and they were probably just trying to help a person who appeared to be crack pot (chuckles). So ya so that was like one that was even though I didn't I felt like I was in denial that I was delusional and it still helped to know that they weren't actually out to get me. I stopped being so paranoid with people.

I found that a therapeutic approach that builds a sense of empowerment and comfort with participants is important to foster steps toward recovery. Leah recalled how much she valued the relationship she had with her inpatient nurse:

...the one nurse that I had like she was the only one I wasn't really scared she used uh come in and like get me to do things. Like she'd get me to do my laundry and like get me to eat and stuff like that so that really helped me. She was the only person like there that I felt really comfortable around....

Leah's inpatient primary nurse further commented that she:

...allowed [Leah] to be empowered...because it's her life...she has to...make the proper choices for herself...I was there when she [Leah] needed someone to talk to, or to vent... if she wasn't having a good day...if I was there and could talk to her and hopefully make her feel better...

Laura recalled that when she was first admitted to the hospital she found the staff to be very helpful stating, "I took a liking to them like very easily and I think they did the same for me and uhm and so they were a huge help." When Carly first learned about her illness, and very early in treatment, she recalled recommendations from clinicians who advised her that she should take a break from her life's activities. In retrospect, she recognizes the importance of 
this recommendation in contributing to her feeling better, despite of her initial reluctance and disbelief:

I came to see Dr. [name] ... I finally uh, had come here and at that point I decided to move home but I was still thinking you know well hopefully I'll get back into school. I'd taken some time off school...But not really taken it seriously, it was when I came to see [her psychiatrist] in [name of month] like he really sat me down and said you know you need to drop out of school, you need to take some time off, you need to take like a good chunk of time and you need to relax and you need to not do anything...And he was like I don't want you to work, I don't want you to go to school like basically and I was like quite shocked at the time, like I was just like, who do you think you are you know like (laughing)... Like you don't know what you're talking about too but, basically like he talked to me about like you know this is what's happening, it's serious...like I talked to him about a few things like, one of the key things in like psychosis is stress...so he really put me like in my place like that...I was like okay I'll do that if you think that's what's best but it was like what am I gonna do like... I've just come out of this place where I'm, you know working 40 hours a week and I'm going out with my friends, and I have school and I have homework and I have all this stuff and...I was like I don't know what to do with myself. Like I've never had that experience where you know, since I was [in my early teens], I've had a job.

However, upon reflection and consultation with her family, Carly's feeling eventually

changed to acceptance:

I was pretty upset... about it and I didn't agree ...it was [name] that actually talked to me right afterwards and was like I think that what their saying is for the best um, and you know [name of family member] was very supportive but...he sort of, cause the doctor I'm seeing can be a little bit, a little bit, he's sort of a bottom line kind of a guy (laughing)...He's very much like this is it and that's it... [name of nurse] is also there to provide extra warmth I think... and then I talked to [family member's name] who's more, you know like, you know like, like he gave sort of a family member perspective of...He sort of convinced me that that was gonna be you know the important thing to do.

In summary, in my analysis it became clear that trust and the feeling of being understood played critical roles in helping to establish participant's willingness to eventually engage in services and supports. The evidence in the interviews also supported the need for health care providers to engage in behaviour that reinforced trust and collaboration. Carly's narrative above demonstrates an example, when trust is not firmly established and when a 
participant (who was an emerging adult) perceived that she was being told what to do, and therefore did not accept recommendations initially until she came to the decision on her own.

\section{Striving to Get Better: The Role of Medication}

Once trust began to build between participants and their health care team, eventual commitment to taking medications emerged as another important element that supported recovery. This subcategory highlights participants' initial views/perceptions as they began treatment. In retrospect, all participants stressed the importance of medication as a key aspect of their treatment. The majority of participants welcomed the idea of taking medications to alleviate symptoms, however, for some it was a time marked with uncertainty. What I found interesting is although some participants were uncertain at first about taking medication it did not appear that medication "compliance", as I have encountered in clinical practice, was an issue. Was it because the symptoms were so distressing that they welcomed any intervention to alleviate them? For the majority of participants, there was also no apparent "power struggle" that at times results from having been strongly encouraged to take medication by clinicians. Although not explored in the interviews, I am assuming that they were voluntarily offered the choice to take medications, therefore leaving them in control to make this decision on their own. It would appear that the hope medications offered to bring out a desired changed seemed to override the uncertainty for participants. Leah welcomed the idea of commencing medication despite some of the side effects. As she recalled:

...they put me um on [name of medication]... which is an antipsychotic and uh it was good because I [was] sane and I was grateful to feel sane but I gained all this weight and I was like really exhausted all the time...I was just sort of like a zombie a lot of the time. But uh then they put me on [name of medication] and like I just felt normal like I felt normal before because I was sane but uh I actually felt like myself again.

Michael recalled his psychiatrist told him that "as long as I'm taking the pills there's not gonna be any problems." He also added: “...I just hope the pills are gonna make me better." 
Sandy initially struggled with the idea of taking medication. However, she came to

understand that there must be a reason for taking them:

... when you're in denial like you don't believe that you are sick and then and then maybe what made me believe that I was sick, why was I taking medication, why were they [clinicians] making me take the medication... when you take medication, like say you have a cold and you take medication to get better. When ... you have a sore throat you take Tylenol to relieve the pain...I also experienced that medication relieves the pain, I knew from my experience that medication relieves the pain... when I was in hospital and taking medication...maybe it was taking medication for issues causing me the mental change...

John specifically recalled the conversation he had with his psychiatrist that highlighted the

possible benefits of the medication; his initial reluctance to taking medication, and ultimately

his provisional acceptance of the medication. He recalled:

Whatever he said was making sense. Like he was telling me, you know you see these imaginations and you see all these things and all... voices. You know that could be cured away, you don't have to be like...you don't have to feel the same way in the future, right. So you got to take the medication because it will help you a lot, right? I believed him, right. So I started to take the medication, if, I, if the voice and the hallucinations don't go away in 2 months I would stop taking the medication, but it went away right. Then I started believing the medication can help me. It was a risky choice you know...

Similarly, Henry described feeling unsure about his treatment in hospital including taking

medication. He described persuasive arguments from hospital staff and ultimately the support

from his father that seemed to enable him to stay in the hospital and take medication:

I don't know I never thought it [recovery] would happen at first... I was like unsure about it but since I was in the hospital it was like they were like if you don't take the medication then you're not going to get out. Like I know some hospitals like they let you out even if you don't take the medication and stuff like that. At [name of the hospital] they're like you don't take it then the doctors are going to write that you're not getting better you're getting even worse and like it's going to take longer time for you to get out and so you might as well take the medication and then you can finally like go out into the real world you know? Otherwise you're not going to get better and you're just going to stay in the same place and so I like sort of just kept on taking the medication and stuff like that and when I finally reached home my dad was like yeah you have to continue the same way your going cause I see you getting better. 
Sandy recalled her initial response related to being hospitalized for treatment. She remembered that after a while she wanted to leave because she felt like the nurses and doctors could not understand what she was going through. As she described:

...maybe they don't understand that we are in denial, that we don't believe that we are sick so or maybe...they're frustrated with getting people to, getting people to take medications.

Furthermore, she believed that clinicians needed to welcome questions by patients "I think that nurses and doctors should expect or anticipate patients asking what kind of medication they are taking and what does it do." I found both of these clinical recollections of interest. I wondered what made these clinical interactions different from others that participants described. Was it the particular treatment philosophy on these inpatient units? Although I did not ask during the interviews, I considered if these participants were admitted involuntarily into hospital, therefore, making their admission more restrictive and suggestive of having a power imbalance.

Although they realized the need to take medication, some participants struggled with side effects such as weight gain and fatigue. As Linda described, "I want to recover soon, I don't like to take medication, cause I am getting fat everyday." She also added that she was "kind of lazy now," a quality which she attributed to the medications. Laura described her experience with side effects:

... when I was first diagnosed they were experimenting with medication, they didn't know what kind of medication I was supposed to be on, so I had lots of side effects and the side effects were like really bad and it was like terrible experience, it was just I was taking so many different kinds of medications and sometimes it would make my symptoms worse and most of the time they were worse, and now that they've found the right like medication for me, so I'm doing a lot better than I was.

Four participants described having to try various types of medications before they found the one that helped them feel better. Although they had to deal with ongoing symptoms 
and resultant side effects that were challenging at times, they were pleased once the proper

medication was found. Laura recalled:

...they were testing a lot of different medications on me. Some of them were really terrible and made my symptoms worse and some of them were actually good. Now I'm on really good medications so I think they finally found the right like medication.

Leah also recalled the changes she experienced over time once she began taking the correct medication:

...first I was ill which hit me all at once I was too paranoid and disturbed and absorbed in my own little world to understand that people were trying to help me. Medications didn't work and they made me feel the worst side effects such as body aches, exhaustion and drooling. Then something did work with [medication name] but I slept fourteen hours a day and ballooned up to [number of pounds] and I still heard voices from the transmitter so then enter [medication name] and suddenly the transmitter melted into my own internal voices. I deflated went from [number of pounds] to [number of pounds] pounds in three weeks...

Steven recalled challenges he encountered when changing medication:

...it took actually a while, it wasn't a smooth transition at all... it was uh, completely different. These were sedatives right? They made me really, really exhausted. It was tough I knew that they were working... I just stuck with it and now I'm pretty immune to you know the tiredness.

Other participants experienced lingering symptoms despite taking medication. John

described that after one year the voices in his head stopped, however it took additional time

for his mood and energy level to improve, which he found frustrating:

.... it [medication] changed me a lot, right. Like even in the beginning I thought the medication is not always going to work any more, cause now I used it for a year, right. Only thing that was done away with was hearing the voices, and the hallucinations right, but the other feeling, like feeling sick, feeling down and everything, that hasn't gone away, right. But after year and a quarter, it went away....

John also acknowledged that his "mind is weak" as he described: "I can't think. I can't concentrate, I have no memory. I have memory of things I do, but like say if I wanted to ask myself what did I do yesterday, Right. I have no idea. It's weak." Michael also described struggling with ongoing symptoms, "I just hope I get to go somewhere without feeling 
paranoid." He also described the ongoing need to challenge his thinking: "there's no point of like worrying about all that stuff when it's not really true, it's not really happening like hearing voices and stuff, like everyone in the world doesn't hear voices so I guess like it's not true." Michael acknowledged that he wanted to try his best to manage lingering symptoms because as he described 'you can't let the disease take over [his] mind...if it does then they'll probably have to lock me up. " Furthermore, he stated:

I feel like it's good to fight it [symptoms of schizophrenia] ... if you let it [symptoms of schizophrenia] take over your mind... if you let the disease take over, like take over you... Then you'll never uh, you'll never get better...I can't say schizophrenia is gonna be absolutely gone but as long as I'm taking the pills I won't have to worry about uh schizophrenia, I won't have to worry about the symptoms...

Again, what is striking with these participants is that despite the challenging side effects, and having to trial numerous medications they continued to take the medications. I wondered why the struggle to continue to take medication, an occurrence that I have encountered in clinical practice, was not an issue for these participants? Possible reasons included that they trusted the efforts of the clinicians and as a result continued with medication, or that they were determined to find relief of their symptoms, or it was simply a personal choice? Regardless of the answer, clearly "medication non-compliance" was not an issue for them. Furthermore, two participants chose medications as the personal objects which symbolized their recovery. Michael described why he selected his pill bottle to symbolize his recovery:

Maybe I should've just brought my pill jar cause Well, it's something that I, like that I look at almost everyday of my life and I know that every time I take out some pills from it and pop into my mouth tat I'm gonna get better...Cause when I, everytime I see it, it's like, I don't like smile like you know. I see it and I'm just like Yeah, I'm gonna get better, you know. Like I'm gonna pop a pill. 
Linda also chose her medications as an object which symbolized her recovery. According to Linda her sleep pattern was altered as a result of the illness, she found great relief in taking medication which seemed to improve this for her as she described:

...my medications, because it helped me alot to my recovery...helps my because of anti depression [name of medication] helps me to sleep well... some people don't sleep well because of [name of medication] I don't know it worked for me.

To summarize, it is clear that medications created the acute symptom stability required to support participant's first steps toward recovery allowing them to begin to feel better.

\section{Striving to Get Better: Beyond Medication}

In my analysis, it became apparent that participants entered a period of symptom stability when they began to use strategies beyond medication that also helped to manage their symptoms early in their process of recovery. Making lifestyle changes with the support of their health care team, engaging the support of non professionals, challenging their thoughts, and resuming participation in personal interests were examples of effective strategies participants used.

Participants acknowledged that they made efforts to commit to lifestyle changes that helped them get better. I believe that a participant's desire to make lifestyle choices that support recovery is an important part of the recovery process. It was apparent that all participants remarked that they had clinicians that supported them in making these changes, and that their clinicians believed in their ability to bring about change in their lives. I suspect that the clinician's experience with the illness and their belief in the positive effects of change served to motivate and empower participants to make changes to their lives despite illness symptoms. Carly acknowledged that working with, and taking suggestions from her 
clinicians, such as her outpatient nurse, was a learning process marked with times of

uncertainty. As she described:

I think for the first few weeks that I was a patient here, they were a little bit like you know I'm sure they're used to it too but I was a little bit put off I was like you know I don't like these people or you know I don't think that they know what's best...but she was really helpful and you know she was just really encouraging and made a lot of suggestions for me about like you know what kind of books do you like to read and maybe you should go to the library and you can get books that you can read and you could you know, learn about cooking... she would also try and think of things that, to help me learn more you know healthy habits...for my life... she was like, you have to think about exercise...I think it is important to, to learn, to learn a lot of that stufffor yourself too you know and so no matter you know if you're in a relationship or if you're with your parents or if you're, like you can always, the things that you will always be able to know just for yourself...

Furthermore, support was sustained over time. As Carly remembered:

... she [the nurse] was really good so she encouraged me a lot and she, she would like I would, come in here right once a month so she would always give me ideas and you know always asking about my progress... like so what have you done, what did you try, how did you, you know what did you think of it, how did it make you feel you know...

Henry remarked that his psychiatrist and case manager were "here all the time they definitely made me think differently", providing encouragement to him and pointing out to him that "you're too hard on yourself [Henry] you have to pat yourself on your back." Steven remarked that his psychiatrist encouraged him to change his ways and stay away from drugs and "all that kind of stuff."

It is notable that seven of the ten participants identified a family member or girlfriend as individuals who influenced their recovery. This enforces the notion that recovery does not happen in isolation and further underscores the valuable contribution that such support provides to an individual's recovery. In addition to choosing to make lifestyle changes, my analysis indicates that another strategy participants used during their process of recovery was to leverage the help of family and/or friends during their acute phase of illness. 
Linda began to think about her country of origin. While in hospital she asked her parents if she could go back to the country where she was born. She recalled "I went back home... and I stayed [a number of] months there, I think that time I started little bit recovery." Being there allowed her to be around family, and attend religious events both of which stood out as important occurrences that helped her get better. Henry acknowledged the support he received from his girlfriend:

She used to come to the hospital like everyday come visit me and make sure I wasn't bored, she'd buy me stuff from the store because like, at first I wasn't allowed out. So she'd come here. So like now she's trying to get me to quit smoking as well cause like she doesn't want me um getting like bad lungs or anything she doesn't want anything to happen to me she like really cares you know really glad that I am with her.

Henry's girlfriend also acknowledged the role she played in supporting him to feel better by reinforcing the value in having Henry go to hospital and the importance of taking medication. As she described: "don't ever make them stop [taking medication] cause then the schizophrenia will come back and they'll...think the pills are trying to kill them." Linda's father commented that "she was in the hospital everyday we visited her. Not a single day we spared. Everyone, either myself or my wife or children or sometimes two or three of them, they were there daily." Michael described the reassurance and support he received from his grandmother and relative as he experienced his symptoms.

.... anytime I'd phone her and I'm going crazy on the phone she just like she just like relax don't even worry about it like my [relative] too...their both just like relax don't worry about it you know what I mean it's schizophrenia you know it's not you actually you thinking like that it's it's just the disease.

He also described the benefit of the love he received from his family:

I know I'd have my doctors and stuff and my friends and stuff but if I didn't have them I would feel lonely so with this with them calling me it just makes me feel more loved and with the love it just it helps me with my schizophrenia...Just knowing that they care about me and phoning me to find out if I'm alright and stuff like that when they call me and stuff like that um it makes me feel better it makes me it makes me like wanna battle the schizophrenia more. 
Michael's grandmother also commented on the support she believes she provided to Michael and stressed the importance of showing him love "I think just being there and knowing that he can reach me any time and whenever he needs help like I'm always there to help him. So I think the love that I show." Linda commented that her parents reminded her to take medication and cooked her meals as she did not "do much activity at home after 6. " Carly described how helpful it was to talk with her mother and her mother's partner about the changes she was experiencing:

I think my mom and [name] are also helpful, because they're family, that's because they're interested in sort of mental health and stuff like that, like they're, they're, good to talk to about you know just about you know feelings change and the way people react to you...it's a different level than with your friends right?

Early in her daughter's illness, Sandy's mother provided support by encouraging her to resume a "normal routine," as she described:

Another thing with people who have a schizophrenic attack is they need people to get them out as soon a possible to a normal lifestyle rather than accepting that okay they're on medication they can't do any better. Because once you let them think okay you're on medication, it's okay you can sleep in all day, you don't have to do the normal things, you have to get them back as soon as possible into a normal routine...

Some participants acknowledged the support they obtained from their friends early in their recovery, while others described how they lost contact with their friends. This loss of friendship will be discussed in the following phase. For some of the participants, they continued with friendships they had that were outside of the illness experience, while others were cautious about which friends they chose to keep. Carly described the time she spent with a friend and how helpful it was in particular with filling some of the time she had as she was recovering:

...one friend took me away...for a weekend and it was so nice...those moments can be really important to you know, when your, when your feeling down or your having you know, problems and someone really reaches out to you...it was really nice cause it was like, we'll just do something relaxing, everyone's just understanding like oh you had all this stress and you need to calm down so it was just like we'll just... relax and 
you know...that kind of stuff...it was really fun and it was really nice because there was a lot going on, like all of a sudden I started to see like these endless stretches of like, oh my God I have all this time to fill so you know like, and so it was nice to have something you know, something happening.

Michael described the support he has received from his friends in encouraging him to take his medications:

... they don't mind their their just like their cool with it their just like their always trying to preach to me about stuff like getting better... I have my friend [name] and I knew him since since I was [in my teens] and he's one of my good friends... he's always telling me he's always telling me don't worry your gonna get better and things are gonna be good and don't worry just take your pills and and just relax and stuff like that.

Two participants specifically described establishing friendships with other individuals who also had mental illnesses. For example, Steven's new close friend was someone whom he met while in hospital. As he described: "all the walls are broken down you know...There's nothing to hide...it's really, really, it's really cool to be around somebody like that." $\mathrm{He}$ further elaborated:

...some other people that have the illness I can share with, yeah, so just being able to share with somebody and trusting them is the big deal and not always worrying about being kind of like exposed is another thing, like its already all out there.

It is clear from these accounts that obtaining support from family/friends played a key role in a participant's process of recovery.

Another strategy some participants used during their recovery process was to actively challenge their thoughts as a way to manage their symptoms. As Curtis described:

I did lots of reading my mom bought me this book and I definitely learned a lot like about your thoughts...Okay once a thought leaves you like that's the end of it. You know what I mean? Like lets say I thought I can't do this and it leaves you in an hour. It's already forgotten... So don't keep thinking about it over and over again... Once you have a thought it's always forgotten. And then you also have to realize that ok you might have a thought that is actually not really there your just being a worry wart making it into problem. You know? Making a mountain out of a mole hill. Uh what else does the book teach me? Uh positive thinking...always make decisions when you're on your on a clear mindset... 
Michael also challenged his thoughts as a way to manage his symptoms. As he recalled:

“When you're like schizophrenic, if you don't challenge your thinking, it's just gonna take over your like, your, your way of life...And it's just gonna mess you up and you'll end up like in a rubber room."

All participants described pursuing activities based on their own established personal interests in order to help manage their symptoms early in their recovery. I found the selection of activities that, for example, included engaging or re-engaging in forms of spirituality, reading, writing, listening to music, or exercise, served to empower participants by providing them with additional resources, beyond medications, they could use to manage their symptoms. Four of the participants evoked their belief in a "higher power" to assist them during their recovery. Both Henry and Curtis re-acquainted themselves with their religious faith. Henry recalled accepting the invitation by his mother who told him "I know if you pray to God, God will help you. It may not be now, it may not be in a week, but He will help you." He described:

... at first I didn't want to pray with her I was like no, then after she convinced me then that's what I needed to do so I learned to pray with her, and then she says that she's gonna come and pray with me like from now on, and stuff like that, so that I can get better.

Henry also mentioned that reading the bible helped him to calm down:

...I've started to read my bible and stuff, that helped me a lot because like I found when I was reading my bible like everything calmed down. I never heard anything I was concentrating, trying to learn a little bit more you know.

Two participants chose objects representing spirituality that symbolized their recovery. For example, Leah described the context of the photograph she selected:

This [picture] was taken...in the morning, I was seeing like all these layers of the branches going up. And uh I was just looking up in the sky and there was this little break in the tree. I just when I look at this [the photograph] it just kind of reminds me about whole thing about mother earth. Like uh I really like trees that was another thing I was going to mention like uh I I sort of got into health foods in natural 
medicine and stuff like that and I went to a homeopath and he told me that if I was really stressed out he says to put my back against the tree and then just ask for this energy and it'll calm you down, and I was like uh it sounded like such horse shit but it actually works. It it does work, trees are alive to, and they have this energy I get this like I just feel like a lot calmer...Yeah it really does work so I just really appreciate trees and stuff like that and nature...I don't know it just reminds me of like as I said with mother earth if you need help it will come.

In addition, earlier in her interview Leah mentioned that she did not believe in God but did believe that we are part of a "bigger organism," termed "mother earth," that provides what is needed. Based on our discussion about her photograph, it became clear that for Leah, being open to receiving help from sources, in this case "mother earth," promoted her recovery.

Participants also used other personal interests in their recovery process including reading and listening to music. Carly and Laura used reading as a mechanism to control symptoms and monitor improvement during their recovery process. Carly described struggles with reading early in the course of her illness which she discussed with her doctor. In efforts to address this, she used strategies to overcome this symptom of illness: ... when I first, when I first came out of it, I couldn't even sit down and read a book you know um, it was like my mind was just so you know almost like rattled. It is a hard feeling to describe. Like you can't even sit there and read. Like I said, I started with, and I talked to the doctor about it and he was like yeah that's the typical symptom you know, um, your brain has to get used to, it's just the process, you know the focus and uh you know retain the information. Um, so I started off with um reading, I think I was just reading [name of magazine], you know just short articles and stuff but it would be quite difficult cause I'd get distracted...you have trouble focusing on you know a whole paragraph. And them um, my [relative] came up with this idea where she gave me some of her sort of um trashy novels... you know their fairly easy to read and they keep you interested because their, you know their wild and exciting....so I started to read them, finally around [name of the month] I was like okay I it was pretty big but it was like I'll see if I could get through this book and I could so that was good. But it took about a couple of months for me to even be able to read. Um, and read it like I mean, reading is such a huge part of my life, I was just like I can't read, that's just shocking...it took me maybe just 6 months that, then I could read you know full, whatever I wanted... 
Laura stated that she used reading as a way to occupy her time in hospital instead of eating

which made her gain a lot of weight. She also found it mentally challenging to do:

I spent a lot of the time in the hospital reading and that was a great influence on like in so much because uhm I was never a big reader... my tolerance for reading went up like a lot and now I'm reading like huge big hardcover books and it's like...it's it's sort of mentally challenging and I really like admire that.

She added that she used writing as a way to take her mind off the symptoms. As she described:

I got sick like right at that time and so I couldn't write with [a] pen, I started writing with computer and so I would sit down and write for hours and hours just to get my mind off my illness and the symptoms that I was feeling. And I would just write and write and write. And a lot of good came out of it. I wrote a lot of [literature] and stuff like that...

Michael and John stated that listening to music helped them feel better. Michael recalled, "When I listen to music it's like it takes me away from like the reality of having schizophrenia and it just makes me feel better... It just makes me it makes me um it just makes me think that everything's alright." John acknowledged listening to cultural specific music allowed him to think and imagine "how like I'm going to be developing myself..." As a way of further highlighting the use of music as being important to his recovery, John selected his MP3 as the object that symbolized his recovery. As he described:

I like listening to music because it keeps my head from wandering off. I am able to listen to music and do my imagination thing, so that is why I like to listen to music.

He further acknowledged that going into this the imaginary world freed his mind to think about his hopes and dreams for the future and what he wants to accomplish. He also added that watching sports helped to give his mind a rest as he described, "it takes away my mind for 2 1/2 hours, 3 hours, I don't think about anything except trying to like...shoot the basket ... "Another activity that John engaged in to "strengthen his mind" during his recovery was smoking cigarettes, although he stated that eventually, he would like to quit. He described: 
...when I smoke, right, I just think of things that make me happy, right. And when I do that it's like I just go into my own mind imaginary world start thinking and then I would smoke right. Well when the smoke finishes, I don't like it because like I won't have that thought again. When I have it, it just lets me relax...

Curtis, Linda and Carly used exercise as a way to handle stress and manage the side effects of the medication as they recovered. Specifically, Linda began walking as a way to manage her weight gain. Leah participated in programs "at [name of hospital] art therapy...recreational therapy, music therapy", which she acknowledged "all helped" her recovery. She recalled:

Like when I was in the [name of the hospital] they tell you everything like when you if you go out with them during the day like on little tours and they'll show you every drop in center you can go to...they'll show you... how to get a membership to the [name of the community centre] for free...or pretty cheap...

In summary, it would seem that engaging in established personal interests and/or activities, while challenging at first for some provided participants with effective mechanisms to monitor symptom improvement during their process of recovery. Engaging in these activities also served to inspire, build confidence, provide distraction, and ultimately provide a sense of familiarity and routine to participant's lives.

\section{Beginning to Feel Better}

Once participants began to feel better, they were able to look back on their illness experience and recognize the importance accepting help from others had on their recovery.

As Henry recalled:

...if you are not getting help if you're not receiving help then you can't help yourself. Like it's very hard to help yourself I'm not saying you can't but it's very hard. Cause like even though like really I didn't want to believe that it was happening but there was nothing I could do to control it.

Steven described:

...if I didn't reach out and try to get help like I think probably who knows what would have happened. Like I've been around people that go so long without getting help. When I was at the [name of the hospital] they [patients] go like 6 or 7 years with pure 
psychotic episode you know, and then finally getting help but by that point there's a lot of damage so they're very slow...It's a good thing that I got help...

It became apparent that following the initial phase of treatment for their acute symptoms, participants began to notice changes in themselves indicative of improvement over time and evidence that they were beginning to feel better. Henry stated that "I used to feel like the world was mad at me or something. So then since I take my medications like I realized that it's nothing like that." Sandy acknowledged that the medication helped her feel "a bit more alert." Michael recalled that when he started a new pill:

...the voices slowly were going away... [he] felt uh good that it [the voices] were going away...I'm getting better now I've been taking my pills and my pills are making me better but um I know that I stop taking my pills I'm gonna go back to the way I was before...

John remembered feeling pleased when he started to take medications stating he felt "so happy... you know...like 1 more day till recovery, that's what I keep thinking to of myself. I wake up, I take medication I feel happy right." He also acknowledged that within two months of taking medications, he noticed an increased ability to look after personal grooming again and help out around the house by doing laundry. John's mother also commented when she noticed her son was feeling better based on resuming how they would relate to each other:

...before the sickness started, the relationship was very good, but ah when the sickness started he started to hate me and for some time he couldn't even call me [specific name], that is the normal way of addressing the mother, he was refusing to do that. And he did not have faith...in me, ah was telling me that all the advices are wrong. And so he had some problems with the police and then I had to force him to because of his sickness he got into trouble like this with the police and then I forced him to take medication so he started recovering gradually and now he has almost reached a stage where now our relationship has come to normal, like before the sickness.

John also described how he hoped for ongoing improvement:

I'm recovering from schizophrenia and when I started it was very dangerous to me, I was thinking about suiciding, but now I'm recovering really well, right it taking the 
medication every day. I have a hope that I like will recover right soon it cause I see a lot of changes right now. I feel a lot happier than before... I feel my mood is changing, I don't have any more wild thoughts, my mind is in one place and I'm able to focus and do things on my own. But still there is some discomfort in it, but I know that will change so I'm just hoping for it.

It would appear that the hope he felt, sustained him through his recovery. In a sense it appeared to motivate him. I believe that through this period he was able to draw on the foundation of hope that had been established during earlier discussions with clinicians.

Other participants also described feeling better. Leah (who was hospitalized for several months as an inpatient) had to endure medication trials over a period of two years in order to effectively manage her symptoms that eventually resulted in her feeling better. As she described:

I don't feel like I have chemical burnout, and like, I don't have a lot of side effects from my medication, and I'm in like pretty good health, I don't have as much back pain as I used to and stuff like that. Uhm, cause I'm just feeling a lot better in general...

She further added: "I felt like I've been punished for a while and suddenly rewarded with feeling much better." In addition, she "felt normal" and started to feel like herself again when her medications were changed from one anti-psychotic to another. As she described, "I haven't felt like myself in two years" She acknowledged that she "was sane" and "wasn't as paranoid" she "still heard voices and things like that...but it wasn't so bad." She further endorsed that taking medications had allowed her to be "a healthier version" of who she was, and that because of the switch in her medication she "kind of came out of my shell." Leah's art therapist also commented on the changes she noticed in Leah once her medications were changed. As she described:

She's on a new medication and ah I've seen quite a dramatic change in her since then. She's not as...uhm she's much more talkative now, uhm, initiates conversation more, it used to be sort of my asking her questions and ah she could, you know, give lengthy detailed answers but I would have to initiate that before and since she started the new medication she's quite... ah she can... she doesn't need a lot of prompting to 
discuss things any more and some of that might be that she's more comfortable with me now.

She also commented on the changes she has seen through Leah's art, reflecting that Leah was beginning to feel better:

...before her delusions used to be in the art, if she drew a picture of a star then, ah, part of her conversation would be about... those types of things. That's not part of the conversation anymore. So that part has changed. Now she just wants to...she's concerned with, ah, making a picture that would be worthy of hanging on her wall...

Steven described that once he switched medications he felt that he was starting to recover. He recalled, "...I got on the right medication and almost right away I started like you know, everything kinda just like disappeared...It actually was alot better than what I was on before..." He also stated that overall the medication helped him not "to drift off and get involved in things that weren't real..." but rather "to focus on things that are better." Michael described that he was hearing voices a lot but then started to take a new pill and then "the voices slowly were like slowly they were going away...I felt uh good that it [the voices] were going away."

It seems participants had the expectation that there symptoms would eventually be managed. What also became apparent was that the examples participants provided that described their feeling better were largely attributed to the effects of medication. I wondered why the other non-medication strategies that they used were not attributed to symptom improvement as much as medication. I also wondered by focusing so much on the beneficial effects of medication, if participants were underestimating the impact that other strategies were having on their overall recovery?

Although, most participants experienced some sense of improvement, for some this feeling was accompanied by a sense of sadness. This emotional response seemed to be related to the realization that they had been ill, and a dawning awareness of the challenges 
ahead of them. This I believe this posed a challenge for them because although they arrived at a point where they were feeling better, it came with an emotional price. I wondered how participants were able to cope with these changes in key areas of their emerging adult lives which included work and/or school. Were they able to compartmentalize it whereby it did not overshadow their sense of self? For example, Carly first described the positive effects of the medication, but she quickly followed up with a description of how difficult the improvement had been for her. As she described:

I was actually only really sick like having psychotic symptoms for about $21 / 2$ months, and it was only about, probably for about a month into that they put me on medication. And then once the medication started to take effect, it generally all went like almost, like almost all my symptoms went away.

Carly then went on to describe her feelings especially concerning the change in her daily routine:

... when my medication kicked in and it was quite a downer because, not really a downer, like how do you explain, like the sort of the crazy feelings like, like I think at one point...one of the doctors suggested that I was having manic feelings because it was such a relief of stress and stuff like that. So um, like all that sort of the ups, the highs and lows and the confusions sort of like all cleared at once. So all of a sudden it was just like you know, it was almost like cold water on the face you know...It was sort of like okay now, look at your situation and look at where your life has gone up until now and you can look at it with a clear mind right so, so it was quite, you know, it was, it was kind of um, it was kind of a down period for a while because I was like you know I don't have school, I don't have work...

As some participants described beginning to feel better, they also began to think about recovery. The notion of recovery as something more than management of symptoms began to emerge, and was described as a process that occurred over time. The length appeared to vary for each individual, and was not specifically indicated. For example, Steven described that it was after he "was institutionalized for like [number of] weeks" that he began to think about recovery. Henry described the process of recovery: "like every day is one step closer [to recovery] cause you can't you can't get worse from this point...I don't see 
anything worse that can happen. "He also described that the important idea that symptoms

do not have to be totally resolved for recovery to occur:

...you just need to reassure yourself and you will get better. Take your medication and you will get better...Recovery basically means going through steps, processes to get to the best shape you can get. Recovery may not like till it's completely gone and you don't [sounds like] hear it anymore, your not agitated with yourself like you learn to love yourself and love what you are.

\section{Summary}

This phase served to highlight how participants transitioned from an initial uncertainty, to openness to treatment, to a full engagement in services and supports. What emerged from the data was that it was essential that clinicians and participants needed to build a trusting relationship. It was important for participants to be open to treatment and for clinicians to share optimistic yet realistic messages of hope and engage in ongoing behaviour that reinforced trust and collaboration. Once trust was established, participants showed a greater willingness to collaborate with clinicians in their treatment plans which included a preparedness to make choices that supported their recovery. Participants also showed a desire to engage in activities such as reading, writing, and exercise that helped them selfmonitor and manage illness symptoms. While medication initially posed challenges, and caused side effects, participants began to feel better and see improvement. Once participants' active symptoms were being managed, it appeared that they began to consider recovery as beyond symptom management. Some participants acknowledged a sense of sadness, in realizing the challenges ahead of them. However, they did not allow this sadness to overshadow their recovery, as they were committed to moving on with their lives. The phase to follow will describe how participants re-engaged in their lives and the challenges associated with doing so. 


\section{Re-Engaging in Life}

"I wouldn't be coming to school...I wouldn't be going out...I wouldn't be doing like all that kind of stuff if I wasn't getting better...I know I'm getting better...slow but steady" (Michael)

\section{Overview}

Participants were encouraged, strengthened, and inspired as they realized they were getting better and began to re-engage in life beyond symptom management. While participants re-engaged in their lives they began to ask important questions relevant to their illness. For example, they sought answers to questions like what may have contributed to their illness and what was important to their recovery. As they discovered the answers to these questions, with the support of others, they made choices to let go of harmful behaviors that may have contributed to illness onset. They sought to get on with their lives by resuming previously set life goals consistent with their development as young adults, as well as setting new short term goals. Participants identified the importance of having the support of others as they re-engaged in life and also described challenges to their recovery.

The subcategories that characterized this phase were:

a) Engaging the support of others - a period during which participants made initial steps towards re-engaging in life activities that was facilitated by a greater engagement in terms of support and interactions with others.

b) Reflecting on the past: Changing their ways - participants took greater control of their illness by choosing to make lifestyle changes and eliminating those things they believed had contributed to the onset of their illness.

c) Getting on with life -participants began to view their symptoms as less intrusive and were then able and determined to focus on resuming non-illness related activities. These included formulating short and long-term goals that reflected their interests and promoted independence. 
d) Challenges to recovery -participants recalled facing challenges as they recovered.

These included the fear of stigma on relationships, decreased independence, and unhelpful interactions with family members.

\section{Engaging the Support of Others}

It became evident that as participants were re-engaging in life they found it helpful to obtain the support of others such as friends, family, and became involved with outpatient programs and clinicians. These interactions provided participants with routines, encouragement, and social interactions that they described as missing during the acute phases of their illness. They were able to use their support system to help change behaviour they believed contributed to illness onset, and/or help set new or re-establish life goals. In essence, participants' re-engagement in life did not occur in isolation but was facilitated by the interactions with others around them.

Carly described that she began to re-connect with her friends and family stating: ... at first I was dealing with boredom and I was doing a little bit, I was feeling anxious because I had this thing where I was like oh I'm not accomplishing anything...you know just bored because I never really had that thing [feeling of not accomplishing anything] before so...I had a few that I was like close friends with they would come out and visit...it was nice to have something you know, something happening...Like a social time or something... I also spent a lot of time visiting relatives, which was nice because um, I hadn't done that you know in quite a few years.

She recalled that she also availed herself to the support of her outpatient nurse who assisted her to make changes to her lifestyle over time stating:

I would, come in here [the outpatient clinic] right once a month so she would always give me ideas and you know always asking about my progress...Always like so what have you done, what did you try, how did you, you know what did you think of it, how did it make you feel...?

Laura described that she "lost touch with a lot of my good friends when I was trying to recover... which I totally regret more than anything." She did however resume friendships 
with them stating "they help me with my recovery in a way I guess sort of never

imagine...their just supportive, very supportive. " Laura also recalled a number of individuals

that were supportive of her recovery:

I guess that they're focus is the same as my focus, that I do recover. And that I am recovering. Like we're all on the same wavelength. We all want the same thing, so that combination of like my family, clinicians, me, and my friends, all wanting the same thing that is like a huge boost and its just in my recovery.

Leah described the support her sibling provided by helping her find flattering clothing to hide weight gain that resulted from the medications that she was taking:

...she's like really good at flattering people but without like sounding insincere...Like she...made a whole description of some people with soft fat and firm fat and she's like you have firm fat so you look good and then she like helped me dress up and stuff like after I switched medications I finally became interested in the way I looked...

Sandy and Linda became involved in an outpatient education program offered

through their hospital. The program not only offered them the opportunity to meet other individuals who had a similar illnesses, but also provided added structure to their day, as well as opportunities for social and interpersonal skill development. Sandy described the beneficial aspects of the program:

...at [name of program] I eventually made like some friends with my best friend...I saw the people who had similar problems. I mean I think that quite a few of them, um they were just like me had trouble making friends in the beginning of our lives...I think that maybe at first we had trouble making friends with each other but through activities, the social activities and the recreational activities, like we played badminton together and uh and uh since we go to class together we had basically the same schedules and time table...

Leah continued to see her art therapist after she was discharged as an inpatient from

hospital. Her art therapist commented on the support she was able to provide to Leah, as well

as Leah's active involvement in seeking her support:

...whenever she comes to see me I'm at the next stage with her and ah the goals of art therapy have changed to accommodate that and I think that's maybe what's important and beneficial, just...she can probably count on, ah, me to sort of accept her and be non-judgemental and just sort of accept where where she's at. And you 
know celebrate with her, I mean, she doesn't come to me when she's in crisis uhm necessarily. She comes ah to me when she has good news. And I think so often the system, the so-called system is about crisis intervention more so than celebrating achievements and accomplishments. I think that's an important part of the relationship that Leah and I have.

As participants re-engaged in life they reached out to individuals that supported their recovery by providing them with social interaction, structure to their day, and encouragement. They sought to establish or re-establish personal relationships with family and/or friends that for some participants were missing during the acute phase of their illness.

\section{Reflecting on the past: Changing their ways}

Participants' perceptions of what may have contributed to their illness varied. In light of this, at this point in their recovery process, they re-evaluated their lifestyle. Regardless of what they believed contributed to their illness, and however difficult, they vowed to change since the perceived cause specifically, drugs, stress, and/or lifestyle compromised their capacity to feel better. It would appear that participants' acute symptoms were under control when they decided to change certain aspects of their lifestyle. As a result of their commitment and follow-through with the changes, I believe participants felt a greater sense of control of their recovery.

Six participants drew on the trust they had built with family, friends, and/or clinicians, considered their advice, and made the choice to stop using drugs. After continued discussions with his psychiatrist, family, and friends, about the detriments of marijuana, John stopped using drugs and stated that he will "never do marijuana again", and he "might be able to [have] alcohol when I recover...but never do marijuana." He also recommended that others not use the drug. Leah stated the "longer I've stayed away from it [drugs] the better I feel." Steven stated that his psychiatrist informed him that "marijuana is 3 steps forward and 5 steps back and its completely true... he gave me that insight, I felt connected, and I never 
thought that there was really any disadvantages but definitely is..." He also identified that

the health teaching provided by his nurse helped him to understand the impact of drugs on

brain chemistry. As he recalled:

I never thought that there was really any disadvantages [to smoking drugs] but a lot of people didn't explain it to me when I was in the hospital, I had a really nice nurse and she talked to me about dopamines...I didn't know that you know that it increases and neurotransmitter and all that...Didn't really know about that so I got a little insight about the whole chemical thing.

John believed his prolonged drug use caused him to have schizophrenia. As he stated:

“Marijuana caused it [schizophrenia].” Other participants, such as Henry, were uncertain

about what was causing his symptoms but eventually listened to his girlfriend, who believed

that drug use was contributing to his illness symptoms. As he described:

...I realize now that it was just a waste there was no sense in doing that [smoking weed], it just made everything worse for me, and like I didn't wanna, at first I didn't wanna believe that like like it was the weed doing it [illness symptoms]...I was like you no it would happen anyway you know, like I wouldn't I wouldn't actually say that yeah it's because I'm smoking that's why it is happening, my girlfriend kept telling me that and I didn't want to believe her either I was like, no it's not, it would happen anyways you know, but then after I just said you know...it's not me doing it, I don't know what's doing it, but it's not helping me so I might as well just stop. I listened to her...

Changing lifestyle habits was not always easy for some participants. Henry recalled

that he continued to use drugs while on medication, which he later regretted, and how he was

able to eventually decline the offer by his friends to use drugs:

... when I first when I first like started taking the medication, and stuff then I would go out with my friends they would have like drugs there...I would smoke weed and that just makes everything go right back down the drain, it wasn't good at all... Like if I could I wouldn't of done it, if I could take it back, I wouldn't have done it...sometimes maybe friends and stuff that will tell me no like it's okay to smoke up or something like that so then like even a friend that like [name] you know he's helpful, not helpful would be some of those types of friends like I still have them, I just don't don't listen to them because like I've known them for a long time and stuff like that, and I do know they're trying to convince me but I say naw, I don't do that [use drugs] anymore... 
What struck me about Henry's re-collection of this circumstance was that he was now able to resist the peer pressure to use drugs. His sense of self was now strong enough to decline this offer, whereas before when he started taking medications, he still joined his friends in their drug use.

I believe that some of the participants were able to draw on the trust they established with clinicians and took their advice to stop using drugs. Others made this choice or consulted with friends. Regardless of who they consulted, it was clear that recognizing the negative influence that continued drug use was having on their recovery, and making the choice to stop drug use was a milestone for many participants. It is worth noting, that these young adults were able to make choices to support their recovery (e.g., stopping drug use) despite the tendency to engage in risk taking behavior which is sometimes characteristic of emergent adulthood (Arnett, 2000).

Apart from drug use, other participants had different views of what may have contributed to illness onset. Carly recalled a discussion she and her psychiatrist had regarding the role stress plays in illness onset. As she described:

...the doctor said to me that you're know certain people, everyone reacts to stress... every person's body reacts to stress differently and it's like, you know like people can be like pressure cookers, eventually if you, if you give an individual enough stress um, something will crack...And people react to it in different ways. Some people have you know delusions and psychosis, some people have depression... and bad feelings, some people anxiety... and basically he said that you know, the type of person that I am that's how I react to um, you know to that kind of pressure I have, I go you know psychotic...

Furthermore, she now understands the importance of managing stress as a method to prevent another episode from occurring. As she recalled:

...stress is a major factor so if, if you're having a episode and you don't give yourself, and you don't allow yourself time to recover, and to completely recover... and to get your mind... and your body sort of strong again and in sequence again, then you're really vulnerable to it... So it's important to you know, to get real strong again... 
Linda also made the connection between stress and illness onset when she said:

I went to classes too...that is more stress for me because working full time and at the same time I have to go to the class. And I couldn't sleep 3 or 4 days continuously, because I was always studying... that's why I got sick.

Following the onset of her illness, Linda began using relaxation techniques, such as going to the gym that also improved her sleep pattern. Leah suggested that it was a combination of life circumstances and a chemical imbalance that contributed to her illness when she stated, "for me it just wasn't the chemical imbalance. There was also a lot of things that were happening in my life...that sort of screwed everything up...you've got to look at the whole person." She also commented on her chemical imbalance when she stated:

...it took me a while to admit it was a chemical imbalance... honestly cause when you're sick it feels normal for you...but ah and that dopamine is actually good for you in normal quantities cause I heard somewhere like a lot of people who were schizophrenics have too much in their brain...that's what make you think too much and cause I used to think about satellites and space and stuff and like that I used to think they give us [name of disease] or weird things like that's more like [type of] conspiracies...the little bit of it is good cause I went from having too much of it to having none of it when I as on [name of medication] because it completely blocks the dopamine receptors in your brain and that's far as I know I might be completely wrong and then I went from [name of medication] it lets a little bit of it... so I have a normal amount so I'm like happy now...

What I found interesting about Leah's comment was that she did not refer to herself as "schizophrenic" but to others who were "schizophrenics". In reviewing my memos, I wondered what may have contributed to this exclusion; could it be attributed to how she viewed herself and the illness? Perhaps it was because she did not strongly associate her illness with her sense of self. Leah also commented on how she is now able to manage the stress in her life:

I just find that I'm getting better at figuring out when I'm under stress. Whereas, before I couldn't always tell I was under stress, I would be like irritable and high strung or something and wouldn't, wouldn't...couldn't figure out what it was. Sometime, I just find if it's something that I don't know what's going on, like I don't know what's causing me stress, Like I don't know what's sort of triggering it, then it kind of goes into psychotic symptoms, cause I just get, I just get like really high strung 
and so but uhm, I just what I try to do now is just reduce stress as much as possible and just like work on that instead and try to figure out... like, like people around me. Like I find it's normally... what will cause me stress that will cause a psychotic symptom is something that somebody is doing something that's really bothering me, like if they're stepping on my boundaries, that is what will trigger it for me.

Furthermore, she acknowledged that she:

...didn't used to talk to people as much about stuff, I used to get really frustrated about things and like blow up and stuff like that but now if something upsets me I just talk to people it and get different opinions about it.

What I found noteworthy, admirable and courageous was that participants seemed to undertake a re-evaluation of their lives at a time when they were in the midst of overcoming an illness. They were not only recovering from the onset of illness but also choosing to make lifestyle changes at this time in their lives. Steven recalled that his case manager taught him that "letting go...can be really a good thing. So like letting go of old friends, and old habits." Carly commented that the illness "sort of forced me to stop and to slow down and to sort of re-evaluate... what was important to and adjust my own health. " She added:

...when I got sick when I was having you know, psychosis... I was having like previous to that I think what drove it like I was really, like I was having some really poor habits, concerned with my health ... you know just being under too much stress and not sleeping and uhm, not eating properly I used to be really, I was really thin and one point and like really pale and just I was living on my own and I wasn't really at the time very connected to my family...I'd been off on my own...I was so busy you, you know I was so busy doing my own thing um, but not really taking care of myself you know... So a lot of that I think contributed to it and so it's been, it's not something like recovery from um, you know from, from mental health issues but it's, it's been like a really life changing experience for me...Because I had to learn, I just, it was almost like starting all over again.

Henry described that although he still associated with friends who used drugs and alcohol he made the decision not to. As he recalled:

Like you could still have a good time without drinking...or anything like that...Cause like that will affect you and you know it will but just because they're your friends and they're telling you to do it you are going to want to do it a little bit. But like you shouldn't make that affect you because like I'm still hanging around some people that like smoke weed and stuff like that but I don't do it anymore they just call you like who you sober you're sober. But like I don't have a problem with it anymore. 
Reflecting on their past and changing their ways appeared to be a milestone for participants. During this part of the recovery process they re-evaluated their lifestyle, reprioritized what they considered important, and made the decision to change what they perceived had contributed to their illness. They also made lifestyle changes to help reduce the risk of re-occurrence. While sometimes challenging, participants were able to draw on their sense of self and support structure to help them overcome obstacles to their recovery.

\section{Getting on with Life}

Once their symptoms were being managed, participants began to view them as less intrusive and were then able and determined to focus on resuming activities and formulating short and long-term goals that reflected their interests and promoted independence. With the support of others, they set out to accomplish goals that were reflective of their developmental phase of emerging adults. These goals were typically centred on work and/or school, and living arrangements that helped them to get on with their lives. Furthermore, participants saw setting non-illness related goals as further evidence that they were recovering.

All participants identified goals that allowed them to have something to strive for as they re-engaged in life. For the majority these goals were not overshadowed by the illness nor were they illness related. For example, Leah described that she wanted to "learn how to budget." Most importantly, as participants set these goals they continued to believe in themselves and their own abilities. Carly had a sense of determination in wanting to resume her life stating, "I do want to recover...its important to me...to get back to the place where I was but you know do it in a way that I can keep up that balance."

For Sandy, "independence, and self-esteem and confidence" were important goals to achieve adding that "when you've got schizophrenia like you're dependent on others... when you're sick they tend to make decisions for you sometimes. Because... like you're not able to 
make the decisions." She added that for her recovery meant "that you're able to now to resume to start doing things on your own again." Sandy's mother also stressed the importance of her daughter having goals in life as she described "...she has to have a goal...that's important, she has to have a goal, something to look forward to."

For the majority of participants future goals were not limited by the illness. For example, Curtis acknowledged that he was not going to let his illness control him, but rather he was going to control what was going on in his life. He also commented that everyone around him was:

...kind of letting me stand more on my own to feet...let me do my own thing, and me control everything and plus I'm also [in my late teens] and time to become a man... You're you're able to do all all the things you wanna do. Like go to school, like go to work um be able to excel in it and do the best that I possibly can. Uh like there's no need like to withdraw from anything. No time taken to go to the hospital ... and Dr's [name] talk about like we never talk about crisis anymore...talk about how well I'm doing...how's school going.

Laura also stated her determination to resume her life activities:

...even though I was diagnosed when I was [in my teens] and I'm [in my twenties] now that uhm my goals my goals and my efforts are still...still gonna to be pursued. Like the illness is not going to conflict with them, so I mean like for school and volunteering and trying to you know be a better person and not let the illness take over.

In light of this, Laura stated:

I had a lot of contacts since I have been in the hospital like [name of outpatient program] and... [name of hospital] and my parents were also very supportive, I started going to the [name of recreation centre], I started volunteering at different places.

As she began to work on her goals she highlighted the importance of having a structured schedule to her day:

...I was starting to get into that routine so at home when I was out of the hospital and back at home I was uhm out of the house from 9:30 to 3:30 every single day. Uhm So I had to find things to fill my day. So I started volunteering at different places. I started working on my goals, I started meeting new people and uhm I started moving around the city more often and getting to know [name of city] better and just being on 
my own and doing things that helps the community and trying to get jobs and I'm still doing that even though I'm not at the [name of] residence any more. I'm still out there, you know, getting things accomplished every single day and that's a huge part to my recovery that I'm not kind of at home all the time just dwelling on you know either depression or illness stuff. Like just I'm out in the world doing stuff.

For other participants, their efforts to resume their lives and goals centered on securing a job and establishing future career plans. Carly recalled resuming her interests as well as expressing the desire to find a job:

...so I guess I sort of you know changed, you know, gradually, like probably by the summer like, basically by um, during that spring I started to feel a lot better, I was taking some cooking classes and starting to see my friends again, um, that's when I started thinking about okay I'm really broke, I have no money, I don't wanna be asking my parents for money (laughing)...So thinking that I wanna get a job...

Although initially worried, Carly described how pleased she was in her ability to find a part-

time job. As she recalled:

...it had sort of stress me a little bit when I started thinking okay am I ready to go back to work, am I clear headed... and it's funny because you know I'm [in my twenties] and I'm just thinking about, I talked to the doctor about how I wanna try to get a low key job, I wanna do something that's not too stressful, I'm only going to work 25-30 hours/week just to start... I started handing out my resumes to different places and looking around to see, but I was actually like concerned just, as an individual like, um, you know, I am a grown-up and that's a hard thing can I handle a part time job you know? but um I went, well they called me, and I went and met with the owner and he was a really great guy and he's really nice and I talked to him and said I did really well in the interview and he hired me right on the spot...so that was just a really good feeling for me because that was sort of the first time after...the whole drama had happened it was sort of like the first time I had made a really big step...I was saying to myself that like, okay you are, your recovered enough to impress this guy (laughing), he wants me to work for him.

Laura also discussed her focus on finding a job and the activities she was involved in, so she could achieve this:

I'm kind of more focused on getting a job at the moment so I've been attending [name of community centre] and I'm going over my resume, and I've participated in a resumé seminar and...uhm and uhm and so now my resumé is up to date and all I have to do is go out and try to find a job. 
Michael commented on his desire to begin looking for work. As he described: "In the future some time like when I get a little, like when I get a lot better. Like when I like don't hear any voices at all and at any point then I'm gonna start, I'm gonna start looking for a job or I'm just gonna." Steven stated that he was busy in school and work: "if I'm not at work I'm you know studying. Like not even in school, I'll be studying like stuff, like towards my future." His mother also stressed the importance of having goals concerning school and work and being motivated to accomplish the goals as she described:

...having a goal for school and wanting to work and knowing what he wants to do after. Uhm that's the key, having the support, having his family support as well and having a goal and being motivated, being motivated... you know wanting to get over it and wanting to do something with your life.

What also emerged was the importance the support of clinicians played in helping to set and encouraging participants to achieve their goals. For example, Curtis' psychiatrist recalled that one of the main goals they established in working together was to assist him with getting re-connected with school, mainly "psycho social rehabilitation...getting back to school, taking things at his [Curtis's] own pace." Leah's art therapist recalled how Leah's future goals related to independence were reflected in her art work:

....she likes directives sometimes...I think once I gave her a directive, the ah new Lisa and she drew somewhat of a self portrait and ah that reflected her independence and working and things like that and talked about having having money and what that meant in terms of buying new clothes and maybe she's older now and should buy...ah wear different types of clothes.

Laura's case manager underscored the importance of creating small goals during recovery, because as he described he thought: "a lot of people [recovering from a mental illness] have issues around self-esteem, self--identity ah and being able to achieve small goals goes a long way. And then it allows an individual to feel good about themselves and then being able to take on bigger tasks." He also added that with respect to Laura, this meant her ability: 
... to structure her day, being able to identify goals that are important to her, in particular taking writing courses, art courses. Now making that transition to independent housing and ah now looking for work...

It appeared that this treatment approach highlighted his belief in the importance of selfesteem in order for participants to move on to achieving other desired goals.

Sandy recalled the support she received from her outpatient therapist, who she described: "[name of therapist] thought I was ready and recovered enough to go back to school and work or work. Most likely school, cause at that point...so I still had a negative attitude towards work. So school was better." Leah's art therapist described how she supported Leah in meeting another one of her goals, namely, the transition from living in a group home to living on her own. As she recalled:

...there was another transition in Leah's life, she was going from the group home to living in ah...I think she rented a room in someone's home. So I was with her while she went through that next ah transition. And she was working at that time. Uhm, so that was the theme of art therapy at that that point. She still did the very same art, it was, uhm, flowers and hearts and ah kind of craft things and the goal at that point was to make ah pictures that she could put on her wall in her house to decorate in her house...

In reflecting of what I know of past clinical experience this is a clear change. It would appear that expectations that clinicians and clients have has increased. Specifically, that the possibility of returning to school, gaining employment, and/or independent housing once not even considered an option for clients who had a mental illness are the realities of their recovery process. Clearly, for this group of participants achieving these types of goals were critical to their recovery.

In summary, resuming life's activities by establishing or resuming their identified goals was important to their recovery as it provided some participants with a mechanism to build self esteem and foster independence. With the support of their clinicians, participants set achievable goals that enabled them to get on with their lives. 


\section{Challenges to Recovery}

Participants recalled various challenges they faced through their process of recovery. Some participants described their unsuccessful efforts to re-acquaint with friends they had known prior to their illness. Others shared stories about the effects stigma had on their friendships that seemed to reinforce that participants' reluctances were justified. Many also described a need to be viewed as "normal" and to lead a "normal" life. Some of the participants expressed challenges in re-establishing their independence, and described unhelpful interactions with family members.

Carly described her concern about re-acquainting with a friend who was previously intertwined in her delusions; she was uncertain of how she would respond to her should they meet again. As she described:

....sort of a year after you know, I've had all my symptoms and everything like that and I was hanging out with just a small group of friends and I had one friend who was close to me but um, we were actually she's one of my oldest friends um ... she made a few sort of snide comments in front of my friends about like 'oh is that where you went crazy and you thought that this was happening and this was happening?' And it sort of really, like it really sort of um, you know, it's really sort of a sensitive subject at the time and it really sort of hurt my feelings...I don't know if she was even meant it or was just being caddy or you know, the way to put me down I'm not even sure...those kind of things are particularly like, it's just sensitive...like that's just really unsupportive thing I guess and it just makes you not wanna, you know...cause the thing is, the reason that she even knew about it is because you know, I had told her things or confided in her you know...it just really makes you think...you have to choose your friends wisely...

Steven also experienced a similar reaction with his friends describing it as "a risk" in

telling them about his illness. As he recalled:

...even when I did tell my friends, I didn't tell them what I have, I just said I had a psychotic episode. And ah I told a few people that and I even explained to them like it's a risk for me to be telling you this, it's a real risk for me to be telling you this because I know uhm that it's something that is something that isn't easily understood. And I don't know what you're going to do about it but I felt I should tell you... At the time they were you know very supportive and they sympathised with me and all that and then they'll just like disappear. Like I'll call them, they won't pick up the phone and I what I think happened they would go off with other friends and it's obviously 
just kind of slips out or they tell people. It's kind of an interesting subject for people who don't know what's going on oh yeah psychotic episode, and ah I think people definitely say woh, like they just jump to conclusions, he's crazy, woh he's probably dangerous or something and you know they just want to stay away from you like... as if as if it's transferable, like contagious. And I think people just try to avoid...like even their parents probably, oh really oh you should stay away from him...

Steven also described his need to prevent people from pitying him due to his illness. As he recalled:

...I don't want...people to treat me like you know with pity and all that kind of stuff. Like oh 'I feel so sorry for him.' You know, I hate that...I don't know it, it just it's a different dynamic when people, people are like, 'oh yeah he's been through so much'...I don't want people to you know 'oh, go easy on him eh,' 'he's got this and that.' You know what, 'he might freak out or he might you know try to kill you, he's he's gonna be a psycho' and all that shit...like I really hate that like....like there's so many people that are so uneducated right, it's like...I heard a song the other day it's like talking to myself like crazies do. It's just something like that that really bugs me...like maybe like the criminally insane, that's one thing. But like most people that have gone through psychosis their not, their not aggressive or violent people. You know they are...just regular people who you know, whether it was genetics or whatever it was that happened and not much they can do about except to make sure it doesn't happen again.

John described how having a mental illness had affected his reputation with others:

...When you're mentally ill they will still greet you the same way right but when they talk to other people they'd be like this guy is an idiot and everything, he has a mental illness and you know...

While some participants attempted to re-acquaint friendships, others were selective in whom they approached. An inherent feature of re-visiting their relationships was the need to show others that they were "normal" and did not appear to have an illness. As John described:

Now I'm more like normally, back to normal. Right? So they [friends, family] can't say that I have schizophrenia, you can't even tell that I'm schizophrenic right. Can you? You can't....right that's what I'm saying, no one can say that I'm schizophrenic... 
Curtis also stressed the importance of ensuring that others did not know about his illness. As he described: "it's not anything that anyone has to know...of all my friends I think yeah only one of them knows." Curtis, felt reassured knowing his illness was concealed as he described: ...coming to a point where...you are aware of the fact that that you have an illness. But you also aware of the fact where uh it doesn't affect you and uh daily life and like your symptoms don't really appear. So no one knows unless you tell them. Like I know me, if I never told anybody you probably wouldn't know. That sort of thing (Pause). Uh it's also partly because I am so young....

Linda also described “my parents don't like to tell others I got [an] illness. ” Her

father also stated that he was selective with whom he would discuss his daughter's illness.

As he recalled:

...our relatives back home we met on the way and we were talking and the way she was looking at my [Linda] is quite different because, because of the medication or something... I didn't want to say she is not well or something like that. I don't want, that is not the issue, I didn't say she is not well. No, no she is ok. She's a normal like that and we just finished our conversation. She is walking in another direction, and we are going in another direction...we should not go and tell her, you know, that is what happened, like that. So they don't need the details of it.

Linda also discussed what her recovery would mean and underscored the notion of becoming "normal" again. As she described recovery for her would be "improvement in my health...because I have mental problems...becoming more...like a normal person, like a student doing everything..." I wondered what is contributing to the need of being perceived as being normal again, after a mental illness, and if other individuals experiencing first episode illnesses have a similar need.

Some secondary participants also used the term "normal" in the context of determining if someone is recovered. Steven's mother commented that one can tell if a person is recovered when "you can look at him and he what's you know looks like a normal person, so to speak. Someone that is working, someone that can go to school, is able to 
learn." John's mother also brought up the idea of looking "normal" as an indication that her son is in the recovery process. As she described:

...When compared to the stage when he was having sickness, and there are lots of differences now lot of differences now and now by looking at him, nobody could guess that he is suffering from a mental sickness. He behaves like a normal person.

She also expressed her desire for her son to think less about his illness and more about the activities he enjoys as she described what recovery for her son would be: "to get away his mind from this affliction or disease and to occupy his mind in activities like watching the TV or ah going to work and he could lead a normal life."

In reviewing my memos, I wondered where the importance of others not knowing about a participants' mental illness stems from. Why was concealing important to participants? Was it related to the participant's age? Did the age of the participant influence how important it was for them to keep their illness a secret from others? I wondered if participants did not want people to know about their illness because they believed it would impede their ability to reach their goals. Or was it due to the pervasive effect of stigma associated with mental illness. I believe the need to be or appear normal in the face of having a mental illness, highlights the prevailing stigma associated with mental illness which I also view as a challenge to recovery. This led me to question how this need to conceal their illness affected their sense of self, why is it that once an individual has a mental illness they no longer consider themselves "normal?"

Another challenge some participants faced as they recovered was gaining their independence. A number of participants were living at home with their parents as they recovered. Overall, this situation was viewed as supportive but seemed challenging since their developmental drive for independence was compromised. Sandy believed that her 
independence and desire to live independently was threatened because of her illness. As she described:

...when you've got schizophrenia like you're dependent on others ... when you've recovered you've gone through the process of recovery you become eventually independent...I'm not...I don't consider myself to be independent because I'm still living with my parents but eventually I think that I know that I will be independent in the future...

Furthermore, she stated: “...after all... I'm in my 20's and most people when they're in their

20 's, mid 20's are on their own." Although she had this desire, Sandy also acknowledged her

fear with being independent:

...what I know is a life being dependent. A life being dependent. I don't know what a life is like being independent...At the same time I do fear it, some aspects of it...Well I know that with freedom comes responsibility and uhm being able to deliver things that you have time to clean up after yourself, to do laundry, to cook for yourself, to handle your finances, being able to do two at once managing it. Like it raises your self-esteem. But uhm I think what scares me...I think...that scares me the most is what if I am living on my own and I fail and I have to go live with my parents again.

Similarly, Carly recalled that although she had the support of her parents by moving back into their home, this was difficult for her as she was living on her own before she became sick:

...I was living with my parents it was a nice change... Because you know to have company there and to have your family around but they also both, like a big thing for me was like they also have full-time jobs...You know and their gone all the time and you know, so it's like, I'm in this big house by myself... So that, that, it took me maybe probably like 3 or 4 months to really get used to that whole idea. Um...it was, it was difficult...

Steven's mother commented on the benefits of living at home in helping to manage her son's illness despite his age:

...now he's still at home, he's [in his twenties] ... being able to do the right things living on his own. That would be interesting for me... Well because he knows what he has to do, but will he take the time to rest, he needs lots of rest he needs. At home he's got the routine, he's got his privacy, he's got his space where he can go and relax and nobody can bother him, a smaller apartment and maybe living downtown would be noisy, maybe too many distractions. 
However, she also hoped one day he would be "independent."

A final challenge faced by some participants was the "unhelpful" interactions they had

with their parents at times. Laura described:

Well sometimes my dad is not very helpful, he was...we...get along sometimes and sometimes we don't and when we don't it's really bad, we get into a lot of like huge fights and uhm we just yell and scream at each other and at one point I was living with him and I ran away from home and I didn't know where to go, do I go to the hospital, do I go to my mom's and and I eventually decided to go to my mom's and I said to him I'm living at my mom's now and I'm not coming back. So that dynamic was really unhelpful that he wasn't being a supportive father in provoking, your provoking me, your provoking someone with an illness you shouldn't do that.

Leah described that her relationship with her mother was unhelpful during her recovery:

...sometimes I get annoyed with my mom because like every time like like when I was still like recovering and when I was still on [name of medication] I used to call her up and cry sometimes and she'd be like did you take your medication and I was like I'm just not my medication like I didn't find that very helpful like like it was helping but it was like um sometimes when I'm emotionally a wreck it's just like it's not just that didn't take my medication or something it's also like something's in my system that I need to get out.

She suggested a similar unhelpful experience with her boyfriend when she added: "he tried to help in his own way but he wasn't very helpful because he was like there's just too much tension between the two of us." She went on to say:

...we actually broke up but then uh I gave him a call when I was in the [name of the psychiatric hospital] and when he found out I was in the [name of the psychiatric hospital] and he kind of felt bad for me and we got back together but we only got back together for a few months...I just found it really stressful cause he was still not working and still like that... he has addiction issues and stuff like that...

Curtis described that certain interactions with his father had also been unhelpful to his recovery especially given that Curtis is ambitious and wanted to pursue new activities. He recalled his father's response when he suggested: "I'm like ah dad I wanna do this I wanna do that, he'll go oh don't take on too much you know." Furthermore, Curtis recalled that his father was not encouraging at times "every time I wanted to do it was a no and then I just 
started thinking you really can't do much right. I was thinking that at one point (Pause)...I

don't pay attention to those things anymore."

I wondered if these unhelpful interactions were related to the developmental stage of emerging adulthood, or were they a consequence of the illness. Were the tense interactions with parents at odds with the features of emerging adulthood, specifically with these participants trying to assert themselves as adults?

\section{Summary}

Participants were encouraged and strengthened as they realized they were getting better. They were inspired and began to re-engage in their lives. They sought answers to the questions such as what may have contributed to their illness, and what was important to recovery. Furthermore, they were committed to making necessary lifestyle changes in their lives. They began to resume their life goals, and engaged the support of others, highlighting the fact that their recovery did not occur in isolation. They were also able to describe challenges they faced, such as changes in their friendships that occurred as a result of stigma associated with mental illness, their struggles to attain independence, and having unhelpful relationships at times. The phase to follow will describe how participants envisioned the future while continuing to meet ongoing challenges. It will also show how some began to question the need for continued treatment as they were increasingly aware of their overall improvement. 


\section{Envisioning the Future \\ "I've learned more about what I want for my future" (Carly)}

\section{Overview}

Participants reached a point in their recovery where they were able to resume life beyond their illness and envision their future. In essence, they were more fully engaged in their lives and were increasingly hopeful and optimistic about the future. Participants were also able to engage in future thinking and identified long-term dreams they would like to achieve. Challenges to recovery such as fear of relapse seemed to emerge as participants experienced progress in their recovery. In addition to fear of relapse, participants were also concerned about the impact stigma could have on the future relationships and employment. Given that they were able to more fully resume their life activities, and perhaps in efforts to cope with the stigma, participants began to question the need for ongoing treatment as they strived to sustain changes in their lives.

The subcategories that characterized this phase were:

a) Future thinking - as participants worked to sustain recovery, their focus shifted from their illness to striving toward long-term dreams indicative of their development as young adults such as career plans, marriage, and starting a family.

b) Meeting ongoing challenges - as they resumed their lives, participants faced ongoing fears and challenges including fear of relapse, and stigma associated with mental illness. During this time they also wondered about what the overall impact of these challenges would have on their lives.

c) Questioning the need for treatment - as they continued to experience improvements in their lives, and possibly as a way to assert their independence and cope with fears of 
stigma, participants began to question the need for ongoing treatment and the nature of support required.

\section{Future Thinking}

Striving for long-term dreams such as career plans, marriage, and starting a family appeared to be important for participants as they worked to sustain their recovery. This was in contrast to the acute phase of the illness when participants were faced with illness symptoms and were unable to focus on other areas of their lives. During this phase of recovery, participants' goals were reflective of the developmental phase of emerging adulthood. John outlined his future dream:

...I want to [work in the financial field] ... Right now after I get cured, right, I want to take college, university, [number of] years in college and [number of] years in university...And after that, like after working at a good job in [the financial field] and I make lots of good money, in a couple of years, like 4 or 5 years... [and have investments]....

John's mother had similar hopes for her son: "I have the hope that he would recover fully and enter university." Michael described his dream: "I'd really like to go into working in [the arts] actually, like that's what I getting excited about..." In light of this, he wanted to try "to surround [himself] with only the stuff [he] likes to do" so he "could make money from it." Curtis described his long-term goal of graduating from university in four to five years with “two degrees not just one.” Laura stated that her “ultimate goal is to become a [language] teacher." She also stated that "she wants to go to school full time." Henry described that he is "probably gonna be doing an apprenticeship course [in the hospitality industry]." Steven described that he is "trying to find out what would be right for [him]" with respect to starting a business. He added:

I just hope that you know I, in the competitive business that I'm going into I hoping that I do you know, find some way in it and uh, do well at it, and you know, have, have things that people in their you know, mid 20's or late 20's should have like you know a home and you know, a family maybe... 
Once Sandy completed her college program she had aspirations of resuming her university studies as she described:

... when I'm done [college program] I plan on getting a job part time, I did a job part time...before I got sick, I started...the [name] program, a 4 year [name]program [name of university]. And uhm I want to go back there... and after I'm done at [name] College, I'm going to go back there part time and finish my degree...I'm hoping that with this education I am getting [that]I would get a better job.

Participants not only expressed their future career plans but also described their dreams concerning relationships, marriage, and starting a family. John stated: “... I want to start my own family." Steven voiced his future dreams:

I think once I move out on my own, I will be able to get back into the relationship world...some reason girls have expectation guys like [in their twenties] should be living on their own. Some girls are like you've got to move out of your mom's house, like you're still living with your parents.

Steven's mother echoed her son's desire to have a girlfriend: "I think the best thing for him is to have a girlfriend...someone who is really good that could help him go through life (laughter) that's everybody's dream I guess to have a partner." Carly's mother also expressed her desire for her daughter to have a "good relationship" in the future. Carly described her future goals of getting married, having a family, and career and wonders whether her illness experience has contributed to an added appreciation of her life goals:

I've learned more about like what I want for my future like if I think about you know having a family and stuff like that or getting married...I want to be the type of person who, you know can take care of my kids and you know be with my husband and that kind of thing like um...it's, it's almost like, I think that was a really big thing that I was missing before because I didn't think about you know I was like barely able to take care of myself right. So when, when you think of it from the perspective of you know you have a whole a family to be responsible for like, that really changes your priorities so much you know like because it is important for me to work and to have a career...I think I've really learned too that that those are the things that I want. I don't know if that, it's come out of you know my [illness] experience... 
Curtis also described his future desire to "get a wife, meet a nice girl." Sandy stated "It's something that I think about from day to day and it makes me feel depressed sometimes...I'm [in my twenties] and I haven't had a boyfriend yet."

It would appear that during this phase participants were able to envision their future well beyond their illness. Participants found themselves setting and exploring professional, educational, and relationship goals with having dreams that reflected their developmental stage.

\section{Meeting Ongoing Challenges}

As they resumed their lives, challenges emerged. For many participants fear of relapse was a concern, as was dealing with the stigma associated with their illness. As participants faced these challenges they wondered what the impact these challenges would have on their lives.

Over half of the participants voiced their concerns regarding fear of relapse during the interviews. For Carly fear of relapse was associated with having to put her life on hold again:

I think probably my biggest fear is that I'm gonna start having symptoms again. Which would mean that I think what it would really mean which is the scary thing is that I would have to put sort of my life aside again... I would have to change things like you know I'm, I'm really trying to refocus on getting my life back in gear and you know, so going for the goals I had before like graduating school. Getting a better job and that kind of thing you know potentially moving out on my as sort of a long-term goal again so um, it's, you always are in fear of like you know, I could wake up one day and be hearing voices again you know and that's, you know that's sort of the area of concern. I can always come back there [her outpatient first episode psychosis clinic] and I know they can adjust my medication...you know and we could talk through it ...So I know I have the support here [her outpatient clinic], but that's, that's always a fear you know.

Leah stated "I just get worried that's [symptoms of illness] going to come back." Henry described that his fear of his symptoms returning was associated with having to start over:

I don't know what's gonna happen tomorrow like if it comes back... Then I am doing the same process all over again. Basically not just in the process but I have to go back to the start...I'm not too keen about it...But it's just something I [would] have to 
do to recover and I'm willing to take those steps...Otherwise it...[would] just...get worse later on. And it's not gonna benefit anybody it's just gonna make matters worse...And there's no sense in doing that.

He added "there is always a fear and like it can happen again," however he acknowledged the progress that he has made when he stated "it wouldn't affect me as much as it did before." I suspect that his optimism was related to the supports and strategies that he has developed in managing his illness over the course of his recovery. Similarly, Laura also described the fear that she will “...have another attack again” but acknowledged that because of her progress she is hopeful that a relapse could be delayed. As she described, "I don't think that will happen any time soon which is good...that I'll have to go back into the hospital...because I'm recovering...I've just I've gone through huge transformations and I'm recovering. " John attributed the importance of taking medication as a way to prevent relapse. He stated:

I got to stay on it [the medications] for 2 years, right?... I'm thinking of going 4 years because I don't want it to come back again. I want to keep the medication for longer period, so I won't have to experience it again... Because I know what I went through at the beginning right, and if I have to go through it again, I won't like it.

Michael also described his fear of relapse and the ongoing need to take his medications, stating, 'I'm thinking like this could happen anytime... It's just a fear that if I stop taking my pills...If I don't stop taken them, I'm gonna be in trouble I'm gonna be in some serious trouble."

In efforts to manage their fear of relapse participants continued to engage in self monitoring of symptoms. Although participants described an overall reduction in their symptoms they continued to self-monitor for triggers and symptom re-occurrence. As Leah described, "I still have episodes, like I call them glitches. I still sort of like oh there's nothing wrong with me I just have a glitch once in a while you know. So uhm I guess like I'm I just find like that when I'm under a lot of stress." Michael stated that despite experiencing 
lingering symptoms he still continued on with his goal of finishing school. As he described, “I'm going to school anyways even if I do hear voices...Because like I'm, I'm [in my twenties] now I don't wanna have to be 30 and like go to school. " He did however acknowledge that despite encouragement from his clinicians to find a job he was not yet ready as he felt that his lingering symptoms may interfere with his ability to work. As he described:

...like when working with a customer or something I might start hear voices and, and I might get distracted...And then they'd be like what's wrong with this guy you know? So I don't really wanna do something stupid like that cause it's gonna interfere.

When commenting on her ability to self-monitor, Carly captured the challenges of balancing her life with stress and the risk of symptom reoccurrence. Overall, Carly is pleased with the balance that she has achieved:

I still have to watch so I have to keep myself in check and my mom knows too because sometimes I do like to go out with my friends and we get carried away and stay up all night... then I'll come home and be just you know exhausted and grumpy for a couple of days (laughing). So you know there's kinda stuff like that where I have to it's till I have to monitor myself...I have to keep myself in check and um, and I also, you know thinking about the next year and stuff I'm still trying to make sure like I wanna really plan, like I don't wanna get myself in a position where I'm going to be really stressed out or something you know, I'm going to leave myself vulnerable so I wanna make sure that I'm making the right decisions in terms of going to school full-time...so it's hard like you always have to um, you know, you always have to question things but I think I'm doing very really well which is good like I, I feel good... You know my mood is good I'm definitely you know my head has felt better than it has... in you know, over the last two years um, you know, I feel, I feel definitely clear and my emotions are balanced which is you know a good thing and generally up feeling... So that's really good.

Her mother also commented on her daughter's ability to self-monitor when she described:

"she's actually is better at watching herself watching when she gets tired, knowing when to slow down and knowing when she is you know, taking on too much." Steven's mother also acknowledged her son's ability to self-monitor: 
...he'll get little things when he's tired you know but he can ignore them, they are just that, he can just write them off. Well you know in the first year, no, he couldn't write them off. They were stronger.

Another challenge that participants met as they resumed their lives was the impact of external stigma on relationships. During this phase, participants appeared to see stigma as having a prominent and potentially lasting effect on their relationships. As Carly described:

I think that's probably the biggest challenge I had faced is that people, there are people out there that don't understand you know, that don't understand and I'm left, like I mean obviously didn't understand before it happened to me, so there really isn't you know, there isn't a lot of knowledge out there... Well I just think, I think psychosis and schizophrenia in general, like I think people um, you know, they have, they sort of categorize people as being crazy... and a lot of times that, that's a term that means well you have to write them off as like their crazy and that you know, and I just you know, won't associate them, or you know, they'll never be healed...Nothing else to them but their, their crazy... that's totally not the case, it's like you know people can have their crazy moments...And uh, can completely recover from it...

Steven described the changes to his social circle following his illness:

...they have not helped in any way, when do I meet my old friends from back then, and... We see each other and I, I just don't even, I don't even try with the people that I used to know anymore. Cause I know that their gonna meet them and hey I ran into him and next thing you know, 'yeah well he's got this and that and you know. '...People are treating me like I got [a type of disease]. Its just like I don't even care...About, most people in the past which a huge group of people, all my neighbours and everything...Moved on.

Steven also voiced his concerns regarding relationships should his future partner find out about his illness. As he described:

I mean if somebody was there... I don't really know how to approach the whole thing right now, I think it's like you have got to be really honest in relationships and I think if a girl found out exactly what I have had she's probably think twice. You know you have to find a girl that I don't know that would be able to understand that. I don't know I think people in general are sometimes pretty shallow about stuff like that, they just wouldn't understand or care to really understand. If the girl really, really was you know an understanding person.

Similarly, Carly acknowledged the importance of finding an individual who will understand what she has been through when she is ready for a relationship: 
I think it's just a question of waiting for the right person you know I think, I think it's really key because I also know I come along with all this other baggage (laughing) but I come along with this whole package of you know there's a lot...You know that's gone on there so you know it's obviously gonna have to be someone who's gonna understand where I'm coming from...And the kind of stuff that I've been through right?

Some of the participants also expressed uncertainty about the impact of external stigma on their future employment. Linda identified a future goal of finding a "career job" once she has completed her studies, however she expressed concern about the potential impact stigma may have on her job prospects. As she described:

I want to become a normal person like everything in my health and my studies and my work so...[I'm] always wondering to find a job after I finish my studies so maybe takes a problem I don't know... maybe a problem in my health to find a job, as a disability I don't know.

Steven also described his desire to earn his own living and his reluctance to rely on disability payments due to an underlying fear he had of being pitied for his illness:

...I really just wanna get out there you know. You can't accomplish much by you know, sitting on the couch... just wanna get out there, I don't wanna be another statistic you know... A lot of people that have illnesses are on disability for the rest of their life...Making seven hundred bucks a week and I don't know...I don't see myself doing that...And I don't wanna rely on it and I don't want...People to treat me like you know with pity and all that kind of stuff. Like oh 'I feel so sorry for him.' You know, I hate that.

To a lesser extent participants were challenged to resist the impact of internal stigma on their sense of self. As Linda recalled:

I am the one that gets mental illness I'm different from others because uhm that's a bad thing I think...Because I get ill with mental illness...we can't share our things... with other people because my [relatives], many people don't know I get illness. Only close friends, my [relatives] they know...my parents don't like to tell others, I got illness...I don't like to tell that too.

As I reflected on my clinical experience, I noted how their behaviour was similar to anyone who has experienced a major illness. For example, like individuals who are recovering from cancer, these participants were also concerned about the possibility of a re- 
occurrence. And similar to these individuals they used various strategies to reduce this likelihood. It was also apparent these individuals were deeply concerned about the impact external stigma could have on their future relationships and goals. Again drawing from my own clinical experience, there was a time when illnesses such as cancer and diabetes were stigmatized which has since diminished. It is unfortunate that in spite of the prevalence of anti-stigma campaigns for mental illness, the perceived affects of stigma continued to be a major concern for participants as they envisioned their future.

\section{Questioning Need for Treatment}

As participants continued to experience improvements in their lives, they began to question the need for ongoing treatment and the nature of support required. Participants continued to take their medications, however some questioned when they might be able to stop. As Leah reflected:

I'm hoping I can go off medications completely cause I uh like I was pretty normal before I went psychotic so I'm thinking I can get probably get back to that... he [her psychiatrist] said that I don't have to be on medication like my whole life he says I won't tell you that but he said for now you should be on medication I said I could live with that.

Henry expressed that although he recognized the need for medication he is waiting for the time when he might be able to stop. He had previously discussed this possibility with his psychiatrist and case manager:

... without it [medications] things can go like right down the drain like you have to start everything all over again you don't know how long it's going to take again. Like it might take you even longer because you stopped it you know cause you should just keep going at it until everything is clear complete. Then you can stop taking the medication and stuff like that like there will come a time you just have to be patient until that time comes.

Steven also expressed his desire to eventually stop taking medication:

...I think I want to reduce the medication though. I want to see if I can handle without it, about the same amount...I just don't want to believe that I have to be on medication for the rest of my life, cause I think if it they lower it, it might be harder to 
get used to it, but I think I would adapt, I would be able to handle it. Cause right now they give me the medication and I have like my own system for taking it cause I know what works best for me and I think I could find what works best for me with less medication.

Sandy's mother commented that her daughter reached a point where she was no longer taking very much medication as she recalled:

...it's [the medication] is very, very minimal. They've even decreased it this last week, this week again. She's doing much better, she said there's no voices around her, you know, there's nothing.

Similarly, Carly's mother stated that her daughter has reached a point where "she's still on like one milligram of [name of medication] and I think they were very, very, very slowly weaning her..."

In reflecting on my field notes, I wondered why in spite of all participants endorsing the benefits of taking medication to help provide symptom relief, some participants wondered about the need for taking medication in the future. Perhaps my lack of exploration with participants was reflective of my own clinical bias in my practice; that is endorsing the need to continue to take medication (even in small doses) as a way to maintain their recovery.

As they were able to sustain changes over time, participants commented on how the nature of their therapeutic relationship with clinicians evolved. For example, Curtis' outpatient psychiatrist commented how their relationship has changed:

I'm an observer now rather than an active therapist for him even, he is really been dealing with his case manager right now... but really the issues around medication, are pretty minor... ah so really I've moved into the background, I feel that I've done my work.

Leah's art therapist also noticed a change in the goal of their relationship as seen through art. She described:

I don't see her as an inpatient with schizophrenia, I see her as someone sort of developing still and...uhm so it has changed, it's a little professional, of course, but a 
little more uhm relaxed, it's not as structured any more, you have an appointment at this time. It's whenever we meet we sort of catch up with what's going on in her life.

Laura's case manager commented on how over time his relationship with her has changed:

"They [clients like Laura] become their own case manager, they identify their own goals, they achieve their own goals, they problem solve, ah they're not in crisis..." Steven commented that he felt optimistic about leaving his outpatient clinic “...now that I'm kind of past the recovery stages, now there kind of like yeah, I think they're [name of outpatient clinic] waiting for me to leave this place. Ah I feel pretty good about that."

Although the majority of participants welcomed the change in the nature of their clinical support, Linda expressed her worry of being discharged from an outpatient psychiatry clinic and being left to be followed by her family doctor who was not as specialized in mental illness. As she described "the psychiatrist is good because I have a mental illness right...so if it's my family doctor that's different, they don't know so much [about mental illness]. " In reviewing my field notes, I wondered why only Linda expressed her concerns about being discharged to the care of her family doctor. Was she less certain about sustaining her recovery without the support of specialists? Or was this based on her previous experience whereby her family doctor did not adequately provide her with the care she needed at the time of symptom onset. I believe it was related to her lack of confidence in the skills of her family doctor, given that she did not receive the necessary help when she and her family first went to him.

\section{Summary}

This phase served to highlight how participants envisioned their futures. In doing so, participants described their long-term dreams concerning career and long-term relationships in the context of resuming their lives as young adults. Having identified these dreams participants met challenges such as fear of relapse and confronting the prevailing impact of 
stigma associated with their illness. As participants were more fully engaged in living their lives, they also questioned the need for ongoing treatment and support from clinicians. The following phase describes how participants experienced a reshaping an enduring sense of self throughout their recovery process. Although they acknowledged aspects of the self that endured participants also described changes in aspects of themselves that occurred as they were recovering.

\section{Reshaping an Enduring Sense of Self}

"I'm recovering. I've gone through huge transformations and I'm recovering” (Lisa)

\section{Overview}

Participants described a reshaping of their sense of self as they experienced their process of recovery. This reshaping of an enduring sense of self occurred to meet the benefits and challenges associated with the illness that was central to the process of recovery. This phase can be defined as the core category that, according to Charmaz (2006), subsumes all other categories. The core category reoccurs frequently in the data and relates meaningfully and easily with other categories (Holton, 2007). Reshaping the self involved a complex process of affirming the characteristics of self that were of value and constituted strengths, while simultaneously recognizing the need for change in other aspects of the self. Reshaping the self seemed to occur through an ongoing process of self-reflection that allowed this process to occur.

Although they acknowledged aspects of the self that endured, participants also described changes in characteristics of themselves. By identifying these changes they were able to contrast how they were in the past to how they are currently, and in doing so recognized that they had matured through the process. Participants also identified key aspects of themselves that helped them through their journey towards recovery and were able to 
describe what others valued about them. As participants sought to understand their recovery experience, they also engaged in a self-reflective process that served as a tool in their being able to offer (when asked during their interviews) words of wisdom to others who may be experiencing a FES. Furthermore, they also discussed the importance of hope in their recovery.

The subcategories that characterized this phase were:

a) An enduring sense of self - is reflective of the enduring aspects of themselves participants leveraged through their recovery process, and the valuable insights they gained related to their sense of self. Participants also identified traits that others valued in them and the challenges they faced in order for their sense of self to endure.

b) Growth through recovery - many participants used the recovery process as a "call to action" when they developed new skills, made better choices, and developed more fulfilling relationships with others.

c) Enablers for reshaping an enduring sense of self - refers to personal qualities, beliefs, and approaches that facilitated a reshaping of the self throughout their recovery process.

\section{An Enduring Sense of Self}

Participants reflected on their recovery experience and commented on the valuable insights they gained related to their sense of self. The majority of participants identified enduring aspects of themselves that they leveraged through their recovery process connecting who they presently are to who they were. Frequently these valued traits were positive in nature and were described as strengths thus supportive to their recovery process. Participants also identified traits that others valued in them and the challenges they faced during their recovery process. 
Participants described traits and strengths within themselves that endured and helped them during their process of recovery. For example, Henry stated that he is "a positive thinker even before, even before I took ill." Steven described his ability to work hard when faced with tasks:

I've always done pretty well in things that I've enjoyed...in school now I'm enjoying what I'm doing and I put a lot more effort into it. And uh like when I enjoy something and I feel like I'm getting something out of it, I don't care I'll put tons of hours into it and then the final result is what motivates me...

Similarly, Steven's mother drew attention to this strength when she described his ability "not to walk" when faced with a challenging task and his perseverance to return to school despite struggling with symptoms when she stated:

I guess he was still having hallucinations or visions so that when he was in school he would do a presentation and he had voices. He would be on the medicine and he would be fine but I guess if he got nervous doing the presentation they would just come at him, so he couldn't always...but he must be very strong, because he would just go through it, he wouldn't walk away from it, he would just fight it off and do...maybe not to the best or as good as he would liked to have done it, but he would do it anyway.

Carly identified herself as "resilient" acknowledging her ability to problem-solve and deal with challenges throughout her life:

I think I'm, I'm pretty resilient which is good because I think I can you know deal with challenges...because um like you know I always, I always thought that you know in a work environment you know, like people would come to me with their problems and I'm good at solving problems and you know organizing and managing and stuff like that but more in like a life sense you know in a real life sense...in terms of you know relationships with people and you know personal crisis and stuff like that.

Laura's case manager emphasized her innate strengths that have endured through her recovery. "I think that she is a pretty strong, ah intelligent, articulate person who has goals. And has hopes and dreams, right...It's something innate, right... it's part of her constitution." 
Participants were also able to identify what they continue to value within themselves. Linda valued her ability to complete tasks once she has begun them when she described: "from my childhood... if I take one task I want to finish I'll work hard to finish task." This strength was illustrated during her recovery process when she persevered in continuing her studies; a part of her life which was important to her. Sandy, who had a history of doing well in academics, commented that being involved in the [name of program] during her recovery enabled her to reconnect with the part of herself that does well academically. This program helped her to feel "good to do something that I'm good at" and promoted what she valued namely a sense of accomplishment. As she reflected:

I valued a sense of accomplishment um, um there...they [staff of program]offered us courses for credits and um and um I think that I just pride myself on um on um doing well like as far as academics, like its something that I have always done well in and uh how I felt, I felt confident, like it was the first time in a long time when I felt confidence like um I was in despair because I couldn't find myself a job, and um that is one thing that I have always...like I've had bad experiences at that time I had bad experiences in the past with jobs. So it felt good to do something that I'm good at.

Curtis identified that he has always valued his intelligence and identified this as an important attribute. He suggested that he was able to retain this value despite having to endure negative comments from his relative. As he described: "sometimes my [relative] she jokes around and calls me dummy right? And I take offence." He counteracted this statement by telling this relative "I don't insult your intelligence so don't be saying anything about mine." Recognizing the strained relationship he has always had with his father he also added that he thought his father "thinks I'm a fool...I don't know what it is but I get that impression." Despite the adversity from his family, he still valued his intelligence, adding that "you can't really take it away."

His belief in the strength of his intelligence was also seen through the object he selected to symbolize his recovery. Curtis selected trophies that had been awarded to him 
when he was younger because of his work and determination. He described the trophy he would now give himself as being "gold" in color, having a "wide rectangular" and a "mahogany" colored "prism” base, "diamond encrusted", with a "\#1" on top of it. Curtis described that the trophy symbolized the work that he has done, and the progress and drive that he continues to have which he is very proud of. He acknowledges his ability to continue with his ambitions despite having gone through his illness experience.

I believe Curtis' personal strength in the past, present, and future was revealed through his choice of personal object. Specifically, the belief he has in himself was symbolized through the trophy he described. By recovering, he was able to award himself "a trophy", and to continue to describe himself as number one. By reflecting on this image of the trophy, Curtis was able to acknowledge his personal strengths and desire to continue with his ambitions especially involving school.

I believe that being able to identify aspects of their character that endured supports the notion that a majority of participants did not see their identity in the context of their illness. Sandy's mother stressed the importance of treating an individual with schizophrenia " $a$ s a person" when she described:

If a person has schizophrenia or any other mental problem, you put them in the hospital and they don't talk to them as if they're a person. They talk to them as if they're a thing, you know, a number and that's very critical. They need to be treated as a person.

Although he described himself as a type of artist during the introduction of our first interview, Michael was the only participant who did not explicitly identify aspects of himself that have endured through his recovery. Instead, he identified himself as a "schizophrenic" at times during the interview. Michael was also the only participant that identified an illnessrelated trait, specifically his ability to challenge his thinking, as something he valued about himself. I view this exception as an example of a negative case. As described in my 
methodology chapter a negative case is one that does not fit within the pattern, for example the pattern within this subcategory. I suspect a possible reason for Michael identifying this value was that he appeared to be the only participant still actively struggling to manage his symptoms at the time of our interviews which may suggest that his sense of self was overshadowed by the illness.

In addition to acknowledging aspects of the sense of self that endured, participants were also able to identify what others have always valued about them, thus supporting their own observations of an enduring self. Sandy who had previously identified her intelligence as a strength and acknowledged that this is what others value stating "everybody said that I'm smart, that I'm nice to talk to... and that I'm friendly quiet. I think they value my friendship. They like me, they want to stay friends with me." Laura also identified her ability to talk with others as a characteristic that others value about her:

I'm easy to talk to. That's what like a lot like that's what all my friends say. They say so easy to talk to and and I think that's I mean like a really big achievement like you know to and you know sometimes have people say that, like just like my friends will phone me up or I'll phone them up and they'd be like we don't necessarily get together but we just talk on the phone for you know long periods of time...

What I noticed during our interviews, in particular when I asked her the question what she valued about herself and what others valued in her, was Linda immediately began to smile. Interestingly, she identified her smile as something that others value about her. As she described: "Everyone says... my smile...In my childhood my parents said it's very good my smiling..." She also drew attention to other traits people valued in her including her ability to work hard, and to be honest, which her father also identified as traits she's always had. Describing his work ethic Steven stated:

I always you know, try to, try to do more, not to impress people, just like, you know, be able to you know, feel assured in me...Like that I am competent that I usually do that. I go out of my way to do a lot. Especially if they are paying me well (Laughing). 
I believe that hope played a critical role in allowing participant's sense of self to

endure and not become overshadowed by the illness. Henry described the importance of not giving up hope and that individuals experiencing schizophrenia can indeed overcome the illness:

I would just say don't give up hope you know like you maybe going through a terrible time like you never know what could've happened, you could've actually lost your life if you think your losing your life, it could've actually happened but since you didn't, might as well make the best of it and try and push forward and do the best you can do if you think like your not doing well in life then try to make somebody else's life better and you already now benefiting two people's lives not only theirs but yours as well...I just hope that like, somebody will hear this you know and benefit from it and realize that somebody can actually live through schizophrenia, it's no it's no joke you know. I know how hard it is to face it but it's something that just has to be done, you have to overcome it... and look for a better for the future.

Henry went on to use the metaphor of an engine in representing the role of hope in recovery.

He described the factors that contribute to this "hope engine" running:

If you don't have hope then they say your not gonna recover. Cause you need to have hope in order to deal with your problems like hope helps you to carry on to the next stage because like being like okay because basically because you hope that tomorrow, a week from now, or a year from now, maybe even 10 years from now, you will recover and you like that hope makes you like it's like your engine...You can't just start the key, you need everything, you need the gas, you need the spark otherwise the engine's not gonna start... Basically, you are the key factor in this, yourself you're the biggest factor there. Cause if you don't believe in yourself your not gonna get anywhere. People will try to help you trying to show you the right path to take, but if you don't believe you can do it, then your not even gonna to step outside...So like you're the number one factor.

Henry also added the importance of not giving up hope, making a comparison that there are worse things than having schizophrenia that can happen to an individual. As he acknowledged:

Like don't give up cause like you're life is something worst could have happened to, you know and there are people who are paralyzed and still don't give up hope you know they still try and try and some of them even come back from being paralyzed. To having recovery with all their limbs and like if they can do it with such a terrible time and like what they've been through you can do it you can do it with schizophrenia. Don't let it overcome you and like cause like that's not the worst there's plenty of 
other things out there that can happen to you like don't...make it take over you and don't make it control you because like you can fight it and you can control it.

Steven underscored the importance of resuming life activities and provided hope by stating that others have gone through this and have continued on with their lives as he did.

I guess they really just, just get out there cause when, when your at home, and your, your not doing much. Unless your, doing something extremely proactive but yeah, you gotta out there and interact with people. If you don't feel like interacting with people go, go walk around you know, go do something, and uh, just, just, try to you know, get back, get back in the system I guess...And be employed and all that kind of stuff...Go to school. You know don't feel discouraged cause you know, there's other people out there and they've gone through it.

Michael also stressed the need "to continue with your life" to others recovering from schizophrenia. Linda encouraged others who are recovering from a FES to share their stories with others especially those who are alone and have no family support as way to building hope. She acknowledged that because the illness experience can be a distressing period in a person's life, sharing a personal story may help to minimize the level of distress. Sharing their experience with others going through a similar experience helps build hope by showing others that they are not alone; that others have been through it, or in the process of getting through it. Sandy described the importance of hope and the role it had on her recovery: Well I think um hope, hope drives...hope drove me... hope boosted my drive to become a better person and to become um to get into the higher the other end of the spectrum. Um hope is um it's a powerful thing, especially... when like you know when God is involved, when you pray. I think um like hope comes through prayer and believing and having faith and believing in God.

Sandy chose a necklace with a cross pendant as her personal object that represented her recovery. When asked to describe how it symbolized her recovery, Sandy acknowledged that it provided her with a feeling of hope as she recovers.

During the interviews participants expressed their desire to let others who may be experiencing a similar situation know that they are not alone; that others are recovering from a FES. While not specifically mentioned, I believe participants benefited from sharing their 
experiences because they felt they could have a meaningful impact on another person's life

by helping them to understand that they are not alone in their experience with schizophrenia.

It was also a way to acknowledge how far they have come in their recovery. One way that

Carly thought about sharing her experience with others was to write about her experience.

This desire was reflected in the book that she selected to symbolize her recovery. She

acknowledged the hopefulness that this book represented for her and inspired her want to

write about her experience. As she described:

[The book] also made me think about writing too, um a lot of you know there has been a lot of times...I've done a lot of writing in my life creatively as well and through you know school...I really wasn't able to write very much of anything for like, just like, the first year and it actually made me think about doing my own writing because it's such an interesting experience that you want to try to capture it in words and it's very difficult to do that and I had been thinking about that at the time and I thought this book sort of, without even, you know, knowing the author I don't know if he's got any experience like I've had or anything but it seemed to capture, you know, some of the things that I've been thinking about, so I thought that was really kind of inspiring.

Some of the participants' parents fostered a sense of hope for their children during

their recovery. As John's mother stated:

I encourage him by telling him that he had to lead a normal life like others, so that if he had some sickness he had to take medication to recover from that sickness and encouraged him, to take medication. So, I gave him hope to get out of this situation and his life would be like others and he could lead a very good life. I always always reminded him of his future, I told him that he did not have this sickness when he was born, he did not have it from birth. It is a sickness that came in-between, so by medication he could be cured completely. That is the encouragement I gave him. Because it is not, this sickness is not from his birth and none in the family has this sickness.

She went on to add her wish that "he would recover fully and enter the university." Linda's

father also underscored the role a message of hope plays in helping individuals like his

daughter move beyond illness to recovery. As he described:

...the people who are involved, the parents or husband or wife they should be having a firm hope of the patient will recover very soon. ....You know the hope, because the thing that hope, that vibrates positive things in the family and the patient too. So we 
should not, not get alarmed. We may get alarmed in, inside but we must not express it to the patient. And also among the members of the family, we must say it is as a normal course of action is if something happen we must say, say that the patient is recovered, nothing more, nothing less. But we must have that firm conviction in our heart that it is going to be so that she will be recovered, the patient will recover. She will be as ah status quo, after patient status will be, will come back or it will regain like that. It is like that. You must have the conviction on our own you know, first.

Steven's mother also acknowledged the importance of "hope" in managing the illness. As she described:

There is hope. I mean you got to keep going. You just have to do what you're supposed to do and you know what you have to do so just keep doing... They [clinicians] keep telling you stay away from the street drugs. You know if the medicine isn't working tell your doctor.

Some clinicians also expressed the importance hope plays in recovery. As Laura's case manager described the supports around her help to build hope:

I think she's had some good supports...And credit needs to be shared right? Cause I think she has found that inspiration, that hope from many different people outside of myself. Residents, teachers at [name of outpatient first episode psychosis program], family therapist...

Reflecting on my own clinical experience, I am also encouraged to see that the participant's supports, whether they were family members or clinicians, encourage them to be hopeful as they continued to strive for their ambitions that are characteristic of their developmental phase.

A challenge for an enduring sense of self was the risk of being overshadowed by the illness. Michael commented that despite the symptoms he experienced he desired to be like the person he once was:

Cause when I...wasn't schizophrenic I used to be normal like I didn't hear voices or I wasn't scared to go out, or you know what I mean I wasn't I didn't think people were after me or anything like that... But now that I have schizophrenia yeah all that stuff is like is like my reality...It's hard...I try to just go on like being how I used to be.

Sandy described that her values were challenged when she was ill, but resumed again during her recovery: 
I was always um like I have accomplished a lot...since that time I have accomplished a lot of things like um like graduating from high school...I did a lot of accomplishments that I did get awards...I got accepted to university and I got um completed courses and there are times when at university... like I got the highest mark in the class. So um but still sometimes um it didn't feel like I accomplished anything because I was doing nothing when I was depressed and so like and again it ties in with this [name of program], like it is an accomplishment. Like being like uhm being accepted to [name of] program. Like that was an accomplishment in itself...like getting the opportunity to do it.

Steven, described overcoming a sense of loss over his illness experience:

....after like when you go through a psychosis you feel like you loose a lot of yourself, like you loose a lot of, it's very energy consuming and your mind is constantly working and a lot of negativity. So, after you go through that for a couple of months, after all that then you get diagnosed and everything. And it's like you got to almost start over. So it was like starting all over again. Yeah, it was really, really hectic. Like I would be hanging around people and then I just started laughing about nothing. And that I didn't realize that was one of the side, one of the symptoms, you laugh at unusual times. So I kind of turned into a very, very quiet person, thought that I was like living in prudence cause I (chuckles) didn't want to be around anybody. So it definitely made me a little bit more shy and careful about things. And ah just the timing I guess made me accept it and want to be better and not to go back to that place.

During the development of this subcategory, I wondered how participants managed

the threats to self that were presented to them by this first episode of illness. I believe that endurance of the self is fostered when participants can actively identify what they value about themselves and what others value about them that are not illness related. In doing so, they are able to see themselves as more than an illness but quite capable of having an enriched life and also capable of enriching the lives of others.

What was striking in the participants' descriptions of values and strengths was that the traits they identified were the same ones they were able to draw upon throughout their recovery experience. They leveraged their strengths to help them recover. For the majority of participants they understood this experience in a way which did not overtake their sense of self so as to protect their emerging adulthood. I believe that what prevented the majority of 
participants' from being overshadowed by their illness was that they had values, goals, and strengths that were not tied to the illness.

\section{Growth Through Recovery}

Many participants identified the recovery process as a catalyst for change and growth in their lives. Participants described a maturity that occurred during the process of recovery at which time they developed new skills, made better choices, and developed more fulfilling relationships with others. Some participant's used the illness experience as a "call to action" to change behaviour that had slowed or damaged relationships in their past. It was clear that the person that was emerging from the illness was, in many instances, similar yet stronger,

more focused and more aware of the impact their behaviour could have on their recovery and relationships with others. This subcategory accounts for some of the common changes and growth experiences that occurred during the recovery process.

As Henry described: "I guess it made some things better though, it made some things better. Sometimes I'm not too upset that it happened." He stated:

Cause like before I was into like negative company and stuff like I was doing the wrong things all time, ending up in the wrong places but like now since I got better, I don't do that anymore, I stay positive and try and be the best I can ... and now since I got schizophrenia, I started school again I got got all my credits this year...like now that I see like what could've happened to me what coulda what I coulda turned out to like it's not good, it's not good at all. Who knows like I could've turned out to be like such a bad person...

Henry also described that he has an added level of self respect and has changed the activities

he was once involved in following his illness experience:

...now my life is...gonna be like better than it was looking before like cause before cause who knows, I wasn't even I wasn't even thinking about going back to school and stuff like that I was like whatever I was just gonna drop out or something......now I can actually have like I actually respect for myselffor what I've done, the accomplishments that I've made and before I was just like you know I didn't like wasn't too thrilled about stuff that I did like all I did... all I did, was like sell drugs to people and stuff and no one knows where that's gonna lead you...You can get caught 
up somewhere and get going and walking in the alley and you get shot or something you know now I don't I don't have those risks to take anymore.

In further highlighting how his life has changed for the better, Henry chose song lyrics to

symbolize his recovery. As he described the song is:

...basically like an alcoholic...,, a prostitute, and and like a gang banger so they all were leading the wrong lives at the time, all going through their struggles and like not having a good time going through it, you know they thought it was like the right way for them and then they all end up going into a church to repent their sin...That they could lead a better life, Jesus like touches them all and saves them from from their world cause it shows it like what would've happened to them like the drug dealer would've got shot, she would've gotten beaten up stuff like that so you see see like that road won't lead you to the right place but like you need to trust yourself and trust that, your gonna do the right thing.

As he reflected on this song, Henry was able to describe why he may have had to experience the illness:

...Because like I don't know you never know why why schizophrenia or anything will happen to you like it might happen for a reason cause maybe for me cause like the wrong life I was leading and I would still be doing if it wasn't for the fact I got schizophrenia. So like maybe God wanted me to attend to him and gave me a cause to do so. So like the song pretty much touched me because like I I didn't go to church in so long probably like two years maybe if anything and even though I was grown up in the church I used to go every week like morning and afternoon service and to not go for two years is pretty pretty serious...And that something must must be affecting me. Yeah um but like I actually went to church last week ...I went by myself to, cause nobody else went with me I was just glad that I went...You know so I don't know I guess this song basically talks to you about how there's a lot of trouble in the world but no matter what the trouble is could be gang member, a prostitute, a homeless person help to a homeless, God will forgive you for whatever whatever it is your doing and as long as you come to him and and ask for forgiveness but he can't forgive those who don't ask... at the end of the church scene like they make doves fly out to symbolize life like a new life...So that was pretty good as well. It showed that they were all forgiven and now they're living their life basically like they were going to change their life around and start living to the best of their abilities instead of like doing wrong all the time you know and not caring.

Carly described how going through the process of recovery helped her develop skills that assisted her to deal with the stress of life challenges more effectively:

I mean things have continued to progress, I guess you learn a little bit about, start rolling with the punches too and life goes on after this whole experience that you've had, you know um like you know there's ups and downs but I mean I think what one 
of the things they[her outpatient clinicians] taught me here too is to have a lot better coping skills in terms of stress and like you're daily life stresses and things like that and there's also...I mean there's always really neat and exciting things that are coming up as well...

Carly also commented that through this experience she believes she has become a "better person." As she reflected:

I definitely think I'm a better person but you know at the same time I don't want to say you know well maybe you should have a psychosis experience then you would really benefit, it's definitely not a pleasant thing, not a pleasant thing to go through... but I would think maybe I'm more enriched because of my recovery process as opposed to yeah my psychosis experience, that is more like something that sort of maybe scared the pants off me that made me think you know, I really have to make some big changes.

Similarly, Carly's mother commented that she believes Carly is "a better person now than she was before" and stated:

It's not something you want suggest to people or wish they have but she is a better person for it. She's stronger she realizes she got people who love her and uhm she's getting stronger just I think she is going to do better know than she was before.

Leah commented how her life momentum has picked up as a result of becoming ill:

When I got ill [I] felt really trapped by my life...I felt like it was never gonna change and wasn't going to improve. But you know I just kept hoping and praying that something was going to happen. And something did happen and it wasn't great that I went crazy but it's it's pretty much changed my whole life around. And so things are like a lot better now.

She further commented and reflected on the behavioural changes she has experienced:

... when I was ill I was like I've come a long way like I was really skinny and I didn't bathe and like I screamed a lot and I don't do that anymore. Like I don't I can't remember the last time I cried or had a tantrum or anything.

Leah also identified that she valued her "coping skills" and acknowledged a change in her temperament which appeared to be prompted by the illness experience:

I don't get like I don't know maybe it's the medication or something I don't get so upset about things anymore...Like no matter what happens even when I'm like I'm broke yeah it really sucks that I'm broke but at least I have food you know it could be worse I could be on welfare or something...Like I'm always kind of optimistic so... I like try to be nice a lot of the time, cause I used to be like really temperamental and 
stuff like that, not temperamental but I was kind of like an angry person. So, now I try to be nicer because I want to ah be more positive and stuff like that. But, at the same time I got to make sure that people aren't taking advantage of that.

Leah's art therapist comments on the changes she has seen with Leah as they relate to her sense of self and indicative of her developmental stage of emerging adulthood. As she described:

Well it's ah independence, definitely more confidence, uhm, (pause) I think she has friends now. For the longest time she was quite lonely and her only friend really was her [relative] who she would go out with. Now she has her own apartment, she has friends over. Now she's she's talking about sort of normal problems that young adults have, like paying the bills. I think she has a sizable cell phone bill right now...A lot of sort of normal young adult uhm tasks.

Steven also reflected that he takes life a little more seriously than he used to and how his personality has changed by wanting to try harder in life. He also mentioned:

I did did grow from where I was. Uhmm I think I was really...Ah I don't know, I was just a different person... I gained so much more than you know, I feel like I'm just growing and growing more and more and I'm getting better and better at everything that I do...Because I'm more careful and more persistent.

He also commented that he has noticed improvements in his ability to focus on tasks at hand.

As he recalled:

...my attention span is a little better than it used to be too. So, I can sit down and read for like 3 hours without taking breaks and stuff. Before, before I had a very short like attention span, I could barely do anything without in class I was constantly running to the [type of room] to go see people. And it's more of a focus too, I'm not being distracted as easily. So when you're focused you take more in and that that keeps your interest level up.

Some of the participants' parents described the growth they have seen in their children's recovery in terms of a percentage. It would appear that doing so allowed parents to monitor changes and growth over time. As John's mother described "I think there is 75\% recovery as he's also taking medications and he has improved 75\%...so I have hope that he will recover $100 \%$." When asked how she is able to determine that her son's recovery is $75 \%$ she stated: "He seems like a normal person, doing all the normal things without problems 
(chuckles) and that is what lead me to think that he is almost recovering, 75\%." Linda's father acknowledged that he and his wife believe that "more or less say $70-80 \%$ [he has] recovered [his] child." He states this because he has noticed memory improvements, she continues to go to school, and engage with her family. In his opinion, the remaining $20 \%$ will be achieved when his daughter becomes more physically active.

The recovery experience also appeared to initiate a reflective process for the participants where they were able to account for the growth they experienced. The descriptions they provide appeared to have a developmental quality to them. Specifically, some of the participants were able to recall how they were when they were younger and how they have changed and grown having gone through this experience. It also appears that having gone through this experience seemed to push their development forward, unique to this growth occurrence was a maturity that developed. John acknowledged a growth process on his part during his recovery experience related to changes in his attitude and behaviour. As he described:

... when I was like you know young back then, right. So you know you all act like idiots back then right. I was acting like that too, when I got home like I hadn't had no respect for my family, right. I would just call them names and everything. I would hurt my feelings right. I had no thought about them, thinking that I would hurt their feelings. But now I think back and I say to myself, why did I do it? Now I respect them, right.

He also described what appeared to be a call to action when he stated "I'm not young any more, I feel like I've matured right. I'm not those things that I wanted to do when I was young, right. I have some responsibility, I have organized my life." Henry also acknowledged changes from how he was in his younger years:

Well like as a kid I don't know my teacher used to tell me that like if people were around me I'd bring them down and I'd make them worse in school and stuff cause I was talkative and stuff telling jokes and they wouldn't do their work and things like that...So like I don't know so now I make sure people get their work done and stuff so that they can succeed. 
Leah acknowledged that she used to "play head games" with people and now no longer engages in this behaviour. She provided her understanding as to why this change has occurred:

I think some of it is getting older and I think some of it is just learning how to deal with stress. Yeah cause honestly I have never really been the type of person who would play head games but like when I was really under stress and really angry I kind of...I would kind of do that without realizing I was doing it.

Curtis recalled that in middle school he had "issues" with anxiety further stating that he would "internalize everything". He acknowledged that "now I share how I feel...and I think that that I one way I've changed. Definitely definitely. "Carly reflected that when she was in her teens she may have moved out too soon before she learned to prioritize in life which she feels having gone through this experience she is now able to. As she recalled:

...it's not something like recovery from...mental health issues but it's, it's been like a really life changing experience for me...Because I had to learn, I just, it was almost like starting all over again. Sometimes I think, I moved out of my house when I was just [in my teens] I moved out. I was just you know, itching to get out of high school and to get out in the world...Do my own thing and be on my own and be independent. Sometimes I think that I didn't sort of stick around maybe long enough to, to, to really learn some of that stuff or you know, I, I don't know, I'm not, I'm not exactly sure what it is but it just seems like I got really tied up in, and I didn't have my priorities in order and, and I wasn't focused on by my own physical health...

In keeping with the focus on increasing maturity, some of the participants also identified how their relationships with others changed during the course of their recovery. As Steven described "my relationship with my parents... has become so much stronger..." He acknowledged that he is closer with them now and also remembered "coming home and being yelled at that kind of thing and you know yelling back and...I was just like a bad kid, I think. I guess it's regular for most teenagers but I'm glad I'm wasn't that person..." There also seemed to be a noticeable improvement in relationships over time with participants and others around them. Steven's mother added 'I think it's been better, its been better, we can 
talk more." She further elaborated by describing how her relationship with her son has

improved:

... you listen better too, you listen and you try to you know...just try to allow him to keep being positive you know without babying him and letting him get away with things that he shouldn't do. We've relaxed a lot more. We've not as strict with certain things around the house. Sloppiness, he'd start out with this sloppy thing left a trail just basics, you just didn't harp as much, you just you know didn't nag. Mother's are always nagging (laughter) you just backed of. You realized what was important and what wasn't, you grab a pillow or throw his bed together, who cares. If not what I read once, what's important today, is it really going to be important 5 years from now you know...

Henry's girlfriend acknowledged that their relationship has also improved during Henry's recovery. As she described: “now he's able to tell me what's wrong. Before he wouldn't tell me. He'd just get mad." Sandy's mother also described a closeness that evolved with her daughter during her recovery. As she stated:

...we talk more, we seem to be closer...during some of her episodes she would tell me what was going on, she was okay, who she's talking to or she would be laughing, and telling me she's seen such and such a person, what they're telling her, and we would joke about it...

During her daughter's recovery, Carly's mother also described a change in her relationship

with her daughter as she recalled:

It's like a miracle to watch her recovery...I've got my daughter back, is that what you mean? Yeah, I feel that she's back, she's a part of the family. She's interactive. Uhm, she's more caring about others around her, where she wasn't before. She was in her own little world for the longest time and now it's more an adult interactive relationship and I realized and I am just realizing...you know as a parent you just keep on doing and doing and you don't really what I'll notice that all of the sudden she'll say how are you feeling mom? So that's pretty neat again, uhm since I love my daughter. She's just wonderful to have her back as part of the family.

Participants and those around them noticed changes that reflected that they were

further and further away from their illness experience and that these changes were sustained

over time. In essence, they were doing better. Curtis stated he is now able to:

...do all all the things I wanted to do. Like I'm able to go to work, fully function to be the best that I can be uh you know without any challenges you know if I need to 
come back my mind or when I'm off focused cause I'm listening to thoughts or something like that. You know what I mean? So none of that stuff is happening. I'm just 100\% immersed in whatever I'm doing. With school I'm just like okay school at the same time do the best I can do at work and in every area of my life.

Curtis' out patient psychiatrist also commented on his ability to move beyond his illness over time as he described:

Curtis is in... university, doing well, living his dream, working hard all summer, ah meeting other people his age in that respect, so he really doesn't appear when you speak to him, or if you look at his social history right now appears to not be suffering from his illness, he really appears to be thriving.

He also mentioned how encouraged he was in seeing Curtis' sustained improvements "he's a success story (chuckles) and I guess he encourages me ah when I see someone else coming in today whose moving forward and that's encouraging." He further described Curtis as:

I guess he's resilience, in spite, most kids...would have in the same condition, the same set of values and such an assertive father... he could have been very weak, he could have regressed...And that's the other remarkable thing. A lot of the people we see there's a real sense of developmental arrest or regression. I can show you, you know, a $4^{\text {th }}$ year university student who really functions on the level of a 15 year old now. [Curtis] has done the opposite, he's gone from being a 15 year old to being a very mature young man who works hard, but more importantly has gone...in some ways he's progressed in life experience beyond his dad's experience which is to me that's remarkable. In spite of that he challenged, he found his own way so to speak.

Carly also acknowledged that she has arrived at a point where she describes herself as "pretty stable emotionally," however stated that being able to reach this point did have its challenges.

As she recalled:

I feel like I have, I wouldn't say fully recovered, but I would say I've mostly recovered...I haven't had any symptoms, and it is probably 2 years now which is a good thing. I'm really conscious of being under stress and try to avoid being being under too much stress, but at the same time I've managed to progress, you know, with my life, so I think that's a really good thing...there was a period too where I was like so worried about stress that I just didn't want to get myself involved in things because I didn't want to take too many classes or I didn't want to think about getting a better job because I just didn't want to... you know, not so much the fear of being really stressed out, you know part of it maybe was lacking confidence, but I just didn't want to get involved in a situation where, you know, it would snowball where I would end up being sick again so um but I mean physically I feel really good and mentally I feel, you know, pretty stable emotionally as well so... 
Carly's mother also noticed changes in her daughter over time recalling:

...I think it was pretty immediate that she was better...because it was almost flicker just like you'd see flickers of her and right up until I would say 3 months ago, maybe 6 still flickers and then all of a sudden it's gone, we haven't seen anything in 4 or 5 months.

Laura's case manager commented on the apparent evolution of changes that he witnessed in

her over time which he attributes to her hard work and self-growth:

....she was very symptomatic, I think she was a very mistrusting person, very very bottled up, ah would really never really bring much to the table in terms of things she wanted to talk about, ah things that were bothering her. So I think that has evolved. You know, getting her to a point where she is able to kind of talk about her conflicts, her, her turmoil, things that she would like to change. So that has changed dramatically, cause there was a period where she would not just talk about it. She was angry, hostile, ah disappointed that she had to be involved with this whole system. And then I think a lot of self awareness is like you know okay this is happening to me, but what am I going to do now? ...You know seeing somebody go from a stage of disappointment, loss and anger to being hopeful and taking charge and not playing the victim...it takes a lot of courage, not everybody is able do that...

Clinicians commented on the changes related to their role over the course of a

participant's recovery further highlighting the notion of sustained changes being apparent in participants. Curtis' psychiatrist described how his relationship with Curtis has changed as his process of recovery evolved:

I think I've become just...I'm an observer now rather than an active therapist for him even, he is really been dealing with his case manager right now, he's had 2 case managers and they're both very good...but really the issues around medication, are pretty minor... ah so really I've moved into the background, I feel I have done my work...

Similarly, Leah's art therapist also commented on how her relationship with Leah has

evolved and that the once active role she had has now decreased. As she described:

I don't see her as an inpatient with schizophrenia, I see her as someone sort of developing still and...uhm so it has changed, it's a little professional, of course, but a little more uhm relaxed, it's not as structured any more, you have an appointment at this time. It's whenever we meet we sort of catch up with what's going on in her life.

Laura's case manager also remarked on how his role with her has changed. He described: 
I used to meet with her at least once a week so that's changed because she's doing so well uhm I work around her visits with the psychiatrist, so I see her probably yeah see her every $3^{\text {rd }}$ week, maybe sometimes once a month... Because of the compliance, because she was disorganized, responding to voices, inappropriate laughter, judgment was a little impaired. So there was safety concerns and she needed that much more support... Because there was time... in combination with her positive and negative symptoms, I think she was having a difficult time identifying goals and ah achieving those goals but since that time and now uhm she's able to identify goals

and achieve them and really move on with her life. I would say I see her as recovered.

In summary, participants were emerging from their illness experience with a greater self-awareness, using skills and strategies that sustained their recovery.

\section{Enablers for Reshaping an Enduring Sense of Self}

In the preceding subcategories it was evident that the illness experience necessitated changes to the self. However, there were many aspects of the self that endured from the time prior to illness. I argue that the process of reshaping an enduring sense of the self is integrally linked to the process of recovery. What seemed to support the process of reshaping the self were certain enablers, specifically, a participant's desire to move away from their illness experience, a focus on the self that was not illness-related, an ability to continue to experience personal accomplishments, viewing the illness experience as an opportunity for growth, and finally the passage of time.

Participants' ability to engage in a self reflective process that included a capacity to hold ideas about the self across time was central to the process of reshaping the self. Namely, these young people were able to observe how far they had come from the acute phase of the illness to the present and were able to integrate these observations into their sense of self. By doing so, they recognized that they did not want to go back to feeling symptomatic but rather wished to look towards the future with ideas for ongoing goals and accomplishments. For example, Steven described his "bad stage" as a time when his symptoms were not being managed and commented that he "didn't want to go back to mine [his bad stage]. "Curtis was 
clear that his focus was towards the future and that he was not looking back. As he described, "I'm not looking back anymore...I only know what's happening right now... I just focus on the present." Leah's out patient art therapist also observed that Leah did not want to experience another episode of acute illness but rather she wanted to focus on the gains that she had made since then. As she described:

I think she has a lot of insight, she knows that she she has an illness, she knows that she does not want to be an inpatient again. And she, at this point, she knows that she has a lot to loose, because she has made so many gains.

Another enabler that contributed to participants' capacity for reshaping a sense of self was the ability to resist being overwhelmed by the challenges of the illness. It appeared that participants were able to identify qualities within themselves that were not illness related, which then facilitated their ability to continue on with life without being completely overshadowed by the illness. For Henry, it was very important to know that he would be perceived by others as a "regular person" and not someone with a mental illness:

I just like see myself as a regular person as long as I don't do anything, that will cause me to cause others, to think that you know like something's wrong with me... Like look at the way he's acting right now...Like that's, that's how it was if I never took my medication like people could see like something's wrong with me I looked depressed all the time or something.

Curtis also suggested that he did not feel defined by his illness, rather he felt able to resume

his life activities without a need to focus on his illness or any treatment issues:

You're you're able to do all all the things you wanna do. Like go to school, like go to work um be able to excel in it and do the best that I possibly can. Uh like there's no need like to withdraw from anything. No time taken to go to the hospital or I know me like myself and Dr's [name] talk about like we never talk about crisis anymore. For like I dunno the past year and a half to two years now...

Laura stressed that individuals who are recovering are "more than just the illness." She also advised other young people who are recovering to "continue and to find other qualities [other then illness] in yourself that will help you." Sandy encouraged those who are 
recovering from a FES to search for positive qualities within themselves "try to do something that raises your self esteem, builds self confidence, try be more independent any way you can..." Steven acknowledged that unlike others his illness only comprised a small percentage of his life:

...one of the people here actually showed me like a chart, and they're like a pie chart and they're like the illness is like in most people's lives is like 90\% of their life and only like only $10 \%$ is like family, school all that. But with me the illness is actually only like maybe 5\%, like oh so it's not something that I really think about and now that I'm being distracted as much and I focus on like the right things.

Another enabler that contributed to reshaping a sense of the self was the propensity of participants to identify values that emphasized aspects of themselves unrelated to illness. For example, Laura commented that she valued her family, love for literature, and her ambitions. John described that he valued his life, happiness and his recovery. He also stated that "my family values my attitude, my good behaviour, and leading support for my [siblings] to follow my footsteps." Curtis acknowledged that others value his ability to talk with others. Steven described two values that others around him appreciate namely, his ability to diffuse tense situations, and his ability to exceed expectations especially at work. As he stated: ...like sometimes in tense situations and that kind of stuff I bring you know a lighter side to the table. I'm might you know, perk things up a bit. Um, like I know my [siblings], one my [sibling] has a lot of faith in me, not faith in me but, well he probably has faith in me but like, with, with humor and joking around.

Some participants continued to be goal achievers and continued to experience personal accomplishments through this experience. Sandy's goal was to be more independent which she worked towards during her recovery. An example of this was her acceptance into a work program. She acknowledged that this was a major accomplishment and described it as “career accomplishment” that also promoted her self-confidence. She further acknowledged how far she had come and how proud she is of herself. "Especially being able to [use public transportation] by myself that is the latest use...in becoming...major uhm improvements in 
becoming independent." Carly was optimistic about a recent job interview. If successful it would help her meet a major goal namely, her first professional job upon graduating from university. Leah acknowledged the recent accomplishment of a goal when she mentioned: "I just moved recently and I got my first apartment by myself... I figure I'm [in my twenties] and it's about time I got my own place." Laura also commented that she was also meeting a goal by "moving out soon...getting [her] own place."

Participants also viewed the illness experience as an opportunity for growth that further promoted reshaping of the self. As Carly described: ...you can't live your life like that obviously like you know tend to be a workaholic and that kind of thing but, but You know, it was just like that, I just let it really get out of hand. And then so this [the illness] sort of happened to me and um, like you know, there's a lot of ways I can look at it and see it as a good thing, well being a learning experience for sure...

Carly recalled that she faced many uncertainties during her recovery experience, and yet from my point of view, she was able to resist becoming overwhelmed by the illness. In fact, she viewed her illness as a growth experience that will continue to influence her life, as she described:

...but I really wasn't sure, you know, at that point [during the acute phase of her illness] if I would ever be moving out again, you know, I wasn't sure if I would be well again, you know I didn't know if I was going to go to finish school, I couldn't imagine I mean I remember thinking too, I don't know if anyone would hire me because of having this whole experience, um it's been...it's taken a long time but you know it's really um I mean I'm really happy that because of all the help that I've gotten that all those desires are going to happen for me and it hasn't been an enormous amount of time but I think it's been, it's been a really good uhm you know it's a bad experience to have but it's been a good...I've learned a lot through it that I think will carry with me.

It is noteworthy that participants adopted attitudes toward their illness and recovery that appear to be consistent with life philosophies that had been held prior to the onset of illness. For example, Carly describes an openness to learning from new experiences that is a fundamental part of her being. As she reflects: 
...my own sort of personal philosophy is just to become a better person, gain a better understanding of you know life and what's going on around you. I mean that's why I went to university, because I wanted to learn more and more about the world and about society and about other people and what was going on right, so I mean I kind of see it [recovery] all as a growing experience too... Well yeah, for sure, it just changes...you know it's definitely is going to change my outlook on the world, I've learned a whole lot about mental illness which is...you know it's sort of like just sort of opened my eyes to new things the way I look at other people and the way I look at my friends too and those closest to me and even how I view other people that I come into contact with in the world...

Henry's optimistic outlook on life is reflected in the following quote. He also warns about risks associated with a pessimistic outlook on life:

...everybody should be able to uh experience life to the fullest like instead of living a negative life they should be able to live life like how most most people live it I should say like (Pause) um like I don't know because there's so much risks and stuff you're taking when you don't and you don't know what could happen to you. So it doesn't make sense really because you don't want the time to come when it's just too late you can't do anything about it...And you might as well just start living positive from now.

Henry's belief in the positive nature of life is reflected in his belief that there is a positive side to schizophrenia as long as treatment is sought. He described feeling fearful when he first experienced the illness however, hopes through his example, that others can realize the "positive side" of the illness:

I hope hope that like if I see anybody that has schizophrenia that has to deal with it that I can help them so that they don't face the same like fears that I faced when I first went through it. Like I could show them the steps to take to make...their time or period that they have it or their fear from it like more enjoyable and that they could see the positive side of it...Like basically coming to the realization that you have schizophrenia like something's wrong like you need to be treated for it, like maybe maybe if you don't don't have to go to the hospital like as long as you come to realize it you know you need treatment for it, you you like, hope for the better and don't do anything negative that's gonna like bring out what happened in the past back up.

It is clear from the participants' recollections that time enabled the reshaping of self and recovery to occur. There are several processes that emerged regarding time. First, time allows healing to occur, which reinforces a sense of strength, wellness, and ultimately the possibility of recovery. In essence, time heals. As healing is initiated, time allows a place for 
self reflection and reshaping of the self in the context of their illness experience. Steven acknowledged the notion of time being needed for his recovery when he selected a watch as an object that symbolized his recovery. As he described:

...watches are like a symbol of you know time, and time heals all wounds, time is everything, I mean you just got to give things time, like you said earlier recovery doesn't happen overnight. So I brought a watch because I felt I was pretty patient with everything and ah I was very patient with the doctors when I was at the hospital switching medications around. And I thought I was very patient and uh eventually through time you know grow, you become stronger, that kind of stuff too. And uh also you know time the amount of time you put into your work, time is money, time is everything. You know, when it comes to recovery though, I definitely think along the lines time heals all wounds. That's why I [brought a] watch.

Reflecting on my field notes of my interaction with Steven and his description of his watch that symbolized his recovery, what struck me during our interaction was how insightful his description was and how proud he was of his selection. He emphasized how important time is to recovery, and that you have to be patient and realize that recovery is not going to occur overnight, it's going to take time to evolve and move forward. By incorporating the description of the meaning of his watch into the interview the unique aspect of time to recovery was revealed.

Leah also chose objects (two $27^{\text {th }}$ birthday candles) that symbolized the importance that time played in her recovery. She recognized the importance of time and also felt relieved that there is plenty of time to recover and live her life. As she described:

...I had a really good birthday this year that is what these these candles remind me of... it's been 2 years since I have been in the hospital. So you know I am [in my twenties now] now, I was 25 before and things have gotten better...Everything takes a bit of time considering that we all live to be like close to 100 these days, like I got plenty of time to do stuff.

Carly also underscored the importance time played to help enable recovery and as a way to learn more about herself, underlining the relationship between time, recovery and the reshaping of the self. As she described: 
Time is very important um, just to take a break, and it's, you know, it's, it can be very good too because you learn about yourself and you learn you know, what you wanna do but anything you can do that makes yourselffeel better I think that taking cues from your, your you know the way you feel.

She also endorsed the idea of giving yourself as much time as possible to recover:

I think it's really important that right off you know to start your recovery that you clear you know everything off your schedule and take some time for yourself even if you are not coming from like a stressful environment. Like me, like I think that all the stress is like a huge trigger in these kinds of cases and even just for a learning perspective, it's gonna be really hard too, cause you like come out of psychosis, like I think it's really important to take cues from your physical sense of well-being. And you can really learn from that but you have to, you have to question yourself you know like do you feel good about moving on, do you feel like you need time? And don't be afraid to take time for yourself and as much time as you need.

Linda's father stressed the importance of taking time to heal during recovery stating:

Recovering, you know this is something you know will take some time. But of course as a layman I think it is that longer time...than any other sickness because normally you know any sickness or something like that it won't take nearly it is now over more than $11 / 2 \ldots$ a little more than $11 / 2$ years... It's taking a longer time than we expected...I do not enforce, force anything you know because this is the mental process, it takes some time to heal it. It is not like any other thing like that you know...It must take it's own time to heal it.

Steven's mother also alluded to the passing of time that is needed in recovery:

Initially, during psychosis, no they can't absorb, they can't remember, they don't know whether they're coming or going. But slowly they are able to learn and absorb and keep that because they don't have the distractions in their brain.

Supporting the notion of time needed for reshaping a sense of self, some participants

described their movement towards recovery as a process. Linda described that she was “doing well step by step.” Leah, who was hospitalized for several months as an inpatient, described that her recovery "was in stages." Carly acknowledged that she knew people:

... [that] had much stronger symptoms than me... but I had symptoms for maybe 3 months and it just you know like it just completely rattled me out I get, I don't think I was, I was ready to even go back to work again for about 5 or 6 months after that... 
John states he is taking his recovery "step by step." Linda described that it would be easy to see for anyone who knew her a couple years ago when she "was too sick at that time," that she is recovering now.

Participants' reshaping of their sense of self began with their illness experience and continued through their process of recovery. Some grew from their experience with several participants commenting that aspects of themselves have changed and their lives became better as a result of going through their recovery experience. In essence, rather than their sense of self being destroyed, aspects of their sense of self endured. They were able to integrate changes and continue with their life aspirations, building on their strengths and identified values. Some participants drew on their interests and used them as recovery strategies.

\section{Summary}

In summary, this phase served to illustrate how reshaping an enduring sense of self is characterized by three subcategories, namely, an enduring sense of self, growth through recovery, and enablers to support reshaping of the self. This section described my interpretation of the participants' reflective process pertaining to the reshaping of the self. Specifically, in response to the illness experience, participants were able to respond to the challenges of this illness by making sense of this experience, not loosing sight of where they have come from, where they are now, and where they would like to be in the future.

Participants were also quite aware of the processes that enabled them to recover with a reshaped sense of self. I elaborated on the optimism and hope participants experienced as well as the necessity of time needed as they moved through the recovery experience. I also reviewed how participants continued to set and worked towards achieving professional, educational and/or personal goals outside of their illness and how they used their personal 
strengths during their recovery. I have suggested that through their process of recovery their sense of self was reshaped and developed beyond their illness. Finally, I explored how participants used their recovery process as an opportunity for personal growth and development. In the discussion chapter that follows, I will demonstrate how the phases relate to each other thus contributing to substantive theory of the process of recovery from a FES. 


\section{Chapter 6: Discussion of Results}

\section{Chapter Overview}

This chapter will focus on the discussion and interpretation of the study findings that led to the development of a substantive theory of the process of recovery from a FES. The core category, reshaping of participant's enduring sense of self will be central to the discussion across all phases of the emergent recovery model. The similarities and differences between this study's grounded theory and the existing literature will be highlighted. I will situate my model with other process of recovery models that primarily draw from studies with participants that have a variety of long-term mental illnesses, highlighting the unique recovery features pertinent to FES.

My aim in this discussion chapter is to answer, as Charmaz (2006) describes, the "so what?" Specifically, so what do the findings of this study really mean? How do they contribute to the understanding of the process of recovery from a (FES)? Furthermore, in the discussion of this study's model, my aim is to, as Charmaz (2006) describes, pull the pieces together. This will be accomplished by discussing the inter-relatedness between phases, with the re-shaping of an enduring sense of self as a central feature to all phases of the model.

\section{Discussion of Emergent Model}

This study's model emerged through analysis and interpretation of its research data which led to the generation of a substantive theory that accounts for the process of recovery from a FES. Based on a total of thirty interviews with individuals who had experienced a FES, family members, clinicians, and a partner, categories and subcategories evolved that can be characterized as phases in this process. This model addresses how a participant's enduring sense of self was reshaped throughout their recovery following a FES. The process of recovery for these participants was interpreted as involving the following phases: 'Lives 
prior to the illness', 'Lives interrupted: Encountering the illness', 'Engaging in services and supports', 'Re-engaging in life', 'Envisioning the future'; and the core category 'Re-shaping an enduring sense of self' that occurred through all phases. As will be described later in the chapter, there are a number of facilitating factors and potential impediments to the evolution of the process of recovery from a FES.

The process of recovery that emerged in this study is comprised of a series of intertwined phases that occur over time but are not necessarily linear. This observation is echoed by Charmaz (2006) in her research on living with chronic illness who asserts that “experiencing illness, much less all its spiraling consequences, does not always fit neatly into one linear progressive process" (p. 173). This is also consistent with Ralph (2005) who states that consumers identify the recovery process as an occurrence where "one may move from any stage, both backward and forward, depending on where individuals are in their mental health journeys" (p. 137).

The unique features which differentiate this emergent model from other models will be reviewed in the following section.

\section{Unique Features of the Model}

Although the concept of recovery has been explored and discussed extensively, this model is unlike previous models of recovery in long-term mental illness (Jacobson, 2001; Spaniol et al., 2002; Young \& Ensing, 1999) and is also different from the common elements of recovery as described by Davidson and colleagues (2005). The differences in recovery elements have particular relevance to clinical practice and will be discussed in the implications chapter. 
Overall, this study's model captures the unique recovery process for young people experiencing FES. One distinct feature of this model is knowing who the participants were prior to the onset of illness. Having the knowledge of who participants were prior to their illness sets the foundation for understanding how participants' sense of self endured and was reshaped throughout their recovery process. Another unique feature is the role of hope which is also experientially different for young adults recovering from FES. These young people did not entirely lose hope with a need to renew it, as has been described in the models of recovery in long-term mental illness. Rather, hope emerged as a phenomenon that was essential to the promotion of their recovery.

In addition to experiencing hope from the onset of treatment, participants also had the expectation that their symptoms would be controlled early in the illness, versus partial or episodic control as in the case of long-term illness. Their ability to confidently manage symptoms was evident by the degree of self-agency participants possessed as they engaged in services and supports and re-engaged in life. Self-agency "refers to the experience of oneself as the agent of one's actions" (David, Newen, \& Vogeley, 2008 p. 523). In addition to highlighting the role of self-agency, this model also considers the developmental phase of emergent adulthood. Given that participants were young adults, parents had an important role in their recovery and were also in need of support. For example, while parents had key roles in the treatment continuum for their young adult children, it appears that they did not always feel like partners in their child's care, sometimes feeling excluded by clinicians and in need of support themselves.

Re-shaping an enduring sense of the self, in contrast to reconstruction of the self, is also unique to this study and is identified as the core category in this recovery model. Given that it is the core category of the model, a more extensive discussion of reshaping an 
enduring sense of self follows. Reshaping an enduring sense of self involves a complex process of affirming the characteristics of the self that were of value (e.g., enduring conceptions of the self as a good student, friend, caring son or daughter), while simultaneously recognizing the need for change in other aspects of the self. Although reconstruction of the self during recovery from long-term mental illness has been described in previous research (Davidson \& Strauss, 1992; Pettie \& Triolo, 1999; Young \& Ensing, 1999), in this study participants' sense of self was reshaped as opposed to reconstructed throughout their recovery process. Specifically, participants were able to preserve aspects of their sense of self and yet, also accommodate to the demands of the illness. It is noteworthy, that the majority of participants did not describe their sense of self as being overshadowed by the illness. Also, while they experienced challenges, participants did not define themselves in terms of a psychiatric patient role, suggesting that FES has a less powerful impact on the sense of self than participants described in other recovery models (Ridgway, 2001; Spaniol et al., 2002).

Re-shaping the self seemed to occur through an ongoing process of self-reflection throughout the participants' recovery process and not at a specific time as in the recovery model described by Young and Ensing (1999). These authors report that the process of self re-definition for their participants occurred in the "middle phase" of their recovery model. Furthermore, they state that the existing self may shatter and require rebuilding or reconstruction:

...Once the recovery process has begun and people have developed attitudes and behaviors that produce positive change and growth, they often engage in an exploration of both their internal and external worlds. Based on participants' input, mental illness can shatter the core sense of self that was present in the pre-morbid condition. This trauma leaves one not only with the daunting task of reconstructing a new sense of self but also with the task of determining how that self fits into the external world. (p. 225) 
The notion of reshaping an enduring sense of self that does not necessitate "a reconstruction" is in contrast to the findings of Davidson and Strauss (1992). Although not focused on the onset of a FES, Davidson and Strauss (1992) explored the sense of self in recovery from severe mental illness. In their sample, 25 of 66 participants had schizophrenia. Their findings indicate that a "rediscovery and reconstruction of an enduring sense of self as an active and responsible agent provides an important aspect of improvement" (p. 131).

As part of their reshaping their sense of self, participants also identified the personal growth that occurred within themselves, and for some, with the relationships they had with others following their FES. As they progressed, participants developed new skills, made better choices, improved relationships, and strengthened their self awareness. Onken et al. (2007) acknowledge that if having a mental illness “is a test of one's resources and a challenge to overcome with creativity, drive, and ambition to be well, then recovery is an expression of one's ability not to only survive but to thrive in the midst of extremely difficult circumstances" (p. 15).

The following sections explore each phase of this study's recovery process model and compare its differences and similarities to the findings of the literature. During the discussion of each of the phases, evidence of inter-relationships between phases as well as how participants reshaped their sense of self will be highlighted.

\section{Lives Prior to the Illness}

Knowing who the participants were prior to the onset of illness was a critical component of the emergent theory of recovery. Specifically, the participants' prior knowledge of self set the foundation for understanding how participants' sense of self endured and was also reshaped throughout their recovery process. Exploring this initial phase of the recovery process is a unique and important aspect of this study, since the recovery 
models reviewed do not address individual's lives prior to the illness. Having an understanding of participants' sense of self with a focus on social participation prior to the illness, is thought to provide a baseline for monitoring recovery and the multiple factors influencing it (Woodside, Krupa \& Pocock, 2007).

As a group, participants were under stress, which included stress typically associated with young adulthood, such as dealing with parental relationships and working while going to school. As well, a number of participants experienced stress related to risk taking behaviour. Specifically a majority used drugs (mostly marijuana) which for some resulted in altercations with law enforcement. Drug use prior to psychosis is a common characteristic that has also been described by Woodside et al. (2007). Sixteen of their 25 participants used illicit drugs or alcohol prior to their first episode of psychosis. In my study, as their recovery progressed, participants stopped using drugs, in order to better manage their illness and as such became better equipped to manage stress in their lives. This highlights how reshaping of the self evolved in the illness context. Specifically, it became apparent to these young people that they had to stop using drugs in order for their recovery to progress. In doing so, their sense of self changed from a young person who takes drugs, to a young person with an illness who does not take drugs.

Despite the challenges associated with drug use and life stressors, participants also had strengths. They had a social circle of friends, most participated in academic pursuits, and some were able to draw on the support of their families. Participants also had varied interests which provided a focus for an enduring sense of self throughout their recovery.

Overall, participants' sense of self prior to their illness experience endured throughout their recovery process, while some aspects of self were reshaped. Participants relinquished aspects of the self that were incompatible with recovery while at the same time drawing on 
strengths while recovering. McCay et al. (2006) also suggest that a young adult's capacity to maintain a healthy sense of self during a FES may help them work towards recovery.

With a greater understanding of who participants were prior to the illness, I will now explore how participants' lives and sense of self were affected when they first encountered the illness.

\section{Lives Interrupted: Encountering the Illness}

The onset of illness was a profound disruption in the lives of participants as they moved into adulthood. This disruption proved to be difficult for participants in a number of ways, including having a significant impact on their sense of self. Addington, van Mastrigt, Hutchinson and Addington (2002) (as cited in Boydell, Gladstone, \& Volpe 2006), describe the process of becoming psychotic as a disruption which is potentially devastating for the individual and those around them, disturbing social networks and relationships with family and peers, as well as disrupting school, work, and occupational functioning.

As participants encountered the illness, they experienced a range of symptoms and strong emotional responses for an extensive period of time. This is similar to other recovery models where there is a marked period during which the individual feels despair, confusion, and disconnection from others (Jacobson, 2001; Ridgway 2001; \& Spaniol et al., 2002). In addition, McGorry (1992) describes how new and unfamiliar symptom occurrence can produce a major crisis for the individual and family system requiring great emotional and cognitive adjustments. Participants in this study were able to describe the onset of their symptoms with clarity and detail, outlining initial adjustments that occurred in their lives. Participants spoke openly and described some of their hallucinations and delusions. During the interview, they were eager to talk about their symptoms, as it seemed to contribute to an understanding of their process of recovery. Participants' attitude toward discussing their 
experiences seemed to reinforce McGorry's (1992) assertion that "the level of ultimate recovery will be the result of a dynamic process involving many factors, including the patient's attitude and response to the experience" (p. 11).

Once participants experienced symptoms, most sought help over time. Although, these young adults were in the process of defining themselves and seeking independence, they still needed the assistance of parents/adults in seeking help. Boydell et al. (2006) also highlight that the role of adults in the lives of young people are a prominent influence in initiating help-seeking.

The process of help-seeking remained an arduous endeavor for participants and their families. Several participants and their families were unable to obtain the necessary help from their family physicians, or from both general and specialized emergency departments. As well, numerous help-seeking attempts were required to obtain effective treatment. One could speculate that these frustrating attempts at help-seeking shook the confidence and selfesteem of participants. Many of the participants and their families described periods of weeks, months, and in some cases years during which time they attempted to "self-manage" symptoms, and sought but failed to obtain the help they required to manage their illness. Help-seeking delays have also been reported in my previous research (Czuchta \& McCay, 2001), where on average over 22 months passed from when parents first reported signs and symptoms of illness in their adult children to the time of their child's hospitalization. Boydell et al. (2006) also found that significant delays occurred between the emergence of symptoms and the initiation of treatment in part because "psychosis is often overlooked or misdiagnosed by doctors" (p. 54). Furthermore, half of the participants described that their symptoms continued untreated until an urgent help-seeking response (akin to a crisis) was required. A study by Bland and colleagues (1997), although not directly 
focused on a FES, also found that as the symptoms in the individual increased in severity there was a marked urgency to secure help by parents. The International Early Psychosis Association (IEPA) working group (2005) draws attention to the fact that the delivery of clinical care of individuals with a first episode psychosis is "often delayed, piecemeal and alienating to patients and families" (p. s120). In their study of trajectory to a first episode of psychosis, Corcocan and colleagues (2007) also found that families focused on the many problems and frustrations they encountered in seeking help for their family members in crisis.

Once participants secured help and found out about their illness, varied emotions ensued. Clearly, feelings of devastation and disbelief were apparent. Initially, this emotional response appeared to challenge some of the participants' sense of self. However, one study participant described that receiving the diagnosis was helpful in that it provided a way to understand the illness experience.

Ridgway (2001) draws attention to the period of despair that often follows the diagnoses of psychiatric disorders, and the negative expectations and stereotypes that accompany such illnesses. In a study by McCay, Ryan and Amey (1996), group members recovering from a first episode of psychosis expressed concern about receiving a diagnosis like schizophrenia because it led to a "fear of permanence" as well as a profound loss of hope for the future. Deegan (1994) who recalled her first episode of schizophrenia and described the shattering of her world, her hopes and dreams when she first learned she had an “incurable illness." Deegan (1994) further characterized her deep sense of despair as "a wound with no mouth, a wound so deep that no cry can emanate from it" (p. 153). 
There appeared to be a parallel reaction of primary participants and their family members upon finding out about the illness. These reactions are also similar to the emotional responses outlined in The "Emotional Stages of Response" by Baxter and Diehl (1998). Although not focused on a FES, this is a conceptual model of family members' emotional resolution following "the trauma of discovering that a family member has a severe mental illness" (p. 353). Baxter and Diehl (1998) suggest that family members may experience quite a shock as they realize that something is seriously wrong with a loved one. As a result, families during this stage may need support, crisis intervention, and an explanation of a future prognosis.

Despite this prominent need for family support in the early phases of treatment a number of participants' parents did not feel adequately supported by clinicians and treatment settings which further served to shake their confidence. Conversely, other participants' parents felt supported when in the care of the specialized treatment centre. Schulz and Zipursky (2002) draw attention to the importance of families being engaged early in treatment process, and that their emotional and educational needs be understood and provided for. Family support is an important component of enabling family members to support their young adult children in the early phases of the illness. The need for support for parents from the onset of their family member's illness, through their continuum of care has been highlighted in this study. This is in contrast to the recovery models in long-term mental illness where emphasis is placed on the individual's need for support from families.

Not only did participants have to grapple with being given a diagnosis, they also had to temporarily curtail their activities during their initial treatment. For some participants, inpatient hospitalization was a necessary component of treatment during the acute phase of illness which further disrupted their lives. Regardless of whether participants were 
hospitalized or not, all felt their independence was challenged (e.g., having to move back home, taking leave of absence from work or school, becoming more dependent on others), their social circle changed, and their life activities were reduced, at a time when they were attempting to assert themselves as young adults. Their lives were undergoing enormous change as a result of experiencing the illness. In essence, their lives were interrupted, as were their life activities that until this point served to define their sense of self. This is consistent with the findings of Woodside et al. (2007) who found that the first episode of psychosis is characterized by a breakdown of organized and socially appropriate activity. As participants experienced symptoms, faced challenges with help-seeking, endured disruption in their life activities, and considered the potential impact of the illness on their lives, a lack of confidence in themselves and uncertainty about the future emerged.

However, uncertainty and loss of confidence early in the illness was relatively shortlived. Participants described how clinicians provided encouraging messaging about the possibility of recovery early in treatment. Inherent within this messaging was hope. Although hope has been identified as an important aspect of the process of recovery, findings from research of recovery from long-term mental illness (Anthony, 1993; Deegan, 1996; Kylma et al., 2006; Onken et al., 2007, 2002; Ridgway, 2001; Russinova, 1999; Torrey \& Wykiz, 2000) suggest that individuals experience a need for renewed hope. In contrast, the finding that hope has not been lost is an important unique contribution of this study. Clearly, hope may be held in abeyance but hope for these young people and their families were not lost and were readily accessed with clinical intervention. Schulz and Zipursky (2002) highlight that "perhaps the most important lesson that the field has learned from studying patients in their first episode of schizophrenia is that of hope" (p. 233). Being met with hope and optimism, especially for young people early in treatment, is of key importance for individuals to support 
recovery (Roberts \& Wolfson, 2004) and is accomplished through interactions that the individual has with others in their environment (Onken et al., 2007).

Using hopeful language is particularly important for young people at the beginning of the illness as it underscores the question of what is possible in life. Andresen et al. (2003) (as cited in Kelly \& Gamble, 2005) state that "using hopeful language that incorporates understanding, optimism, and empowerment, helps a person, heal, and resume their previous social role..." (p. 250). Furthermore, as Torrey and Wyzik (2000) assert "just as hearing a dire prognosis can be devastating, hearing hopeful messages can be inspiring” (p. 212). Deegan, (2004) and Johnson, (2000) (as cited in Onken et al., 2007), also underscores this by acknowledging that statements made by health care professionals that express the supposed chronic nature of the illness and profess limited prospects in life can be detrimental to an individual's recovery process

Ridgway (2001), in her review of accounts of recovery from psychiatric disability, found that these individuals were "told that they should hope for no more than a life of prolonged disability... [and having been told] came to believe: I have a mental disorder and will never get better" ( $\mathrm{p}$ 337). In contrast, participants in this study were told of the possibility of recovery. Unlike participants in Ridgway's (2001) study, this study's participants were able to begin their recovery early on. Not only were they given their diagnosis but also provided with optimistic messaging about the capacity to manage their illness, and their capacity to resume an active life. It is possible that this approach can help these young people avoid what Harding, Zubin and Strauss (1987) have identified as "careers in chronicity". It is evident that providing hope and the positive messaging of recovery served to restore a sense of self-confidence for participants and their capacity to become engaged in services and supports. 
In summary, participants' lives and sense of self were affected by encountering the illness as well as by the process of seeking help and initial contact with clinicians. As supported by the literature, participants in this study experienced strong emotions associated with symptom occurrence, experienced significant disruption in life activities, and were involved in an arduous process of help-seeking. Some of the families described the inconsistent support they received from health care providers. Participants received messages of hope and the possibility of recovery early in treatment which has not been emphasized in existing recovery models. As a result of the strong messages of hope they received from clinicians, and contrary to the literature, participants emerged from this encountering the illness phase better prepared to engage in services and supports.

\section{Engaging in Services and Supports}

It was evident that the optimistic messaging of clinicians was a key factor which facilitated participants' realization that it was possible to recover. As participants heard these optimistic messages they began to feel understood and expressed a strong desire to get better. Increasingly, participants trusted their health care providers which seemed to promote a willingness to engage in services and supports that involved the use of medication and nonmedication related strategies such as reading, writing and exercise to manage illness symptoms and to reconnect with their sense of self. Ultimately, the participants made the choice with the support of their clinicians, to use these strategies to work toward feeling better.

This study's model offers insight into the important role of clinicians with regard to engaging participants early on in the recovery process. Overall, clinicians recognized the individuality of the person and were interested in participants' efforts to resume their lives. In this way the "self" was preserved. It is apparent from the findings that the majority of 
clinicians collaborated with participants in a respectful manner and were committed to seeing participants progress in their recovery. Hamilton Wilson and Hobbs (1995) underscore the importance of individuals with FES being actively engaged with clinicians; in essence working in concert with clinicians who are guided by the principal of empowerment.

Unlike the model described in this study, other recovery models reviewed (Jacobson 2001; Ridgway, 2001; Spaniol et al., 2002; Young \& Ensing, 1999) do not describe the importance of clinicians' role in the recovery process, specifically in establishing and fostering a therapeutic relationship. One model, (Jacobson, 2001), does however identify that recovery is a result of the interactions that occur, both internal and external to the individual. Furthermore, Jacobson states that the conditions in which interactions occur, for example, the attitudes of self and others, do have an impact on the recovery process. Additional authors (Topor, Borg, Mezzina, Sells, Marin, \& Davidson, 2006) identify that "relationships have a tremendous impact on how individuals recover from schizophrenia" (p. 17). Their study, although not focused on a FES, found that therapeutic relationships with professionals were central to recovery. Specifically, because of the expert knowledge that clinicians had, participants described a sense of security and safety, in the context of the relationship, especially in making sense of their symptoms. Participants in the current study underscored the importance of being understood by clinicians. This may be especially important given that this was their first contact with the formalized mental health system.

It was evident in this study that the formation of trusting and optimistic relationships with health care providers was inextricably linked to participants' willingness to take medication. It is increasingly recognized that medication plays a critical role in the resolution of symptoms and is a necessary precondition for recovery. The role of medication in recovery may be related to improved pharmacotherapy in the treatment of schizophrenia 
(Tauscher-Wisniewski \& Zipursky, 2002; Whitehorn et al. 2002). The advent of novel antipsychotic medication and prompt treatment early in the course of illness greatly increases the chance of symptoms resolving in a timely manner as was the case in this study.

The degree of self-agency that participants possessed was highlighted through their choice to take medication as they engaged in services and supports. As cited in Onken et al's. (2007) comprehensive review, recovery is rooted in a sense of self-agency. Onken et al. (2007) has summarized the works of well known recovery authors such as Davidson and Strauss (1992), Harding and Strauss (1992), and Roe and Chopra (2003) and asserted that "recovery is founded on an assumption of individual competency to surmount the challenges posed by the psychiatric disability" (p. 11). Lieberman et al. (2008) add that recovery encompasses a process of assuming self-agency by developing hope, taking responsibility for one's life, actively participating in treatment, and defining and pursuing personally meaningful goals. Although these features which reflect self-agency have been described extensively in the literature (Jacobson \& Greenley, 2001; Kotake Smith, 2000; Lieberman et al., 2008; Lovejoy, 1982; Mead \& Copeland, 2000), there are no studies addressing the concept of self-agency in the context of the recovery process from a FES. Although some participants in this study were initially reluctant to take medication, and had to endure various trials and experience challenging side effects, all of them chose to take medication which is illustrative of self-agency.

Overall, "medication compliance" did not appear to be an issue for this group of participants. In this study, all participants recognized the role that medications played in their recovery, with two selecting their medications as objects that symbolized their recovery. The use of these objects served to emphasize the role of medication in these participants' recovery and allowed for personal meaning to be revealed through their discussion. 
Similarly, Charach, Volpe, Boydell and Gearing (2008) also found that young adults who had recovered from their first episode of psychosis viewed medication as being instrumental to their recovery. Furthermore, despite experiencing side effects they acknowledged that medication had helped them to feel better. Although the importance of medication in recovery is consistent with findings of other recovery models (Spaniol et al, 2002; Young \& Ensing, 1999), a difference in the perception of medication and symptoms did emerge in this FES model compared to the long-term models. Specifically, participants in this study expected that their symptoms would be controlled early in the illness, which varies considerably from models of long-term recovery, where the expectation is for partial or episodic control.

The existence of collaborative relationships with clinicians was also mentioned by participants. Not only were participants able to develop a relationship that was characterized by trust, but one which reinforced the importance of self-agency through collaboration and negotiation concerning difficult issues, such as taking medication. I believe that collaboration with clinicians concerning treatment decisions is especially important for emerging young adults who are experiencing a FES, for whom the experience of having an illness with the need to take medication typically associated with stigmatized illness may be a new and difficult experience. The IEPA working group, (2005) highlight the importance of clinicians' capacity to negotiate with individuals about which interventions should be implemented and in what way. Specifically, they recommend that recovery work "should emphasize development mastery in relation to the psychotic experience" (p. s123).

Deegan (2007) describes the need for shared decision-making versus the use of threats and coercion with regard to the use of psychiatric medication. Deegan (1988) recalls that when she was first diagnosed with schizophrenia as a teenager, her psychiatrist told her 
that she had an illness from which she would not recover, and that she would have to take neuroleptics for the rest of her life. She described that in effect she was given a prognosis of doom; one which undermined her sense of competency and belief in herself. In light of this, she stopped taking the medication to reflect rejection of such a hopeless prognosis. As a result, she recalled that she became psychotic again and had to be re-hospitalized. Deegan (2007) further reflects that had her psychiatrist coupled the use of medication with the goal of recovery, perhaps her endorsement of the prescribed medication would have been different. Similar, to participants in this study, Deegan (2007) described that eventually she was able to adopt the use of medication as an active self-determining stance. She then took medication as a means to a goal, not a goal in itself, which was very different than passively taking medications.

As described, engagement in services and supports involved a variety of strategies participants used (aside from medications) to help self-manage the illness and reconnect with their sense of self. In particular, they identified that having the support of and engagement of others (apart from clinicians) was also helpful early in their recovery. Clearly, for these participants, recovery did not happen in isolation as they had the support of friends and family around them. Participants accessed the help of family and/or friends during their acute phase of illness. For example, participants described visits with others while in the hospital that provided reassurance and support. The importance of having the support of others during recovery is consistent with the literature. Ridgway (2001) analyzed four seminal consumer narratives which revealed a number of themes. One of the prominent themes that emerged revealed that "recovery is not accomplished alone - the journey involves support and partnership...people do not claim to recover on their own; they describe recovery as a process that involves many people" (p. 339). Topor et al. (2006) also underscore the 
importance of social interaction to the recovery process, which may include interactions with family, and or friends.

For participants in this study, recovery did not occur in isolation, which reflects tenets of symbolic interactionism. Jacobson (2001) asserts that "symbolic interactionism suggests that recovery is defined through actions and interpretations that social units, either groups or individuals, make to themselves and to one another" (p. 249). Furthermore, it underscores the notion that individuals give meaning based on interactions with those around them. Jeon (2004) draws attention to Mead (1934/1959) and Blumer (1969) who assert that meaning is a social product made possible through social interaction with others. It is through their interactions with others that participants' were able to derive further meaning for their recovery. For the most part, interactions with significant others mirrored to these young people that they were inherently of value, regardless of their illness.

Aside from having the support of others, participants also began to use other nonmedication related strategies such as making lifestyle changes, challenging their thoughts, and resuming participation in personal interests as a way to enhance their recovery process. Many of these strategies were based on interests participants had prior to their illness, in many instances were self-initiated, and supported their enduring sense of self. This is consistent with authors (Jacobson \& Greenley 2001; Kotake Smith, 2000; Spaniol et al., 2002) who highlight that facilitating recovery can be accomplished by using personal wellness strategies such as contacting or visiting friends, engaging in creative activities, meditating, and exercising, all of which serve to promote health and manage the challenges presented by the illness. Participants in this study engaged in a variety of such activities which offered them a sense of personal fulfillment. 
In this study, four participants highlighted the role of spirituality as a strategy that they used in their recovery. Spirituality is becoming more prevalent in the recovery literature, and is cited as a pillar of many participants' recovery journeys (Onken et. al., 2007;

Russinova \& Blanch, 2007). The value of spirituality is addressed by House (2001) (as cited in Kelly \& Gamble, 2005, p. 249) asserts that "recovery from schizophrenia, like recovery from any catastrophic illness, presents a great challenge to the human spirit." In the model by Young and Ensing (1999) almost all participants described spirituality as an important component of their recovery process in that it allowed them to experience strength, hope, and inspiration during their recovery. Deegan (1993) (as cited in Kelly and Gamble, 2005) describes spirituality in recovery as being about finding meaning and hope in suffering. I found that some of the participants in this study used spirituality as a strategy to find meaning in their illness and protect the self from being overwhelmed by painful experiences by strengthening their resiliency. For example, as we discussed her personal object which was a cross pendant, Sandy equated herself at times with the suffering Jesus whom she derived strength from during her recovery. Henry, in his selection of the song lyrics with religious overtones, derived comfort in knowing that his past ways were forgiven by God. Finally, Leah equated Mother Earth with her source of spirituality as a way of symbolizing help that can be called upon when needed.

Deegan (2005) termed the use of non-medication related strategies for recovery as "personal medicine". This concept refers to "self-initiated, non-pharmaceutical self-care activities that served to decrease symptoms, avoid undesirable outcomes such as hospitalization, improve mood, thoughts, behaviours, and overall sense of wellbeing” (p. 31). Participants in Deegan's (2005) study, although not focused on recovery from a FES, discovered personal medicine strategies in the everyday context of their lives. Also, personal 
medicine did not necessarily replace the use of psychiatric medication for the majority of participants as both were often used together. Deegan (2005) described that two main categories of personal medicine that participants used were related to activities that gave meaning and purpose to life and specific self-care strategies. Deegan (1996) further endorses that the use of such strategies allows individuals to be active in their own recovery rather than a recipient of services or beneficiary of the efforts of others.

Early in the course of illness, participants described feeling better after using medication and non pharmaceutical strategies to manage their symptoms. This finding is in contrast to some of the participants in Spaniol study (2002) who were in the phase "struggling with the disability" for decades, and were identified by these authors as having little hope for recovery. In the current study, once participants began to feel alleviation from their symptoms the notion of recovery as something more than management of symptoms began to emerge. This was described by participants as a process that occurred over time. The length appeared to vary for each individual, and was not specifically indicated.

In summary, as participants received hopeful messages concerning recovery, they felt increasingly understood by the health care team and developed a relationship with them that was based on trust. As a result they were able to engage in services and supports. As they did so and with the help of their clinicians, participants became self-agents making the choice to use medication and non-medication strategies to support recovery. Their non-medication strategies, which very often included activities and interests that they had prior to their illness, helps to support the notion that participants' sense of self endured and was reshaped versus reconstructed through the recovery process. The use of this "personal medicine" was only possible because clinicians recognized participant's individuality, and showed an openness to collaborate and negotiate strategies that helped them progress in their recovery, 
manage illness symptoms, and reconnect with their sense of self. As they progressed through their early phases of services and supports, participants began to feel better, so much so that they began to re-engage in life.

\section{Re-engaging in Life}

As participants re-engaged in life three key points were apparent: their ongoing use of self-agency, continued use of supportive relationships and the development of age appropriate short term goals. As participants re-engaged in life it was apparent that selfagency became increasingly important to their recovery. As active self-agents, they reflected on what may have caused their illness and then elected to make the necessary changes to prevent reoccurrence. They also had the continued support of professional relationships and expanded to using the support of others as they re-engaged in life. Participants shifted their focus from the illness to establishing short term age-appropriate goals that reflected previous activities they were engaged in, their interests, and promoted their independence. As they set these goals, they received positive reinforcement from clinicians and others around them which further reinforced their sense of agency.

An individual's sense of agency to endure challenges associated with having a mental illness can "be augmented by an environment that fosters positive change" (Onken et al., 2007, p. 11). Participants' sense of agency was particularly evident when some of them moved beyond the support of clinicians and family to actively re-engaging with friends they had prior to the illness. These interactions provided participants with routines and social interactions. This reflects the notion put forward by Ridgway (2001) who asserts that "people do not claim to recover on their own; they describe recovery as a process that involves many people" (p. 339). 
As participants renewed their relationships with friends, they also recalled facing challenges in doing so. Specifically, they felt a need to show their friends that they were "normal" and while they personally acknowledged their illness, participants did not want to appear to have an illness often concealing it from others. Perhaps their efforts to conceal their illness and appear "normal" were a result of the perceived external stigma associated with their illness. Relationships outside of the immediate family are a very important developmental feature of emergent adults. It could be that participants may have been afraid that if their friends knew about their illness it would disrupt any possibility for real emotional and physical intimacy or even result in ridicule and/or rejection.

Some participants described encountering unhelpful interactions with their parents as another challenge to recovery and re-engaging in life. This may be congruent to the developmental phase of emerging adulthood, whereby individuals are asserting themselves as adults. As such, there seemed to be an increased focus on discussing relationships with friends versus with their parents.

Unlike other recovery models (Ridgway, 2001; Spaniol et al. 2002; Young \& Ensing, 1999) where the majority of participants endorsed the value of peer support in their recovery, five out of ten participants in this study acknowledged the value of knowing and interacting with others who had a mental illness. One reason may be that the remaining five did not have the opportunity to have contact with others who had a similar illness given the type of treatment they accessed (e.g., individual outpatient services). Furthermore, the remaining participants did not have the opportunity to formulate relationships with other mental health clients over an extended period of time. Another possibility is that perhaps given the worries that participants had about the stigma associated with mental illness, these young people did not want to form relationships with peers who had a mental illness. 
As stated, participants were determined to make the necessary changes in their lifestyles in order to prevent any future reoccurrence of the illness. Participants developed an understanding of the need for change by exploring underlying causes of their illness, either with their clinician or independently. As participants determined what changes were needed, they experienced themselves as self-agents, following their own course. The need to understand the underlying cause of the illness in the context of the recovery process is consistent with Spaniol et al. (2002) and the findings of Jacobson (2001) in her discussion of explanatory models that were found in the recovery narratives that she analyzed. In Jacobson's study, participants appeared to focus on either biological, or a combination of biological and environmental explanatory models for their illness. Similarly in the current study, six out of ten participants understood drugs as an underlying cause of their illness. In doing so, participants took greater control of their recovery by not only continuing in treatment but also by making the personal decision to bring about change in their lives. For example, John (who believed his drug use caused his schizophrenia) considered the advice of his psychiatrist and family when he chose to stop using drugs. In addition, some of the participants viewed stress as contributing to their illness, and therefore, made efforts to manage stress in their lives more effectively with a personal commitment to being healthy.

This capacity to bring about behaviour change reflective of an individual's explanatory model of illness reflects what Jacobson (2001) describes as efforts to make the self “... more congruent with the solutions suggested by the explanatory model” (p. 253). Young and Ensing (1999) conceptualized this ability as self-empowerment whereby participants in their study were able to make a commitment to discontinue destructive behaviours and habits, and viewed this as an important step towards their recovery. According to Linhorst, (2006) the subjective experience of empowerment includes perceived 
agency, control, and self-esteem. In this study, all participants chose to stop using drugs or reduce stress early in their recovery. This is in sharp contrast to the seven out of twelve participants in the Spaniol et al. (2002) study who struggled with continued substance abuse in addition to schizophrenia, and identified this as a major challenge to their recovery. Seltzer, Greenberg, Krauss and Hong (1997) suggest that individuals diagnosed with schizophrenia in early adulthood, may have not yet had the time to establish independent living and employment skills, and a sense of themselves as independent adults. As a result, the onset of schizophrenia in early adulthood can disrupt the attainment of such developmental milestones (Malla, Norman, Scholten, Manchanda, \& McLean, 2005). Participants in this study, with the support of others (e.g., family, friends and clinicians), were able and determined to focus on resuming non-illness related activities. These activities included formulating short goals that reflected their interests, promoted independence and allowed them to get on with life, and were reflective of their developmental phase of emerging adulthood. These goals were typically centred on work and/or school, living arrangements and relationships. Furthermore, participants viewed setting non-illness related goals as further evidence that they were recovering. The ability of this study's participants to set short-term goals is consistent with the general acceptance within the literature that recovery from mental illness encompasses more than just symptom remission, but also reengagement in seeking a meaningful life (Tweedell, Forchuk, Jewell, \& Steinnagel, 2004).

In this study clinicians collaborated with participants in supporting them to achieve their identified short term goals. This approach is consistent with Edwards and McGorry (2005) who draw attention that early intervention in psychotic illness not only requires treatment of presenting symptoms but should also take into account the individual's development and future goals. The premise of a clinician that supports participants' short 
term goals early in recovery is in contrast to the analysis of recovery narratives described by Ridgway (2001). She cites examples whereby individuals recalled having to seek out professionals who would "honor their authority to make their own decisions... and who are able to work from a position of partnership" (p. 340). Participants were not hindered in their pursuit of goals unlike many of the participants in the recovery narratives described in the literature. Ridgway (2001), for example, draws attention to a narrative in Unzicker (1989) stating "alienation also arises from being told by mental health professionals that one has no positive future and will never recover" (p. 74). Furthermore, Ridgway (2001) identifies those participants in her recovery narratives that had to "reclaim a sense of purpose in their life" (p. 339). It was apparent that participants in this study did not feel without purpose, as they had the support of others and were enabled to pursue their goals.

In summary, participants' ability to re-engage in life, and continue with their own defined short term goals, despite experiencing challenges that included the influence of external stigma, and unhelpful interactions with parents, was evident by their own degree of self-agency and use of supportive relationships. As they re-engaged in life, their sense of self continued to be strengthened and reshaped as they began to envision a future beyond their illness.

\section{Envisioning the Future}

Overall, during this phase, it was apparent that as participants worked to sustain recovery they began to envision their future. Specifically, participants focused on setting goals that were indicative of their development as young adults including establishing longterm goals such as career plans, marriage, and one day possibly starting a family. At the same time as they were planning for the future, they continued to be concerned about the effects of stigma and the possibility of relapse which threatened their sense of self. To help manage this 
threat, participants were determined not to be overwhelmed by a potential relapse and described their efforts to employ self monitoring strategies. As participants' recovery evolved, they felt further removed from the illness, and were less reliant on clinicians for support. In conjunction with increased independence they also began to contemplate whether there was a need for ongoing medication, and/or ongoing treatment.

As stated, a central feature within this phase was the capacity of participants to envision their future by establishing goals that were not illness related. In essence, for the majority of participants, symptoms of their illness were well managed resulting in an increased focus on envisioning their futures as emerging adults. They were planning for a life beyond the confines of their illness and continued to have the support of clinicians and others behind them. Onken et al. (2007) highlight literature (Andresen et al., 2003; Jacobson \& Curtis, 2000) that suggests recovery is partly dependent upon the individual's internal drive, but also by the environment surrounding them; an environment characterized by support and opportunity.

Participants described continuing to receive hope inspiring messages from those close to them who believed that they could have a future and continue on with their identified longterm goals. I believe receiving these messages contributed to participants envisioning their future. Onken et al. (2002) and Mancini (2005) cite that receiving hopeful messages and encouragement has been identified as promoting individuals' recovery from mental illness. Furthermore, the statement by Spaniol et al. (1997) seems to underscore the importance of believing in future possibility, when they assert what achievements or what acts of courage and compassion are waiting to be released in every individual who has schizophrenia. This is in contrast to the views of participants in a study by Mancini (2005) who found that they were discouraged from engaging in "normal adult roles" and identified this as a key barrier to 
recovery. One participant in the Mancini study recalled "I was told...I could never go to school, I could never go to work. And I could never be a mother...” (p. 51).

Anthony (1993) describes recovery from long-term mental illness as involving "the development of new meaning and purpose in one's life, as one grows beyond the catastrophic effects of mental illness" (p. 15). This focus on the need to find new meaning can also be seen in the recovery model by Young and Ensing (1999), whereby participants sought “...out a new sense of purpose within their lives by taking on new challenges or new roles" (p. 228). In the extreme, Ridgway (2001) described that receiving treatment for a mental illness may result in becoming a "mental patient" or as she states, "To be a mental patient... is to become a no-thing..." (Unzicker, 1989, p. 77), which certainly supports the need to find new meaning. In contrast to Anthony's description and the long-term models of recovery cited above, participants in this study did not have to establish a renewed purpose in life. Participants in this study were able to continue on with their life ambitions as emerging adults and did not describe a search for renewed meaning. While the illness temporarily halted the pursuit of goals earlier in their recovery, participants were soon able to re-establish plans that helped them to continue to work toward fulfilling their previous ambitions. Also, unlike participants described in recovery models from long-term illness, the participants in this study did not have to experience long unpleasant hospitalizations or be subject to the negative messages by clinicians. Instead, they were supported to continue a self-defined path, relatively free of negative expectation. Consequently, participants in this study were able to identify long-term goals outside of the illness and continue on with their life aspirations, building on their previously stated strengths and identified values, all of which highlight their enduring sense of self. 
As participants recovered and became stronger, they paradoxically faced ongoing fears of relapse and stigma. Yet, it was clear that while they feared relapse, they managed this fear by using self-monitoring techniques and staying committed to their treatment plan. Although participants were concerned about relapse, it was also evident that they were confident that any relapse could be overcome, thus maintaining their expectation for symptom control. The fear of relapse also seemed to be associated with fears of stigma. Specifically, there seemed to be a pronounced fear that illness related external stigma could have a detrimental effect on future relationships and opportunities for employment; key areas which often define a young adult's sense of self. Although stigma has been identified as a challenge to recovery in the other recovery models (Kotake Smith, 2000; Spaniol et al., 2002; Young \& Ensing, 1999), I believe it was of particular concern to these participants because of the importance placed on forming intimate relationships in emerging young adulthood. Arnett (2000) draws attention to the period of emerging adulthood as a time where relationships become more intimate and serious.

Recovery models reviewed (Kotake Smith, 2000; Ridgway, 2001; Young \& Ensing, 1999) have discussed the notion of internal and external stigma, and the importance of reducing internalized stigma and addressing externalized stigma during recovery. However, participants in this study (including their parents) were largely concerned with the effects of external stigma and to a much lesser degree with reducing internal stigma. A possible explanation for this may be that these participants were reluctant to identify with such a stigmatized illness. McCay and Ryan (2002) assert that young people encountering schizophrenia for the first time are faced with the impact of a highly stigmatizing illness. As reflected by these participants, and as previous research has identified, the experience of 
being stigmatized can inspire a greater determination to re-address the societal restrictions on behaviour (Spaniol, Koehler, \& Hutchinson, 1994 as cited in Onken et al., 2007).

Although some participants in this study seemed to struggle with internal stigma to some extent, they did not identify themselves as solely consumers of mental health services, having a "psychiatric disability" or largely having to respond to internal stigma. That is, each participant's sense of self was not overshadowed by the illness experience, but rather reshaped through their recovery allowing them to continue with their lives. This finding is echoed in the views of Sells, Stayner, and Davidson (2004) who describe the notion of a durable self, which they refer to as "an understanding of who one truly is as distinct from an illness that one has" (p. 88). Furthermore, McCay et al. (2006) also highlight the notion put forward in the literature (Lally, 1989; McCay \& Seeman, 1998 ) that "the capacity to maintain a healthy sense of self may help individuals work toward recovery with a realistic acceptance of the illness, while withstanding the risk of being engulfed by the illness" ( $p$. 106). Perhaps this notion of a durable sense of self served as a buffer to prevent the development of internal stigma within participants. This is consistent with the assertions put forward by Davidson and Strauss (1992) who recognize that not having a secure sense of self can, at times, render an individual more vulnerable to the input of others. This occurrence then allows the stigma and the views of pessimistic clinicians to have an undermining impact on the individual's efforts toward improvement and how they see themselves.

As participants worked to sustain their recovery and were planning their future, they began to question the need for treatment. It appeared that most participants did not view themselves as becoming lifetime consumers of mental health services. Perhaps ongoing treatment and follow-up meant the need to accept the stigmatized identity over the long-term; a view they were unwilling to accept. It would seem that while clinicians may be able to help 
allay short term concerns about the stigmatizing nature of the illness, long-term concerns are more problematic especially when addressing internalized stigma associated with mental illness. As they sustained their recovery, some of the participants were looking forward to the possibility of discontinuing their medication.

In summary, during this phase of recovery, participants shifted their focus from overcoming the illness to envisioning the future which involved establishing long-term goals indicative of their development as young adults, such as career plans, marriage, and one day starting a family. They also expressed concerns about fear of relapse, stigma associated with mental illness, and questioned the need for ongoing treatment. These concerns evoked worries about a life long illness and the associated stigma that served to pose as potential threat to participants' sense of self.

\section{Summary Thoughts}

During the critical developmental phase of emergent adulthood, participants in this study experienced a FES, an event that was emotionally jarring and has been described by some of participants and in the literature as traumatic. It resulted in a significant disruption in life activities and independence, and at the same time triggered an arduous process of helpseeking. Their recovery process occurred over time and involved the reshaping of the participant's enduring sense of self.

Comprehending who participants were prior to their illness allows one to appreciate how their lives were affected by the illness. It also provides a baseline for following their recovery and for understanding the multiple factors that influence it. As participants engaged in services and supports, one could speculate that an individual going through this experience could easily loose sight of personal strengths and values. These participants, however, remarked on the personal strengths that had endured throughout their recovery. Reshaping an 
enduring sense of self involved a complex process of affirming the characteristics of self that were of value and constituted strengths, while simultaneously recognizing the need for change in other aspects of the self. The majority of participants identified enduring aspects of themselves that they leveraged throughout their recovery process, connecting who they were, to who they presently are, to who they would like to be. Frequently, these enduring personal traits were positive in nature and were described as strengths which promoted their recovery process. It is apparent that the core sense of self that was present before participants encountered their illness did not appear to be gravely altered or "shattered" by the occurrence of the mental illness to the same extent that previous models (Young \& Ensing, 1999) have suggested. Rather, participants in this study experienced a reshaping of an enduring sense of self.

Hope and hopeful messaging by clinicians and others around them early in the process seemed to support participant self-agency and instill within them a confidence that recovery was indeed possible. As a result, and contrary to the literature, participants were better prepared to engage in services and supports. They worked to become self-agents making the choice to use medication and non-medication strategies to support recovery. Their non-medication strategies very often included activities and interests that they had prior to their illness. Self-agency was reinforced because clinicians recognized participant's individuality, and showed an openness to collaborate and negotiate strategies that helped them progress in their recovery, manage illness symptoms, make necessary changes, and reconnect with their sense of self.

As they progressed through their early phases of services and supports, participants began to feel better, and as a result re-engaged in life. With a continuing emphasis on selfagency, and supportive relationships, participants defined short term goals, despite 
experiencing challenges that included stigma and unhelpful interactions with parents. Their sense of self continued to be strengthened and they began to envision a future beyond their illness. They began to establish long-term goals indicative of their development as young adults, such as career plans, marriage, and to one day start a family. Participants were determined to strive for their aspirations as emerging adults, which I believe is indicative of an enduring sense of self. They shared their concerns about fear of relapse and mostly external stigma, and sometimes questioned the need for ongoing treatment. These concerns evoked worries about a life long illness and the associated stigma which seemed to suggest that participants' sense of self and capacity for ongoing treatment maybe threatened over time. While participants described the impact and challenges the illness presented in their lives at the time of the study, the majority were determined not to let their identities become overshadowed by their illness.

The discussion of these findings provides valuable insights into the process of recovery from a FES and highlights some of the similarities, and unique differences between this emergent model and existing process of recovery models. Furthermore, this discussion offers possible answers to the current discourses surrounding recovery from mental illness raised by Roe et al. (2007). For example, does being in recovery vary [across individuals]? Unlike quantitative methods that are well suited to providing universal truths (Goering et al., 2008), this qualitative study identified a process of recovery from a FES, although ways in which participants experienced this recovery process varied. The chapter to follow will identify this study's implications for clinical practice, research, and policy, as well as the limitations of this study. 


\section{Chapter 7: Study Implications}

I just hope that like, somebody will hear this you know and benefit from it and realize that somebody can actually live through schizophrenia... it's no joke you know. I know how hard it is to face it but it's something that just has to be done, you have to overcome it, and look for a better...future (Henry).

This study's findings, taken collectively, have resulted in an emergent theory of recovery pertaining to a first episode of schizophrenia (FES). This FES model of recovery offers unique contributions to understanding the process of recovery. For example, the theoretical model reveals a recovery process that emphasizes a sense of self that endures and is reshaped throughout each of the phases of the model; it also highlights the pivotal role of self-agency, and the developmental phase of emergent adulthood, all of which have implications for clinical practice, future research, and policy. Without the contributions of a model of recovery, specific to FES, there is an ongoing risk that recovery practices and policies designed for individuals with serious and persistent mental illness will be indiscriminately applied to young adults living with early schizophrenia thus jeopardizing or compromising their potential for recovery.

\section{Implications for Practice}

In order to discuss the unique implications of this model, the study findings pertinent to FES practice will be contrasted with recovery components (as applied to long-term and persistent mental illness) found in the general mental health literature, described by Davidson and colleagues (2005). As stated in the literature review, Davidson et al. (2005) conducted a conceptual analysis of a broad range of consumer/survivor, and psychiatric rehabilitation literature and identified nine conceptual recovery components that serve to guide general mental health practice. Specifically, all nine recovery components will serve as a point of comparison to illustrate how recovery practice for FES needs to be viewed from a different perspective. The components reviewed are: renewing hope and commitment, managing 
symptoms, redefining self, incorporating illness, assuming control, overcoming stigma, becoming empowered and exercising citizenship, becoming involved in meaningful activities, and being supported by others. The nine components of recovery will now be reviewed and contrasted with the present FES model in order to highlight the unique practice implications of this model for FES.

One of the recovery components, renewed hope and commitment identified by Davidson et al. (2005) focuses on the need to renew hope and commitment in order to encourage motivation for a better future in the context of a severe and disabling illness. Typically individuals who have coped with schizophrenia and other types of major mental illnesses for some time have lost hope, and frequently did not receive encouraging messages about the possibility of recovery from clinicians. Until recently it has been observed "that mental health professionals have failed to promote a sense of hope and optimism, failed to give consumers choices, and failed to include consumers and family members as partners in the treatment process" (Bellack, 2006, p. 435). McGorry (2005) draws attention to the fact that the dementia model of schizophrenia endorsed the notion that individuals with schizophrenia be told that they could not recover, and if they did recover the diagnosis then had to be questioned. As such, one of Davidson et al's. (2005) recovery components emphasizes a need to renew lost hope in a life that has endured mental illness.

The experience of hope in FES is quite different from long-term mental illness. Although youth may experience a set-back and can feel acute despair, they have not lived a life without hope. This study's model highlights the need to create a hopeful context for the illness from the initial onset. Unique to this study's model, and as noted in the discussion chapter, participants derived strength from clinicians who, in the context of therapeutic collaborative relationships, shared realistic hopeful messages that were reinforced throughout 
the participants' recovery. Through their interactions with participants, clinicians promoted the view that recovery was possible. One might wonder why clinicians in this study were able to promote a sense of hope for recovery from the onset of treatment for these participants. It would appear that the clinicians in this study most likely worked with other clients who achieved recovery from a FES, thus inspiring hopefulness in the clinicians. McGorry (2005) suggests that clinicians have been encouraged and liberated to think more positively about their patients and their future prospects.

Hamilton Wilson, Hobbs, and Archie (2005) assert that clinicians working with clients' with FES are in a position to "set a stage" for treatment success. These authors share strategies that they describe as directed towards maximizing and empowering their client's recovery efforts that include amongst others the essential need for clinicians to demonstrate hope and optimism to clients and their families. Based on this study's findings, it is therefore imperative that hopeful messages about the possibility of getting better be conveyed to individuals during their initial contact with clinicians, within the context of a therapeutic and collaborative relationship.

Management of symptoms is another recovery component that offers a further point of comparison. For individuals living with persistent mental illness, there is an expectation that managing symptoms is ongoing. Recovery involves periods of good control, as well as difficult times when symptoms are not controlled as well. Furthermore, individuals shift from simply receiving services, to actively participating in, and using treatments of one's choice to bring symptoms under some degree of control.

Management of symptoms differed for participants in this study. From the onset of treatment, participants collaborated with clinicians towards the expected goal of symptom management. Clinicians in this study supported participants to identify and use a variety of 
strategies to manage their symptoms and in doing so promoted their clients sense of selfagency. Furthermore, participants in this study developed a confidence in their ability to manage their symptoms; taking responsibility for personal decisions related to medications and self-help strategies (based on their own established interests). Ultimately, in collaboration with clinicians, participants decided to take medications on their own terms which I believe not only helped to manage symptoms but also allowed participants to gain a greater sense of control in their recovery.

Hamilton Wilson et al. (2005) recommend adopting a consensual educational approach before commencing medication treatment. Specifically, they support the need for client's to make decisions concerning medications that they feel comfortable taking. McGorry (1992) further draws attention to the importance of patients having an active role in the treatment process and emphasizes the powerful influence that this approach can have on the individual's recovery process. Based on this study's findings, and supporting literature, it is important to promote young people's sense of self-agency as they manage their symptoms.

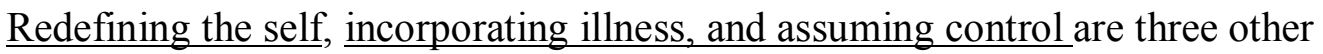
recovery components that enable the differences between the process of recovery for individuals with long-term illness and individuals in this study with FES to be understood. These three components taken together convey that people who live with long-term mental illness tend to initially assume a "primary social role as a mental patient" (Davidson et al., 2005 p. 484) rather than re-conceptualizing their illness as only one of their identities.

According to Davidson et al. (2005) individuals coping with long-term mental illness need to incorporate the illness within the self, which means accepting limitations presented by having the disability. Similarly, the recovery component of assuming control emphasizes the need 
for individuals with mental illness to move away from the identity of a disabled person to a person in recovery.

In contrast, FES participants in this study did not have to redefine their sense of self because they had a mental illness, but rather they carried on with an enduring sense of self by using their strengths, developing their interests, and pursuing their life goals and ambitions as emergent adults. Rather than incorporating the illness within the self, participants in this study reshaped their sense of self; in essence strengthening the self so that they could better manage the illness. Consequently, these young people did not see themselves as being transformed from a disabled person to a person in recovery; instead they felt confident to meet illness related challenges.

The literature also identifies that strength based approaches are essential to support young people's recovery from a FES (Bertolote \& McGorry, 2005; Hamilton Wilson et al., 2005; McCay \& Ryan, 2002). Based on this study's findings and related literature, it is recommended that clinicians implement an interest and strength based assessment to guide care planning, with particular emphasis on an enduring sense of self. It is important that these assessments be ongoing so that the enduring self can be strengthened to support the process of reshaping a sense of self; a self that is able to both pursue future goals and manage illness.

Becoming empowered and exercising citizenship and becoming involved in meaningful activities are two other recovery components that offer points of comparison. Within these components there is an acknowledgement that for people who have lived with long-term mental illness a need emerges over time for them to have the same rights and responsibilities as others. Furthermore, there is also a need to engage in meaningful activities or to occupy "normal" social roles that have the potential to make a contribution to their 
community. Such acknowledgements reflect the need for individuals with mental illnesses to be integrated within the main stream of public life.

In comparison, participants in this study did not have the need to be concerned about exercising citizenship or their rights (e.g., right to decide where to live, how to spend one's time). By contrast these young people were highly engaged in meaningful activities. As described above, they continued with their future ambitions and life aspirations and were encouraged by clinicians and others around them to do so. The literature supports the need for young people with FES to resume their life goals as well as the need to stay connected with their usual social world (Hamilton Wilson et al., 2005). Bertolote and McGorry (2005) state that early psychosis programs generate optimism and expectations of positive outcomes and recovery so that all young people with psychosis and their families can achieve ordinary lives. It is therefore important, for clinicians to promote continued developmental appropriate life activities, when working with individuals recovering from FES. Of interest, is that the young people and their families in this study made reference to feeling fortunate to be recipients of care in a specialized first episode psychosis program. Those who are unable to access specialized services for FES may feel that they need to demand these services thereby exercising their citizenship.

Overcoming stigma is another recovery component that offers a point of comparison. Typically, individuals coping with long-term schizophrenia have frequently been exposed to negative attitudes towards mental illness over time. Davidson et al. (2005) highlight the need to overcome stigma and suggest that recovery involves developing resiliency to stigma and/or the ability to fight against it. This approach appears to be intended as a response to the effects of stigma over the long-term, rather than an approach developed for the individual first encountering stigma. Although participants in this study voiced concern about the 
effects of external stigma, they did not feel demoralized by external stigma. Furthermore the majority of participants were less affected by internalized stigma. Bertolotte \& McGorry (2005) call for the need to challenge stigmatising and discriminatory attitudes so that young people are not disadvantaged by their illness experiences and are able to be included in their communities. McCay and Ryan (2002) identify the risk of internalizing stigma asserting that young people who have encountered a FES must cope with the impact of a highlystigmatising illness on their overall sense of self and well-being. It is therefore important to integrate stigma reducing strategies into clinical care that specifically focus on reducing the development of internal stigma. This could be accomplished by incorporating interventions focused on promoting an individual's enduring sense of self. Such interventions could serve to bolster the self and thus buffer the effects of stigma.

The component of recovery that will serve as a final point of comparison is related to being supported by others. Davidson and colleagues (2005) focus on the support required by the individual who is recovering. Unlike the perspective of this study, the need for supportive interactions with families is not identified, nor is the capacity of individuals to provide support to others. Addington (2007) draws attention to the important role families play in recovery for young people experiencing FES. Participants in this study were reliant on their parents to initiate or be part of the help-seeking process, as they were still emerging as young adults and required the support of their family. However, while parents were instrumental in securing help, offered important information about their child's history, and played important roles in the subsequent treatment for these emerging adults, it appears that they did not always feel like partners in their child's care and sometimes felt excluded by clinicians. The IEPA working group (2005) suggest that families should be engaged as partners, included in the assessment process, and treatment plan, and should be provided with 
emotional support as needed. Collins (2002) asserts that clinicians can also help families of individuals who have encountered a FES overcome feelings of helplessness and vulnerability by involving them in care early. Study findings served to highlight the need to partner with and offer continued support to families, and to develop working relationships with them early in the course of illness. It is important that these relationships be built on trust and respect by allowing families the opportunity to feel heard, and to welcome their own account of their child's illness. It is also essential, that families hear hopeful realistic messages concerning recovery early in treatment so that they do not to loose sight of the possibilities of recovery for their family member.

Study findings also highlighted the role of individuals recovering from a FES to offer support to others; specifically, a need for individualized forums that allow individuals in recovery from FES to share their experiences. Participants were passionate about the opportunity to share their recovery experiences during the interview, and in doing so offer encouragement and support to others who may be experiencing a FES. I believe it also gave them a greater sense of mastery over their illness, by being able to convey to others their recovery experience. In light of this, it is important to implement varied forums that allow individuals in recovery the opportunity to share their recovery experiences, explore challenges (e.g., stigma, ongoing need to take medication) associated with the illness, and their impact on daily routine and life goals in order to provide additional benefits in their recovery. The importance of supporting this type of strategy is identified by Perry, Taylor and Shaw (2007) who investigated the personal experiences of people who had a recent onset of psychosis and explored influences on feelings of hope. Participants in their study found it helpful and hopeful to hear about individuals encountering similar difficulties. 
In summary, the model of recovery process for the young people in this study offers a unique perspective that differs from the conceptual understanding of the recovery components outlined by Davidson and colleagues (2005). These new perspectives related to recovery from FES, have clear implications for practice that should be carefully considered by clinicians. Specifically, in the context of a therapeutic collaborative relationship, it is important to use hopeful yet realistic messaging from the onset of treatment. There is a need to promote an enduring sense of self by implementing an interest and strength based assessment within care planning. The promotion of developmental appropriate life activities that emphasize a continuation of life goals, along with the strategies to prevent the internalization of external stigma should also be given careful consideration in care planning for FES. In addition, improved supports for families, as well as the inclusion of a variety of supportive forums for individuals recovering from FES are also important implications for FES practice. By implementing these practice implications strategies, clinicians may help improve the recovery process and thus the outcome of patients experiencing a FES.

\section{Implications for Research}

Study findings revealed several important research implications. Specifically, this work has generated future research questions related to the process of recovery from a FES. As such, longitudinal studies employing qualitative methods, as well as triangulated approaches are required to further describe and understand the process of recovery over time.

Although this qualitative study has provided an emergent framework for understanding the process of recovery from FES across the initial years of the illness, it remains to be seen how the process of recovery will evolve over subsequent years. Although at the time of the interview participants in this study were engaged in services and supports and were resuming their lives, there was some uncertainty expressed about the need for 
treatment in the future. Given our current knowledge of the recovery process from study participants to date, it would be most helpful to conduct a follow-up study with the same participants to best understand what the ongoing challenges to continued recovery are for young adults living with FES. This need is in keeping with Roe et al. (2007), who suggests the need to address the concept of recovery as a process.

Additional longitudinal qualitative studies are also needed to further explore the recovery process from a FES in varying settings, such as the inclusion of participants from a range of geographic locations and settings (e.g., specialized versus general hospitals) in order to understand how the process of recovery may vary. The results of this study also suggest that cultural beliefs regarding mental illness may influence recovery and that these beliefs need to be given consideration from a research perspective. Accordingly, the IEPA working group (2005) advises researchers to attend to local clinicians and researchers so that culturally "normal" behaviours are not misinterpreted as being pathological.

There is also a need to conduct longitudinal studies that examine the impact of stigmatized attitudes on recovery. Participants in this study were concerned about the impact of external stigma on their lives and goals and most were able to resist internalizing stigmatized attitudes. Corrigan and Wassel (2008) call for the need to challenge the stigma associated with mental illness in helping individuals accomplish recovery oriented goals. The Canadian Mental Health Association (CMHA) early psychosis intervention framework for strategic planning (2004) also identify stigmatization as a consequence for individuals who develop a psychotic disorder and yet do not differentiate between internal and external stigma. Longitudinal studies that focus on the impact of stigma on recovery could provide valuable data about these attitudes and how best to address stigma for persons newly 
diagnosed with a mental illness. Ultimately they may help to protect young people from developing negative stigmatized conception of themselves.

Intervention studies are needed to develop evidence-based recovery-oriented care in FES. This emergent theory could serve as a framework to develop studies which test and evaluate recovery oriented strategies that may enhance the quality of care for individuals with a FES and further inform clinical practice. Specifically, studies are needed that focus on specific phases of the model and target key elements of the process, such as hopeful messaging at the onset of treatment and promotion of a sense of self.

Clearly, families in this study continued to encounter challenges as some had to struggle to convince family doctors that their child was in need of help, and often felt left out of treatment related discussions with clinicians. I believe the early help-seeking experience, in part, sets the stage for how participants and families interact with the health-care system and is influential in setting the tone for the recovery process. Schulz and Zipursky (2002) assert that families should be engaged in the treatment process as soon as possible, and that services be provided to meet their needs and capacity to participate in this process. This study's findings are aligned with Boydell et al. (2006) who recommend that further examination is required in order to understand the perspective of others involved in the process of help-seeking for a first episode of psychosis. This study's findings also highlight the need for assessment of specific family supports needed during their family member's continuum of care and identification and exploration of interventions to best meet their needs.

Finally, there is a need to increase the number of studies using a triangulated approach in order for the multiple dimensions of recovery to continue to be explored over time; approaches that combine both outcome and process. To further understand outcome, 
Menezes, Arenovich and Zipursky (2006) recommend that a multi-dimensional globally used definition of outcome is required for future research. This would include a combination of symptomatic, functional, and personal elements that would be measured at multiple points in time.

In order to inform our knowledge of early intervention in psychosis, Addington (2007) asserts that not only do research efforts in FEP need to be of the highest quality, but they also have to be accompanied by political and community demand in order to move this field forward. In light of this, I will now explore this study's implications for policy.

\section{Implications for Policy}

It is worth noting, that some progress has been made in beginning to develop FES recovery oriented policy. In 1999, nine mental health regional implementation task forces were created in Ontario to develop regional implementation plans for mental health reform consistent with Making it Happen, the current policy framework guiding mental health reform in Ontario. These task forces recommended the development of a policy framework for first episode psychosis. An Early Intervention in Psychosis Policy Work Group (2004) was established and developed a provincial Program Policy Framework for Early Intervention in Psychosis. This framework has adopted recovery as a guiding principal that underlies the delivery of treatment and support services for early intervention psychosis programs. The need for recovery oriented policy to guide reform is also supported by the Kirby Report (2006) which adopted recovery as the primary framework to drive mental health reform in Canada; yet the need to adopt recovery perspectives for FES is not specifically mentioned.

Although the recently established international practice guidelines for early psychosis (which includes schizophrenia) make reference to recovery principles, (IEPA working group, 
2005), as well as specialized early psychosis programs that are guided by recovery oriented principals (McGorry, 2005), there is no one definitive published model of policy driven recovery oriented care for FES. It is noteworthy that these recovery principles were originally developed for individuals with long-term mental illness with no modification for the needs of FES clients. As has been described within the practice implications, the process of recovery from FES is uniquely different. Policy development should be guided by a model, such as the one found in this study that reflects the perspectives of individuals recovering from a FES, and their families. What this study also highlights is the importance of policy to support the development of recovery standards specific to FES that are based on a model of recovery for FES. These standards could then be adopted and measured by national health care accreditation bodies and strategic plans of health care organizations.

Findings from this study highlight the need for a policy driven comprehensive mental health care system that has the resources available to families who are not only faced with the challenge of obtaining help for a child with a FES, but who are in need of support themselves throughout the continuum of illness. Bertolotte and McGorry (2005) stress that young people and their families must be placed at the centre of care and service delivery. This is particularly important given the developmental phase of the participants, and the role that families have throughout the recovery experience. This need for comprehensive service system is also endorsed by the IEPA working group (2005) who state that the "critical period of the early years following initial diagnosis deserves optimal, comprehensive, and phase specific treatment with continuity of care guaranteed" (p. s120).

Based on the observations of this study, the need for ongoing care following the initial critical period after diagnosis is also imperative. Specifically, some of this study's participants expressed uncertainty regarding follow-up care. The IEPA working group (2005) 
recognizes that first episode clients have treatment needs beyond the critical years and recommended frequent monitoring and ongoing support. The IEPA working group (2005) also calls for collaborative relations between specialist early intervention services and general psychiatric services in order to provide follow-up care for a significant subgroup of individuals, who require ongoing follow-up care. This is especially important given that early intervention services are time-limited by definition. Hobbs, Hamilton Wilson, and Archie (2004) offer ways to meet the need for ongoing follow-up. Specifically, they suggest that individuals with FES may be able to successfully engage in a shared-care model of follow-up care that is divided between a specialized service and the client's family practice. Given the uncertainty raised by study participants concerning follow-up care, it is important that particular attention be given to implementing systems that address the extent and frequency of follow-up care for individuals experiencing a FES. Whether family practice or general psychiatry services are able to provide optimal follow-up individuals recovering from a FES given their special need, remains to be seen.

\section{Summary}

In summary, this study offers a unique model that reflects a recovery process from FES that is different from recovery models from long-term illness. Adopting a specific model for FES is necessary to drive clinical care, future research and policy development. In the context of a collaborative relationship, health care providers should consider the following: conveying hopeful yet realistic messaging within the plan of care; implementing an ongoing interest/strength based assessment for care planning with particular emphasis on fostering an enduring sense of self; integrating strategies to prevent the internalization of external stigma; and implementing varied forums that allow individuals in recovery to share their experiences. Study findings also highlighted a need for clinicians to form partnerships with families to 
better meet their needs and include them as partners in care. From a research perspective, this study highlighted a need for further longitudinal studies employing qualitative methods, as well as triangulated approaches to further describe and understand the process of recovery over time. From a policy perspective, it revealed the need to adopt a FES model to develop recovery oriented policy for FES. This FES policy is needed to develop comprehensive recovery oriented services, as well as specific practice standards for those individuals experiencing a FES. By considering these implications, I believe the recovery experience for individuals who have encountered a FES can be further enhanced, supported, and understood.

\section{Study Limitations}

Certain limitations were identified in this study. Knowing I was a clinician may have influenced the degree to which they shared their recovery experience and therefore maybe considered a possible limitation. A second limitation is related to the setting from which the participants were selected. Specifically, the setting where the study was conducted was a specialized first episode psychosis setting in a large urban city, thus potentially restricting the applicability of these findings to other settings where access to specialized services for FES was not available. Another limitation is the limited follow-up time frame in this study. Although I interviewed primary participants twice, approximately over a two month period, further additional longitudinal interviews could have contributed to understanding of their recovery process over time. 


\section{Concluding Statement}

The careful application of constructivist grounded theory methodology in this study resulted in an emergent FES recovery model with features that are inherently unique and differentiated from existing recovery models in long-term mental illness. This model's core category "reshaping an enduring sense of self" represents the uniqueness of the recovery process for young adults experiencing a FES. This model of recovery specific to FES makes a theoretical contribution that has significant implications specific to clinical practice, future research, and policy development necessary to enhance care for these young people and their families. 


\section{References}

Addington, J., van Mastrigt, S., Hutchinson, J., \& Addington, D. (2002). Pathways to care: Help seeking behavior in first episode psychosis. Acta Psychiatrica Scandanavica, $106,358-364$.

Addington, D., Bouchard, R.H., Goldberg, J., Honer, B., Malla, A., Norman, R., Tempier, R., $\&$ Berzins, S. (2005). Canadian clinical practice guidelines for the treatment of schizophrenia. Canadian Journal of Psychiatry, 43, (supp. 2), 25S-28S.

Addington, J. (2007). The promise of early intervention. Early intervention in psychiatry, $1,294-307$.

Addington, D., Addington, J., \& Patten, S. (2007). Relapse rates in an early psychosis treatment service. Acta Psychiatrica Scandanavica. 115, 126-131.

Andresen, R., Oades, L., \& Caputi. P. (2003). The experience of recovery from schizophrenia: Towards an empirically validated stage model. Australian and New Zealand Journal of Psychiatry, 37:586-594.

Anthony, W.A. (1993). Recovery from mental illness: The guiding vision of the mental health service system in the 1990's. Psychosocial Rehabilitation Journal, 16(4), $11-23$.

Anthony, W.A., Rogers, E.S., \& Farkas, M. (2003). Research on Evidence-Based Practices: Future directions in an era of recovery. Community Mental Health Journal, 39(2), 101-114.

Appelbaum, P.S., \& Grisso, T. (2001). MacArthur Competence Assessment Tool for Clinical Research. Sarasota, FL: Professional Resource Press.

Arnett, J.J. (1997). Young people's conceptions of the transition to adulthood. Youth and Society, 29, 1-23.

Arnett, J.J. (1998). Learning to stand alone: The contemporary American transition to adulthood in cultural and historical context. Human Development, 41, 295-315.

Arnett, J.J. (2000). Emerging adulthood. American Psychologist, 55(5), 469-480.

Artinian, B.M. (1998). Grounded theory research: Its value for nursing. Nursing Science Quarterly, 11(1), 5-6.

Baker, C., Wuest, J., \& Stern, P.N. (1992). Method slurring: The grounded theory/phenomenology example. Journal of Advanced Nursing, 17, 135-1360.

Baxter, E.A., \& Diehl, S. (1998). Emotional stages: Consumers and family members recovering from the trauma of mental illness. Psychiatric Rehabilitation Journal, 21(4), 349-350. 
Bellack, A.S. (2006). Scientific and consumer models of recovery in schizophrenia: Concordance, contrasts, and implications. Schizophrenia Bulletin, 32(3), 432-442.

Bertolotte, J., \& McGorry, P. (2005). Early intervention and recovery for young people with early psychosis: Consensus statement. British Journal of Psychiatry, 187(48), s1116s119.

Bland, R.C., Newman, S.C., \& Orn, H. (1997). Help-seeking for psychiatric disorders. Canadian Journal of Psychiatry, 42, 935-942.

Bleuler, M. (1968). A 23 year longitudinal study of 208 schizophrenia and impressions in regard to the nature of schizophrenia. In. Rosenthal D. \& Kety, S (Eds.), The Transmission of Schizophrenia (pp. 244-254). Oxford: Pergammon Press.

Blumer, H. (1969). Symbolic Interaction. Englewood Cliffs, NJ: Prentice-Hall.

Bockoven, J. (1972). Moral treatment in community mental health. New York: Springer Publishing Company.

Boydell, KM., Gladstone, BM., \& Volpe, T. (2006). Understanding help seeking delay in the prodrome to first episode psychosis: A secondary analysis of the perspectives of young people. Psychiatric Rehabilitation Journal, 30(1):54-60.

Bryant, A., \& Charmaz, K. (Eds.). (2007). The Sage Handbook of Grounded Theory. Los Angeles: Sage Publications.

Canadian Mental Health Association (CMHA). (2004). Early psychosis intervention: A framework for strategic planning.

Charach, A., Volpe, T., Boydell, K., \& Gearing, R. (2008). A theoretical approach to medication adherence for children and youth with psychiatric disorders. Harvard Review of Psychiatry, 16(2), 126-135.

Charmaz, K. (1983). The grounded theory method: An explication and interpretation. In Emerson R.M. (Ed.), Contemporary Field Research: A collection of readings (pp. 109126). Prospect Heights, IL: Waveland Press.

Charmaz, K. (1990). Discovering chronic illness: Using grounded theory. Social Science in Medicine, 30, 1161-1172

Charmaz, K. (2000). Grounded theory objectivist and constructivist methods. In N.K. Denzin., Y.S. Lincoln (Eds.), Handbook of qualitative research ( $2^{\text {nd }}$ ed.). (pp. 509535).Thousand Oaks, CA: Sage.

Charmaz, K. (2001). Qualitative interviewing and grounded theory analysis. In J.F. Gubrium., J.A. Holstein (Eds.), Handbook of interview research: Context and method. (pp. 675-710). Thousand Oaks, CA: Sage. 
Charmaz, K. (2003). Qualitative interviewing and grounded theory analysis. In J.F. Gubrium, J.A. Holstein (Eds.), Inside Interviewing New Lenses, New Concerns. (pp. 311-330). Thousand Oaks, CA: Sage.

Charmaz, K. (2003b). Grounded theory. In J.A Smith (Ed.), Qualitative Psychology, A practical guide to research methods. (pp. 81-110). Thousand Oaks. CA: Sage.

Charmaz, K. (2004). Introduction to constructivist grounded theory. Fifth Advances in Qualitative Methods Conference, Edmonton, Canada.

Charmaz, K. (2006). Constructing grounded theory a practical guide through qualitative analysis. Thousand Oaks. CA: Sage.

Chovil, I. (2005). Coping with fires episode psychosis prodrome: Rehabilitation and recovery. Psychiatric Rehabilitation Journal, 28(4), 407-410.

Ciompi, L. (1980). The natural history of schizophrenia in the long term. British Journal of Psychiatry, 136, 413-420.

Cole, A.L., \& Knowles, J.G. (2001). Lives in context: The art of life history research. Walnut Creek, CA: AltaMira Press.

Collins, A.A. (2002). Family Intervention in the Early Stages of Schizophrenia. In R. Zipursky \& C. Schulz (Eds.), The Early Stages of Schizophrenia. (pp. 129-157). Washington, DC: American Psychiatric Publishing.

Corcoran, C., Gerson, R., Sills-Shahar, R., Nickou, C., McGlashan, T., Malaspina, D., \& Davidson, L. (2007). Trajectory to a first episode of psychosis: A qualitative research study with families. Early Intervention in Psychiatry, 1, 308-315.

Corrigan, P.W., \& Wassel, A. (2008). Understanding and influencing the stigma of mental illness. Journal of Psychosocial Nursing, 46(1), 42-48.

Craig, T.K., Garety, P., Power, P., Rahaman, N., Colbert, S., Fornells-Ambrojo, M., \& Dunn, G. (2004). The Lambeth Early Onset (LEO) team: A randomized controlled trial of the effectiveness of specialized care for early psychosis. British Medical Journal, 329, 1067.

Creswell, J.W. (2002). Grounded theory designs. In Educational Research: Planning, Conducting, and Evaluating Quantitative and Qualitative Research. (pp. 438-479). Upper Saddle River, NH: Merrill Education/Pearson Education.

Cutcliffe, J.R. (2000). Methodological issues in grounded theory. Journal of Advanced Nursing, 31(6), 1476-1484.

Czuchta, D., \& McCay, E. (2001). Help seeking for parents of individuals experiencing a first episode of schizophrenia. Archives of Psychiatric Nursing, 15, 159-170. 
David, N., Newen, A., \& Vogeley, K. (2008). The "sense of agency" and its underlying cognitive and neural mechanisms. Consciousness and Cognition, 17(2), 523-534.

Davidson, L., \& Strauss, J.S. (1992). Sense of self of recovery from severe mental illness. British Journal of Medical Psychology, 65, 131-145.

Davidson, L., O'Connell, M., Tondora, J., Lawless, M., \& Evans, A.C. (2005). Recovery in serious mental illness: A new wine or just a new bottle? Professional Psychology, $36(5), 480-487$.

Deegan, P. (1988). Recovery: the lived experience of rehabilitation. Psychosocial Rehabilitation Journal, 11, 11-19.

Deegan, P. (1993). Recovering our sense of value after being labeled. Journal of Psychosocial Nursing, 31(4), 7-11.

Deegan, P.E. (1994). Recovery: The lived experience of rehabilitation. In W.A. Anthony, \& Spaniol, L. (Eds.), Readings in psychiatric rehabilitation (pp. 149-162). Boston: Boston University, Centre for Psychiatric Rehabilitation.

Deegan, P, (1996). Recovery as a journey of the heart. Psychiatric Rehabilitation Journal, 11(4), 11-19.

Deegan, P. (2004). Rethinking rehabilitation: Freedom. Symposium conducted at the $20^{\text {th }}$ World Congress of Rehabilitation International, Oslo Norway.

Deegan, P.E. (2005). The importance of personal medicine: A qualitative study of resilience in people with psychiatric disabilities. Scandinavian Journal of Public Health, 33 (Suppl 66), 29-35.

Deegan, P. E. (2007). The lived experience of using psychiatric medication in the recovery process and a shared decision-making program to support it. Psychiatric Rehabilitation Journal, 31(1):62-9.

Denzin, N.K \& Lincoln, Y.S. (2000). The discipline and practice of qualitative research. In N.K. Denzin \& Y. Lincoln, (Eds.), Handbook of qualitative research $\left(2^{\text {nd }}\right.$ ed.). (pp.128). Thousand Oaks, CA: Sage.

Deutsch, A. (1949). The mentally ill in America. $\left(2^{\text {nd }}\right.$ ed.). New York: Columbia University Press.

Diehl, S. (1995). The emotional stages of recovery: In C. Talley \& Diehl (Eds.), BRIDGES: A journey of hope, a peer education program for consumers of mental health services. Knoxville: Tennessee Alliance for the mentally ill. 
Early Intervention in Psychosis Policy Work Group. (December, 2004). Policy Framework for Early Intervention in Psychosis. Ontario: Queen's Printer for Ontario. Catalogue No. 7610-2242965.

Eaves, Y.D. (2001). A synthesis technique for grounded theory data analysis. Journal of Advanced Nursing, 35(5), 654-663.

Edwards J., \& McGorry, P. (2005). Implementing early intervention in psychosis. Trowbridge: The Cromwell Press.

Fisher, D. (1994). Hope, humanity, and value in recovery from psychiatric disability. The Journal, 5, 13-15.

Forchuk, C., Jewell, J., Tweedell, D., \& Steinnagel. (2003). Reconnecting: The client experience of recovery from psychosis. Perspectives in Psychiatric Care, 39(4), 141150.

Frese, F. (1998). Advocacy, recovery, and the challenges of consumerism for schizophrenia. Psychiatric Clinics of North America, 21, 233-249.

Gagne, C., White, W., \& Anthony, W.A. (2007). Recovery: A common vision for the fields of mental health and addictions. Psychiatric Rehabilitation Journal, 31(1), 32-7.

Glaser, B.G. (1978). Theoretical Sensitivity. Advances in the methodology of grounded theory. Mill Valley, CA: The Sociology Press.

Glaser, B., \& Strauss, A.L. (1967). The discovery of grounded theory: Strategies for qualitative research. Chicago: Aldine.

Goeree, R., Farahati, F., Burke, N., Blackhouse, G., O'Reilly, D., Pyne, J., \& Tarride. J.E. (2005). The Economic Burden of Schizophrenia in Canada in 2004. Current Medical Research and Opinion, 21(12): 2017-2028.

Goering, P., Boydell, K., \& Pignatiello, A. (2008). The relevance of qualitative research for clinical programs in psychiatry. The Canadian Journal of Psychiatry, 53(3), 145-150.

Greene, A.L., Wheatley, S.M., \& Aldava, J.F., IV. (1992). Stages on life's way: Adolescents' implicit theories of the life course. Journal of Adolescent Research, 7, 364-381.

Guba, E.G. (1990). The alternative paradigm dialog. In E.G. (Ed.), The paradigm dialog (pp. 17-30). Newbury Park, CA, Sage.

Guba, E., \& Lincoln, Y. (1994). Competing paradigm in qualitative research. In N. K.Denzin \& Y. Lincoln, (Eds.), Handbook of qualitative research (pp. 105-117). Thousand Oaks, CA: Sage.

Hamilton Wilson, J., \& Hobbs, H. (1995). Therapeutic partnerships: A model clinical practice. Journal of Psychosocial Nursing and Mental Health Services, 33(2), 27-30. 
Hamilton Wilson, J.E., Hobbs, H., \& Archie, S. (2005). The right stuff for early intervention in psychosis. Journal of Psychosocial Nursing and Mental Health Services, 43(6), 2228.

Harding, C.M., Brooks, G.W., Ashikaga, R., Strauss, J.S., \& Breier, A. (1987a). The Vermont longitudinal study of persons with severe mental illness. I. Methodology, study sample, and overall status 32 years later. American Journal of Psychiatry, 144, 718-726.

Harding, C.M., Brooks, G.W., Ashikaga, R., Strauss, J.S. \& Breier, A. (1987b). The Vermont longitudinal study of persons with severe mental illness. II. Long-term outcome of subjects who retrospectively met DSM-III criteria for schizophrenia American Journal of Psychiatry, 144, 727-735.

Harding, C.M., Zubin, J., \& Strauss, J.S. (1987). Chronicity in schizophrenia: Fact, partial fact, or artifact? Hospital Community Psychiatry, 38, 477-486.

Harding, C.M., \& Strauss, J.S. (1992). Chronicity in schizophrenia: Revisited. British Journal of Psychiatry, Suppl (18), 27-37.

Harrison, G., Hooper, K., Craig, T., et al. (2001). Recovery from psychotic illness: A 15 and 25 year international follow-up study. British Journal of Psychiatry, 178, 506-517.

Harrison, B. (2002). Seeing health and illness worlds-using visual methodologies in a sociology of health and illness: A methodological review. Sociology of Health and Illness, 24, 856-72.

Harrow, M., Grossman, L., Jobe, TH., \& Herbener, ES. (2005). Do patients with schizophrenia ever show periods of recovery? A 15 year multi-follow-up study. Schizophrenia Bulletin, 31, 723-734.

Health Canada. (2002). Report on mental illness in Canada. Ottawa.

Hegarty, J.D., Baldessarini, R.J., Tohen, M., Waternaux, C., \& Oepen, G. (1994). One hundred years of schizophrenia: A meta-analysis of the outcome literature. The American Journal of Psychiatry, 151(10), 1409-1416.

Hobbs, H., Hamilton Wilson, J., \& Archie, S. (2004). Evaluation of the alumni program. A shared-care model for psychosis. Journal of Psychosocial Nursing and Mental Health Services, 42(1), 28-36.

Holton, J.A. (2007). The coding process and its challenges. In A. Bryant., \& K. Charmaz (Eds.), The Sage handbook of grounded theory. (pp. 265-289). Los Angeles: Sage.

House, G. (2001). Litanies for all occasions. Cleveland, OH: Judson Press.

Huber, H., Gross, J., \& Schutter, R. (1980). Longitudinal studies of schizophrenic patients. Schizophrenia Bulletin, 6, 592-605. 
Hutchinson, S.A. (1993). Grounded theory: The method, In P.L. Munhall., \& C.A. Boyd (Eds.), Nursing research qualitative perspective ( $2^{\text {nd }}$ ed.). (pp. 180-212). New York: National League for Nursing Press.

International Early Psychosis Association Writing Group. (2005). International practice guidelines for early psychosis. British Journal of Psychiatry, 187(48), s120-s124.

Jacobson, N., \& Curtis, L. (2000). Recovery as policy in mental health services: Strategies emerging from the states. Psychiatric Rehabilitation Journal, 23(4), 333-341.

Jacobson, N. (2001). Experiencing recovery: A dimensional analysis of recovery narratives. Psychiatric Rehabilitation Journal, 24(3), 248-256.

Jacobson, N., \& Greenley, D. (2001). What is recovery? A conceptual model and explication. Psychiatric Services, 52(4), 482-485.

Jeon, YH. (2004). The application of grounded theory and symbolic interactionism. Scandinavian Journal of Caring Sciences, 18, 249-256.

Jobe, T.H., \& Harrow, M. (2005). Long-term outcome of patients with schizophrenia: A review. Canadian Journal of Psychiatry, 50(14), 892-898.

Johnson, E. (2000). Recovery principles: An alternative in Maricopa County for individuals who experience psychiatric symptoms. Phoenix, AZ: Meta Services.

Kelly, M., \& Gamble, C. (2005). Exploring the concept of recovery in schizophrenia. Journal of Psychiatric and Mental Health Nursing, 12(2):245-51.

Kilbourn, B. (1999). Fictional Theses. Educational Researcher, 28(9), 27-32.

Kirby report (2006). Out of the Shadows at last. Transforming Mental Health, Mental Illness and Addiction Services in Canada.

Kotake Smith, M. (2000). Recovery from a severe psychiatric disability: Findings of a qualitative study. Psychiatric Rehabilitation Journal, 24(2), 149-158.

Kraepelin, E. (1919). Dementia Praecox and Paraphrenia. Translated and edited by RB Barclay. Edinburgh: ES Livingston.

Kylma, J., Juvakka, T., Nikkonen, M., Korhonen, T., \& Isohanni, M. (2006). Hope and schizophrenia: an integrative review. Journal of Psychiatric Mental Health Nursing, 13(6):651-64.

Lally, SJ. (1989). Does being in here mean there is something wrong with me? Schizophrenia Bulletin, 15, 253-265. 
Leete, E. (1989). How I perceive and manage my illness. Schizophrenia Bulletin. 15(2):197200.

Leininger, M. (1994). Evaluation criteria and critique of qualitative research studies. In J.M. Morse (Ed.), Critical issues in qualitative research methods. (pp. 95-115). London: SAGE Publications.

Liberman, R.P., Kopelowicz, A., Ventura, J., \& Gutkind, D. (2002). Operational criteria and factors related to recovery from schizophrenia. International Review of Psychiatry, 14, 256-272.

Liberman, R.P., \& Kopelowicz, A. (2005). Recovery from schizophrenia: A concept in search of research. Psychiatric Services, 56, 735-742.

Lieberman, J.A., et al. (2008). Science and Recovery in Schizophrenia. Psychiatric Services. 59(5), 487-496.

Linhorst, D. (2006). Empowering people with severe mental illness: A practical guide. New York: Oxford University Press.

Lovejoy, M. (1982). Expectations and the recovery process. Schizophrenia Bulletin, 8(4): 605-9.

Loveland, D., Weaver Randall, K., \& Corrigan, P.W. (2005). Research methods for exploring and assessing recovery. Recovery in Mental Illness Broadening our Understanding of Wellness. (pp. 19-59). Washington, DC: American Psychological Association.

Malla, A., Norman, R., Scholten, D., Manchanda, R., Mclean, T. (2005). A community intervention for early identification of first episode psychosis: Impact on duration of untreated psychosis (DUP) and patient characteristics. Social Psychiatry and Psychiatric Epidemiology, 40(5): 337-44.

Malla, A., \& Payne, J. (2005). First-Episode Psychosis: Psychopathology, quality of life, and functional outcome. Schizophrenia Bulletin, 31(3), 650-671.

Mancini, M.A. (2005). Making sense of it all: Consumer providers' theories about factors facilitating and impeding recovery from psychiatric disabilities. Psychiatric Rehabilitation Journal, 29(1), 48-55.

McCay, E., \& Ryan, K., \& Amey, S. (1996) Mitigating engulfment: Recovering from a first episode of schizophrenia. Journal of Psychosocial Nursing and Mental Health Services, 34, 40-44.

McCay, E., \& Seeman, M. (1998). A scale to measure the impact of a schizophrenic illness on an individual's self-concept. Archives of Psychiatric Nursing, 12, 41-49. 
McCay, E., \& Ryan, K. (2002). Meeting the patient's emotional needs. In R. Zipursky \& C. Schulz (Eds.), The Early Stages of Schizophrenia. (pp. 107-127). Washington, DC: American Psychiatric Publishing.

McCay, E., Beanlands, H., Leszcz, M., Goering, P., Seeman, M., Ryan, L., Johnston, N., \& Vishnevsky, T. (2006). A group intervention to promote healthy self-concepts and guide recovery in first episode schizophrenia. A pilot study. Psychosocial Rehabilitation Journal, 30(2), 105-111.

McCay, E., Beanlands, H., Zipursky, R., Roy, P., Leszcz, M., Landeen, J., Ryan, K., Gretchen, C., Romano, D., Francis, D., Hunt, J., Costantini, L., \& Chan, E. (2007). A randomized controlled trial of a group intervention to reduce engulfment and selfstigmatisation in first episode schizophrenia. Australian e-Journal for the Advancement of Mental Health, 6 (3), 1-9.

McGlashan, T.H. (1987). Recovery style from mental illness and long-term outcome. Journal of Nervous and Mental Disease, 175(11), 681-685.

McGorry, P. (1992). The concept of recovery and secondary prevention in psychiatric disorders. Australian and New Zealand Journal of Psychiatry, 26(3), 3-17.

McGorry, P. (2005). Early intervention in psychotic disorders: Beyond debate to solving problems. British Journal of Psychiatry, 187(suppl 48), s108-s110.

Mead, GH. (1934/1959). Mind, self and society: From the standpoint of a social behaviorist. Chicago IL: The University of Chicago Press.

Mead, S., \& Copeland, ME. (2000). What recovery means to us: Consumers' Perspectives. Community Mental Health Journal, 36(3), 315-328.

Menezes, N.M., Arenovich, T., \& Zipursky, R.B. (2006). A systematic review of longitudinal studies of first-episode psychosis. Psychological Medicine, 36, 1349-1362.

Mishler, E.G. (1986). The analysis of interview-narratives. In. T.R. Sarbin (Ed.), Narrative psychology: The storied nature of human contact. New York: Praeger.

Neilsen, L. (1998). Knowing her place: Research literacies and feminist occasions. San Francisco, CA: Caddo Gap Press/Backalong Books.

Ogawa, K., Miya, M., Watara, A., Nakazawa, M., Yuasa, S \& Utena, H. (1987). A long term follow up study of schizophrenia in Japan-with special reference to the course of social adjustment. British Journal of Psychiatry, 151, 758-765.

Onken., S.J., Craig, C.M., Ridgway, P., Ralph, R.O., \& Cook, J.A. (2007). An analysis of the definitions and elements of recovery: A review of the literature. Psychiatric Rehabilitation Journal, 31(1), 9-22. 
Patton, M. (2002). Qualitative research and evaluation methods. ( $3^{\text {rd }}$ ed.). Sage Publications: Thousand Oaks.

Perry, BM., Taylor, D., \& Shaw, S. (2007). "You've got to have a positive state of mind": An interpretive phenomenological analysis of hope and first episode psychosis. Journal of Mental Health, 16(6), 781 - 793.

Pettie, D., \& Triolo, A.M. (1999). Illness as evolution: The search for identity and meaning in the recovery process. Psychiatric Rehabilitation Journal, 22, 255-262.

Pink, S. (2004). Visual Methods. In Seale, C., Gobo, G., Gubrium, JF., \& Silverman, D (Eds.), Qualitative Research Practice. (pp. 391-406). London: Sage.

Pressman, J. (1998). Last resort: Psychosurgery and the limits of medicine. Cambridge, England: Cambridge University Press.

Public Heath Agency of Canada, (2002). A Report on Mental Illnesses in Canada.

Ralph, R.O. (2005). Verbal definitions and visual models of recovery: Focus on the recovery model. In R.O. Ralph \& P.W. Corrigan, (Eds.), Recovery in mental illness:

Broadening our understanding of wellness (pp. 131-146). Washington DC: American Psychological Association.

Ridgway, P. (2001). Restorying psychiatric disability: Learning from first person recovery narratives. Psychiatric Rehabilitation Journal, 24(4), 335-343.

Roberts, G., \& Wolfson, P. (2004). The rediscovery of recovery: Open to all. Advances in Psychiatric Treatment, 10, 37-49.

Robinson, D.G., Woerner, M.G., McMeniman, M., Mendelowitz, A., \& Bilder, R.M. (2004). Symptomatic and functional recovery from a first episode of schizophrenia or schizoaffective disorder. American Journal of Psychiatry, 161(3), 473-573.

Roe, D., \& Chopra, M., (2003). Beyond Coping With Mental Illness: Toward Personal Growth. American Journal of Orthopsychiatry, 73(3), 334-344.

Roe, D., Rudnick, A., \& Gill, K.J. (2007). The Concept of "Being in Recovery". Psychiatric Rehabilitation Journal, 30(3), 171-173.

Rosen, K., \& Garety, P. (2005). Predicting recovery from schizophrenia: A retrospective comparison of characteristics at onset of people with single and multiple episodes. Schizophrenia Bulletin, 31(3):735-50.

Russinova, Z. (1999). Providers' hope-inspiring competence as a factor optimizing psychiatric rehabilitation outcomes. Journal of Rehabilitation, 4, 50-57. 
Russinova, Z., \& Blanch, A. (2007). Supported spirituality: A new frontier in the recoveryoriented mental health system. Psychiatric Rehabilitation Journal, 30(4), 247-249.

Salyers, M.P., Tsai, J., \& Stultz, T. (2007). Measuring Recovery Orientation in a Hospital Setting. Psychiatric Rehabilitation Journal, 31(2), 131-137.

Scher, S.D., Unger, D.G., \& Brown, M. (1994, February). Adolescents becoming adults: Attributes for adulthood. Poster presented at the biennial meeting of the Society for Research on Adolescence, San Diego, CA.

Schreiber, R.S., \& Stern, P.N. (2001). Using grounded theory in Nursing. New York: NY: Springer Publishing Company.

Schulz, S., \& Zipursky, R. (2002). Afterword. In R. Zipursky \& C. Schulz (Eds.). The Early Stages of Schizophrenia. (pp. 233-237). Washington, DC: American Psychiatric Publishing.

Schwandt, T.A. (2000). Three epistemological stances for qualitative inquiry: Interpretivism, hermeneutics, and social constructionism. In N.K. Denzin \& Y.S. Lincoln (Eds.), Handbook of qualitative research $\left(2^{\text {nd }}\right.$ ed.) (pp. 189-213). Thousand Oaks: Sage.

Seale, C. (1999). Using Numbers. The quality of qualitative research. (pp. 119-139). Thousand Oaks. CA: Sage.

Sells, D.J., Stayner, D.A., \& Davidson, L. (2004). Recovering the self in schizophrenia: An integrative review of qualitative studies. Psychiatry Quarterly, 75(1), 87-97.

Seltzer, M.M., Greenberg, J., Krauss, M., \& Hong, J. (1997). Predictors and outcomes of the end of co-resident care-giving in aging families of adults with mental retardation or mental illness, Family Relations, 46, 13-22.

Spaniol, L. R., Koehler, M., \& Hutchinson, D. (1994). The recovery workbook. Boston: Center for Psychiatric Rehabilitation.

Spaniol, L., Gagne, C., \& Koehler, M. (1997). Recovery from serious mental illness: What it is and how to assist people in their recovery. Continuum, 4, 3-15.

Spaniol, L., Wewiorski, N.J., Gagne, C., \& Anthony, W.A. (2002). The process of recovery from schizophrenia. International Review of Psychiatry, 14, 327-336.

Stern, P.N. (1994). Eroded grounded theory. In J.M. Morse (Ed.), Critical issues in qualitative research methods. (pp. 212-223). London: Sage Publications.

Strauss, JS., \& Carpenter, WT. (1972). The prediction of outcome in schizophrenia. I: Characteristics of outcome. Archives of General Psychiatry, 27, 739-746.

Strauss, A., \& Corbin, J. (1990). Basics of qualitative research: Grounded theory procedures and techniques. Newbury Park, CA: Sage. 
Strauss, A., \& Corbin, J. (1994). Grounded theory methodology: An overview. In N.K. Denzin., Y.S Lincoln (Eds.), Handbook of qualitative research. (pp. 273-285). Thousand Oaks, CA: Sage.

Taktak, D.S., Zineb, B., \& Cheor, M. (1999).Therapeutic strategies in the first psychotic episode. Encephale, 25(3), 44-51.

Tauscher-Wisniewski, S., \& Zipursky, R.B. (2002). The role of maintenance pharmacotherapy in achieving recovery from a first episode of schizophrenia. International Review of Psychiatry, 14, 284-292.

Thompson, K.N., McCorry, P.D., \& Harrigan, S.M. (2003). Recovery style and outcome in first-episode schizophrenia. Schizophrenia Research, 62(1-2), 31-6.

Topor, A., Borg, M., Mezzina, R., Sells, D., Marin, I., \& Davidson, L. (2006). Others: The Role of Family, Friends, and Professionals in the Recovery Process. American Journal of Psychiatric Rehabilitation, 9, 17 - 37.

Torrey, W.C. \& Wykiz, P. (2000). The recovery vision as a service improvement guide for community mental health center providers. Community Mental Health Journal, 36(2), 209-216.

Tweedell, D., Forchuk, C., Jewell, J., \& Steinnagel, L. (2004). Families experience during recovery or nonrecovery from psychosis. Archives of Psychiatric Nursing, XVIII (1), $17-25$.

Unzicker, R. (1989). On my own: A personal journey through madness and re-emergence. Psychosocial Rehabilitation Journal, 13(1), 71-77.

Whitehorn, D., Lazier, L., \& Kopala, L. (1998). Psychosocial rehabilitation early after the onset of psychosis. Psychiatric Services, 49, 1135-1137.

Whitehorn, D., Brown, J., Richard, J., Rui, Q., \& Kopala, L. (2002). Multiple dimensions of recovery in early psychosis. International Review of Psychiatry, 14, 273-283.

Woodside, H., Krupa, T., Pocock, K. (2007). Early Psychosis, Activity Performance and Social Participation: A Conceptual Model to Guide Rehabilitation and Recovery. Psychiatric Rehabilitation Journal, 31(2), 125-130

Young, S.L., \& Ensing, D.S. (1999). Exploring recovery from the perspective of people with psychiatric disabilities. Psychiatric Rehabilitation Journal, 22(3), 219-231. 


\section{Appendices}

\section{Appendix A1 - Letter of Invitation to the Potential Participants by the Intake Coordinator}

Hello Mr/Ms/Mrs:

Donna Romano is a student at the University of Toronto. She is a registered nurse who is completing a $\mathrm{PhD}$ at the Institute of Medical Science. As a $\mathrm{PhD}$ student, she is doing a research study under the supervision of Dr. Paula Goering \& Dr. Elizabeth McCay. The purpose of her research study is to understand the process of recovery from your first episode of schizophrenia. Your recovery process may involve improvement in symptoms, ability to work or go to school and to interact with others. In addition, you may have experienced a shift in attitude, such as feeling more optimistic about the future.

Your participation in the study will take approximately 1.5 hours of your time for each of the two interviews. There are no right or wrong answers in your description of your process of recovery. You will also be asked to identify one individual who has influenced your recovery, who will be interviewed once for approximately 1.5 hours. It would also be appreciated if you could provide her with a personal object(s) that represent for you, your recovery process. She would also like to take a photograph of your hands holding it. The identification of the artifact is an optional choice for you and is not contingent on your participation in the study.

It is anticipated that this study will provide an increased understanding of recovery from a first episode of schizophrenia with the overall intention of increasing knowledge and enhancing care in this area. If you agree to participate, you will never be personally identifiable in any of the study results. Also, if you agree to take part you may withdraw from the study at any time.

I need your permission to release your name and contact number so that Donna, the researcher, can contact you to further explain the study to you in detail and to determine if you are interested in participating.

Name of potential participant

Contact number 


\section{Appendix A2- Letter of Invitation to the Participant by the Researcher}

\section{Hello $\mathrm{Mr} / \mathrm{Ms} / \mathrm{Mrs}$ :}

My name is Donna Romano and I am a student at the University of Toronto. I am a registered nurse who is completing a $\mathrm{PhD}$ at the Institute of Medical Science. As a $\mathrm{PhD}$ student, I am doing a research study under the supervision of Dr. Paula Goering \& Dr. Elizabeth McCay. The purpose of my research study is to understand the process of recovery from your first episode of schizophrenia. Your recovery process may involve improvement in symptoms, ability to work or go to school and to interact with others. In addition, you may have experienced a shift in attitude such as feeling more optimistic about the future.

In a previous study of mine, I looked at help seeking for parents of individuals experiencing a first episode of schizophrenia. Findings highlighted the role of stigma, caregiver burden \& uncertainty. Now, I would like to continue my research and learn about your recovery from when you were first learned about your illness to the present time.

Your participation in the study will take approximately 1.5 hours of your time for each of the two interviews. There are no right or wrong answers in your description of your process of recovery. You will also be asked to identify one individual who has influenced your recovery, who I will interview once for approximately 1.5 hours. I would also appreciate if you could provide me with a personal object(s) that represent for you, your recovery process; I would also like to take a photograph of your hands holding it. The identification of the artifact is an optional choice for you and is not contingent on your participation in the study.

It is anticipated that this study will provide an increased understanding of recovery from a first episode of schizophrenia with the overall intention of increasing knowledge and enhancing care in this area. If you agree to participate, you will never be personally identifiable in any of the study results. Also, if you agree to take part you may withdraw from the study at any time.

Do you have any questions about this study?

Would you be willing to participate in this study?

If yes, please read and sign the consent form.

If no, thank you for your time. 


\section{Appendix B - Informed Consent Letter to Participate in a Research Study}

Study Title: Exploring the Process of Recovery from a First Episode of Schizophrenia

Faculty Supervisors: $\quad$ Dr. Paula Goering RN, PhD, CAMH, Mental Health Systems

Research, University of Toronto

Dr. Elizabeth McCay, RN, PhD, Ryerson University \& University

of Toronto

Student Investigator: $\quad$ Donna Romano, RN, MSc PhD (student)

You are being asked to participate in a research study. Before agreeing to participate in this research study, it is important that you read and understand this research consent form. You should not sign this form until you are sure that you understand everything on this form.

\section{Purpose of the Study:}

You are being asked to participate in the study conducted by Donna Romano under the supervision of Dr. Paula Goering and Dr. Elizabeth McCay at the University of Toronto. The purpose of this study is to better understand your process of recovery and perhaps the things that helped or hindered you during your recovery from when you first learned about your illness to the present. Your recovery process may involve improvement in your symptoms, your ability to work or go to school and to interact with others. In addition, you may have experienced a shift in attitude such as feeling more optimistic about the future. Ten individuals from [study institution] first episode psychosis outpatient clinic will be interviewed for this study.

\section{Participation}

Your voluntary participation in this study will involve the completion of two approximately 1.5 hour interviews (within one month of each other) and will cover questions related to your recovery process. These interviews will be audio taped. The researcher, Donna Romano, will conduct the interviews. The interviews will happen in a place of your choice where you feel comfortable. During the second interview, you will have the option for a photograph to be taken of your hands holding a personal object(s) that represent your recovery process. The identification of the artifact is an optional choice for you and is not contingent on your participation in the study. You will also identify an individual who has influenced your recovery process, who the researcher will interview once for approximately 1.5 hours.

Your medical record from [study institution] will also be reviewed to obtain general information required for the study, including the kind of treatment you have been involved in, and descriptive information such as our age, marital status, level of education, and employment status. 


\section{Potential Harms:}

The justifications and the possible risks of this study have been explained to you by Donna Romano. You may feel temporarily distressed reviewing your history. If this happens, it is recommended that the researcher will contact your clinical case manager or psychiatrist. If you feel that you are in immediate crisis, the researcher will contact your case manager or psychiatrist.

\section{Potential Benefits:}

Alternatively, you may benefit by gaining insight into your recovery process or from contributing to knowledge concerning recovery from a first episode of schizophrenia.

\section{Participation and Withdrawal:}

Your participation in this project is voluntary and you may withdraw at any time. You also have the right to refuse disclosure of any information that creates discomfort for you. Your agreement or refusal will not jeopardize your present or future care provided at the [study institution]

\section{Assurance of Confidentiality:}

Your answers are confidential. The only people to hear the tapes will be the researcher and the person who transcribes the tapes. Furthermore, the transcribed interviews (with no identification of name) will only be reviewed by the researcher, transcriptor, and members of the thesis committee. Namely, Dr Goering, Dr McCay, Dr. Zipursky, and Dr. Boydell. Your study files may also be reviewed by the [study institution] Research Ethics Board.

To assure that your answers remain confidential, a numeric code will be used instead of your name, and the data will be kept in a locked cabinet in a secure location for 5 years. After this time, the transcribed interviews will then be shredded and disposed of in a confidential material disposal box. The audio tapes will be erased at the completion of the study.

\section{Publication of Results:}

The information you will share will be used for research purposes in academic, health care and community settings. Furthermore, that your name will not appear on any publications or photographs of the research findings. You will not be personally identifiable in any reports or communication of the study findings.

\section{Possibility of Future Contact:}

If the opportunity arises in the future, you may be contacted for further research, or to use this study data for similar future research. 


\section{Questions about the Study:}

If you have any further questions regarding the study you can reach Donna Romano at (416)586-4800 ext. 2618. Additional concerns may be directed to Dr. Elizabeth McCay at 416 979-5000 ext 6331. Should you wish to discuss your rights Dr. [name] may be reached at [telephone number]

\section{Consent}

I acknowledge that the research study described above has been explained to me and that any questions I have asked have been answered to my satisfaction. By signing this form, I am giving my informed consent to participate in this study. I have been given a copy of this form to refer to and keep for my personal records.

Participant's signature:

Name and telephone number of identified Secondary Participant

Witness:

Date: 


\section{Appendix C (a) - Primary Participant Interview Guide Questions}

- Can you tell me what recovery means to you? When did you begin to think about recovery? Did anything happen to shift your ideas about recovery? Why do you describe yourself as recovering?

- What helps you recover? Has anything else helped or hindered you during your recovery?

- Could you describe the most important insights you learned as you recover from a first episode of schizophrenia? Are there supports that you would identify as central to recovery?

- As you look back on your recovery from when you were first learned about your illness to the present, are there any other events that stand out in your mind that are important to your recovery? Could you describe it (each one)? How did this event affect what happened? How did you respond to the event (the resulting situations)?

[If the participant has trouble identifying events than use these probes: How did you happen to seek help for your illness? Who, if anyone, influenced your actions? Tell me more about how he/she or they influenced you. Tell me about your thoughts and feeling when you learned about your illness. What happened next? Who, if anyone, was involved? How were they involved?]

- Are there ongoing struggles, fears, and uncertainties you face as you recover?

- Who has been the most helpful to you as you recover? How has he/she been helpful? With your permission would I be able to contact them to learn about their influence from their perspective.

- Has there been anyone who has not been helpful to your process of recovery? In what way? Can you tell me what that has been like for you?

- How have you grown as a person during your recovery? Tell me about your strengths that you discovered or developed through this. What do you value most about yourself now? What do you think others value most in you?

- Is there a personal object/artifact that symbolizes your recovery? Would it be possible to bring it to our second interview in order for you to describe the meaning it represents for you and why?

- As you recover, what do you hope for in the future? What do you hope for yourself in the future? How would you compare the person you hope to be and the person you see yourself as now?

- After having these experiences, what "words of wisdom" would you give to someone who is recovering from a first episode of schizophrenia? Is there anything that you might not have thought about before that occurred to you during this interview? Is there anything you would like to ask me? 


\section{Appendix C (b) - Secondary Participant Interview Guide Questions}

- What would recovery for (participant's name) mean to you?

- How would you describe the process of recovery for (participant's name)?

- Do you see them as recovering? If yes why? If no why not?

- How do feel you have influenced (participant's name) recovery? Tell me more about how this happened?

- Has anything helped or hindered your role during (participant's name) recovery?

- Could you describe the most important insights you learned through being involved in this experience?

- Has your relationship with (participant's name) changed as the process of recovery unfolds? Can you tell me what that has been like?

- What "words of wisdom" would you give to someone who knows someone that is recovering from a first episode of schizophrenia?

- Is there anything that you might not have thought about before that occurred to you during this interview? Is there anything you would like to ask me? 


\section{Appendix D - Informed Consent Letter for Secondary Participant to Participate in a Research Study}

Study Title: Exploring the Process of Recovery from a First Episode of Schizophrenia

Faculty Supervisors: $\quad$ Dr. Paula Goering RN, PhD, CAMH, Mental Health Systems

Research, University of Toronto

Dr. Elizabeth McCay, RN, PhD, Ryerson University \&

University of Toronto

Student Investigator: $\quad$ Donna Romano, RN, MSc PhD (student)

You are being asked to participate in a research study. Before agreeing to participate in this research study, it is important that you read and understand this research consent form. You should not sign this form until you are sure that you understand everything on his form.

\section{Purpose of the Study:}

You are being asked to participate in the study conducted by Donna Romano under the supervision of Dr. Paula Goering and Dr. Elizabeth McCay at the University of Toronto. The purpose of this study is to better understand (primary participant's name) process of recovery and the influence you had on it.

\section{Participation:}

Your voluntary participation in this study will involve the completion of approximately one 1.5 hour interview at a location of your choice and will cover questions related to your influence on (participant's name) recovery. These interviews will be audio taped. The researcher, Donna Romano, will conduct the interviews. The interviews will happen at your place of choice where you are comfortable.

\section{Potential Harms:}

The justifications and the possible risks of this study have been explained to you by Donna Romano. You may feel temporarily distressed reviewing history. If this happens, you will be given the option of terminating the interview, and resuming it at later time if you so chose.

\section{Potential Benefits:}

Alternatively, you may benefit from understanding your influence on the recovery process or from contributing to knowledge concerning recovery from a first episode of schizophrenia.

\section{Participation and Withdrawal:}

Your participation in this project is voluntary and you may withdraw at any time. You also have the right to refuse disclosure of any information that creates discomfort for you. Your agreement or refusal will not jeopardize (participant's name) present or future care provided at the [study institution]. 


\section{Assurance of Confidentiality:}

Your answers are confidential. The only people to hear the tapes will be the researcher and the person who transcribes the tapes. Furthermore, the transcribed interviews (with no identification of name) will only be reviewed by the researcher, transcriptor, and members of the thesis committee. Namely, Dr Goering, Dr McCay, Dr. Zipursky, and Dr. Boydell. Your study files may also be reviewed by the [study institution] Research Ethics Board.

To assure that your answers remain confidential, a numeric code will be used instead of your name, and the data will kept in a locked cabinet in a secure location for 5 years. After this time, the transcribed interviews will then be shredded and disposed of in a confidential material disposal box. The audio tapes will be erased at the completion of the study.

\section{Publication of Results:}

The information that you share will be used for research purposes in academic, health care and community settings. Furthermore, your name will not appear on any publications or photographs of the research findings. You will not be identified in any reports or communication of the study findings.

\section{Questions about the Study}

If I have any further questions regarding the study I can reach Donna Romano at (416)5864800 ext. 2618. Additional concerns may be directed to Dr. Elizabeth McCay at 416 9795000 ext 6331 . Should you wish to discuss your rights Dr. [name] may be reached at [telephone number]

\section{Consent}

I acknowledge that the research study described above has been explained to me and that any questions I have asked have been answered to my satisfaction. By signing this form, I am giving my informed consent to participate in this study. I have been given a copy of this form to refer to and keep for my personal records.

Secondary Participant's signature:

Witness:

Date: 


\section{Appendix E - Overview of Data Analysis}

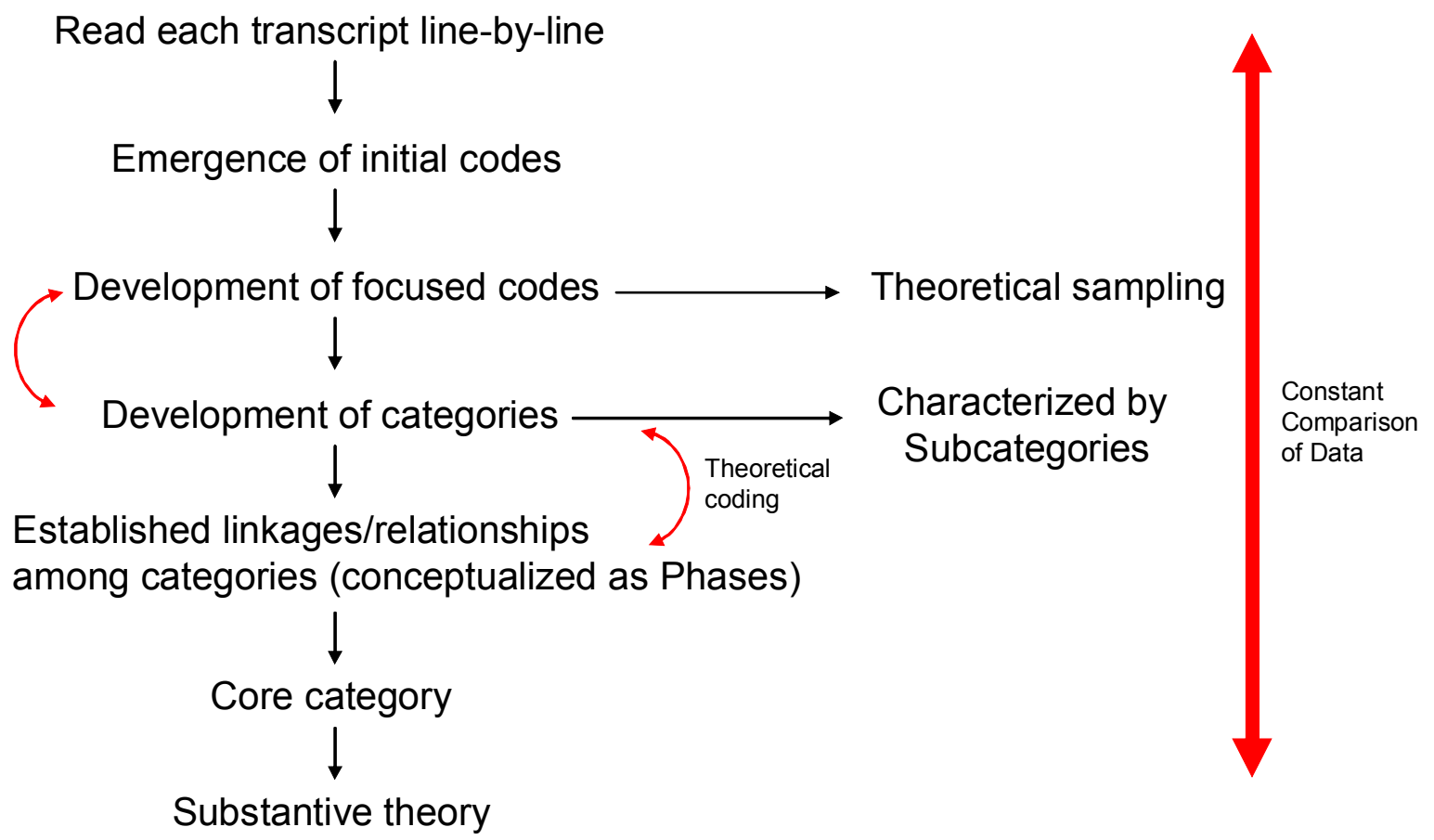




\title{
Appendix F - Initial Codes that Emerged Under Primary Participant \\ Interview Guide Questions
}

\section{Who was he/she prior to his/her illness?}

Background

Demographics

Life before the Illness

\section{How did the illness enter his/her life?}

Time line:

Treatment

Prior to treatment

Illness Experience:

Help-seeking

Causal explanation

Drug Use

Emotional Response (includes uncertainty)

Finding out about illness

Hope (i.e., at time of acute illness)

Impact of symptoms

Perception of mental illness

Prior to treatment

Search for understanding

Symptom recollection

Time flies

How did he/she arrive at help?

Time line:

Prior to treatment

Help-seeking

\section{Illness Experience}

Treatment:

\author{
Help-seeking \\ Process of accepting help \\ Hospital experience \\ Initiation \\ Stopped meds \\ Strategy \\ Perception of treatment \\ Discharge planning
}




\section{How does he/she perceive his/her illness?}

Recovery: $\quad$ Identification of illness label

Perceptions of illness

Self-identity: Changes in self

Continuity of self

Identity within context of illness

Stigma (definition

at a societal level): $\quad$ Perceptions of mental illness

\section{How did he/she realize he/she was recovering?}

$\begin{array}{ll}\text { Recovery } & \text { Accepting help } \\ \text { Accomplishments } \\ \text { Activities }>\text { Interests } \\ \text { Emotional response> uncertainty } \\ \text { Engagement/Enjoyment>Enjoyment } \\ \text { Fear of relapse/uncertainty/worry, concern, relief } \\ \text { Helpful } \\ \text { Housing (i.e., own place) } \\ \text { Impact of illness on life } \\ \text { Impact of symptoms } \\ \text { Important event } \\ \text { Important insights } \\ \text { Independence } \\ \text { Meds } \\ \text { Meaning/description of recovery } \\ \text { Not helpful } \\ \text { Outcomes } \\ \text { Rebuilding } \\ \text { Recovery strategies (def'n: deliberate and planned) } \\ \text { School } \\ \text { Searching for understanding } \\ \text { Strengths discovered } \\ \text { Supports (i.e., not primary based such as family/friends) } \\ \text { Symptoms improved } \\ \text { Symptom occurrence } \\ \text { Perceptions of others } \\ \text { Work }\end{array}$




\section{What was his/her process of recovery?}

Time line: $\quad$ Length of time in recovery

Recovery: Areas for further development

As a process

Challenging thinking/battling thinking

Changes (def'n: occurs overtime)

Desire to be better

Feeling better (actually are)

Self-monitor

Struggles

What are the salient features of his/her recovery?

Self-reflection: $\quad$ Contrasting past/present

Inner shift

Life philosophy (shift may also occur)

Positive attitude (as it relates to primary participant)

Values about self

Values of self by others

Meaningful object:

Words of Wisdom:

Relationships: $\quad$ Community

Family

Friends

Professional

Peer

Partner

What are his/her future goals? How does he/she see himself now?

Relationships: $\quad$ Desire for girlfriend/boyfriend (negotiating the illness)

Recovery: Hopes> Future goals

Having gone through their recovery process what needs have been identified?

Need for Public education:

Need for Support

System Needs \& Recommendations

Stigma (def'n: at a societal level)
Strategies

Perceptions of mental illness

Combat strategies

\section{Summary of Interview}

Summary 


\section{Table 2a - Summary of Initial Codes for Primary Participants}

(Shading is first interview)

\begin{tabular}{|c|c|c|c|c|c|c|c|c|c|c|c|}
\hline & $\mathbf{C A}$ & $\mathbf{C U}$ & HE & JO & LI & $\mathbf{L E}$ & LIN & MI & SE & $\mathbf{S A}$ & Total \\
\hline BACKGROUND & 1 & 1 & & 2 & 2 & & 4 & 3 & & 3 & 16 \\
\hline BACKGROUND & 1 & 6 & 1 & & & 2 & 2 & & & 1 & 13 \\
\hline DEMOGRAPHICS & & & & & & 1 & & & & & 1 \\
\hline DEMOGRAPHICS & & 1 & & & & & 2 & 3 & & & 6 \\
\hline RECOVERY & & & & & & & & & & & 0 \\
\hline RECOVERY & & & & & & & & & & & 0 \\
\hline Accepting help & & & & & & & & & & & 0 \\
\hline Accepting help & & & 1 & & & & & & 2 & & 3 \\
\hline Accomplishments & & & 1 & & & & & & & & 1 \\
\hline Accomplishments & & & & & & & & & & & 0 \\
\hline Activities & & & & & 3 & & & 2 & & & 5 \\
\hline Activities & & & & 2 & 1 & & 1 & 3 & & & 7 \\
\hline Areas for further development & & & & 2 & & 1 & & & & & 2 \\
\hline Areas for further development & & & & 4 & & & 1 & & & & 5 \\
\hline As a process & 3 & 2 & 3 & 1 & & 2 & 1 & & & 3 & 15 \\
\hline As a process & 1 & & 2 & 3 & & 1 & 1 & 2 & & 3 & 13 \\
\hline Changes & 1 & 3 & 2 & 5 & 2 & 6 & 2 & 3 & 3 & 2 & 29 \\
\hline Changes & 3 & 2 & & 3 & 3 & 2 & 2 & 1 & 1 & & 17 \\
\hline Challenging thinking/battling thinking & & & & & & & & 2 & & & 2 \\
\hline Challenging thinking \& Battling thinking & & & & & & & & 2 & & & 2 \\
\hline Desire to be better & & & & & & & & 1 & 1 & & ? \\
\hline Desire to be better & & & & 1 & & & & 1 & 1 & & $?$ \\
\hline Emotional response & & & & 2 & & & & 3 & & & 5 \\
\hline Emotional response & & & & & & & 1 & & & & 1 \\
\hline Uncertainty & & & & & & 1 & 1 & & & & ? \\
\hline Uncertainty & & & & & & & 2 & & & 1 & ? \\
\hline Engagement/Enjoyment & 2 & & 2 & 2 & & 1 & 1 & 3 & & & 11 \\
\hline Engagement \& Enjoyment & & 1 & 1 & 3 & & & & & 2 & & 7 \\
\hline Fears & & & & & 1 & & 1 & & 1 & & 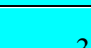 \\
\hline Fears & & & & & & & & & & & 0 \\
\hline Fear of relapse & 1 & & 3 & & & & & 3 & & & 7 \\
\hline Fear of relapse & & & & 1 & & & & & & & 1 \\
\hline Feeling better & 1 & 2 & 1 & & & & & & 1 & & $\varepsilon$ \\
\hline
\end{tabular}




\begin{tabular}{|c|c|c|c|c|c|c|c|c|c|c|c|}
\hline & CA & $\mathbf{C U}$ & HE & JO & LI & LE & LIN & MI & SE & SA & Total \\
\hline Feeling better & & & 2 & & & 1 & & & & & 3 \\
\hline Hopes $>$ Future goals & 4 & 1 & 4 & 2 & 2 & 1 & 1 & 3 & 2 & 4 & 24 \\
\hline Hopes $>$ Future goals & 1 & 4 & & 2 & 1 & & 3 & 7 & 4 & 1 & 23 \\
\hline Helpful & & 1 & 1 & 3 & 2 & 3 & 8 & 3 & 3 & 1 & 25 \\
\hline Helpful & & & & 3 & & & 2 & & 2 & & \\
\hline Housing & & & & & & 2 & & & & & \\
\hline Housing & & & & & & & & & & & 0 \\
\hline Identification of illness label & & 1 & & 1 & & & & 1 & & & \\
\hline Identification of illness label & & 2 & & & & & & & & & ? \\
\hline Impact of illness on life & & & & 1 & & & & & & & \\
\hline Impact of illness on life & & & & 2 & & & & & 1 & & 2 \\
\hline Impact of symptoms & & & & 1 & & & & 2 & & & \\
\hline Impact of symptoms & & & & 1 & & & & 2 & & & 0 \\
\hline Important events & 2 & 2 & & 1 & 3 & 3 & 1 & & 3 & 4 & 10 \\
\hline Important event & 2 & & & & & & & & & 2 & 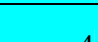 \\
\hline Important insights & & 1 & & 1 & 2 & 3 & & & 1 & & e \\
\hline Important insights & & 1 & & & 1 & & & & & & 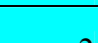 \\
\hline Independence & & & & 1 & & & & & & & 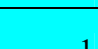 \\
\hline Independence & & & & & & & & & & & 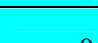 \\
\hline Interests & & & & 2 & 1 & & 2 & 1 & & & \\
\hline Interests & & & & & & & & & & & 0 \\
\hline Keeping busy & & & & & & 1 & & & & & 1 \\
\hline Keeping busy & & & & & & & & & & & 0 \\
\hline Meaningful object & 1 & 1 & 1 & & 1 & 1 & 1 & 1 & 1 & 1 & 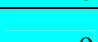 \\
\hline Meaningful object & 1 & 1 & 2 & 1 & 1 & 1 & 1 & 1 & 1 & 1 & 4 \\
\hline Meds & 2 & 1 & 2 & & 3 & 6 & 1 & 7 & 4 & 1 & 27 \\
\hline Meds & & 1 & 1 & 3 & 1 & 1 & 3 & 2 & 1 & 2 & 15 \\
\hline Meaning/description of recovery & 1 & 4 & 1 & & 1 & 1 & 2 & 2 & 1 & 3 & 16 \\
\hline Meaning/description of recovery & 1 & & & & & & & & & 2 & , \\
\hline Not helpful & & 1 & 2 & & 2 & 3 & & & 1 & 2 & 11 \\
\hline Not helpful & & & & 4 & & & 1 & & 1 & & 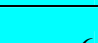 \\
\hline Outcomes & & & & & & & 2 & & & & 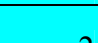 \\
\hline Outcomes & & & & & & & & & & & D \\
\hline Outside belief system & & & & & & & & & & & \\
\hline
\end{tabular}




\begin{tabular}{|c|c|c|c|c|c|c|c|c|c|c|c|}
\hline & CA & $\mathbf{C U}$ & HE & JO & LI & LE & LIN & MI & SE & SA & Total \\
\hline Outside belief system & & & & & & & & & & & \\
\hline Perceptions of illness & & & 1 & & & & & & & & 1 \\
\hline Perceptions of illness & & & & & & & & & & & 0 \\
\hline Perceptions of others & 3 & & & & & & & & 1 & 2 & 6 \\
\hline Perceptions of others & & & & & & & & & & 1 & 1 \\
\hline Rebuilding & & & & 1 & & & & & & & 1 \\
\hline Rebuilding & 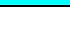 & & 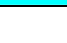 & & & & & & 1 & & \\
\hline Recovery strategies & 2 & & 2 & & 2 & 1 & & 6 & & 1 & 4 \\
\hline Recovery strategies & 5 & 2 & 3 & 4 & & 3 & & 1 & 1 & 2 & 21 \\
\hline School & 2 & 1 & & 1 & 1 & & 4 & & & & 0 \\
\hline School & 3 & 2 & & & 1 & 3 & 5 & & 3 & & 17 \\
\hline Searching for understanding & 9 & & 2 & & & & & & 1 & & 12 \\
\hline Searching for understanding & 1 & & & & & & & 1 & & & 2 \\
\hline Self-monitor & 1 & & & & & & & & & & \\
\hline Self-monitor & & & & & & 3 & & & & & 3 \\
\hline Stopped meds & & & & & & & & 1 & & & 1 \\
\hline Stopped meds & & & & & & & & & & & \\
\hline Struggles & 2 & & & & & & & & & 1 & 3 \\
\hline Struggles & & & & & & & & & & 2 & ? \\
\hline Strengths discovered & 3 & 1 & 1 & 2 & 1 & & 1 & & & 1 & 10 \\
\hline Strengths discovered & & 1 & & 1 & & & & & 1 & & 3 \\
\hline Supports & & & & 1 & & & 1 & & 1 & & 3 \\
\hline Supports & & & & & & & & & & & 0 \\
\hline Symptoms improved & & & & & & & 1 & 1 & & & \\
\hline Symptoms improved & & & & & & & & & & & 0 \\
\hline Symptoms occurrence & & & & 2 & & & & 1 & & & 3 \\
\hline Symptom occurrence & & & & 1 & & 1 & & & 1 & & 3 \\
\hline Work & 2 & 1 & & 2 & & & 2 & & 1 & 2 & 10 \\
\hline Work & 3 & & & & 1 & 1 & 2 & & 1 & & 8 \\
\hline Worry & & & & & & 1 & & & & & 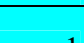 \\
\hline Worry & & & & & & & & & & & ( \\
\hline SELF-REFLECTION & & & & & & & & & 1 & 2 & , \\
\hline SELF REFLECTION & & & & & & 3 & & & & & 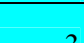 \\
\hline Contrasting past \& present & 1 & 2 & 1 & 5 & 1 & & 2 & & 2 & 2 & 16 \\
\hline
\end{tabular}




\begin{tabular}{|c|c|c|c|c|c|c|c|c|c|c|c|}
\hline & CA & $\mathbf{C U}$ & HE & JO & LI & $\mathbf{L E}$ & LIN & MI & SE & SA & Total \\
\hline Contrasting past/present & 6 & 1 & & 5 & & 1 & & & 2 & 2 & 17 \\
\hline Inner shift & & & & 1 & & & & & & & \\
\hline Inner shift & 1 & & & & & & & & & & \\
\hline Life philosophy & & 3 & & 1 & & & & 1 & & & 5 \\
\hline Life philosophy & 1 & 2 & 3 & & & 1 & & & & & \\
\hline Positive attitude & & 2 & 6 & & 1 & & & & 1 & & 10 \\
\hline Positive attitude & & & 3 & & & 2 & & & & & \\
\hline Values about self & 1 & 1 & & 1 & 1 & & 1 & 1 & 1 & 1 & \\
\hline Values about self & & & & & & & & & & 1 & 1 \\
\hline Values of self by others & & 1 & & 1 & 2 & & 2 & & 1 & 1 & 0 \\
\hline Values of self by others & & & & & & & 1 & & & & 1 \\
\hline SELF-IDENTITY & & & & & & & 1 & & & & \\
\hline SELF-IDENTITY & 1 & & & & & & & & & & 1 \\
\hline Changes in self & & & & 1 & & & & 1 & 2 & 2 & \\
\hline Changes in self & & & 1 & & & 1 & & & 2 & & 4 \\
\hline Continuity of self & 1 & 2 & & & 3 & & & 4 & 1 & & 11 \\
\hline Continuity of self & & 1 & & 1 & & 2 & & & & & 4 \\
\hline Identity within context of illness & & & & 2 & 3 & & & & & & 5 \\
\hline Identity within context of illness & & 1 & & 1 & & 1 & & & & & 3 \\
\hline RELATIONSHIPS & & & & & & & & & & & 0 \\
\hline RELATIONSHIPS & & & & & & & & & & & ( \\
\hline Community & & & & & & & & & & & 0 \\
\hline Community & & & & & & & 2 & & & & ? \\
\hline Desire for girlfriend/boyfriend & & & & & & & & & & & 0 \\
\hline Desire for girlfriend/boyfriend & & & & & & 1 & & & 1 & & , \\
\hline Family & 7 & 1 & 2 & 2 & 6 & 6 & 3 & 5 & 3 & 3 & 20 \\
\hline Family & 1 & 6 & 1 & & 1 & 3 & 4 & 2 & 4 & 1 & 23 \\
\hline Friends & 8 & 1 & & 1 & 5 & 3 & & 2 & 4 & 2 & \\
\hline Friends & 3 & 3 & 2 & 3 & 3 & 1 & & 2 & 3 & & 0 \\
\hline Professional & 3 & 1 & 2 & 2 & 4 & 6 & & 4 & 5 & 2 & 0 \\
\hline Professional & 7 & 2 & 1 & 3 & 2 & 5 & 10 & 1 & 2 & & 22 \\
\hline Peer & & & 1 & & & & & 1 & 2 & 2 & 6 \\
\hline Peer & & & & & 1 & 1 & & & & & 2 \\
\hline
\end{tabular}




\begin{tabular}{|c|c|c|c|c|c|c|c|c|c|c|c|}
\hline & CA & $\mathbf{C U}$ & HE & JO & LI & $\mathbf{L E}$ & LIN & MI & SE & SA & Total \\
\hline Partner & & & 4 & & & 4 & & & & & 0 \\
\hline Partner & & & & & 1 & 1 & 1 & & & & 3 \\
\hline ILLNESS EXPERIENCE & & & & 1 & & & & 1 & & & \\
\hline ILLNESS EXPERIENCE & & & & & & & & & & & 0 \\
\hline Causal explanation & 1 & & & 1 & & & 1 & & & & ? \\
\hline Causal explanation & & & & 1 & & & 3 & & & 1 & 5 \\
\hline Drug use & & & & 1 & & & & & & & 1 \\
\hline Drug use & & & & 3 & & 1 & & & & & 4 \\
\hline Emotional response & 1 & & & 1 & 2 & & & 5 & 3 & 2 & 14 \\
\hline Emotional response & & & & 2 & & 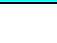 & & 1 & 1 & 1 & 5 \\
\hline Uncertainty & 1 & & 2 & & & 1 & & & & & 4 \\
\hline Uncertainty & & & & 1 & & 1 & & & & 1 & \\
\hline Finding out about illness & & & & & 1 & 1 & & 2 & & & \\
\hline Finding out about illness & & & & 1 & 1 & 2 & & & 2 & & \\
\hline Help-seeking & 4 & 2 & 3 & 2 & 2 & 1 & 1 & 1 & 5 & 5 & 0 \\
\hline Help-seeking & & & 1 & & & & 1 & 2 & 1 & & 5 \\
\hline Hope & 1 & & & & & & & & & & 1 \\
\hline Hope & & & & & 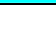 & & & & & & 0 \\
\hline Impact of symptoms & & & & & 3 & & & 3 & & & ( \\
\hline Impact of symptoms & & & & & & & & & & & D \\
\hline Perception of mental illness & & & & & 1 & & & & & & \\
\hline Perception of mental illness & & & & & & & & & & & 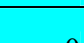 \\
\hline Prior to treatment & & 2 & 2 & & 4 & & & 1 & & 1 & م \\
\hline Prior to treatment & & 1 & 1 & 1 & 1 & 2 & & & 2 & 1 & 0 \\
\hline Search for understanding & & & & & 2 & 2 & & 1 & 1 & & 6 \\
\hline Search for understanding & & & & 2 & & 1 & & & & & 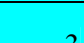 \\
\hline Symptom recollection & 3 & 1 & & 2 & 2 & 3 & 2 & 2 & 3 & 2 & \\
\hline Symptom recollection & 1 & 1 & & 2 & 1 & 2 & 1 & 3 & 1 & & 12 \\
\hline Time flies & & & & & & & & & & & 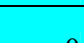 \\
\hline Time flies (process) & & & & & & & & & & & 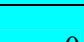 \\
\hline TREATMENT & & & & & & 1 & & & & & 1 \\
\hline TREATMENT & & & & & & & & & & & 0 \\
\hline Discharge planning & & & & & & & & & & & 0 \\
\hline Discharge planning & & & & & & & 2 & & & & 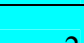 \\
\hline
\end{tabular}




\begin{tabular}{|c|c|c|c|c|c|c|c|c|c|c|c|}
\hline & CA & $\mathbf{C U}$ & HE & JO & LI & $\mathbf{L E}$ & LIN & MI & SE & SA & Total \\
\hline Hospital experience & & & & & 3 & & & & 1 & 1 & 5 \\
\hline Hospital experience & & & & & 1 & 1 & 1 & & 1 & 1 & 5 \\
\hline Initiation & & 1 & & 1 & & & & & & & \\
\hline Initiation & & & & & & & & & & & 0 \\
\hline Strategy & 2 & & & & & 3 & 3 & 2 & 1 & 1 & 12 \\
\hline Strategy & 1 & & & & & & & & & & 1 \\
\hline Perception of treatment & & & & & & & & 1 & 1 & & 2 \\
\hline Perception of treatment & & & & & & & & 1 & & & 1 \\
\hline Process of accepting help & 1 & & & & & 1 & & 2 & & & 4 \\
\hline Process of accepting help & & & 1 & & & & & & & & 1 \\
\hline TIMELINE & & & & & & 2 & 2 & & & & 4 \\
\hline TIME LINE & & & & & & 1 & & & & & 1 \\
\hline Length of time in recovery & & 1 & & 1 & & & & & & & 2 \\
\hline Length of time in recovery & & & & & & & & & & & 0 \\
\hline Prior to treatment & & & 1 & & & & & & & & 1 \\
\hline Prior to treatment & & & 1 & & & & & 1 & & & 2 \\
\hline Treatment & 1 & 3 & 1 & & 3 & 1 & & & 1 & 1 & 11 \\
\hline Treatment & & & & & & & 1 & & & & 1 \\
\hline NEED FOR PUBLIC EDUCATION & & & & & & & & & & & 0 \\
\hline NEED FOR PUBLIC EDUCATION & 1 & & & & & 1 & 1 & & 1 & & 4 \\
\hline Strategies & & & & & & & & & & & 0 \\
\hline Strategies & & & & & & & & 1 & & & 1 \\
\hline LIFE BEFORE THE ILLNESS & & & & & & & & & & & 0 \\
\hline LIFE BEFORE THE ILLNESS & & & 1 & & & & & & & & 1 \\
\hline WORDS OF WISDOM & 1 & 1 & 1 & 2 & 1 & 1 & 2 & 2 & 2 & 1 & 14 \\
\hline WORDS OF WISDOM & & & 1 & & & & & 2 & & & 3 \\
\hline STIGMA & 1 & & & & & 1 & & & 2 & 2 & 6 \\
\hline STIGMA & 1 & & & & & 2 & 1 & & 4 & 1 & 9 \\
\hline Perceptions of mental illness & & & & & & & & & 2 & & 2 \\
\hline Perceptions of mental illness & & & & 1 & & 1 & 2 & & & & 4 \\
\hline Combat strategies & & & & & & & & & & & 0 \\
\hline Combat strategies & & & & & & 1 & & & & & 1 \\
\hline NEED FOR SUPPORT & & & & & & & & & & & 0 \\
\hline NEED FOR SUPPORT & & & & & & & & & & & 0 \\
\hline $\begin{array}{l}\text { SYSTEM } \\
\text { NEEDS/RECOMMENDATIONS }\end{array}$ & & & & & & 1 & & & & & 1 \\
\hline $\begin{array}{l}\text { SYSTEM NEEDS \& } \\
\text { RECOMMENDATIONS }\end{array}$ & 1 & & & & & & 1 & & & & 2 \\
\hline SUMMARY & & 2 & 3 & 1 & 12 & 1 & 2 & 11 & & 1 & 33 \\
\hline SUMMARY & 2 & 4 & 1 & 3 & 3 & 3 & 10 & 5 & & 6 & 37 \\
\hline
\end{tabular}




\begin{tabular}{|l|r|r|r|r|r|r|r|r|r|r|r|}
\hline & CA & CU & HE & JO & LI & LE & LIN & MI & SE & SA & Total \\
\hline SYSTEM GAPS & & & & & & & & & & & 0 \\
\hline SYSTEM GAPS & & & & & & & & & & & 0 \\
\hline $\begin{array}{l}\text { REQUESTING A COPY OF FINAL } \\
\text { RESULTS }\end{array}$ & & & & & & & & & & & \\
\hline $\begin{array}{l}\text { REQUESTING A COPY OF FINAL } \\
\text { RESULTS }\end{array}$ & 1 & & & & & & & & 1 & & \\
\hline TOTAL \# OF CODES & 81 & 51 & 58 & 66 & 91 & 77 & 59 & 102 & 71 & 65 & 721 \\
\hline TOTAL \# OF CODES & $\mathbf{5 0}$ & $\mathbf{4 6}$ & $\mathbf{3 2}$ & $\mathbf{6 9}$ & $\mathbf{2 5}$ & $\mathbf{6 1}$ & $\mathbf{7 2}$ & $\mathbf{4 7}$ & $\mathbf{5 2}$ & $\mathbf{3 4}$ & $\mathbf{4 8 8}$ \\
\hline
\end{tabular}


Table 2b - Summary of Initial Codes for Secondary Participants

\begin{tabular}{|c|c|c|c|c|c|c|c|c|c|c|c|c|}
\hline & $\mathbf{C A}$ & $\overline{\mathbf{C U}}$ & HE & JO & $\mathbf{L I}$ & $\begin{array}{c}\mathbf{L E} \\
{[\mathbf{N R}]}\end{array}$ & LIN & MI & SE & SA & $\begin{array}{c}\mathbf{L E} \\
{[\mathbf{T A}]}\end{array}$ & Total \\
\hline BACKGROUND & 2 & 5 & & 1 & & 1 & 9 & 13 & 4 & 1 & 3 & 39 \\
\hline \multicolumn{13}{|c|}{ RECOVERY: Secondary participant's observations of primary participant's recovery } \\
\hline Activities & & & & & & & 1 & & & & & 1 \\
\hline $\begin{array}{l}\text { Areas for further } \\
\text { development }\end{array}$ & & & & 2 & & & 1 & & & & 4 & 7 \\
\hline As a process & & 3 & 1 & 3 & 2 & 1 & 3 & & 1 & 1 & 2 & 17 \\
\hline Changes/Signs & 3 & & 1 & 1 & & 2 & 1 & 3 & 3 & 2 & & 16 \\
\hline Contrasting past \& present & & & & 1 & 1 & & 1 & & & & & 3 \\
\hline Doing better & 2 & & & & & & & & & & & 2 \\
\hline Emotional response & & 1 & & 3 & & 1 & & & & & & 5 \\
\hline Uncertainty & & & & & & & & 1 & & & & 1 \\
\hline Expectations for recovery & & & & 2 & & & 1 & & 3 & & & 6 \\
\hline Fear of relapse & 1 & & & & & & & & & & & 1 \\
\hline Future hopes/goals & 1 & & & & & & 2 & 3 & 2 & & & 8 \\
\hline Helpful & & & & & 1 & 1 & 3 & & 1 & & & 6 \\
\hline Helpful influences & 3 & & & & & & & & 2 & 1 & & 6 \\
\hline Hope & & & & & & & 1 & & & & 1 & 2 \\
\hline Housing & & & & & & & & 1 & & & & 1 \\
\hline $\begin{array}{l}\text { Identification of strengths } \\
\text { within context of illness }\end{array}$ & & 6 & & & 1 & 2 & & & 1 & & 1 & 11 \\
\hline $\begin{array}{l}\text { Identification within context } \\
\text { of illness }\end{array}$ & & & & & & 1 & & & & & & 1 \\
\hline Insights & 1 & & 2 & 1 & 2 & 1 & 1 & & 2 & 3 & & 13 \\
\hline Meaning of recovery & 2 & 1 & 3 & 1 & 3 & 1 & 2 & 1 & 3 & 4 & 2 & 23 \\
\hline Meds & & & 2 & 2 & & 1 & 1 & & 2 & 2 & 2 & 12 \\
\hline Not helpful & & & & & 1 & & & & 1 & & 1 & 3 \\
\hline Outcomes & & 1 & & & & & 1 & & & & & 2 \\
\hline Perceptions of & & & & & & & & & & & 1 & 1 \\
\hline Recovery strategy & & & 1 & & & 3 & & & & 1 & 2 & 7 \\
\hline School & & & & & & & 1 & & & & & 1 \\
\hline Search for understanding & & & & & & & & & 1 & & & 1 \\
\hline Symptom occurrence & & & & & & & & & 2 & & & 2 \\
\hline Work & & & & & & & 1 & & & & & 1 \\
\hline \multicolumn{13}{|c|}{ RELATIONSHIPS INVOLVING CAREGIVER: Care-giver centered, through the eyes of the care-giver } \\
\hline Family & 1 & 2 & & 1 & & & 1 & 4 & 3 & 1 & & 13 \\
\hline Family conflict & & & & & & & & & & & & 0 \\
\hline Family dynamics & & & & & & & 1 & & & & & 1 \\
\hline $\begin{array}{l}\text { Friends of primary } \\
\text { participant }\end{array}$ & & & & & & & & & 1 & & & 1 \\
\hline Professional & 4 & 7 & 1 & 1 & 1 & & & 2 & 3 & 2 & 6 & 27 \\
\hline $\begin{array}{l}\text { Relationship changes with } \\
\text { primary participants }\end{array}$ & & & 1 & 2 & 1 & & & 1 & 1 & & & 6 \\
\hline
\end{tabular}




\begin{tabular}{|c|c|c|c|c|c|c|c|c|c|c|c|c|}
\hline & $\mathbf{C A}$ & $\mathbf{C U}$ & HE & JO & $\mathbf{L I}$ & $\begin{array}{c}\mathbf{L E} \\
{[\mathbf{N R}]}\end{array}$ & LIN & MI & SE & SA & $\begin{array}{c}\text { LE } \\
{[\text { TA] }}\end{array}$ & Total \\
\hline \multicolumn{13}{|c|}{ PERCEPTIONS OF ILLNESS: Secondary participant's observations of what is happening with the primary participant's illness } \\
\hline $\begin{array}{l}\text { Perception of illness [no sub- } \\
\text { code] }\end{array}$ & 1 & & & & & & & & & & & 1 \\
\hline Causal explanation & 1 & & & 1 & & & 1 & & 1 & 1 & & 5 \\
\hline Emotional response & 3 & & & 1 & & & 1 & 8 & 2 & & & 15 \\
\hline Uncertainty & 1 & & & & & & & 1 & 2 & & & 4 \\
\hline Finding out about illness & & 1 & 1 & & & 1 & & 1 & 1 & & & 5 \\
\hline Help seeking & 8 & & & 2 & & & 4 & 5 & 3 & 5 & & 27 \\
\hline Prior to treatment & 1 & & 2 & & & 1 & 2 & 4 & & & & 10 \\
\hline Search for understanding & 3 & & & & & & & 3 & 3 & 2 & & 11 \\
\hline Signs \& Changes & & & & & & & 1 & 1 & & 2 & & 4 \\
\hline Symptom recollection & 4 & & & 1 & 1 & 1 & & 3 & 1 & 2 & 1 & 14 \\
\hline Time flies & & & & & & & & 1 & & & & 1 \\
\hline CARE-GIVING & 1 & & & & & & & 1 & & & & 2 \\
\hline Caring for self & & & & & & & & 1 & & & & 1 \\
\hline Care-giving network & & & 1 & & & & & 1 & & & & 2 \\
\hline Emotional response & 4 & & & & & & & 7 & & 3 & & 14 \\
\hline Influence of & & 2 & & 1 & 1 & 1 & 1 & & & 3 & & 9 \\
\hline $\begin{array}{l}\text { Impact of illness on family } \\
\text { relationships }\end{array}$ & & & & & & & & 1 & 1 & 1 & & 3 \\
\hline Helpful for recovery process & & & & 1 & & & & & & & & 1 \\
\hline Multiple demands & 1 & & & & & & 1 & 3 & & 1 & & 6 \\
\hline Need for support & & & & & & & & & & 1 & & 1 \\
\hline $\begin{array}{l}\text { Not helpful for recovery } \\
\text { process }\end{array}$ & & 1 & & & & & & & & & & 1 \\
\hline Philosophy & & & & 1 & 4 & 1 & 6 & 1 & & 3 & & 16 \\
\hline Process of care giving & & & & 1 & 1 & & 1 & & 5 & & & 8 \\
\hline Providing support & & 1 & & & & 2 & 1 & 6 & 1 & & 4 & 15 \\
\hline Receiving support & & 2 & & & 3 & & & & & & & 5 \\
\hline Reluctant for support & & & & & & & & & 1 & & & 1 \\
\hline Ability to self-monitor & & & & & & & & & & & 1 & 1 \\
\hline Ability to self-care & & & & & & & & & & & 1 & 1 \\
\hline $\begin{array}{l}\text { Description prior to } \\
\text { treatment }\end{array}$ & & & & & & & $\overline{1}$ & & & & & 1 \\
\hline $\begin{array}{l}\text { Identification of strength } \\
\text { within context of illness }\end{array}$ & & & & & & & 2 & & & & & 2 \\
\hline $\begin{array}{l}\text { Perception within context of } \\
\text { the illness }\end{array}$ & & & & & & & & & & & 1 & 1 \\
\hline
\end{tabular}




\begin{tabular}{|c|c|c|c|c|c|c|c|c|c|c|c|c|}
\hline & CA & $\mathbf{C U}$ & $\mathrm{HE}$ & JO & LI & $\begin{array}{c}\text { LE } \\
\text { [NR] }\end{array}$ & LIN & MI & SE & SA & $\begin{array}{c}\text { LE } \\
\text { [TA] }\end{array}$ & Total \\
\hline TREATMENT & & & & & & & 1 & & & & & 1 \\
\hline Early challenges & 5 & & & & & & 1 & 1 & & & & 7 \\
\hline Access to treatment & & & & & & & & & 1 & & & 1 \\
\hline Hospital experience & & & & & & 1 & 1 & & 1 & & & 3 \\
\hline Perception of treatment & & 2 & & & 1 & & 1 & 2 & & 3 & & 9 \\
\hline Response to treatment & 1 & & & & 1 & & & & & & & 2 \\
\hline $\begin{array}{l}\text { Strategy } \\
\end{array}$ & & 6 & & & & 1 & & & & & 2 & 9 \\
\hline TIMELINE & & & & & & 1 & 2 & & & & & 3 \\
\hline Help-seeking & & & & & & & & 1 & & 1 & & 2 \\
\hline Illness experience & & & & & & & & & & 1 & & 1 \\
\hline Prior to treatment & & & & & & & & 1 & & & & 1 \\
\hline Treatment & & & & & 1 & & & 2 & & & & 3 \\
\hline $\begin{array}{l}\text { PERCEPTIONS OF } \\
\text { MENTAL ILLNESS \& } \\
\text { TREATMENT }\end{array}$ & & & & 2 & 1 & & & 1 & & & & 4 \\
\hline RECOMMENDATIONS & & & & & 1 & & & & & & & 1 \\
\hline WORDS OF WISDOM & 1 & 1 & 1 & 2 & 1 & 1 & 1 & 2 & 2 & 1 & 1 & 14 \\
\hline STIGMA & 1 & & & 4 & & 1 & 1 & & 1 & & & 8 \\
\hline Perceptions of mental illness & & 2 & & & & & 2 & & & & & 4 \\
\hline Combat strategies & & & & 1 & 3 & & 1 & & 1 & & 2 & 8 \\
\hline $\begin{array}{l}\text { NEED FOR PUBLIC } \\
\text { EDUCATION }\end{array}$ & & & & & & & & & & 1 & & 1 \\
\hline Strategies & & & & & & & & 1 & & & & 1 \\
\hline SUMMARY & & 1 & 2 & 2 & 2 & & 9 & 6 & & & 1 & 23 \\
\hline SYSTEM GAPS & 1 & 1 & & & & & & & & 3 & & 5 \\
\hline Recommendations & 1 & 4 & & & & & & 1 & 5 & & 3 & 14 \\
\hline Support for care-giver & & & & & & & & & & 1 & & 1 \\
\hline TOTAL \# OF CODES & 60 & 48 & 19 & 44 & 34 & 27 & 74 & 95 & 70 & 52 & 44 & 567 \\
\hline
\end{tabular}



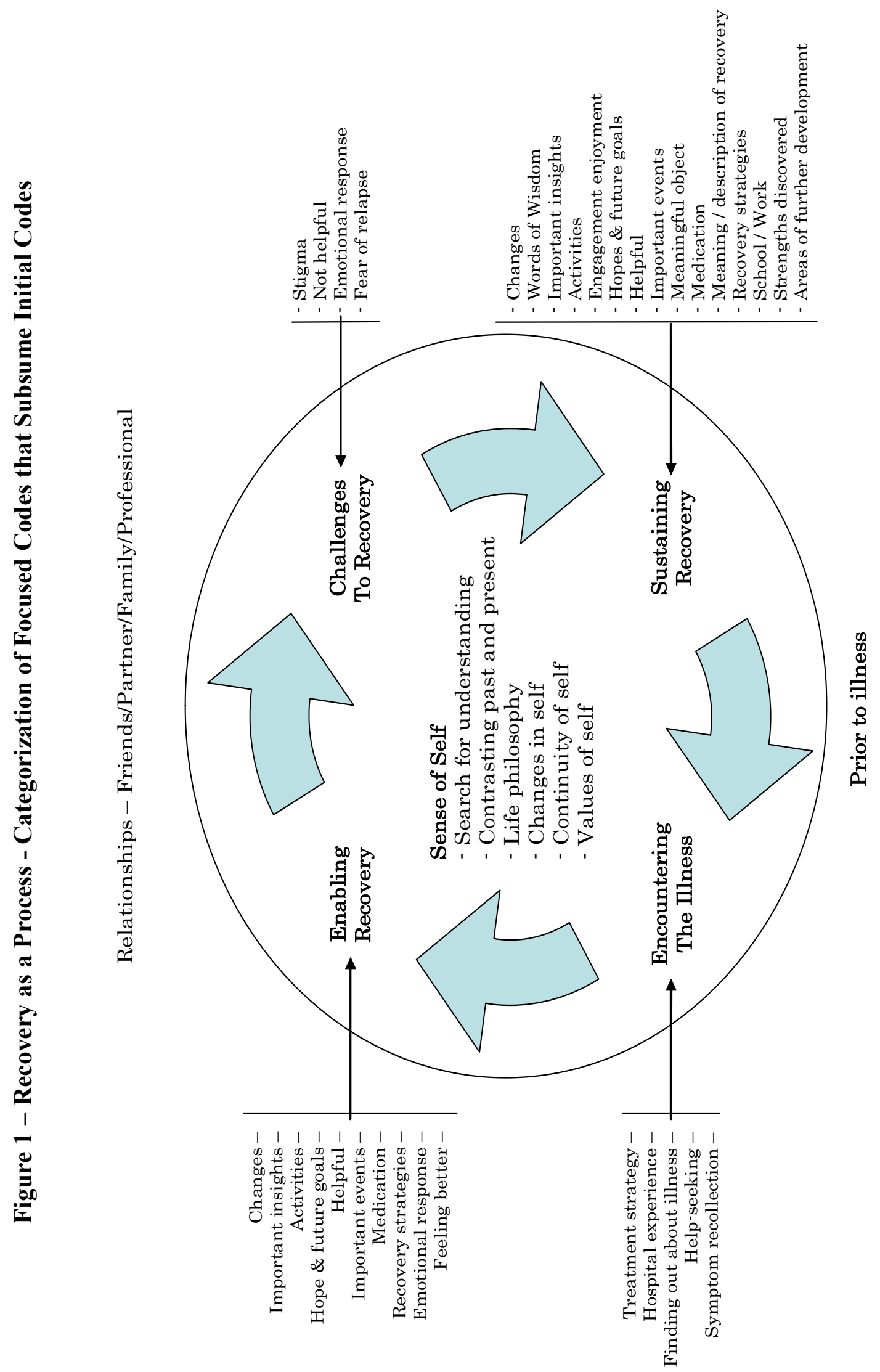

ồ 

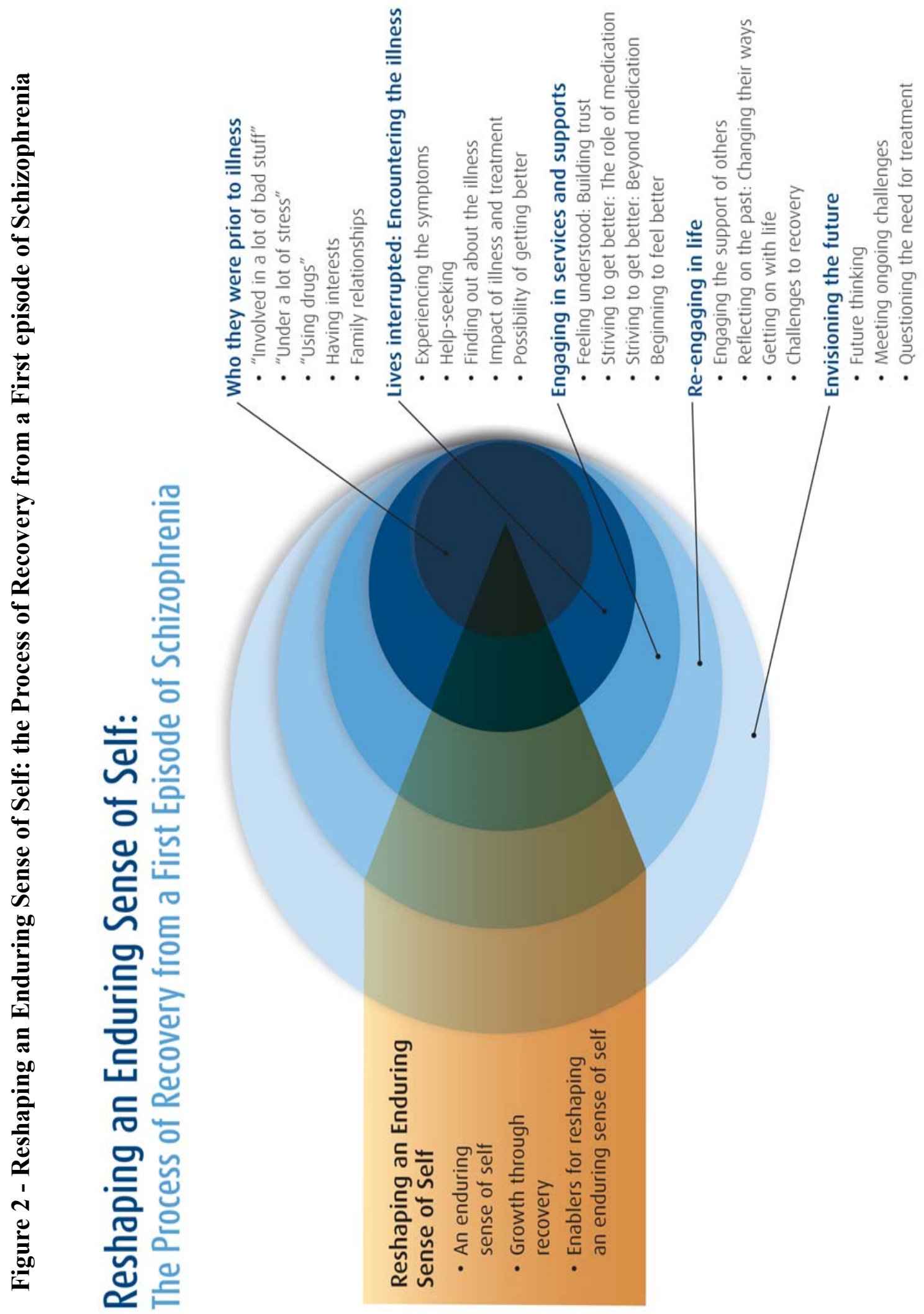